SR/ICID/90-01

\title{
An Analysis of Increasing the Size of the Strategic Petroleum Reserve to One Billion Barrels
}

\author{
January 1990
}

Energy Information Administration Office of Energy Markets and End Use

U.S. Department of Energy Washington, D.C. 20585

Service Reports are prepared by EIA upon special request and may be based on assumptions specified by the requestor. Information regarding the request for this report is included in the Preface. 


\title{
An Analysis of Increasing the Size of the Strategic Petroleum Reserve to One Billion Barrels
}

\author{
January 1990
}

\author{
Energy Intormation Administration \\ office of Energy Markets and End Use \\ U.S. Department of Energy \\ Washingtor, D.C. 20585
}

\section{DISCLAIMER}

This report was prepared as an account of work sponsored by an agency of the United States Government. Neither the United States Government nor any agency thereof, nor any of their employees, makes any warranty, express or implied, or assumes any legal liability or responsibility for the accuracy, completeness, or usefulness of any information, apparatus, product, or process disclosed, or represents that its use would not infringe privately owned rights. Reference herein to any specific commercial product, process, or service by trade name, trademark, manufacturer, or otherwise does not necessarily constitute or imply its endorsemen:, recom. mendation, or favoring by the United States (jovernment or any agency thereof. The views and opinions of authors expressed herein do not necessarily state or reflect those of the United States Government or any agency thereof. 


\section{Preface}

This study was undertaken at the request of the Department of Energy's Office of Energy Emergency Policy and Evaluation to analyze the expansion in the size of the strategic Petroleum Reserve (SPR) from its currently planned 750 million barrels to 1000 million barrels. This service Report documents the assumptions, methodology, and results of the analysis.

A cost benefit approach was chosen to complete this analysis. The costs associated with the SPR include the development, operation, and maintenance costs of providing storage in underground salt domes as well as the cost of acquiring the crude oil. Benefits from the SPR result mainly from the reduction in economic damage (during an oil supply disruption) due to its drawdown. The 750 million barrel reserve is assumed to have a maximum drawdown rate of 4.5 million barrels per day while the 1000 million barrel reserve has a maximum drawdown rate of 6.0 million barrels per day.

The assumptions used in this study were developed by the SPR sizing study group, an interagency group consisting of the Departments of Energy, Treasury, Commerce, Defense, State, and Interior, the Council of Economic Advisers, the office of Management and Budget, Economic Policy Council, National security Council, the Federal Emergency Management Administration, and the Central Intelligence Agency. This Service Report was prepared by the Energy Information Administration's, Office of Energy Markets and End Use, under the direction of $\mathrm{W}$. Calvin Kilgore. Information on the study can be had by contacting Mark Rodekohr, Director of the International and Contingency Information Division ((202)586-1130), Derriel B. Cato, G. Daniel Butler, Debra Paxson, and Erik Kreil, of the Analysis Branch.

Additional copies of this report are available from:

International and Contingency Information Division office of Energy Markets and End Use

Energy Information Administration

1000 Independence Avenue, S.W.

washingtcn, D.C. 20585

(202) 586-1130 


\section{Contents}

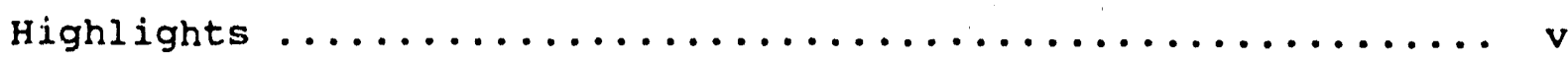

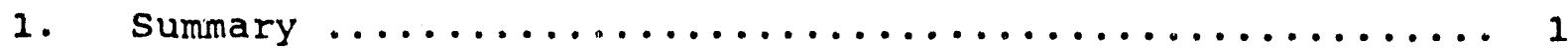

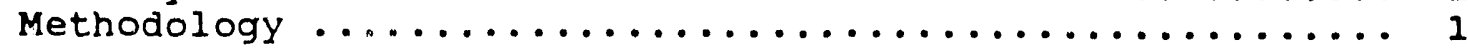

Results ................................ 4

2. Overview of Methodology ..................... 8

Price Response/Demand Elasticity ................. 8

Economic Benefits .......................... 9

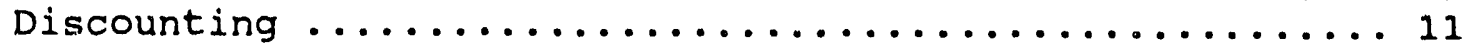

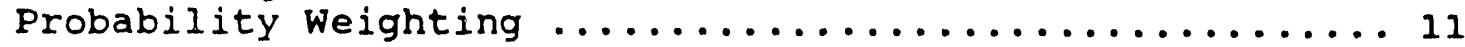

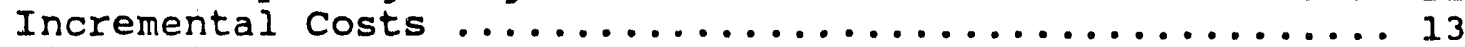

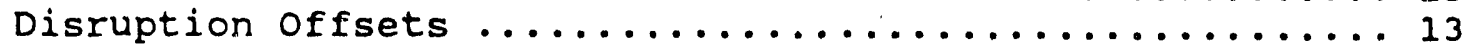

3. World oil Market and Price Projections............. 16

4. Price Elasticities ......................... 20

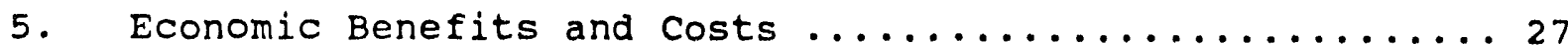

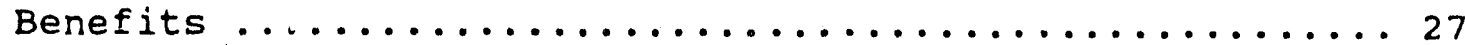

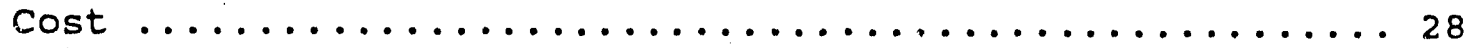

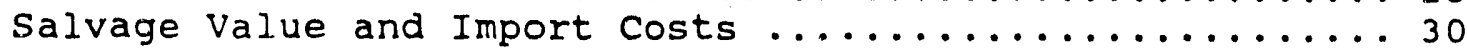

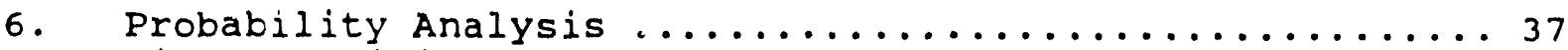

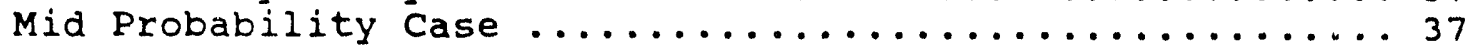

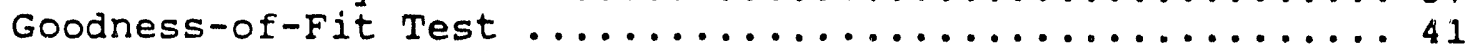

Low and High Probability Ranges ................... 44

Multiple worst Case Disruptions and scenarios ........ 44

7. Offsetting Assumptions to Reduce Gross Disruption

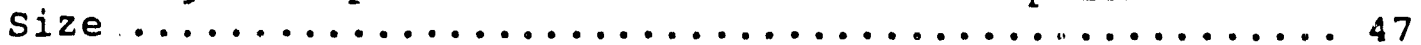

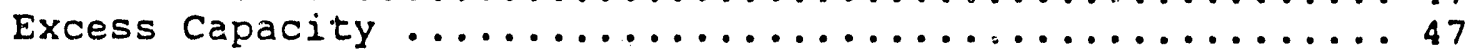

Foreign stock Draw/Fuel switching Assumptions ......... 49

8. Summary Results of Sensitivity Analysis ............ 50

Appendix A: Macroeconomic Impact of an Oil supply

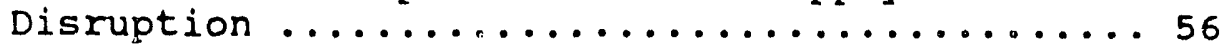

Appendix B: Detailed Results ...................69 


\section{Contents}

(Continued)

Tables

1. Probabilities of a Disruption .................. 13

2. SPR sizing study - Price scenarios ................ 19

Unifier Matrix for the United States ............... 22

4. Unifier Output at Different Disruption Sizes ........ 25

5. Comparison of studies on Crude Oil Price

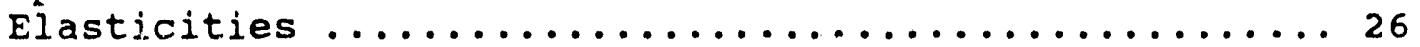

6. SPR Fill Schedule and costs -750 MMB ................ 31

7. SPR Fill Schedule and Costs, Mid Case - 1000 MMB ...... 32

8. SPR Fill Schedule and Costs, Low Price Case -

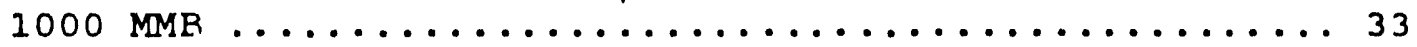

9. SPR Fill Schedule and Costs, High Price Case -

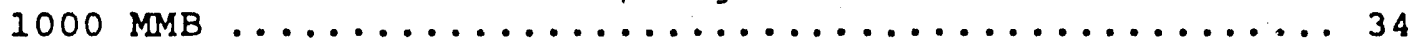

10. Salvage Value and Increased Import cost -

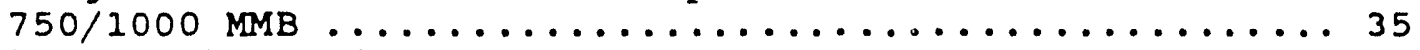

11. Salvage Value and Increased Import cost -

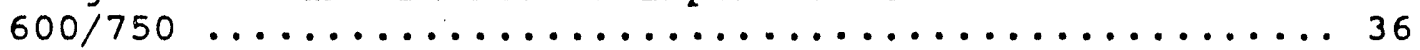

12. World Oil Supply Disruptions; $1951-1989 \ldots \ldots \ldots \ldots \ldots \ldots$

13. Weibull Cumulative Probilities for SPR Sizing

study ............................ 40

14. Disruption offset Assumptions $\ldots \ldots \ldots \ldots \ldots \ldots \ldots \ldots \ldots \ldots$

15. Summary Kesllts .......................... 51

\section{Figures}

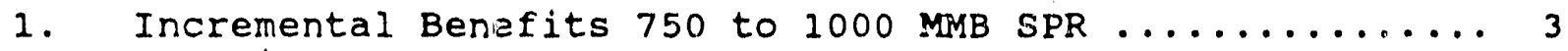

2. Benefit/Cost of Incremental $250 \mathrm{MMB} \ldots \ldots \ldots \ldots \ldots \ldots \ldots \ldots$

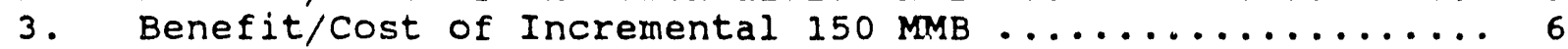

4. World oil Prices/year $2010 \ldots \ldots \ldots \ldots \ldots \ldots \ldots \ldots \ldots$

5. Economic Worth of Last $250 \mathrm{MMB}$ - Not Discounted ....... 10

6. Economic Worth of Last $250 \mathrm{MMB}$ - Discounted .......... 11

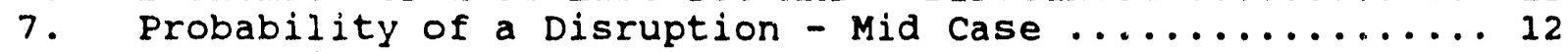

8. Cumulative Gross Benefit 1990-2020 ............... 14

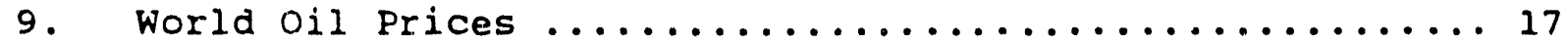

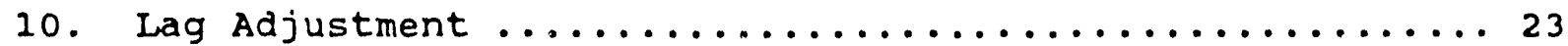

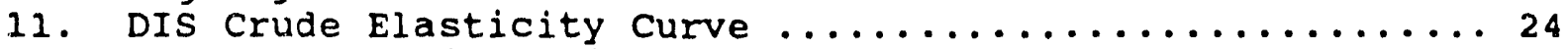

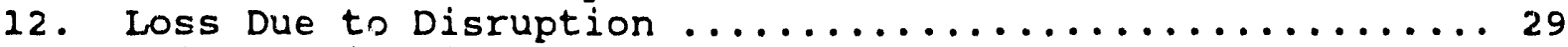

13. Weibull Distribution (Tail only) ............... 42

14. Probability of a Disruption - 3 Cases ............445

15. Probability of a Disruption - 15 Years .............46

16. Gross Benefit Versus Discount Rate ................ 52

17. Gross Benefit versus Probability ................. 53

18. 15 - Year Probability of a Disruption .............. 54 


\section{Highlights}

The Department of Energy's Office of Energy Emergency Policy and Evaluation requested that the Energy Information Administration complete an analysis of the proposed expansion in the strategic Petroleum Reserve (SPR) from its currently planned size of 750 million barrels to 1000 million barrels. Because the SPR contains only 580 million barrels at this point in time, the benefits and costs of increasing the SPR from 600 to 750 million barrels were also estimated. This report documents the assumptions, methodology, and results of the analysis.

A cost benefit approach was chosen to complete this analysis. The costs associated with the SPR include the development, operation, and maintenance costs of providing storage in underground salt domes as well as the cost of acquiring the crude oil. Benefits from the SPR result mainly from the reduction in economic damage due to the drawdown of the reserve if a disruption in oil supply occurs. The 600 million barrel reserve has a maximum drawdown rate of 3.5 million barrels per day, the $750 \mathrm{million}$ barrel reserve has an assumed maximum drawdown rate of $4.5 \mathrm{mill}$ ion barrels per day, and the 1000 million barrel reserve has a maximum drawdown rate of 6.0 million barrels per day.

The mid case results of this analysis indicate that expected discounted benefits are below costs for expansions beyond 600 million barrels. All costs and benefits have been discounted to the present and the benefits have been weighted according to the probability of a disruption of a given size. All costs and benefits are expressed in millions of 1988 dollars:

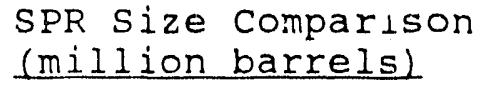

From 600 to 750

From 750 to 1000
Incremental Gross Benefit

$\$ 940$ 750
Incremental Cost

$\$ 2,000$

3,370

Several sensitivity cases were also analyzed in order to determine the impact of the various assumptions on the final results. These cases examined variations in:

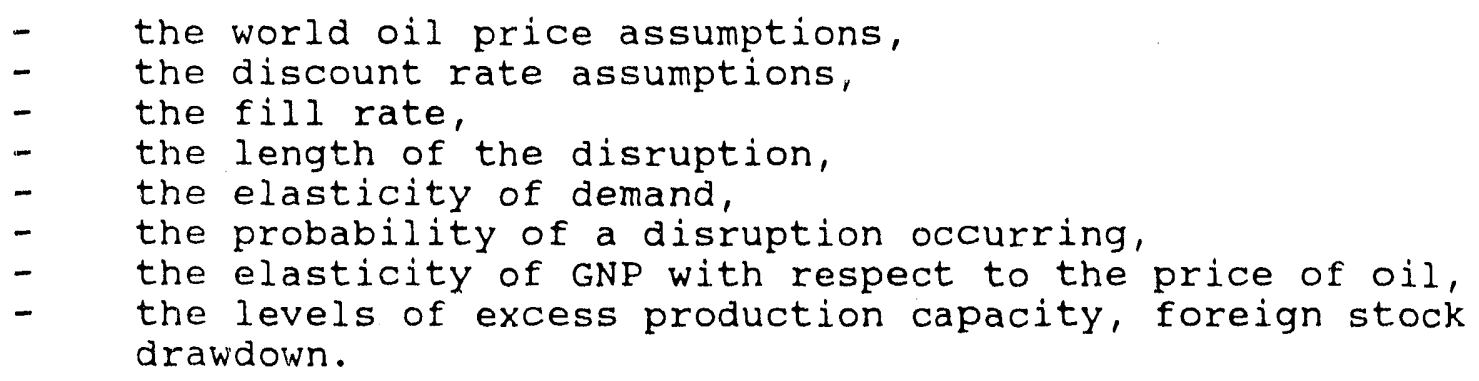

Individual sensitivities (that is, cases which examined the sensitivity with respect to only one variable) also produced benefits which were below costs. Most of these sensitivities produced benefits that were plus or minus $\$ 200$ to $\$ 300 \mathrm{milli}$ ion from the mid case.

Only when several variables were combined in a manner that tended to maximize benefits did the benefits exceed the costs. For 
example in the case where low oil price assumptions were combined with low offsets (low excess capacity and low foreign stock draws), for a 9-month disruption did benefits exceeded costs.

The costs and benefits calculated in this analysis exclude a number of factors which could be important when considering an expansion of the SPR. Some of these factors include:

- The national security value of the SPR.

- The strategic value of the SPR with respect to our allies.

- The deterrent effect on future oil supply disruptions of a larger SPR.

These issues are addressed separately in the overall SPR size study conducted by the Department of Energy. 


\section{Summary}

The Department of Energy's Office of Energy Emergency Policy and Evaluation requested that the Energy Information Administration (EIA) assist it in completing a study regarding the propossed expansion in the size of the Strategic Petroleum Reserve (SPR) from its current planned size of 750 million barrels (MMB) to 1000 MMB. As of the end of 1989, the SPR held 580 MMB. In addition, an evaluation of the benefits of increasing the SPR from 600 to 750 MMB was also requested. All of the assumptions used in this analysis were provided by the Interagency working Group established for this study. This report documents the results of this study.

The SPR is designed to reduce the economic cost of a disruption in energy supplies. During a disruption, the shortage of oil on world markets causes world oil prices to increase. This price increase would tend to increase inflation and unemployment and hence reduce economic output or Gross National product (GNP) from what it otherwise would have been. Past disruptions, like those experienced in $1973 / 74$ and $1979 / 80$, have resulted in significant downturns in economic growth. The current SPR was therefore designed to mitigate some of this economic damage by allowing the Federal. Government to sell the oil at the time of a disruption and thus limit the resulting price increase. Therefore, the major benefit of the SPR is its ability to limit price increases and hence limit the damage to the economy.

In this analysis, the benefits of using the SPR are calculated by examining the economic damage caused by various disruption sizes. Alternative SPR sizes are assumed in conjunction with the various disruption sizes, and calculations are made of the reduction in economic damage as a function of the size of the SPR. Over a six month period, a 600 MMB SPR can be drawn down at a rate of 3.5 million barrels per day (MMBD), a 750 MMB SPR at a 4.5 MMBD rate, and a $1000 \mathrm{MMB}$ SPR at a $6.0 \mathrm{MMBD}$ rate. It is this incremental drawdown capability which reduces the price impact of a disruption and therefore determines the level of the benefits.

The remainder of this section will discuss the methodology used, the mid case results, and the many uncertainties associated with the analysis.

\section{Methodology}

Benefits are determined by a multistep process which calculates for each SPR system $(600,750$, or 1000 million barrel SPR):

(1) The change in world oil prices for various disruption sizes after accounting for all of fsets (excess production capacity, foreign strategic stocks, fuel switching, and drawdown of the SPR). 
(2) Then based on the price change between a base price and the price for each net oil shortfall, calculate the GNP loss foregone and "terms of trade" loss at each disruption size.

(3) Next, at each disruption size, for each SPR system, the incremental reduction in economic loss from the larger $S P R$ system is calculated as the incremental gross benefit of that SPR system.

(4) These benefits are then discounted to the present value.

(5) The discounted benefits are next multiplied by the probability of occurrence of each disruption size and summed across disruption sizes to provide the incremental gross benefits in any given year.

(6) Next the probability weighted benefits associated with each of the 30 years from 1990 to 2020 are summed to determine the total incremental gross benefit.

The change in the world oil price is a function of the price elasticity of demand discussed in section 2 and the size of the disruption after accounting for all offsets.

Estimates of the GNP loss elasticit:y and methodology for computing the "terms of trade" benefit were provided by the Department of Treasury, office of Management and Budget, and Council of Economic Advisers (see Appendix A). After the benefits are calculated according to ti:e procedure outlined above, they are then discounted to the present (using a 10 percent discount rate in the mid-case). The discounted benefits are then weighted by the probability associated with each gross disruption size. The discounted probability weighted benefits are illustrated in Figure 1 . The benefits are zero for small disruptions because of the assumption that excess capacity and foreign stocks can be used to offset the impacts of these small disruptions. Benefits are also zero in the early years because the $1000 \mathrm{MMB}$ system contains no additional oil (over a 750 MMB SPR) in these years.

The probability distribution associated with various cisruption sizes was developed by using an analysis of data on past disruptions and expert opinion to determine the shape of the distribution (discussed in more detail in section 6). After the benefits are weighted, they are first summed across all years for each disruption size and then summed across all disruption sizes in order to determine the overall present discounted benefit of increasing the size of the SPR. The benefit can thein be compared to the cost of increasing the SPR. In this analysis, benefits accruing because of the possibility of multiple very large disruptions are not incorporated because the probability of such an event is considered insignificant. Furthermore, possible 
Figure 1

\section{INCREMENT'AL BENEFITS 750 TO 1000 MM BARREL SPR}

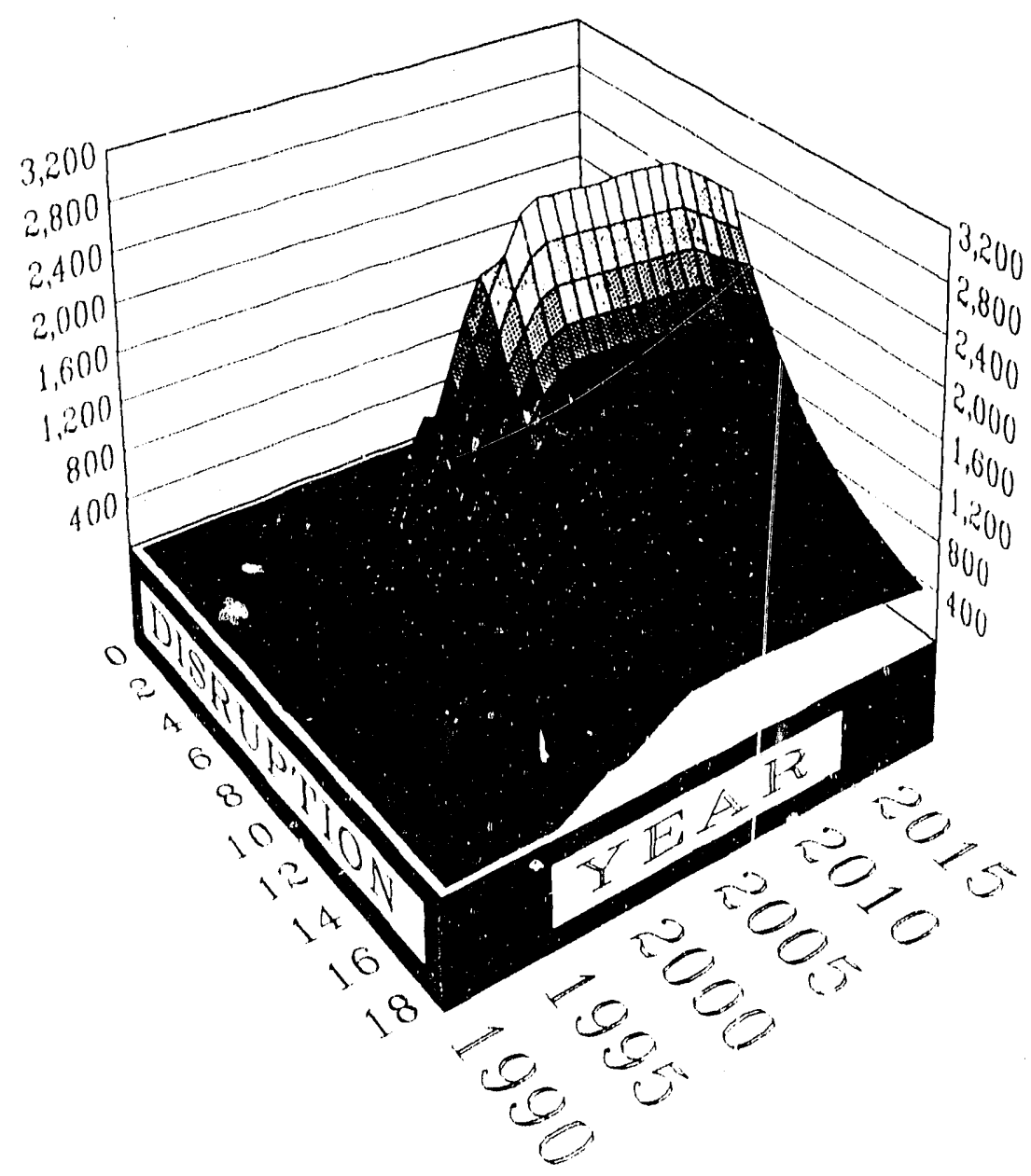

Thousands of 1988 Dollars 
benefits arising from the fact that an increased SPR could have a deterrent value, in other words, decrease the chance of having a disruption at all, were also not considered, because quantifying this value is not possible.

In order to examine the inherent uncertainties involved in this analysis, reasonable ranges of values for the major independent variables were developed. These ranges were then assumed and the impact on the resulting benefits and costs calculated. Variables which have a large impact on the determination of the level of benefits include:

(1) the size of the prise elasticity of demand;

(2) the size of the elasticity of GNP with respect to price;

(3) the world oil price case;

(4) estimates of the size of excess world oil production capacity and size of foreign stock drawdown ability;

(5) the probability of having a discuption of a certain size;

(6) the discount rate; and

(7) the duration of the disruption.

These variables represent the major uncertainties that are explored in this analysis. A detailed discussion of the results of this analysis is contained in section 8 and Appendix $B$.

\section{Results}

Figure 2 summarizes the results of the analysis for the $1000 \mathrm{MMB}$ SPR for three cases. These cases are: the mid case, which assumes middle values for critical variables; an extreme low case, which arsumes a combination of values for all the variables which would tend to decrease the benefit; and an extreme high case in which converse values are assumed.

Almost all of the cases produce benefits that are less than the cost. This result is primarily due to the probability distribution used in the analysis. For example, a disruption in 2005 of greater than about 11.5 MMB must occur before any significant benefits are realized from the additional $250 \mathrm{MMB}$ of SPR oil between a 750 and a 1000 million barrel SPR. The annual probability of such an event occurring in any year is one-half of one percent. Given this low probability, the expected (or probability weighted) benefits of the additional oil are quite low. The 11.5 MMBD figure is the sum of 4.5 MMBD drawdown capability from the reserve of 750 MMB plus mid 


\section{Figure $2(a)$}

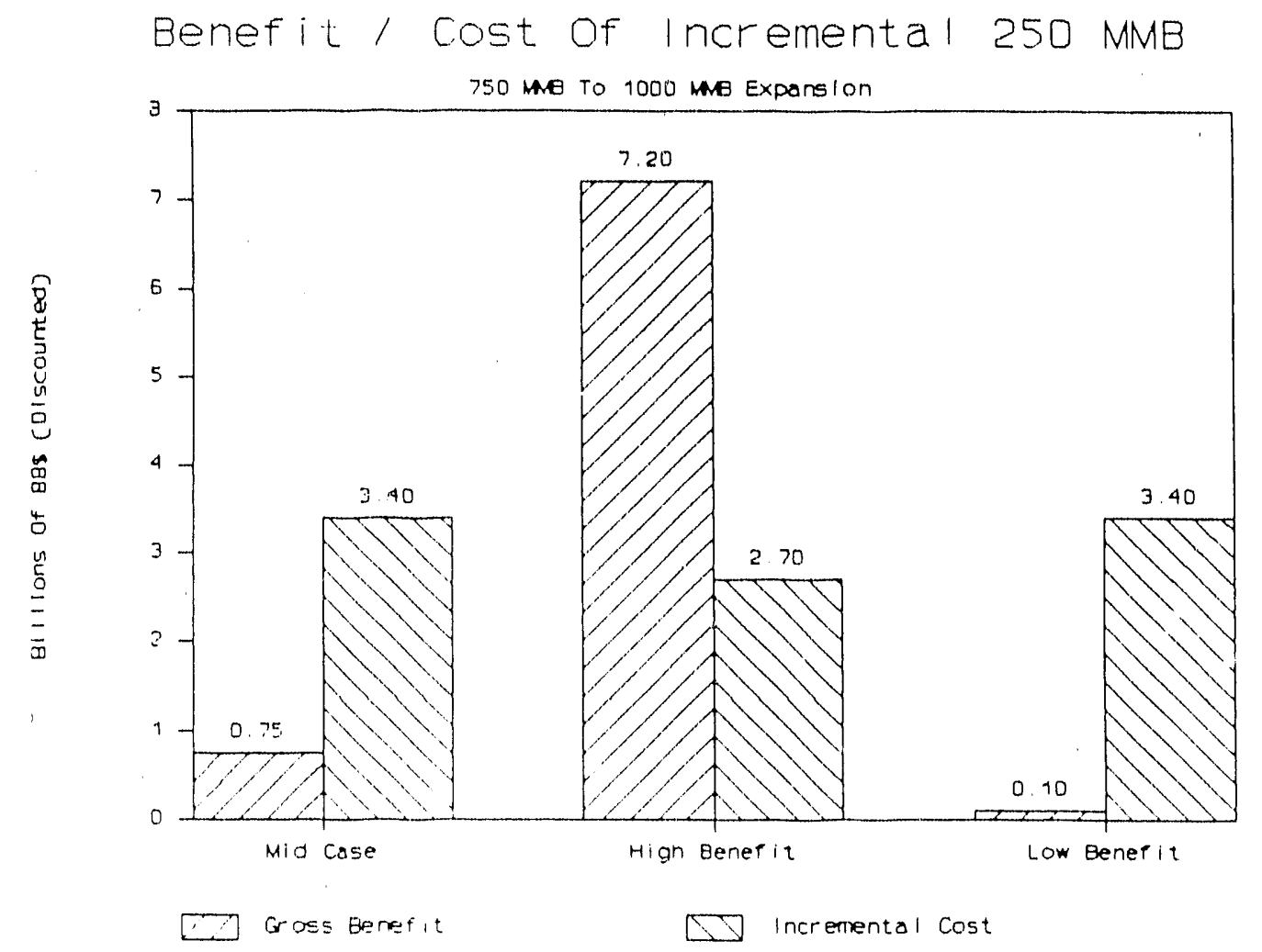

(a) Excludes salvage value and incremental imported oil costs.

case excess production capacity of about 4 MMBD and 3 MMBD of foreign stock draw. When variations of the individual uncertainties are examined, there are no cases where the expected benefits exceed the costs on a discounted basis (see Appendix B). The only instances where benefits exceed costs are when combinations of values for individual variables are combined in such a manner as to maximize the benefits (as shown by the extreme case in Figure 2). While most cases would produce negative net benefits, not all cases produce this result. For example the case which combines low world oil prices and low offsets (low excess capacity and low foreign stock draws) for a 9-month disruption produces benefits which exceed costs. 
All of the cases presented in this section exclude one noteworthy benefit and one significant cost because there is some debate as to the appropriateness of including them. On the benefit side, the salvage value of the extra $250 \mathrm{MMB}$ at the end of the time period is excluded. The savage value is the value of the addition SPR Oil if it were left unused anc sold "o the market. For the mid case, when no SPR draw has occuirred by 2020 , this value is about $\$ 0.5$ billion. On the cost side the purchase of the extra 250 MMB could cause world oil prices to increase if production capacity was assumed to be fixed and the increased SPR fill was viewed as an increase in demand. The extra cost to consumers of this increase in all oil import expenditures is estimated to be $\$ 0.97$ billion and was not included in the cost analysis.

\section{Figure 3 (a)}

Benefit / cost of Incremental $150 \mathrm{MMB}$

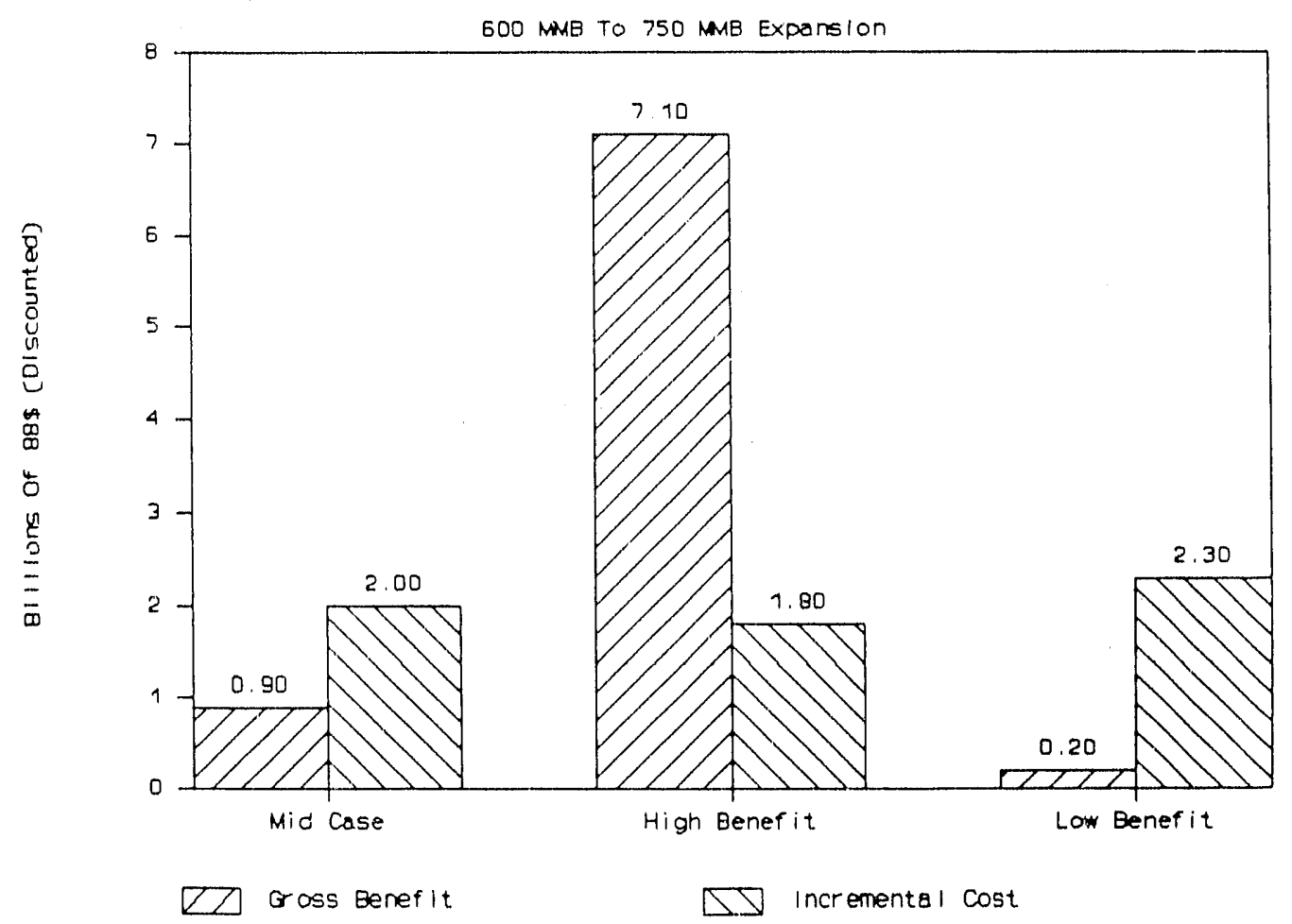

(a) Excludes salvage value and incremental imported oil costs.

Figure 3 summ rizes the results of the analysis for the scenario in which the SPR is increased from $600 \mathrm{MMB}$ to $750 \mathrm{MMB}$. In this scenario costs are lower because the volume of oil purchased is 
lower and the costs of the additional storage capacity is excluded because it was purchased long ago. The incremental benefit

(although less than its cost) is greater for the $600 / 750$ MMB increment than the $750 / 1000 \mathrm{MMB}$ increment because the probability of using this increment is greater and the oil would be available sooner so that the effect of discounting is not as dominant. 


\section{Overview of Methodology}

A cost benefit approach was chosen as the most appropriate method for this analysis. This method was selected because it allows for the clear presentation of all the calculations necessary to determine both costs and benefits, and because it easily lends itself to an examination of the many uncertainties surrounding the analysis. The costs of the $1000 \mathrm{MMB}$ SPR include the cost of purchasing the oil as well as the cost of building and maintaining the extra storage space. These costs are discounted to the present for the purpose of comparing them to the benefits. The benefits consist of the reduction in economic damage due to the use of the additional SPR volume during a disruption. These benefits are discounted to the present and multiplied by the probability of a disruption of any given size occurring. The remainder of this section will discuss these calculations in more detail.

\section{Price Response/Demand Elasticity}

During a disruption, economic damage is caused by the resulting increase in crude oil and refined product prices. Since the economy cannot adjust immediately to higher prices, higher inflation and unemployment result in lower real GNP than would have been the case in the absence of a disruption. This damage is proportional to the increase in prices. To determine the benefits of having a 1000 million barrel SPR the differense between two scenarios is considered. The first scenario is the currently planned 750 MMB SPR, which can be drawn down at a rate of 4.5 MMBD. The second scenario is the 1000 MMB SPR, which can be drawn down at a rate of 6.0 MMBD. It is the difference in the resulting price increase between these two scenarios that determines the level of benefits realized from purchasing the larger SPR.

The price increase resulting from disruptions of different sizes is computed from the EIA Disruption Impact simulator (DIS) model. This model determines the price necessary to clear the market of any excess demand after all offsets to a disruption, such as foreign strategic stocks, excess production capacity, and fuel switching have been considered. Next the price elasticity of demand is utilized or:

$$
P_{d}=P_{b} *\left(Q_{d} / Q_{b}\right)
$$

where $P$ refers to prices, $N_{c}$ is the crude oil price elasticity of demand, $Q$ refers to the non-OPEC free world demand, $b$ refers to the base or undisrupted case, and d refers to the disrupted case. It is the difference in this change in price for the $750 \mathrm{MMB}$ and the 1000 MMB SPR's that determines the level of benefits. This can be seen more clearly by examining Figure 4 which shows the price increases across selected disruption sizes (after offsets for the use of excess capacity and fuel switching) using the mid case assumptions for all of the other variables. Prices would be much greater than shown here if U.S. and foreign strategic stocks were 
not used. The demand elasticities were developed in the "Unification spreadsheet". The DIS model. uses one set of elasticities for the United states and another for the rest of the free world countries. However, the composite world elasticity is generally about -0.1 in the short run. The elasticity is assumed to increase over time as adjustments can fe made to higher prices and also to increase as the level of prices increase. The development of these elasticities are discussed in more detail in Section 4 .

\section{Figure 4}

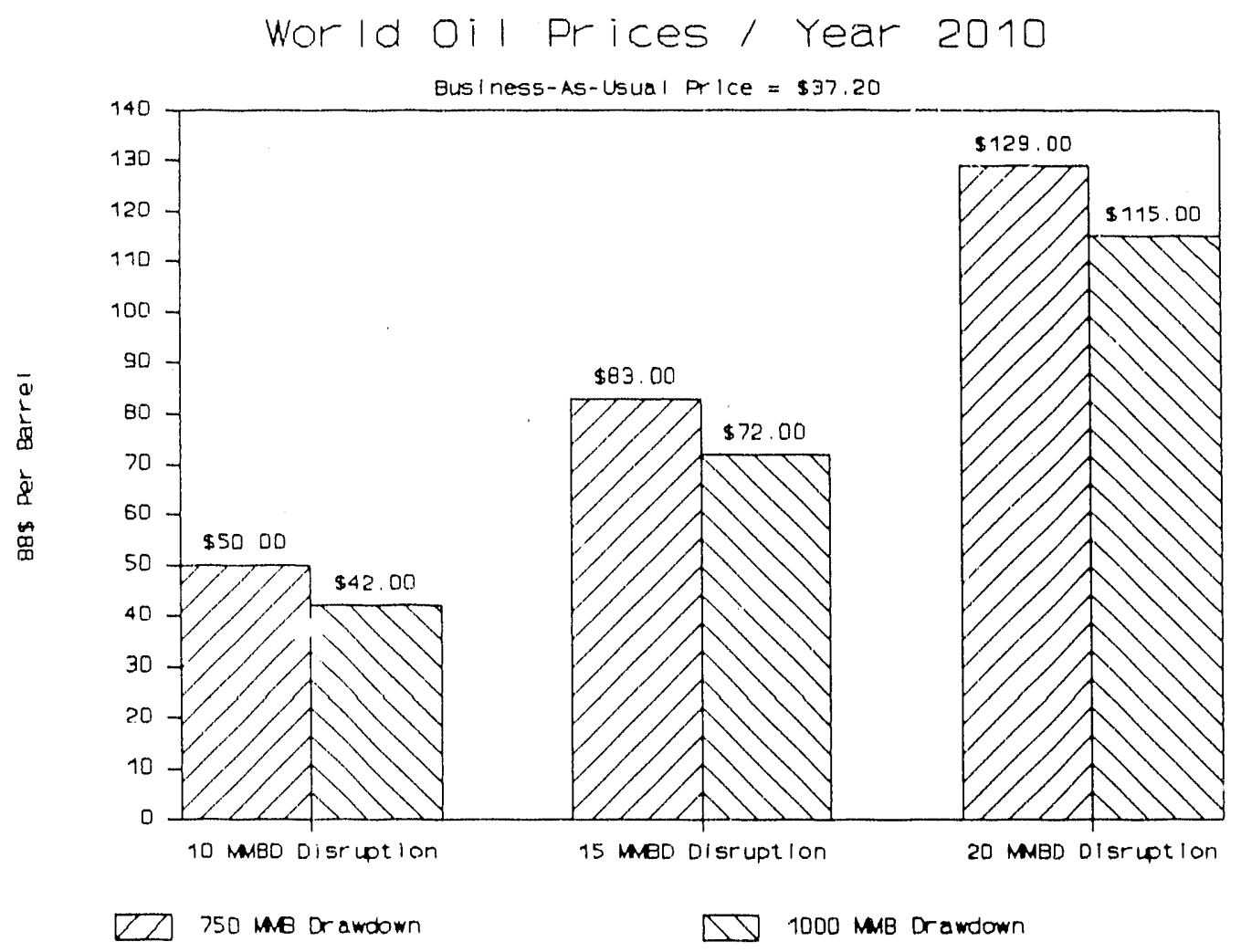

Economic Benefits

As stated earlier, the economic benefits of the 1000 MMB SPR are calculated as the reduction in economic damage due to the increased SPR drawdown rate. These economic benefits consist of two factors. The first, or the macroeconomic benefjt, refers to the change in GNP due to a change in oil price, and is expressed as follows:

$$
G N P_{d}=G N P_{b} \star\left(P_{d} / P_{b}\right)^{\circ},
$$


where GNP refers to the level of Gross Natiunal Product, $d$ is the disruption case, b the base or non-disrupted case, and ${ }^{-}$is the elasticity of GNP with respect to oil prices. This GNP elasticity averaged -0.025 in the mid case and was taken from an analysis completed by the Department of the Treasury, office of Management and Budget, and Council of Economic Advisers as documented in Appendix A. The second benefit derived from decreases in the terms of trade loss (TTL), refers primarily to the microeconomic loss associated with having to pay more for oil imports after deduction of SPR sale receipts. Hence, with a higher SPR drawdown rate less imports would be needed and a lower TTL would be experienced. This is calculated approximately as:

(3) TTL $=\left(P_{d}-P_{b}\right) *\left(I_{d}+I_{b}\right) / 2-P_{b} * S P R$

where I represents net imports and SPR is the volume of the SPR draw. Again it is important to remember that these benefits are calculated by examining the impact of the two SPR sizes and expressed as the difference between the two cases. Both the macro and micro benefits are added together to estimate the total benefit. Figure 5 shows the level of these benefits across disruption sizes.

Figure 5

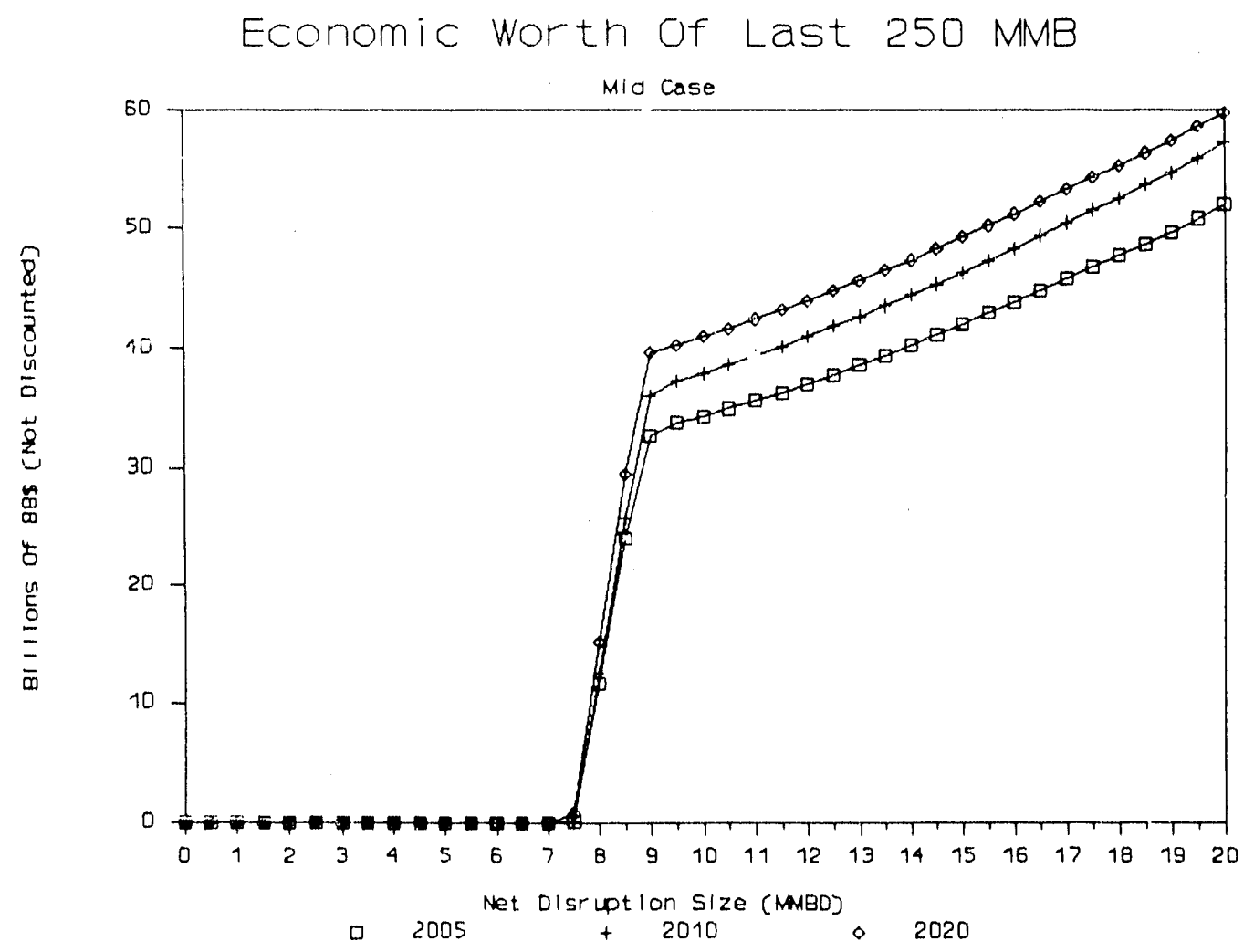




\section{Discounting}

Discounting is used to compare future streams of costs or benefits. In the mid case, a discount rate of 10 percent is used which represents the official office of Management and Budget discount rate. Therefore, the discounted benefits (DB) are expressed as follows:

$$
D B_{d}=B_{d} /(1+D R)^{\prime}
$$

where DR refers to the discount rate and $t$ stands for time. Figure 6 illustrates the discounted benefits across a number of disruption sizes.

\section{Figuxe 6}

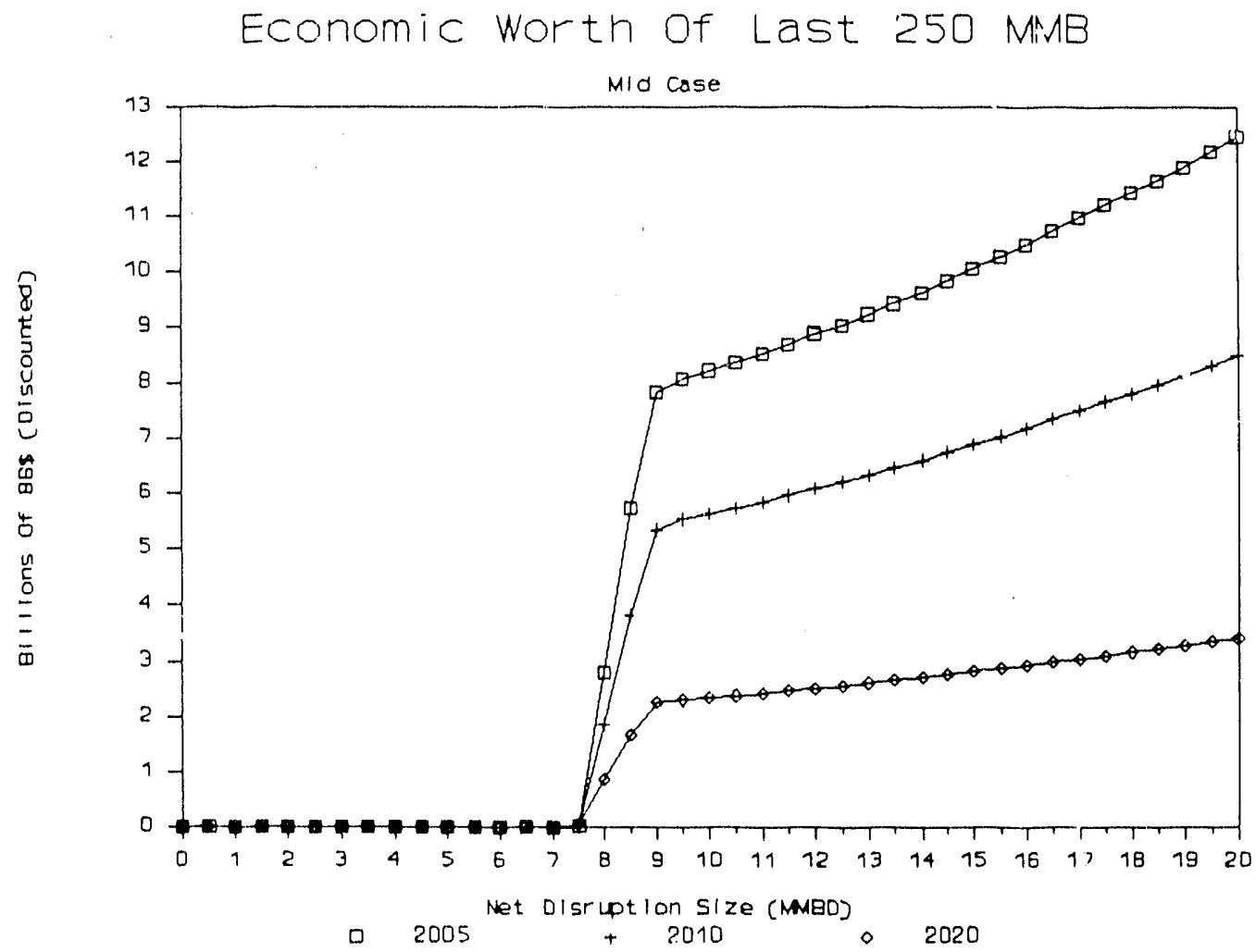

Probability weighting

The next step in determining the aggregate benefits involves probability weighting. In any given year thore is some chance that there will be a disruption. Since 1950 there have been 13 gross oil supply disruptions which have accounced for more than one percent of consumption at the time. There have ween several more 
which have accounted for less than one percent but these are not considered to be important enough to warrant the use of a SPR and therefore were not included in the probability analysis. This analysis used a weibull probability curve (which is a particular form of a probability density function) to characterize the chances of having a disruption. Figure 7 shows the mid case cumulative one year probability function used in this analysis. Note that this distribution is expressed as a function of the percent of WOCA (world outside communist area) consumption. The development of this particular curve is discussed in section 6. For the mid case probability function, the Table l summarizes the chances of having a range of disruptions over a one-year, fifteen-year, and thirtyyear period.

\section{Figure 7}

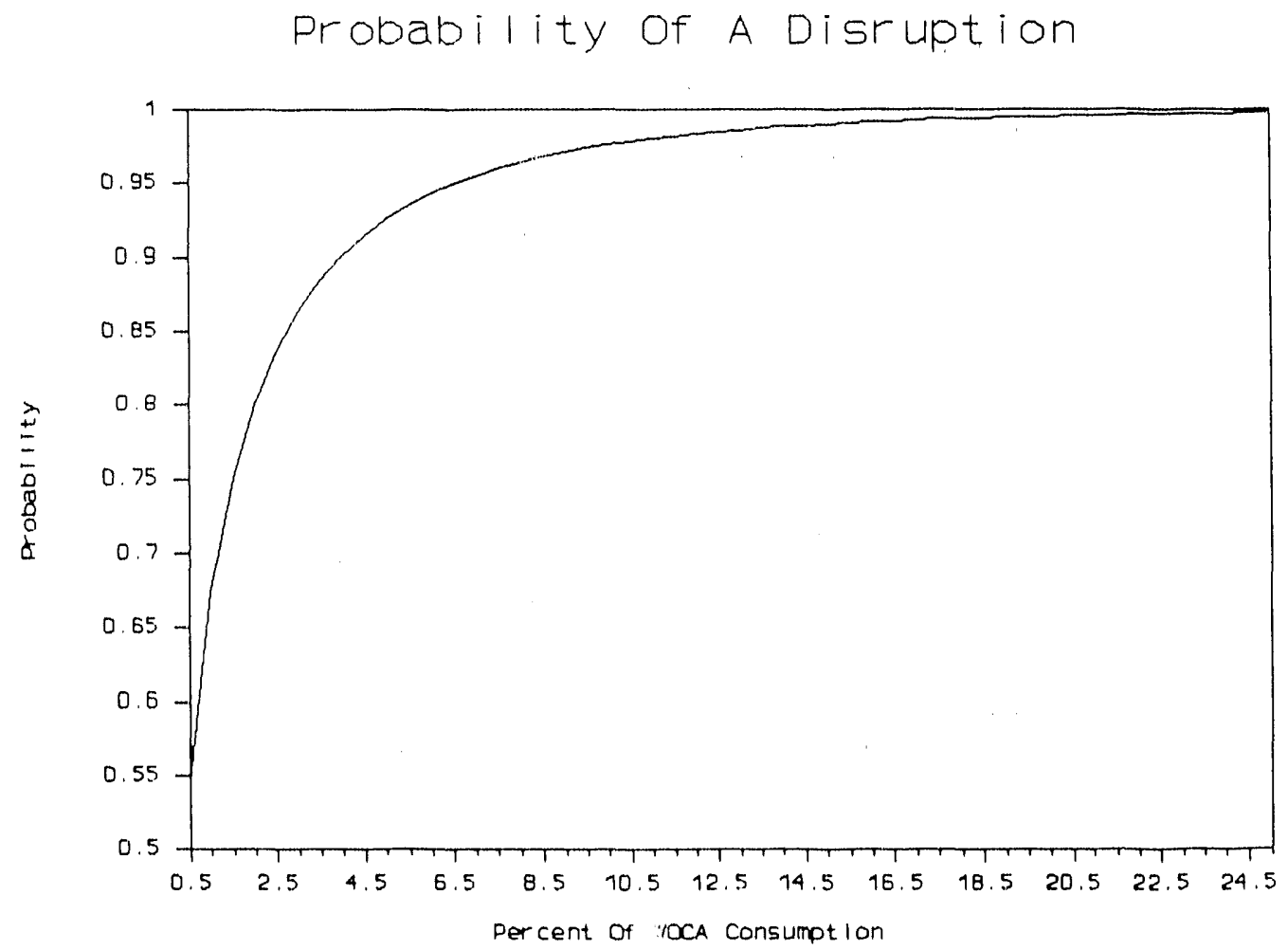


Table 1

Probabilities of a Disruption

$\begin{array}{llll}\begin{array}{l}\text { Disruption Size } \\ \text { Percent }\end{array} & 1 \text { year } & 15 \text { year } & 30 \text { year } \\ 0-5 & 0.926 & 1.000 & 1.000 \\ 5-10 & 0.050 & 0.562 & 0.798 \\ 10-15 & 0.014 & 0.202 & 0.355 \\ 15-20 & 0.005 & 0.081 & 0.151 \\ 20-25 & 0.002 & 0.036 & 0.069\end{array}$

(a) Percent of consumption

The probabilities within the size classes are then used to weight the benefits. These weighted benefits are shown in Figure 8. The benefits across all disruption sizes are then added together (the area under the curve is computed) to determine the final discounted benefit for all disruption sizes across all years analyzed.

\section{Incremental costs}

On the other side of the analysis, the incremental cost of filling the SPR by the additional $250 \mathrm{MMB}$ and providing the storage for this additional oil had to be determined. The cost of filling the SPR includes the acquisition costs of the oil and capital cost to acquire additional storage capacity of the 1000 MMB system. Acquisition costs are estimated using the alternative world oil price cases and alternative fill rates detailed in Tables 6 through 9. Capital costs were taken from a studyl/ developed by the oak Ridge National Laboratories. These costs (C) are summed and discounted (DC) as:

(5) $\quad \mathrm{DC}=\mathrm{C} /(1+\mathrm{DR})^{\prime}$

\section{Disruption offsets}

In this part of the analysis a certain volume of oil is assumed to be available during a disruption which can be used to offset the effects of some of the disrupted supplies. This oil comes from one

1/Preliminary Results of The SPR Size Cost Benefit Study, Oak Ridge National Laboratories, November 17, 1988 


\section{Figure 8}

Cumulative Gross Benefit 1990-2020

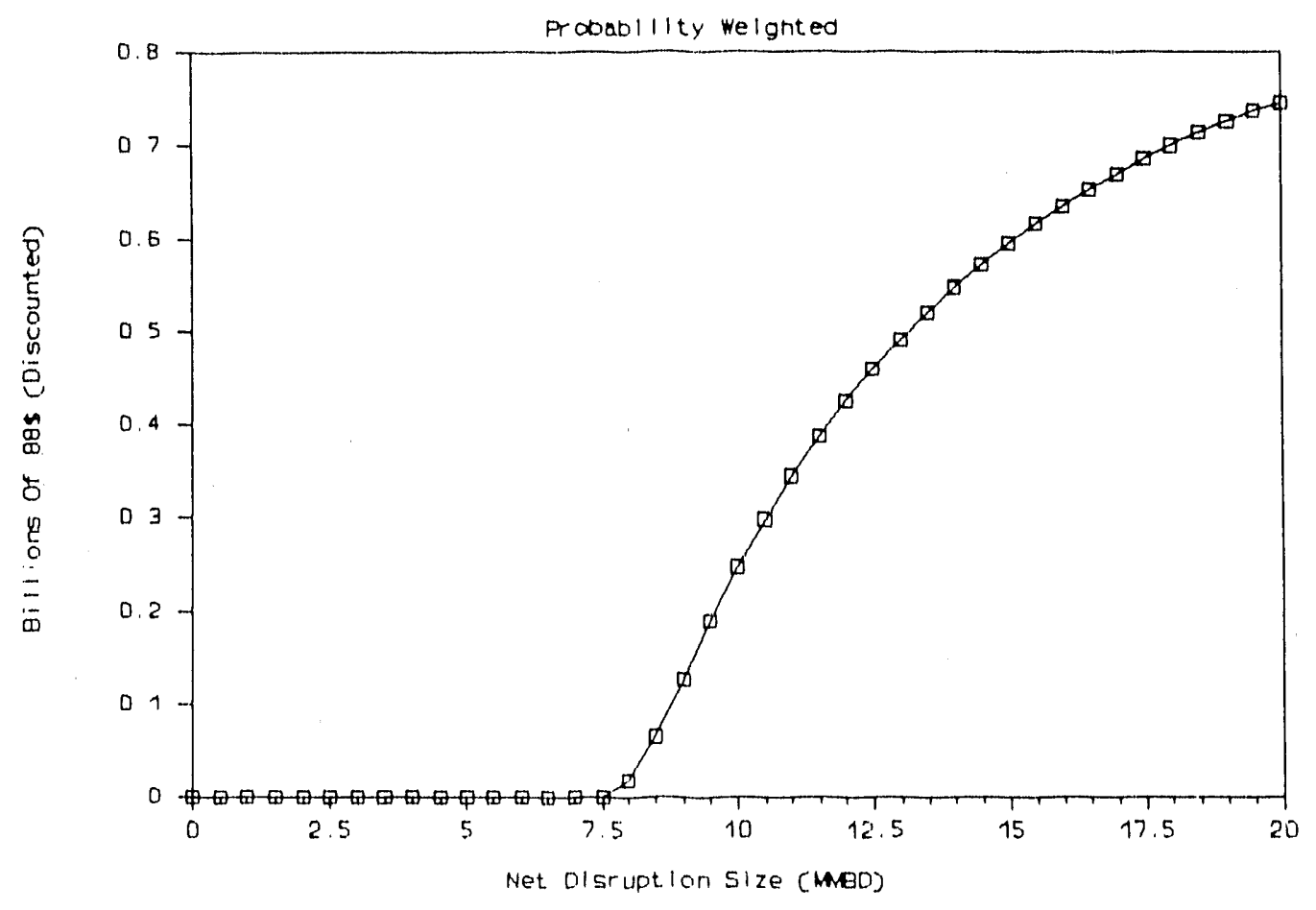

of three sources which include foreign stocks, excess crude oil production capacity, and fuel switching from oil to gas. Both Japan and West Germany hola or control large quantities of oil which can be used during a disruption. In the mid case between now and 1995 it is assumed that 2 MMBD of theise stocks can be drawn down and after 1995 the rate increases to 3 MMBD. At present there is significant excess crude oil capacity throughout the Middle East. Although this excess capacity is projected to decline over time depending on the assumed production capacity utilization and the area of disrupted supplies, there should, in most cases, be some amount of excess capacity available to offset a disruption even in the distant future. The assumptions for this excess caplacity are explained in Section 7, Table 14. In addition, during a crisis some oil users will be able to switch to natural gas. In this analysis it is assumed that fuel switching could reduce oil demand by 350 thousand barrels per day from 1995 forward. In this analysis it is assumed that all of the excess capacity, foreign strategic stocks, and fuel switching supplies will be made available at the outset of a disruption. There is however, a range of values for these factors that is considered in the sensitivity analysis. All of these factors can be used to reduce the gross oil disiuption and thereby reduce the volume of SPR oil needed during a disruption. These factors (U.S. strategic and Foreign stock 
and Foreign stock draws, axcess production capacity, and fuel switching) account for the difference between a gross disruption and the actual oil shortage. 


\section{World Oil Market and Price Projections}

The world oll market projections were derived from previously published Department of Energy analyses. The assumptions used in making these profections were as follows:

- EIA's 1989 International Energy Out look DOE/EIA-0484 (89) oll production, consumption, and price projections were used for 1989-2000.

- World oil market production and consumption trends from the Department of Energy's Long Rainge Energy Projections to $2010 \mathrm{DOE} / \mathrm{PE}-0082$ were used for 2001-2020.

- EIA's Electricity Generation from Natural Gas: Prospects and Implications for the United State SR/EPD/89-01 price projections were used for 2001-2020.

World oil prices, in constant 1988 dollars, are projected to double between 1988 and $20: 20$ under low-price assumptions, and almost triple under the high-price assumptions, as lilustrated in Figure 9. In both cases, a substantial part of the increase in prices is projected to occur in the late 1990's as growing demand for oil reduces the current excess in world oil production capacity, and as oil production from sources other than OPEC levels off and begins to decline. prices continue to rise between 2000 and 2020 as OPEC gains a larger share of the world oil market.

The price cases used in this report are based on the assumption that oil demand can be met primarily from conventional supplies and enhanced oil recovery (EOR) techniques. It is assumed that additional supplies will be forthcoming in sufficient quantities from more costly synthetic fuels to limit further price increases.

Economic and energy trends in the free world and alternative estimates of world energy resources were considered in formulating these ranges for world oil prices. A number of sensitivity cases were investigated in which several basic assumptions were altered. These sensitivities include varying assumptions for economic growth, energy/GDP ratios, non-OPEC oil supplies, OPEC production capacity, and oil's share of energy consumption. The price effects of these variations in assumptions were first estimated individually and then a combined uncertainty range was derived.

This range of prices does not capture extreme market scenarios such as a supply disruption or an oil price war which could easily cause prices to fall outside of this projected range for at least short periods of time. However, while oil prices in any given year could li.e outside this band of uncertainty, it is believed that price fluctuations outside of this band are not sustainable. Prices above this range of uncertainty would discourage demand, encourage the higher cost non-OPEC production, and lead to increased excess oil production capacity in the OPEC countries, with the result that 


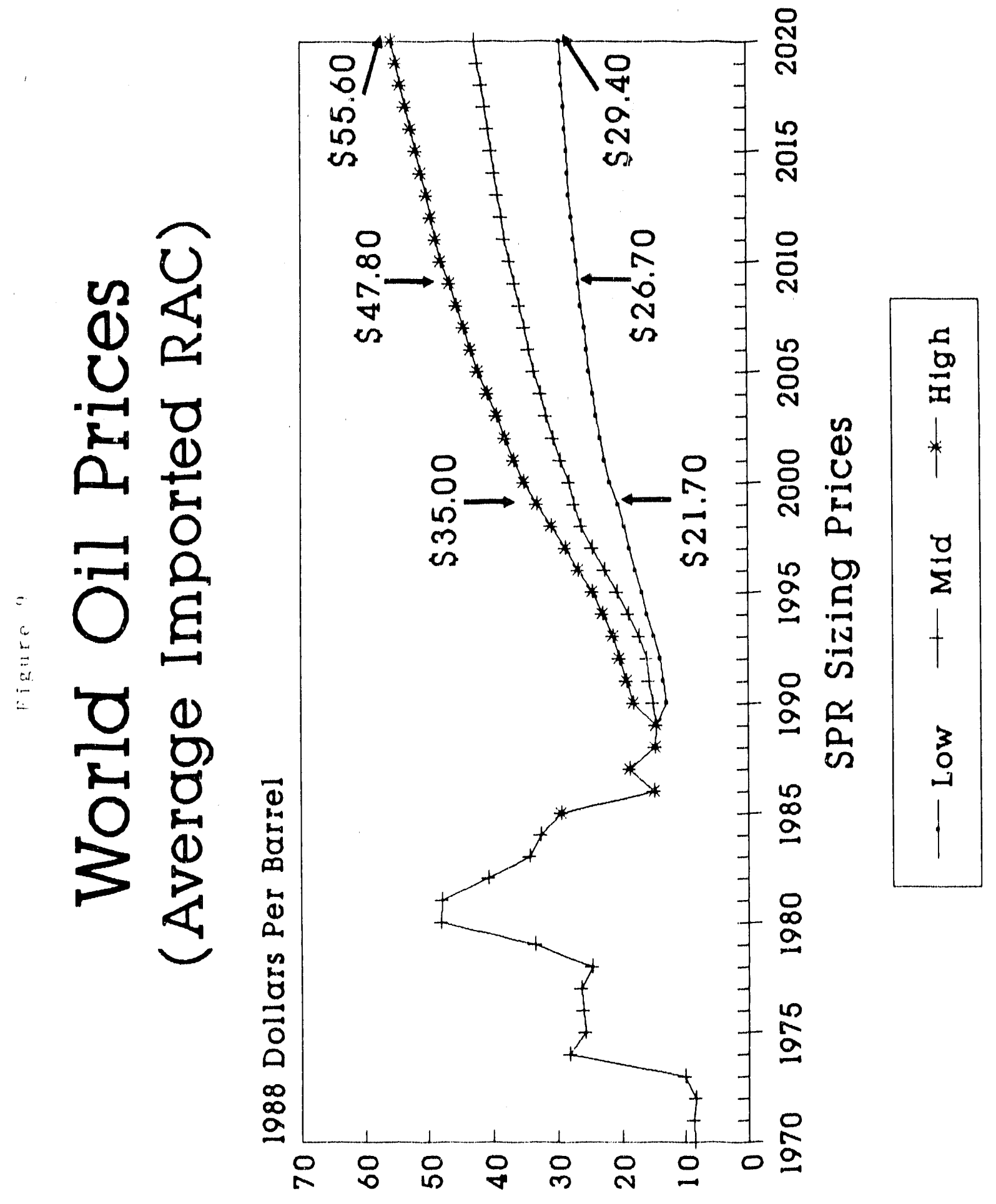


prices would fall. Prices below this band would have the opposite effect. Given these market pressures, prospects for prices to be sustained outside this band are considered unlikely.

Table 2 summarizes the demand and supply outlook to 2020 under the three price paths. The low price path results in increased demand, lower non-OPEC production, and an increased demand for OPEC production, while higher prices have the opposite effect. The variations in demand and non-OPEC supplies resulting from varying prices were first estimated individually and then a combined uncertainty range for OPEC production was derived.

Prices used in the National Energy strategy (NES) were not available at the time this analysis was being completed and therefore were not used. However, the NES prices are only marginally lower than those used here. 


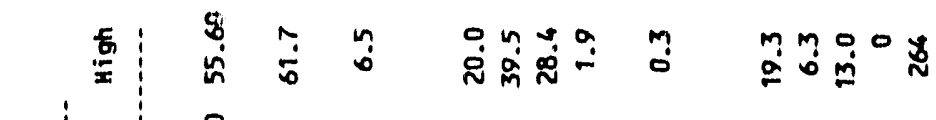

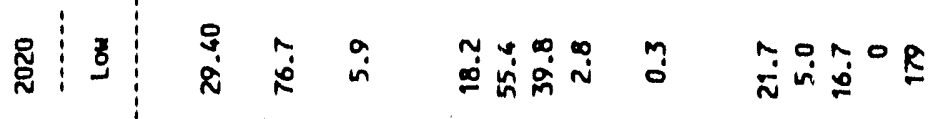

$$
\begin{aligned}
& \text { 華 }
\end{aligned}
$$

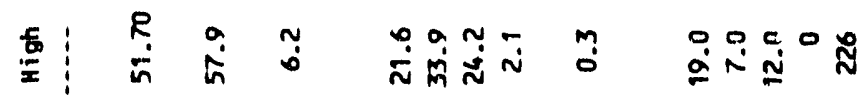

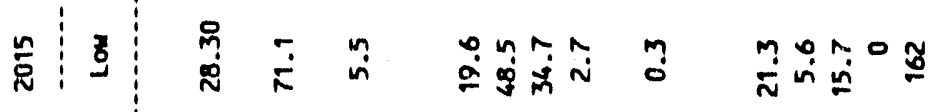

$$
\begin{aligned}
& \text { D. } \\
& \text { 重 }
\end{aligned}
$$

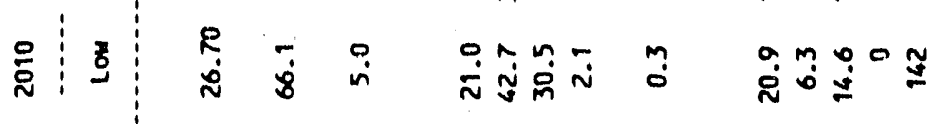

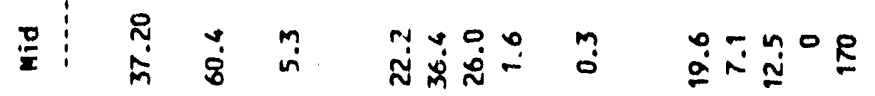

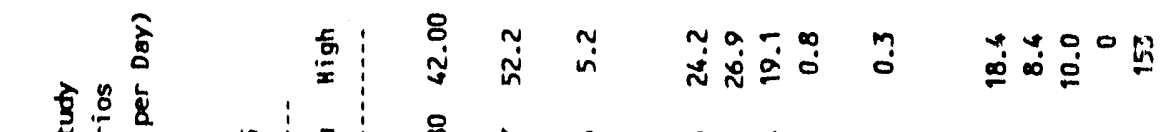

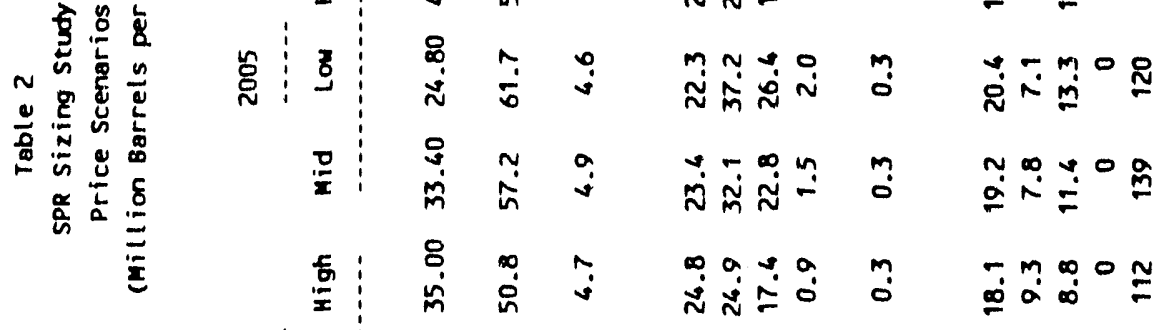

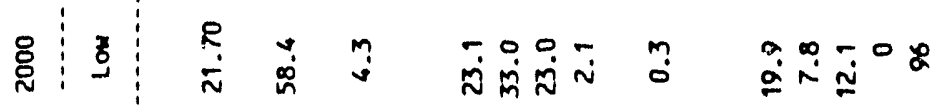

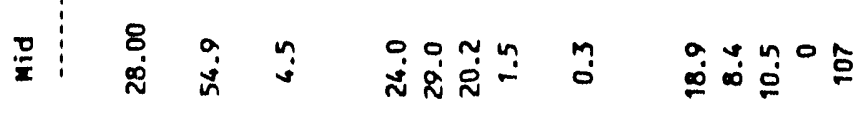

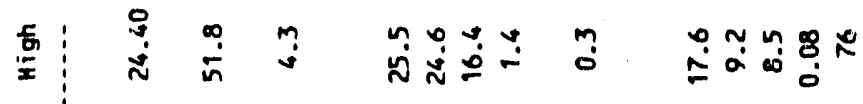

$$
\begin{aligned}
& \text { \&) }
\end{aligned}
$$

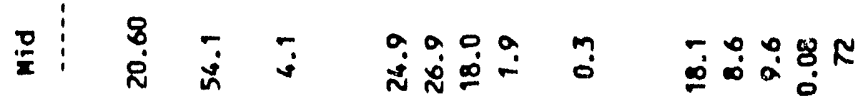

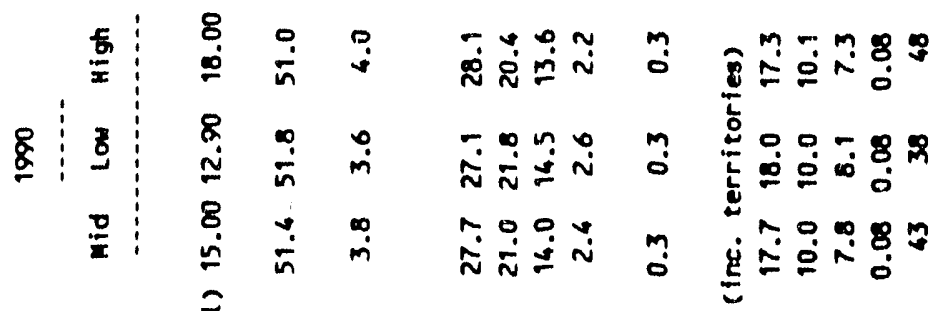

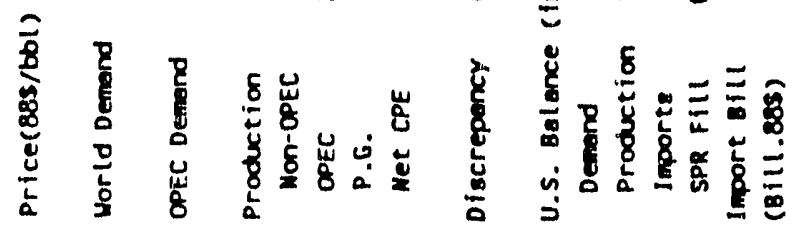




\section{Price Elasticities}

The price elasticities used in this analysis were developed by the Unification Spreadsheet (UNIFIER). The Unifier is used to provide consistent crude price elasticities between the EIA's oil Market simulation (OMS) and DIS models.

The OMS model is used to make business-as-usual (BAU) forecasts of world crude oil prices, while the DIS model is used for supply disruption analyses of impacts on the U.S. economy, hence the DIS model is only concerned with short-term elasticities of demand. Estimates of crude price elasticities are needed to calculate price impacts at different disruption sizes. The Unifier uses BAU regional crude price elasticities from the OMS model as input to generate crude price elasticities for disrupted scenarios in the DIS model.

Although retail petroleum product price elasticities are commonly used ir many models, the OMS and DIS models concentrate on the demand for crude oil instead of petroleum products. For OMS and DIS models, it is necessary to develop crude price elasticities that will consistently capture consumer responsiveness of demand for petroleum products to changes in crude prices. To understand the Unifier's disrupted crude oil price elasticity, the following relationships must be clear:

- Consumer behavior at the retail level -- petroleum product demand changes versus crude price changes.

- The nature of the mark-up between crude price and weighted average retail product prices.

- The role of changing prices on economic growth and demand (feedback effects).

- The lags in consumer response to changing prices.

The following equation for a crude price elasticity captures a relationship between crude and average retail product prices which reflects the responsiveness of the tocal petroleum demand changes:

$$
N_{c}=\left(P_{c} / P_{1}\right) \cdot N_{t}
$$

$N_{c}$ is the crude price elasticity; $P_{c}$ and $P_{r}$ are the crude and retail prices, respectively; and $N_{r}$ is the retail price elasticity.

The Unifier requires a BAU iorecast of petroleum demand and base crude prices with associated crude price elasticities, for five regions. A study of the difference between crude oil prices and the weighted average retail product prices in each region was undertaken to develop the constant retail price mark-ups for each region. It is assumed that these mark-ups, such as taxes, transportation, and other charges, do not usually filuctuate with changes in crude oil prices, so the: 


\section{Retail Price $=$ Crude Price + Mark-up. \\ Constant Retail Price Mark - up \\ (1988 Dollars Per Barrel)}

$\begin{array}{ll}\text { United States } & \$ 13.57 \\ \text { Canada } & \$ 33.95 \\ \text { Japan } & \$ 52.67 \\ \text { Western Europe } & \$ 44.17 \\ \text { Other } & \$ 19.12\end{array}$

Retail price elasticities are larger (in absolute value) than crude price elasticities because of this assumed constant retail price mark-up. If crude and product price elasticities were assumed to be equal, the implied demand response to a change in crude oil prices would be overestimated.

The crude price elasticity must be smaller than the retail price elasticity in order to reflect the responsiveness of product demand to a change in crude prices. Yet, as the crude oil price increases, the percent change of crude and retail prices approach each other, and the crude price elasticity gets closer to the retail price elasticity.

Also, the retail price elasticity is assumed to increase as prices increase through the incorporation of an economic feedback measure, added in lieu of a separate economic variable in the equation. Economic feedback occurs as crude oil prices increase, and petroleum expenditures become an increasing share of an individual's budget. For example, the U.S. retail price elasticity ranges between -0.19 and -0.25 at crude prices of $\$ 20$ to $\$ 75$ per barrel respectively. (See Table 3)

The Unifier also assumes the demand response to changes in crude prices will not be immediate, there will be a lag in the full response. A quarterly adjustment is applied so crude price elasticities increase over time, but they increase by a smaller amount every quarter.

Figure 10 exhibits the lag response percent change assumed in the Unifier. During the first quarter, 90 percent of the first year's elasticity is assumed, and by the fourth guarter 110 percent, so that all four quarters average 100 percent. The next year is assumed to experience a 40 percent average increase, while the third year is assumed to experience another 20 percent. (This assumes an annual lagged coefficient of 0.4 )

With the above relationships in mind, it is clear why the Unification spreadsheet was named in that it unifies five regional oms crude elasticities at a base price to crude elasticities as a function of crude disruptions for the DIS model. Starting with those base price OMS crude elasticities, originally derived from retail petroleum product elasticities from various EIA models, crude elasticities are calculated

\footnotetext{
'Other includes less developed countries, excluding OPEC countries, Australia and New Zealand.
} 
Table 3

Unifior Matrix for the onited states*

$\begin{array}{ccccc}\begin{array}{c}\text { Reference } \\ \text { Crude } \\ \text { Price }\end{array} & \begin{array}{c}\text { Average } \\ \text { Mark-up }\end{array} & \begin{array}{c}\text { Reference } \\ \text { Retail } \\ \text { Price }\end{array} & \begin{array}{c}\text { Crude } \\ \text { Elasticity }\end{array} & \begin{array}{c}\text { Retail } \\ \text { Elasticity }\end{array} \\ \$ 5.00 & \$ 13.57 & \$ 18.57 & -0.0462 & -0.1606 \\ \$ 10.00 & \$ 13.57 & \$ 23.57 & -0.0743 & -0.1703 \\ \$ 15.00 & \$ 13.57 & \$ 28.57 & -0.0960 & -0.1801 \\ \$ 20.00 & \$ 13.57 & \$ 33.57 & -0.1120 & -0.1862 \\ \$ 25.00 & \$ 13.57 & \$ 38.57 & -0.1256 & -0.1924 \\ \$ 30.00 & \$ 13.57 & \$ 43.57 & -0.1374 & -0.1985 \\ \$ 35.00 & \$ 13.57 & \$ 48.57 & -0.1481 & -0.2047 \\ \$ 40.00 & \$ 13.57 & \$ 53.57 & -0.1579 & -0.2108 \\ \$ 45.00 & \$ 13.57 & \$ 58.57 & -0.1671 & -0.2170 \\ \$ 50.00 & \$ 13.57 & \$ 63.57 & -0.1759 & -0.2231 \\ \$ 55.00 & \$ 13.57 & \$ 68.57 & -0.1843 & -0.2293 \\ \$ 60.00 & \$ 13.57 & \$ 73.57 & -0.1923 & -0.2355 \\ \$ 65.00 & \$ 13.57 & \$ 78.57 & -0.2001 & -0.2416 \\ \$ 70.00 & \$ 13.57 & \$ 83.57 & -0.2078 & -0.2478 \\ \$ 75.00 & \$ 13.57 & \$ 88.57 & -0.2152 & -0.2539 \\ \$ 80.00 & \$ 13.57 & \$ 93.57 & -0.2226 & -0.2601 \\ \$ 85.00 & \$ 13.57 & \$ 98.57 & -0.2298 & -0.2662 \\ \$ 90.00 & \$ 13.57 & \$ 103.57 & -0.2369 & -0.2724 \\ \$ 95.00 & \$ 13.57 & \$ 108.57 & -0.2439 & -0.2785 \\ \$ 100.00 & \$ 13.57 & \$ 113.57 & -0.2508 & -0.2847\end{array}$

These estimates are point elasticities (not average) and include economic feedback. 


\section{Figure 10}

\section{Lag Adjustment}

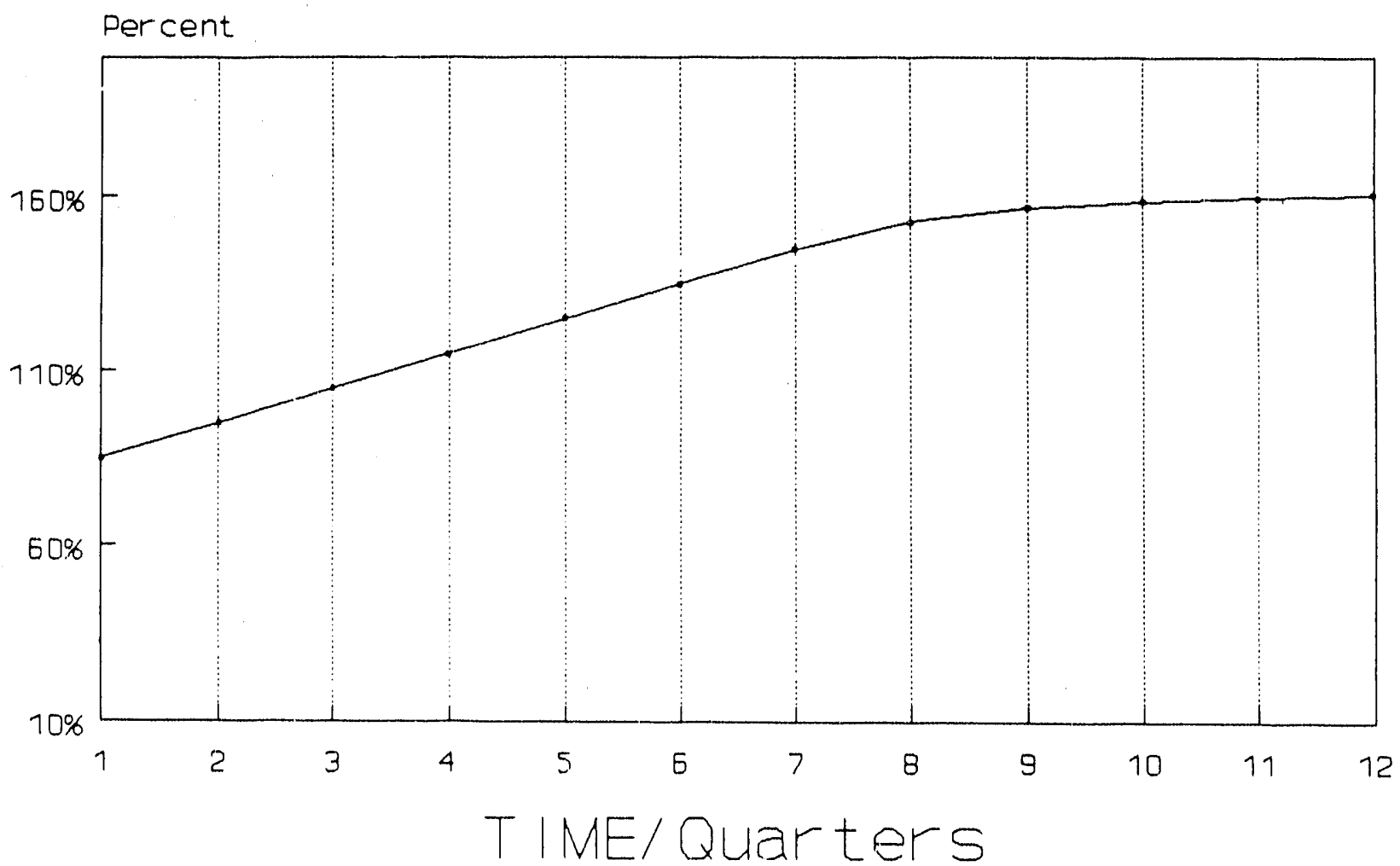

by region for any price level.

Figure 11 plots a demand curve generated by the Unifier. If a 10 million barrel per day (MMBD) disruption were specified, the Unifier would indicate a clearing pricc of about $\$ 70$ at an elasticity of -0.155 . This is compared to about $\$ 160$ if the elasticity were constant at -0.1 , or almost $\$ 50$ if the elasticity were constant at -0.2 .

Table 4 is an example of the elasticity output the unifier generates for various user-specified disruption sizes. For each disruption size, an annual average world total elasticity is first determined, then annual averages for the United states and rest of the world (other) are determined as demand weighted averages of the total. Since DIS models quarterly disruptions, quarterly elasticity estimates are made using the lagged adjustment curve. The level of uncertainty surrounding these midpoint elasticity estimates is assumed to be fairly high and is estimated at 25 percent on the high and low sides to create a range of elasticities. The assumption is based on the uncertainties found in 
Figure 11

\section{DIS Crude Elasticity Curve}

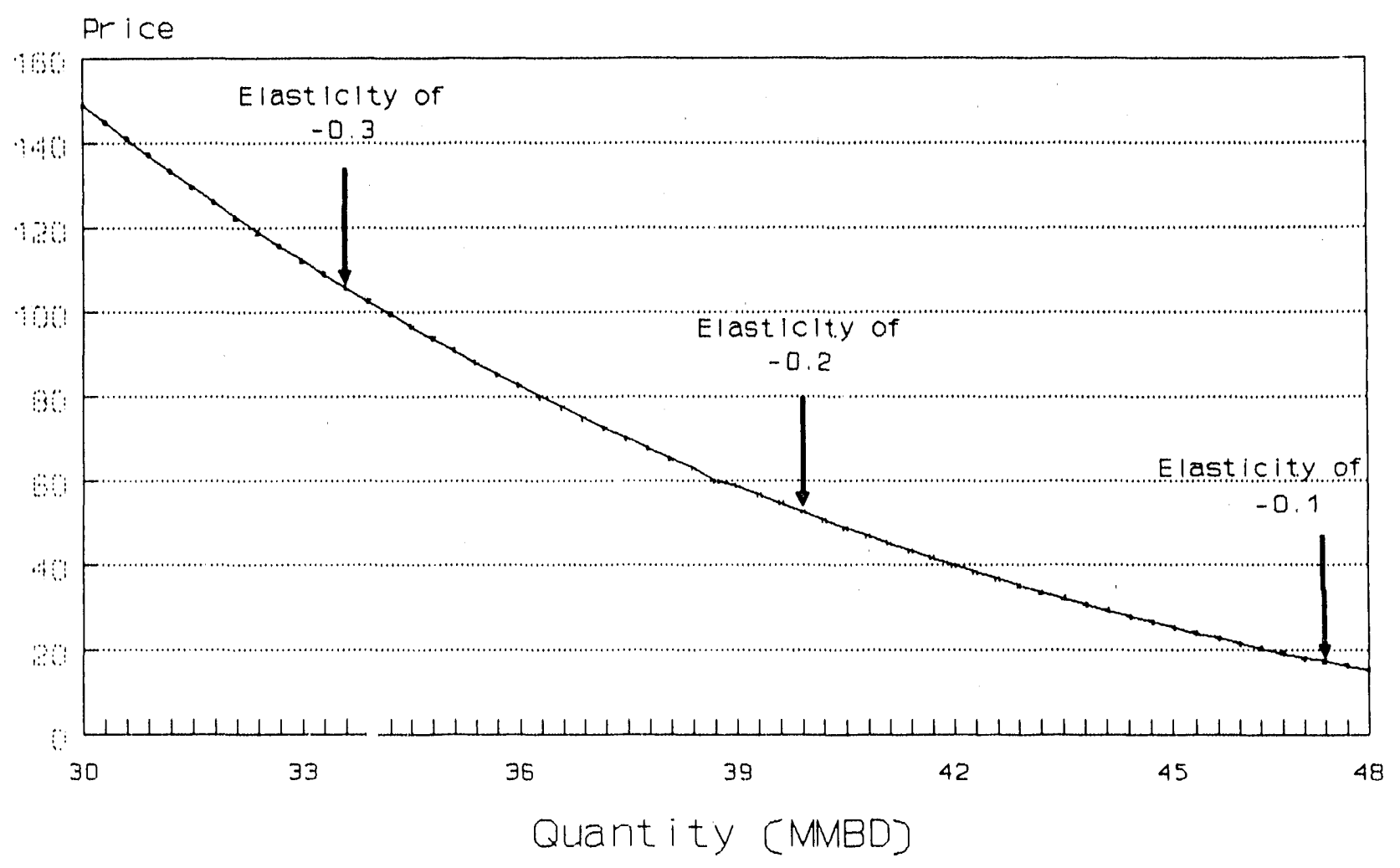

other surveys which range from 25 to 50 percent. (Table 5)

The elasticities generated by the Unifier for the SPR Sizing Study can be found at $A 1$ through $\mathrm{AX} 403$ in the elasticity spreadsheet used by the "extended" DIS model in this study. 
Table 4

Unifier Output at Different Disruption sizes

Year 1990

\begin{tabular}{lll} 
Base Case* & \multicolumn{2}{c}{ (Base Price $=\$ 15.00)$} \\
\hline Total Avg. & -0.095 & Other High \\
Other Avg. & -0.094 & Other Low \\
U.S. Avg. & -0.097 & U.S. High \\
Demand & 47.547 & U.S. Low
\end{tabular}

Disruption Size $=5$

Total Avg -0.126

other Avg. $\quad-0.124$

U.S. Avg. $\quad-0.129$

Demand $\quad 42.647$

Disruption Size $=10$

Total Avg. $\quad-0.155$

Other Avg. $\quad-0.154$

U.S. Avg. $\quad-0.159$

Demand $\quad 37.647$

Other High

other Low

U.S. High

U.S. Low

Other High

other Low

U.S. High

U.S. LOW

$\frac{\text { Disruption Size }}{\text { Total Avg. }}=\frac{15}{-0.185}$

Other Avg. $\quad-0.183$

U.S. Avg. $\quad-0.190$

Demand $\quad 32.647$

Other $\mathrm{High}$

other Low

U.S. High

U.S. LOW

Disruption Size $=20$

Total Avg. $\quad-0.218$

Other Avg. $\quad-0.216$

U.S. Avg. $\quad-0.223$

Demand $\quad 27.647$

\begin{tabular}{lrrr}
\multicolumn{5}{c}{ Quarterly Elasticities } \\
\hline 1st Q & 2nd $Q$ & $\frac{3 \text { rd } Q}{-0.123}$ & $\frac{4 \text { th } Q}{-0.135}$ \\
-0.099 & -0.111 & -0.123 & -0.081 \\
-0.060 & -0.067 & -0.074 & -0.139 \\
-0.103 & -0.115 & -0.127 & -0.139 \\
-0.062 & -0.069 & -0.076 & -0.084
\end{tabular}

$\begin{array}{llll}\text { 1st } Q & \text { 2nd } Q & \frac{3 \text { rd } Q}{-0.163} & \frac{4 \text { th } Q}{-0.179} \\ -0.132 & -0.148 & -0.169 & -0.107 \\ -0.079 & -0.089 & -0.098 & -0.185 \\ -0.137 & -0.153 & -0.169 & -0.185 \\ -0.082 & -0.092 & -0.101 & -0.111\end{array}$

1st 0

$-0.163$

$-0.098$

$-0.169$

$-0.101$

2nd 0

$3 \mathrm{rd} Q$

$-0.202$

$-0.121$

$-0.209$

$-0.125$

4 th $\mathrm{Q}$

$-0.109$

$-0.189$

$-0.113$

$-0.221$

$-0.133$

$-0.229$

$-0.137$

1st $Q$

$-0.195$

2nd 0

$\frac{3 \mathrm{rd} Q}{-0.241}$

$-0.144$

$-0.249$

$-0.149$

4 th 0

$-0.264$

$-0.158$

$-0.202$

$-0.131$

$-0.225$

$-0.135$

$-0.273$

$-0.164$

lst 0

$-0.229$

$\frac{\text { 2nd } \mathrm{Q}}{-0.256}$

$3 \mathrm{rd} 0$

$-0.283$

$-0.170$

$-0.293$

$-0.176$

4 th 8

$-0.310$

$-0.186$

$-0.237 \quad-0.265$

$-0.142-0.159$

$-0.321$

$-0.193$

* Note: Crude elasticities differ significantly depending on starting reference/base price and demand levels. 
Table 5

\section{Comparison of studies on crude oil price Elasticities}

\begin{tabular}{|c|c|c|c|c|}
\hline & $\underline{O M B}^{a}$ & $\underline{\text { stanford }}^{b}$ & OMS/DI8 & \\
\hline Crude Prices & $\$ 35.00$ & $\$ 15.00$ & $\$ 35.00$ & $\$ 15.00$ \\
\hline Mean Elasticity & 0.160 & 0.101 & 0.129 & 0.097 \\
\hline High Elasticity & 0.24 & - & 0.161 & 0.121 \\
\hline Low Elasticity & 0.08 & - & 0.096 & 0.073 \\
\hline
\end{tabular}

- Survey of Demand Elasticity Studies and Development of a Plausible Range of Estimates for Crude Oil; Office of Management and Budget; 1986 Short Run Price Elasticity of Crude Oil Demand; Stanford University; October, 1989

Crude oil Demand Elasticities from the oil Market simulation and Disruption Impact Simulator Model

\section{Notes}

1) The OMB elasticities were averaged from a series of different studies. The time periods of these studies range from 1929 to 1981.

2) All analyses assume the crude price elasticity is approximately equal to the product price elasticity multiplied by the ratio of crude to product prices.

3) All analyses assume a constant retail price markup.

4) Estimates of elasticities listed consider the United states only. 


\section{Economic Benefits and Costs}

The analysis is concerned with incremental benefits and costs of alternative size SPR systems. Due to the greater price reducing potential, larger size systems would lead to lower economic losses during a disruption, or larger incremental benefits and also larger economic costs.

\section{Benefits}

The economic benefit of releasing SPR oil stocks is based on the analysis performed by the T2/T3 working group (which consists of the Department of Tleasury, Council of Economic Advisers, and office of Management and Budget). Their analysis, Macroeconomic Impact of an Oil Supply Disruption, November 27, 1989 (See Appendix A), describes two components of the total effect of an oil market disruption on the U.S. economy. The economic benefit of releasing SPR stocks is derived from its limiting effect on potential price increases. Price increases that are not offset by other policy responses have a negative impact on GNP due to adjustment costs imposed on the economy caused primarily by the sluggishness of the labor market and through the net loss in domestic producers' and consumers' surplus (which includes the terms of trade effect). Gains accrue to producers and losses are incurred by consumers. Since the United States is a net importer, the loss exceeds the gain. Further reducing the overall loss during an oil disruption are receipts from the sale of the SFR oil. In addition, the post2020 salvage value of SPR oil is considered a veneEit but is treated separately and not included in the benefit estimates in this analysis.

The GNP impact is estimated using a simple relationship of GNP with respect to oil price changes. That is,

$$
G N P_{d}=G N P_{b} \star\left(P_{d} / P_{b}\right)^{\bullet}
$$

where $P_{d}$ is the price of oil as a result of the oil disruption reduced by the amount of $S P R$ oil drawn for a given SPR system;

$P_{b}$ is the price of oil before the disruption for a given SPR system;

- is the elasticity of GNP to oil price changes; and GNP is the quarterly rate (not annual) in constant 1988 dollars.

As described in the $\mathrm{T} 2 / \mathrm{T} 3$ working group analysis, this negative impact on GNP is assumed to persist only for the duration of the disruption. The economic feedback parameter (e) is estimated to range between -0.02 and -0.04 with a mid case estimate of -0.025. (These estimates are consistent with a wide range of studies as discussed in the T2/T3 analysis.) 
Benefits arising from producers' and consumers' surplus are estimated using price and oil import levels underlying the oil demand functions and range of demand elasticities assumed for the study. Domestic oll production surge due to higher prices is treated separately and included in the excess capacity offset assumptions (Section 7). The calculation of incremental system benefits will not be affected since the domestic oil surge benefit is the same under the alternative systems. The greater the demand elasticity (in absolute value), the less the extent that price will increase and the less will be the loss in consumers' surplus (and, coincidently, the reduction of GNP). This loss is incurred as long as price is above base case levels even though the disruption may have ended. World oil prices during the hypothetical disruption are calculated as market-clearing prices after offsetting assumptions (such as surge production). Following the end of the disruption, price is assumed to decline at a rate of about 38 percent (of the difference from the base case) per quarter.

Figure 12 illustrates graphically the components used to compute net rurplus loss. By area, the calculation:

\begin{tabular}{ll} 
Area & \multicolumn{1}{c}{ Component } \\
$\begin{array}{l}B+C \\
+D\end{array}$ & $\begin{array}{l}\text { Terms-of-Trade Deterioration } \\
\text { Economic Efficiency Loss }\end{array}$ \\
$-(B+E)$ & SPR Receipts \\
\hline$C+D-E$ & Surplus Loss
\end{tabular}

The model calculates the value of this loss explicitly; however, it can be approximated using the average of pre-and post-shock oil import levels multiplied by the change in price less receipts from the sale of SPR oil using:

$$
T T L=\left(P_{d}-P_{b}\right) *\left(I_{d}+I_{b}\right) / 2-P_{b} * S P R
$$

The total loss of the disruption includes both the GNP loss (macro effect) and the net consumers' surplus loss (micro effect). The economic benefit of the alternative systems is the difference in total loss, referred to as gross benefit. Finally the benefits are discounted to present value and weighted by the probability of the occurrence of a given size disruption.

Costs

The cost of filling the SPR includes the acquisition cost of the oil and capital cost to acquire storage capacity. For this study any additional maintenance costs associated with the larger system is assumed to be zero. Further, capital costs for the 750 MMB size is assumed to be zero since this system has already been planned. 


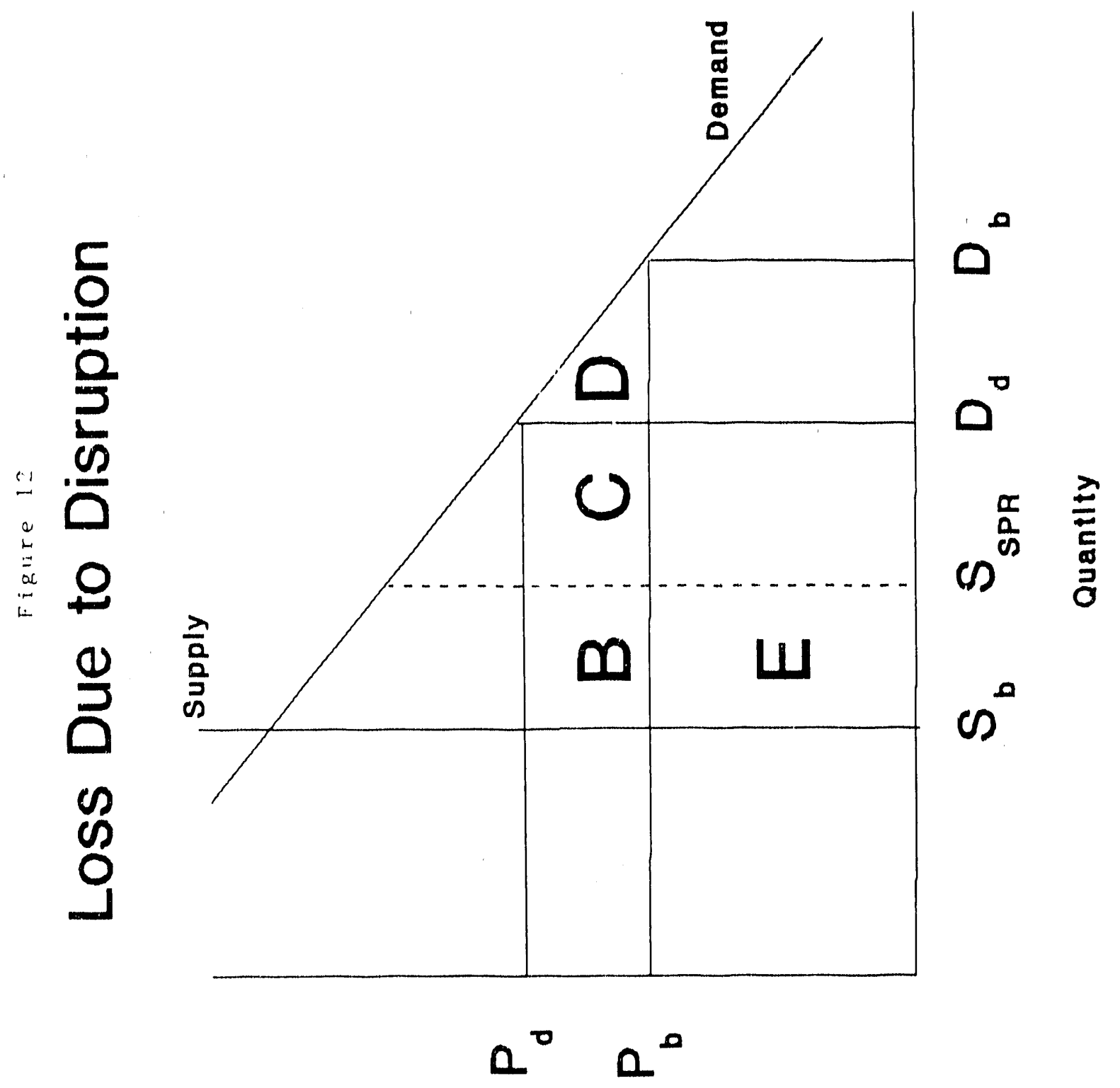

a $\alpha-0 \omega$ 
The incremental capital cost of the $1000 \mathrm{MMB}$ system relative to the 750 MMB system is taken from the Oak Ridge study, footnoted in section 2 .

Tables 6 through 9 contain estimates of incremental capital costs and the developmental schedule for fjiling the 750 and $1000 \mathrm{MMB}$ systems. The fill schedule varies with the fill rate assumed. For the mid case, a fill rate of 75 thousand barrels per day is assumed. Sensitivities were examined using alternative fill rates of 50 and 100 thousand barrels per day.

These costs (C) are summed and discounted (DC) using:

(9) $D C=C /(1+D R)^{\prime}$

Salvage Value and Import cost

The salvage value of oil remaining after a partial drawdown of the $S P R$ and the impact on world oil price of filling the SPR are treated separately in the analysis and are never included in elther the cost or benefit estimates. Salvage value could be viewed as an economic benefit since it would offset some of the costs of the original oil in the context of a cost-benefit analysis. The impact on world oil prices due to filling the SPR at alternative fill rate assumptions is estimated using the EIA's OMS model. Depending on the fill rate, the impact on world oil price ranges between 10 to 15 cents per barrel. This highel price is applied to total imports (since the costs of all imports would be paid at the higher price) to obtain the incremental costs. Tables 10 and 11 provides the range of estimates for salvage value and costs associated with different fill rates. 
Table 6. SPR Fill Schedule and Costs

Post 1989

750 MMB system

Mid price Case

Fll Rate $=50 \mathrm{MBD}$

Capital Year End SPR Fill Cumulative Cost SPR Level

(1988 \$)

(MMB)

Cost

(1988 \&)

Discounted

$\cos t$

Year End SPR FIII Cumulative

SPR Level

(MMB) (19

\section{$=x==$
1989 \\ 1990}

1991

1992

1993

1994

1995

1996

1997

1998

1999

Low Price Case
Fill Rate $=50 \mathrm{MBD}$

Fill Rate $=75 \mathrm{MBD}$

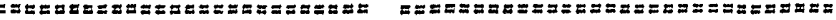

Capital Year End SPR Fill Cumulative

Cost SPR Level

Year

$===2$

1990

1991

1992

1993

$192 \%$

1995

1996

1997

1998

1999

\section{Cost}

(1988 \$)

scounted

$$
\text { cost }
$$

PR Level

(MMB)

Cost Discounted

$\begin{array}{rr}\text { (1988 \$) } & \text { Cost }\end{array}$

582 $=z=z=x=$

353
367
379
405
433
457
65
0
0
0

$==1:=$
PR Level

(MMB)

Cost Discounted

(1988 \$)

$\cos t$
$== \pm$
582

619

655

692

728

750

750

750

750

750

750

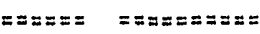

$471 \quad 471$

$489 \quad 915$

$505 \quad 1333$

$540 \quad 1739$

$346 \quad 1975$

$0 \quad 1975$
Fill Rate $=100$ MBD

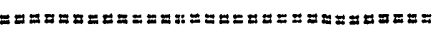

Year End SPil Fill Cumulative

Cost Discounted

(1988\$) Cost

ะr:

$\begin{array}{llll}411 & 619 & 548 & 548\end{array}$

$\begin{array}{llll}796 & 655 & 566 & 1062\end{array}$

$1157 \quad 692 \quad 582 \quad 1543$

$\begin{array}{llll}1509 & 728 & 624 & 2012\end{array}$

$\begin{array}{llll}1862 & 750 & 414 & 2294\end{array}$

$2212 \quad 750 \quad 0 \quad 2294$

$\begin{array}{llll}2259 & 750 & 0 & 2294\end{array}$

$2259+750 \quad 0 \quad 2294$

$2259 \quad 750 \quad 002294$

$\begin{array}{llll}2259 & 750 & 0 & 2294\end{array}$

High Price Case

Fill Rate $=50 \mathrm{MBD}$

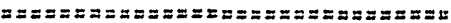
Cost SPR LeV

(1988 s)

(MMB)

SPR Fill Cumulative

Cost Discounted

Cost

$\approx= \pm= \pm=4$

$== \pm=$

1990

1991

1992

1993

1994

1995

1996

1997

1998

1999

\section{9}

637

\section{4}

692

\section{9}

i46

750

750

750

750

Fill Rate $=75$ MBD

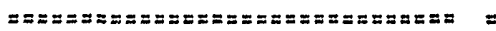

Year End SPR FIll Cumulative SPR Lavel

(MMB)

Cost Discounted

\section{3}

687

1000

1304

1599

1883

1920

1820

1920

1920

1975

1975

1975

1975 
Table 7. SPR Flll schedule and Costs

Post 1989

1000 MMB Systeli:

Mid Price Case

Flll Rate $\approx 50$ MBD

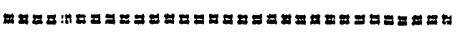

Capital Year End SPR Fill Cumulative Cost SPR Level Cost Discounted
s) Cost

$=2 \pm \approx$

1989

1990

1991

1992

1993

1994

1995

1996

4997

1898

1999

2000

2001

2002

2003

2004

2005

2008

2007

2008

2009

2010

2011

2012

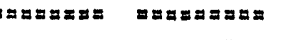

582

30

60

110

200

220

190

120

70

0

0

0

0

0

0

0

0

0
0

0

0

0

0

\section{0}

$$
619
$$

637

$$
655
$$

$$
673
$$

692

710

728

746

765

783

$$
801
$$

819

838

$$
856
$$

874

$$
892
$$

911

929

5,47

965

984

1000
FIll Rate $=75 \mathrm{MBD}$

ax

Year End

(MMB) (1988 S)

$\begin{array}{rr}\text { Cost } & \text { Discounted } \\ 988 \text { s) } & \text { Cost }\end{array}$

$z=a x= \pm=2$

$$
582
$$

304

615

947

1332

1717

2069

2369

2632

2854

3064

3261

3449

3626

3792

3949

4094

4230

4356

4474

4582

4683

4777

4854
609

411

424

436

468

517

564

618

665

712

742

769

802

835

862

889

236

1000

1000

1000

1000

1000

1000

1000

1000

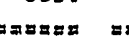

449

881

1333

1834

2338

2806

3223

3600

3032

4247

4543

4824

5090

5340

5.574

5631

5631

5631

5631

5631

5631

5631

5631
FIll Rute $=100 \mathrm{MBO}$

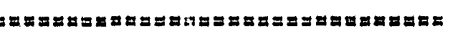

Year End SPR Fill cumulative

(MMB) (1988 \$) Cost

$$
582
$$

619

655

692

728

765

801

838

874

911

947

984

1000

1000

1000

1000

1000

1000

1000

1000

1000

1000

1000

1000
$548 \quad 578$

$566 \quad 9146$

$582 \quad 1718$

$624 \quad 2337$

$752 \quad 3544$

$824 \quad 4076$

$887 \quad 4567$

$949 \quad 5010$

$989 \quad 5430$

$1025 \quad 5825$

$475 \quad 5991$

5991

5991

5991

5991

5991

5901

5991

5991

5991

5991

5991
$690 \quad 2959$ 
Table 8. SPR FIII Schedule and Costs

Post 1989

1000 MMB system

Low Price Case

Fill Kate $=50$ MBD

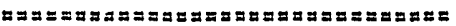

Capital Year End SPR Fill Cumulative Cost SPR Level

(1988 \$) (MMB) (1988 \$) Cost

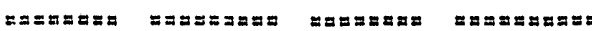

$= \pm= \pm$

1980

1990

1991

1992

1993

1994

1995

1996

1997

1998

1999

2000

2001

2002

2003

2004

2005

2006

2007

2008

2009

2010

2011

2012

$$
582
$$

$600 \quad 235$

$637 \quad 253$

$655 \quad 270$

$692 \quad 305$

$710 \quad 324$

$728 \quad 341$

$746 \quad 356$

$765 \quad 372$

$783 \quad 397$

$801 \quad 409$

$819 \quad 422$

$838 \quad 433$

$856 \quad 443$

$874 \quad 453$

$892 \quad 460$

$911 \quad 465$

$929 \quad 476$

$947 \quad 482$

$965 \quad 487$

$984 \quad 495$

$1000 \quad 447$
$619 \quad 245$

$673 \quad 288$
Fill Rate a 75 MBD

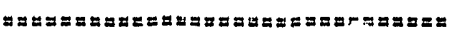

Year End SPR Fill Cumulative

SPR Level

Level Cost Discounted
(MMB) (1988\$)

582

265

542

842

1195

1542

1850

2100

2311

2477

2635

2788

2931

3066

3191

3308

3416

3516

3608

3694

3773

3845

3912

3967
$609 \quad 353$

$637 \quad 367$

$664 \quad 379$

$692 \quad 405$

$719 \quad 433$

$746 \quad 457$

$774 \quad 486$

$801 \quad 512$

$829 \quad 534$

$856 \quad 558$

$883 \quad 596$

911613

938

965

993

1000

1000

1000

1000

1000

1000

1000

1000

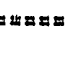

383

771

1175

1630

2075

2477

281:

3118

3367

3604

3833

4048

4250

4438

4613

4655

4655

4655

4655

4655

4655

4655

4655
Fill Rate $=100 \mathrm{MBD}$

:

Year End SPR Fill Cumulative

PR Level Cost Discounted

(MMB) (1985 \$) Cost

582

$619 \quad 471 \quad 501$

$\begin{array}{lll}655 & 489 & 1000\end{array}$

$692 \quad 505 \quad 1508$

$728 \quad 540 \quad 2064$

$\begin{array}{lll}765 & 577 & 2609\end{array}$

$801 \quad 610 \quad 3105$

$838 \quad 648 \quad 3539$

$874 \quad 683 \quad 3925$

$911 \quad 712 \quad 4257$

$947 \quad 745 \quad 4573$

$984 \quad 794 \quad 4879$

$1000 \quad 363 \quad 5006$

$1000 \quad 0 \quad 5006$

$1000 \quad 0 \quad 5006$

$1000 \quad 0 \quad 5006$

$1000 \quad 0 \quad 5006$

$1000 \quad 0 \quad 5006$

$1000 \quad 5006$

$1000 \quad 0 \quad 5006$

$1000 \quad 5006$

$1000 \quad 0 \quad 5006$

$1000 \quad 0 \quad 5006$

$1000 \quad 5006$ 
Table 9. SPR Fill Schedule and costs

Post 1989

1000 MMB system

High Price Case

Fill Rate $=50 \mathrm{MBD}$

Fill Rate $=75$ MBD

Fill Rate $=100 \mathrm{MBD}$

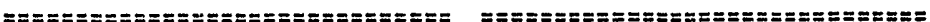

Year End SPR Fill Cumulative

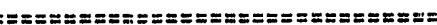

Capital Year End SPR Fill Cumulative Cost SPR Level Cost Discounted SPR Level

Cost Discounted

Year End SPR Fill Cumulative

(1988\$) (MMB) (1988\$) Cost

(MMB) (1988\$) Cost

SPR Level

Cost Discounted

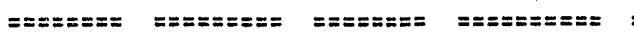

$==\pi== \pm=z=$

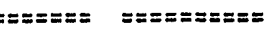

(MMB) (1988 \$)

Cost

1989

1990

$$
582
$$

30

$\begin{array}{lll}600 & 329 & 359 \\ 619 & 349 & 730\end{array}$

$\begin{array}{lll}637 & 370 \quad 1126\end{array}$

$\begin{array}{lll}655 & 387 & 1567\end{array}$

$673 \quad 416 \quad 2002$

$692 \quad 445 \quad 2396$

$\begin{array}{lll}710 & 485 & 2738\end{array}$

$\begin{array}{lll}728 & 522 & 3041\end{array}$

$\begin{array}{lll}746 & 562 & 3304\end{array}$

$\begin{array}{lll}765 & 600 & 3558\end{array}$

$783 \quad 640 \quad 3805$

$801 \quad 668 \quad 4039$

$819 \quad 692 \quad 4260$

$\begin{array}{lll}838 & 717 & 4468\end{array}$

$856 \quad 743 \quad 4663$

$\begin{array}{lll}874 & 767 & 4847\end{array}$

$892 \quad 787 \quad 5018$

$\begin{array}{lll}911 & 808 & 5178\end{array}$

$929 \quad 839 \quad 5327$

$947 \quad 849 \quad 5466$

$965 \quad 872$

5596

5716

582

$609 \quad 493$

$637 \quad 523$

$664 \quad 554$

$692 \quad 580$

$719 \quad 624$

$746 \quad 668$

$774 \quad 727$

801783

$829 \quad 843$

$856 \quad 901$

$883 \quad 961$

$911 \quad 1002$

$938 \quad 1038$

$965 \quad 1076$

$993 \quad 1114$

1000

1000

1000

1000

1000

1000

1000

1000

803

5814

523

1053

1602

2188

2765

3297

3776

4213

4607

4989

5359

5710

6041

6352

661,6

6717

6717

6717

6717

6717

6717

6717

6717
582

619

655

692

728

765

801

838

874

911

947

984

1000

1000

1000

1000

1000

1000

1000

1000

1000

1000

1000

1000

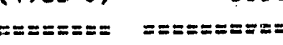

$657 \quad 687$

$697 \quad 1375$

$739 \quad 2077$

$774 \quad 2809$

$832 \quad 3528$

$891 \quad 4199$

$970 \quad 4814$

$1044 \quad 5385$

$1124 \quad 5910$

$1201 \quad 6419$

$1281 \quad 6913$

$593 \quad 7121$

$0 \quad 7121$

7121

7121

7121

7121

7121

7121

7121

7121

7121

7121 
Table 10. Salvage Value and Increased Import Cost $750 / 1000$ Increment

$$
\text { Discount Rate }=0.08
$$

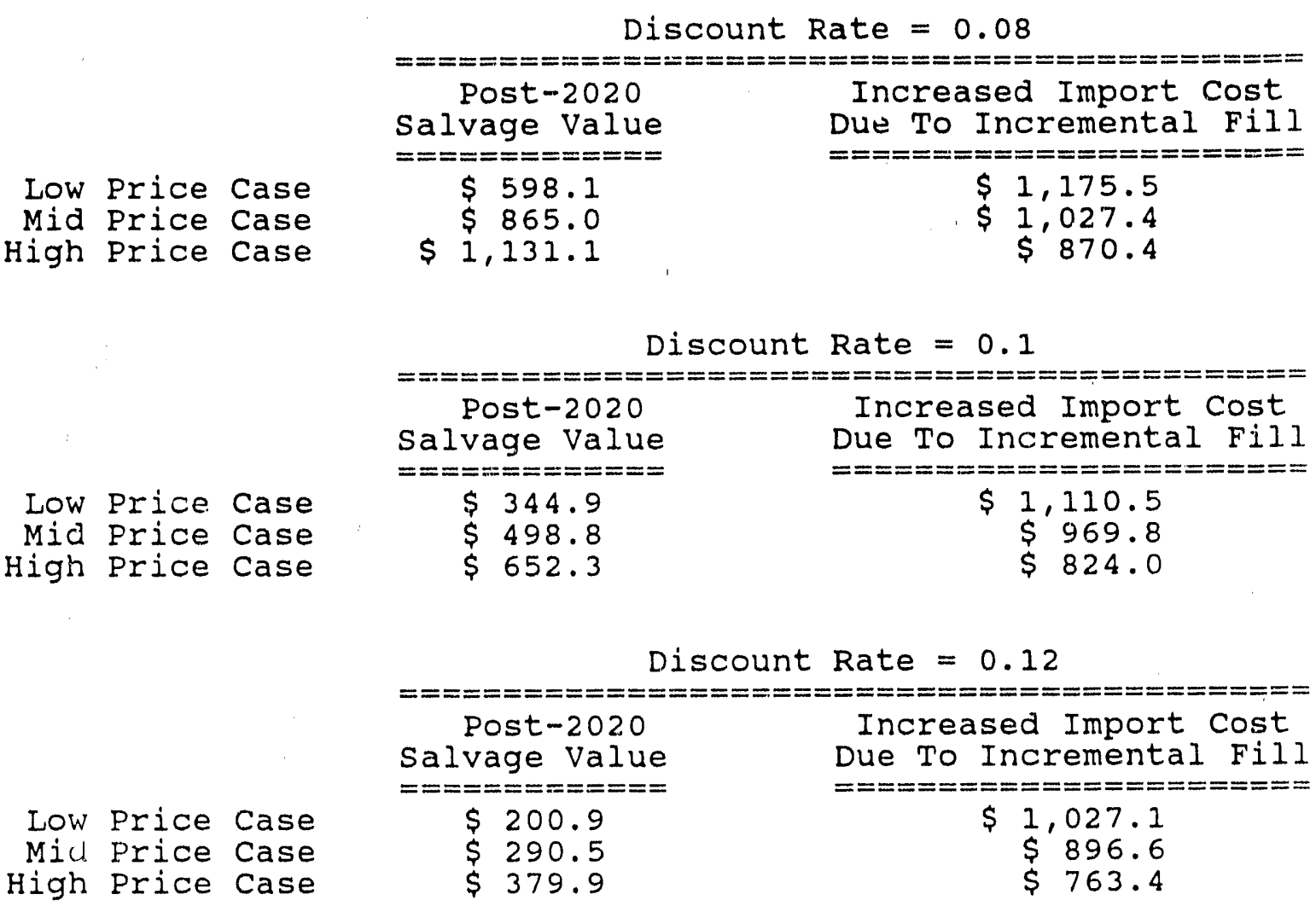

Note: Salvire Value and Import cost are in Millions of 1988 Diss unted Dollars. 
Table 11. Salvage Value and Increased Import Cost $600 / 750$ Increment

Low Price Case

Mid Price Case High Price Case

Low Price Case Mid Price Case High Price Case

Low Price case Mid Price Case High Price Case
Discount Rate $=0.08$

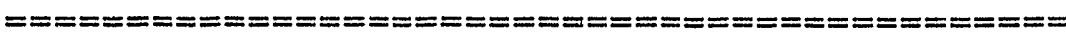
Post -2020 Salvage Value $============$ $\$ 338.2$

$\$ 489.1$

$\$ 639.5$ Increased Import cost Due To Incremental Fill

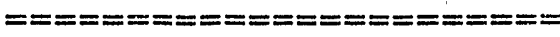
$\$ 296.2$

$\$ 353.3$

$\$ 341.9$

\section{Discount Rate $=0.1$}

\begin{tabular}{|c|c|}
\hline $\begin{array}{l}\text { Post }-2020 \\
\text { Salvage Value } \\
===========\end{array}$ & $\begin{array}{l}\text { Increased Import Cost } \\
\text { Due To Incremental Fill } \\
==================\end{array}$ \\
\hline $\begin{array}{ll}\$ & 195.0 \\
\$ & 282.0 \\
\$ & 368.8\end{array}$ & $\begin{array}{l}\$ 371.9 \\
\$ 414.0 \\
\$ 391.6\end{array}$ \\
\hline
\end{tabular}

\begin{tabular}{|c|c|}
\hline $\begin{array}{l}\text { Post }-2020 \\
\text { Salvage Value } \\
==========\end{array}$ & $\begin{array}{l}\text { Increased Import cost } \\
\text { Due To Incremental Fill } \\
================\end{array}$ \\
\hline $\begin{array}{l}\$ 113.6 \\
\$ 164.3 \\
\$ 214.8\end{array}$ & $\begin{array}{l}\$ 431.5 \\
\$ 461.2 \\
\$ 430.0\end{array}$ \\
\hline
\end{tabular}

Note: Salvage Value and Import cost are in Millions of 1988 Discounted Dollars. 


\section{Probability Analysis}

Over the last 40 years there have been about 13 oil supply disruptions of greater than 1 percent of consumption. Therefore, in any given year there is some probability of having a disruption. This section describes how the frequency distribution of having a disruption of a specific size was developed. This distribution is critical to the analysis because it is used to develop weights, which are applied to the benefits described in the previous sections.

Several steps are used to develop the probability density function used in the analysis. First the type of function must be chosen. Several functional forms including the polynomial, exponential, and Weibull were examined. Trial fits of several skewed distributions indicated that the range of shapes offered by the Weibull distribution provided the best match to the historical data. This distribution is relatively robust with respect to the process or processes that underlie the data. It requires no particular probability structure and tends to conform to the data rather than to any prior assumptions. It is often chosen to represent data with an unknown degree of skewness where the probability structure of the underlying processes cannot be specified with confidence, e.g., extreme value estimation or lifetesting with complex failure modes. It was determined that the Weibull distribution was an appropriate distribution because it was widely used to describe a worst case event which had a low probability of occurring. However, there are some Jimitations to the use of the Weibull against the 1950 to 1989 gross disruption data primarily in the application of equal weights to all historical events, and in the assumption that a single process generated all the historical events, which was high unlikely.

\section{Mid Probability Case}

Two critical parameters of this distribution must be estimated. These are the shape and scale parameters (discussed in more detail below). The values for the parameters were estimated so that:

The frequency of a gross disruption of 1 percent of consumption or greater was 32.5 percent. This percentage is consistent with historic data (13 in 40 years).

- The probability in any given year of having a "moderate to severe" disruption is 1 percent or less and declines over time. This is based on expert opinion.

- The distribution provided a good fit of actual disruption data over the last 40 years. 
The functional form of the weibull probability density function is:

$$
f(x)=c / a\left\{(x / a)^{c \cdot 1}\right\} * \exp \left[-(x / a)^{c}\right]
$$

which gives a standard "at most" cumulative distribution function of the form:

$$
F(x)=\operatorname{Pr}[X<x]=1-\exp \left[-(x / a)^{c}\right]
$$

or an "at least" function of:

$$
F(x)=\operatorname{Pr}[X>x]=\exp \left[-(x / a)^{c}\right]
$$

The "at least", also known as the survival form of this distribution function was the form focused on in this analysis. That is, the probability that a disruption will be "at least" as large as some critical value is examined. In order to estimate the scale (a) and shape (c) parameters, the function was fitted to the two points mentioned above for the mid probability case.

The first point that the function was forced to pass through was estimated based on the historic frequency of a gross disruption size "at least" equal to or greater than 1 percent of consumption. Based on a study of gross disruptions in oil supply over the last 40 years, there have been 13 occurrences of at least this size (see Table 12).

The second frequency point agreed on by the SPR sizing study group was based on expert opinion, which defined possible "moderate" disruptions over the period from 1995 to 2010. The least severe moderate disruption resulted in a supply loss of 15 percent of forecast consumption. The probability of such a gross disruption of 15 percent or greater was assessed to be 1 percent per year in the mid probability case.

The scale (a) and the shape (c) parameters estimated for the mid case projection are:

$$
\begin{aligned}
& a=0 . \frac{M i d}{799050} \\
& c=0.520798
\end{aligned}
$$

Using these a and c values and the Weibull "at least" distribution provides the cumulative probability of a disruption of at least a given percent of consumption occurring in a given year (See Table 13). The "at least" form of the equation is simply one minus the form usually discussed. At the first point used in the estimation, for example, there is a 32.5 percent chance of a disruption of 1 percent or greater. Therefore, a 67.5 percent chance of disruptions less than 1 percent (including 0 ) exists. 
Table 12

World Oil supply Disruptions

1951.1989

(Million Barrels per Day)

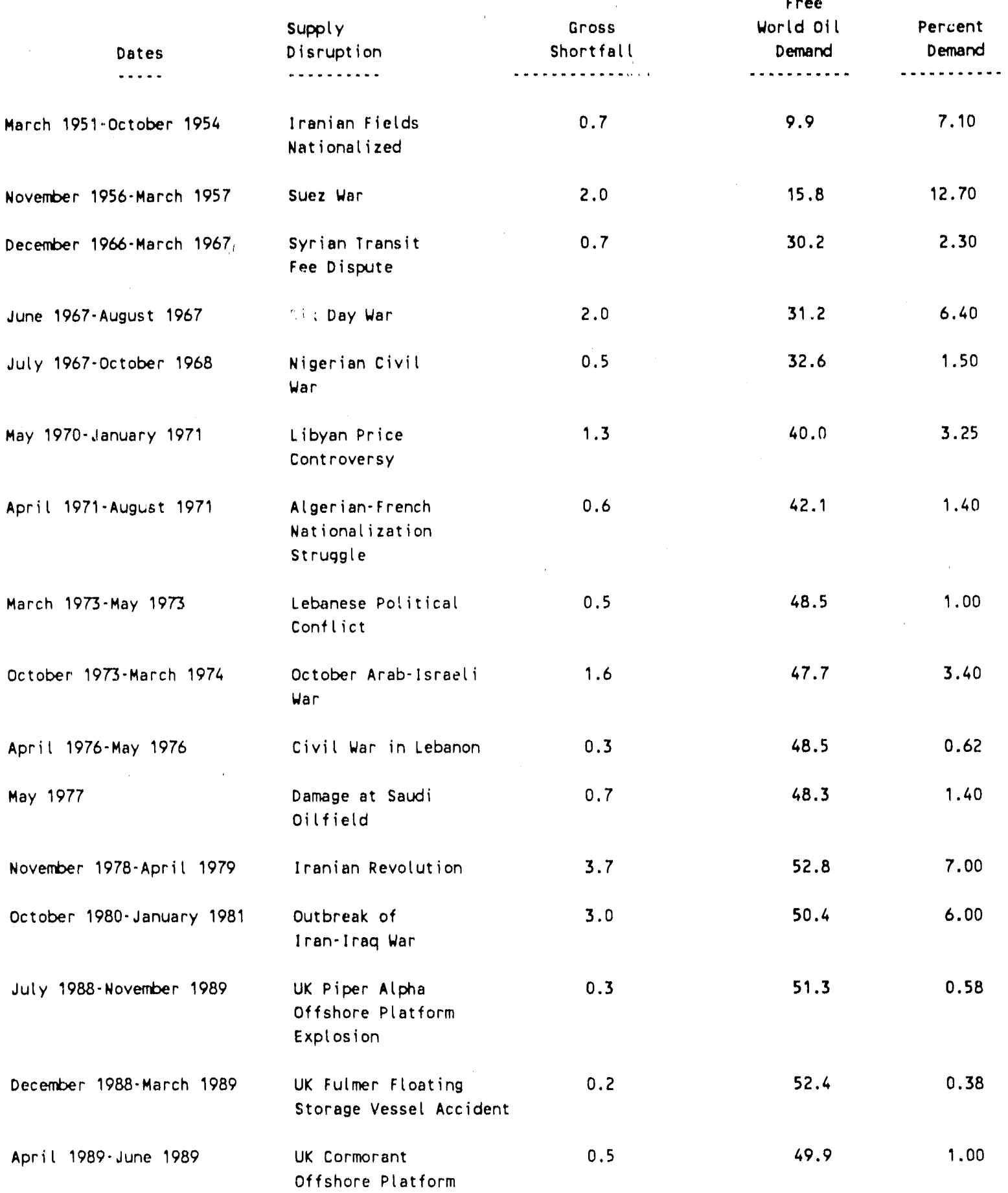


Table 13

WEIBULL CUMULATIVE PROBABILITIES FOR SPR SIZING STUDY

\begin{tabular}{|c|c|c|c|c|c|c|}
\hline \multirow{2}{*}{$\begin{array}{l}\text { Disruption } \\
\text { size } \\
\text { Percent of } \\
\text { consumption }\end{array}$} & \multicolumn{2}{|c|}{$\begin{array}{c}\text { High Probability } \\
\text { at }\end{array}$} & \multicolumn{2}{|c|}{$\begin{array}{l}\text { Mid Probability } \\
\text { at }\end{array}$} & \multicolumn{2}{|c|}{$\begin{array}{c}\text { Low Probability } \\
\text { at }\end{array}$} \\
\hline & least & most & least & most & least & most \\
\hline 0.5 & 0.4493 & 0.5507 & 0.4569 & 0.5431 & 0.4690 & 0.5310 \\
\hline 1 & 0.3250 & 0.6750 & 0.3250 & 0.6750 & 0.3250 & 0.6750 \\
\hline 1.5 & 0.2538 & 0.7462 & 0.2495 & 0.7505 & 0.2427 & 0.7573 \\
\hline 2 & 0.2062 & 0.7938 & 0.1994 & 0.8006 & 0.1886 & 0.8114 \\
\hline 2.5 & 0.1718 & 0.8282 & 0.1634 & 0.8366 & 0.1504 & 0.8496 \\
\hline 3 & 0.1457 & 0.8543 & 0.1365 & $0 . \varepsilon j 35$ & 0.1222 & 0.8778 \\
\hline 3.5 & 0.1253 & 0.8747 & 0.1155 & 0.8845 & 0.1008 & 0.8992 \\
\hline 4 & 0.1088 & 0.8912 & 0.0989 & 0.9011 & 0.0840 & 0.9960 \\
\hline 4.5 & 0.0954 & $\dot{0} .9046$ & 0.0854 & 0.9146 & 0.0708 & 0.9292 \\
\hline 5 & 0.0842 & 0.9158 & 0.0744 & 0.9256 & 0.0601 & 0.9399 \\
\hline 5.5 & 0.0748 & 0.9252 & 0.0652 & 0.9348 & 0.0514 & 0.9486 \\
\hline 6 & 0.0668 & 0.9332 & 0.0574 & 0.9426 & 0.0442 & 0.9558 \\
\hline 6.5 & 0.0600 & 0.9400 & 0.0508 & 0.9492 & 0.0382 & 0.9618 \\
\hline 7 & 0.0540 & 0.9460 & 0.0452 & 0.9548 & 0.0332 & 0.9668 \\
\hline 7.5 & 0.0489 & 0.9511 & 0.0404 & 0.9596 & 0.0289 & 0.9711 \\
\hline 8 & 0.0443 & 0.9557 & 0.0362 & 0.9638 & 0.0253 & 0.9747 \\
\hline 8.5 & 0.0404 & 0.9596 & 0.0325 & 0.9675 & 0.0223 & 0.9777 \\
\hline 9 & 0.0368 & 0.9632 & 0.0293 & 0.9707 & 0.0196 & 0.9804 \\
\hline 9.5 & 0.0337 & 0.9663 & 0.0265 & 0.9735 & 0.0174 & 0.9826 \\
\hline 10 & 0.0309 & 0.9691 & 0.0240 & 0.9760 & 0.0154 & 0.9846 \\
\hline 10.5 & 0.0284 & 0.9716 & 0.0218 & 0.9782 & 0.0137 & 0.9863 \\
\hline 11 & 0.0262 & 0.9738 & 0.0199 & 0.9801 & 0.0122 & 0.9878 \\
\hline 11.5 & 0.0242 & 0.9758 & 0.0181 & 0.9819 & 0.0109 & 0.9891 \\
\hline 12 & 0.0223 & 0.9777 & 0.0166 & 0.9834 & 0.0097 & 0.9903 \\
\hline 12.5 & 0.0207 & 0.9793 & 0.0152 & 0.9848 & 0.0087 & 0.9913 \\
\hline 13 & 0.0192 & 0.9808 & 0.0139 & 0.9861 & 0.0078 & 0.9922 \\
\hline 13.5 & 0.0178 & 0.9822 & 0.0128 & 0.9872 & 0.0071 & 0.9929 \\
\hline 14 & 0.0166 & 0.9834 & 0.0118 & 0.9882 & 0.0064 & 0.9936 \\
\hline 14.5 & 0.0154 & 0.9846 & 0.0108 & 0.9892 & 0.0058 & 0.9942 \\
\hline 15 & 0.0144 & 0.9856 & 0.0100 & 0.9900 & 0.0052 & 0.9948 \\
\hline 15.5 & 0.0134 & 0.9866 & 0.0092 & 0.9908 & 0.0047 & 0.9953 \\
\hline 16 & 0.0126 & 0.9874 & 0.0085 & 0.9915 & 0.0043 & 0.9957 \\
\hline 16.5 & 0.0118 & 0.9882 & 0.0079 & 0.9921 & 0.0039 & 0.9961 \\
\hline 17 & 0.0110 & 0.9890 & 0.0073 & 0.9927 & 0.0035 & 0.9965 \\
\hline 17.5 & 0.010 .3 & 0.9897 & 0.0068 & 0.9932 & 0.0032 & 0.9968 \\
\hline 18 & 0.0097 & 0.9903 & 0.0063 & 0.9937 & 0.0029 & 0.9971 \\
\hline 18.5 & 0.0091 & 0.9909 & 0.0059 & 0.9941 & 0.0027 & 0.9973 \\
\hline 19 & 0.0086 & 0.5914 & 0.0055 & 0.9945 & 0.0024 & 0.9976 \\
\hline 19.5 & 0.0080 & 0.9920 & 0.0051 & 0.9949 & 0.0022 & 0.9978 \\
\hline 20 & 0.0076 & 0.9924 & 0.0048 & 0.9952 & 0.0020 & 0.9980 \\
\hline 20.5 & 0.0071 & 0.9929 & 0.0044 & 0.9956 & 0.0019 & 0.9981 \\
\hline 21 & 0.0067 & 0.9933 & 0.0041 & 0.9959 & 0.0017 & 0.9983 \\
\hline 21.5 & 0.0064 & 0.9936 & 0.0039 & 0.9961 & 0.0016 & 0.9984 \\
\hline 22 & 0.0060 & 0.9940 & 0.0036 & 0.9964 & 0.0014 & 0.9986 \\
\hline 22.5 & 0.0057 & $0.99 / 3$ & 0.0034 & 0.9966 & 0.0013 & 0.9987 \\
\hline 23 & 0.0054 & 0.9946 & 0.0032 & 0.9968 & 0.0012 & 0.9988 \\
\hline \multicolumn{7}{|l|}{ PARAMETERS } \\
\hline Scale & \multicolumn{2}{|c|}{$A=0.787991$} & \multicolumn{2}{|c|}{$A=0.799050$} & \multicolumn{2}{|c|}{$A=0.814623$} \\
\hline Shape & \multicolumn{2}{|c|}{$c=0.490336$} & \multicolumn{2}{|c|}{$c=0.520798$} & \multicolumn{2}{|c|}{$c=0.569829$} \\
\hline
\end{tabular}


Goodness-of-Fit Test

Figure 13 shows the relationship of this mid probability curve to the historical record, and the uncertainties surrolnding that record. These uncertainties arise from two sources:
$\circ$
the small number
and
limited
size
of historical disruptions; and
- the possible differences between the historical period and the future period of interest for this study.

The tool chosen to evaluate the historical fit is the Kolmogorovsmirnov (K-S) statistic. This statistic is designed to measure goodness-of-fit directly from distribution functions. It permits calculation of confidence regions from the actual data, works well with observations that are not evenly spaced, and adapts easily to truncated distributions. (NOTE: all of the data and distributions used in the analysis are truncated on the left -- only disruptions whose gross size exceeds about $1 / 2$ percent of free-world consumption are considered.)

The two "stairstep" functiors " $n$ Figure 13 are boundaries of the 95 percent confidence region determined from the 40-year empirical distribution function using the $\mathrm{K}-\mathrm{S}$ statistic. The region is determined by setting the permissible vertical deviation from the empirical (sample) distribution over the range covered by the observations to a value derived from the 0.05 critical point of this statistic. Any curve that fits the data should fall entirely within this region; curves that fit the data well will pass through the middle of the region. The region is also bounded above by the value 1.0 (since all the functions are distribution functions). The vertical dashed line is included in the figure since the $K-j$, or any other goodness-of-fit statistic, can only be calculated for actual sample points, and thus gives no further information about the extrapolated tail.

The width of the confidence region (indicating large uncertainty) is due to the small number of disruption events that have occurred in the last 40 years, and to the relatively small size of these events compared to those of interest in the future for this SPR study. The absence of extremely large events in this period can be used to set some rough bounds on their probability of occurrence (i.e., the amount of probability in the extrapolated tail) as indicated below. Though free world consumption increased about five-fold during this period, the size distribution has been normalized by expressing the size of tho gross disruptions as a percentage of free world consumption at the time the disruption occurred.

The two lower smooth curves in Figure 13 are the weibull distributions that best fit the data in the first and second half of the historical period. The early (1950-1969) period was 


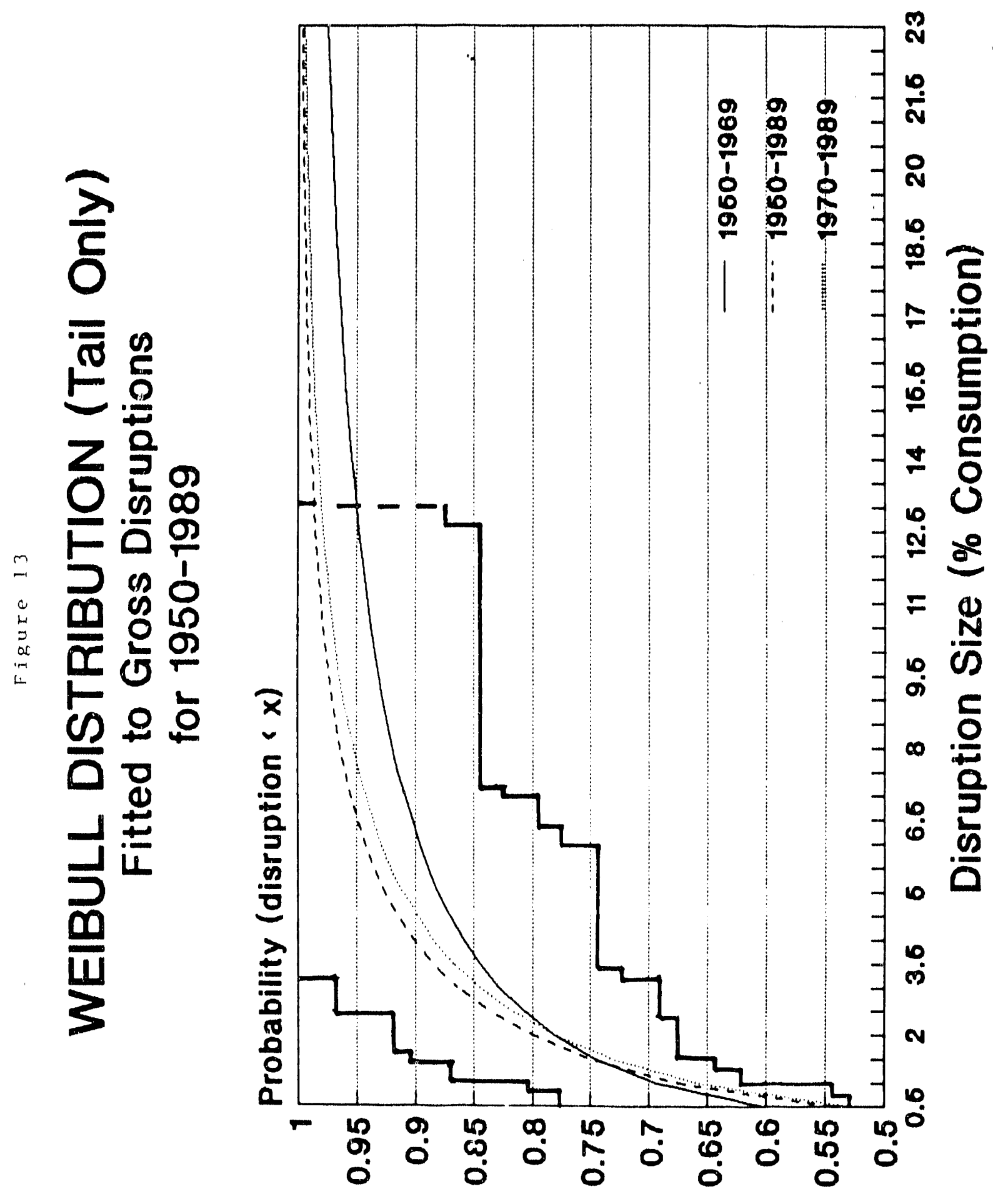


characterized by U.S. dominance of petroleum production, while the later (1970-1989) period was dominated by OPEC. The lowest curve is the Weibull distribution which is derived by minimizing the $\mathrm{K}-$ $S$ statistic without any restriction for the five disruption events that occurred between 1950 and 1969. The middle curve was derived by minimizing the same goodness-of-fit statistic over the ten more recent disruption events that occurred between 1970 and 1989 . NOTE: the lowest curve should be used with caution; the two largest disruptions in this period were quite modest by current standards, but were scaled up because of very low consumption at the time they occurred.

The upper curve in Figure 13 was derived by fitting a weibull distribution to the two points discussed above for the mid probability case. Note that the three curves are similar on the left hand side of the figure. The probabilities of a disruption larger than 1 percent of free world consumption implied by the best-fitting curves $(31$ percent and 34 percent for curves fitted to the 1950-69 and 1970-89 data points) are very close to the 32.5 percent value, which was based on all 40 years of historic data and used for the mid case. In any case, because of the Iimited number of observations the $\mathrm{K}-\mathrm{S}$ statistic suggests that a wide range of distributions (even outside of the high and low probabilities considered in this analysis) could be accepted if one were to rely solely on the data.

To test the uncertainty in the upper point which was used in the mid probability case (gross disruption of 15 percent has a 1 percent chance to occur), distributions bracketing that point were used to calculate the implied probability of hypothetical future events larger than any in the historical record. The set of: projected probabilities derived from each curve was compared with the likelihood of such events by a panel of petroleum experts who selected a range of estimated probabilities consistent with their judgement. In this manner, a middle curve bracketed by two sensitivity curves was chosen to fit both the historical record and expert judgment concerning larger, unobserved events. The sensitivity curve with higher tail probabilities is very close to the distribution that provided the best fit to events in the last 20 years. This is consistent with the judgement of experts that the probability of extreme events will decrease silghtly in the future.

As larger probabilities for extreme events are considered, the odds that such large disruptions would have been seen during the last 40 years also increases. For the lowest smooth curve in Figure 4 (representing 1950-1969), the odds are about 4 to 1 that an extreme event would have been observed already. For the middle curve in that figure (representing 1970-1989), there is a 50/50 chance that an extreme disruption would have been observed already during the 40 year historical period. In other words, if the 1950-1969 pattern had persisted into the OPEC era, much larger disruptions in recent history should have already been seen. 


\section{Low and High Probability Ranges}

If 15 percent or greater disruptions have a 1 percent probability of occurring in a year, they have a 13 percent chance of occurrence over the next 15 years. To develop a range at the 15 percent disruption level, it was assumed that over the next 15 years a chance of plus or minus roughly 5 percent on either side of the mid probability case be used to determine the ranges. The range implied by these assumptions was determined to be consistent with the judgement of experts concerning the probability of a future gross disruption in the 15-year period from 1995-2010. The scale and shape parameters for the high and low probability curves are:

$$
\begin{array}{cc}
\text { Low } & \underline{\text { High }} \\
\mathrm{a}=0.814623 & \mathrm{a}=0.787991 \\
\mathrm{c}=0.569829 & \mathrm{c}=0.490336
\end{array}
$$

The curves are pictured in Figure 14. Figure 15 shows the probabilities over the next 15 years of gross disruptions occurring which are 10 percent of consumption or greater, 15 percent or greater, and 20 percent or greater for each of the three probability cases. As can be seen, the range of plus or minus 5 percent from the mid probability case results in an 7 to 17 percent chance that a disruption of 15 percent of consumption will occur over a 15-year period.

These probabilities are used to weight (multiply) the benefits at various disruption scenarios analyzed. As a net disruption size is determined, and as it differs by 500 thousand barrels per day, its percent of consumption is calculated and the appropriate probability from Table 13 is then multiplied by the benefits to arrive at probability weighted benefits for that case.

\section{Multiple worst Case Disruptions and Scenarios}

Probabilities used in this analysis are probabilities PER UNIT OF TIME -- they do not rule out any combination of frequencies over multiples of that time unit.

Frequency calculations are done with respect to some threshold -and give the probability of one or two or three (or more) events in a span of $\mathrm{N}$ years. In the 15 year ("mid") example we looked at:

$$
\begin{aligned}
\mathrm{P}(\text { no events }>\mathrm{X}) & =.9000 \\
\mathrm{P} \text { (one or more events }>\mathrm{X}) & =.1000
\end{aligned}
$$




\section{Figure 14}

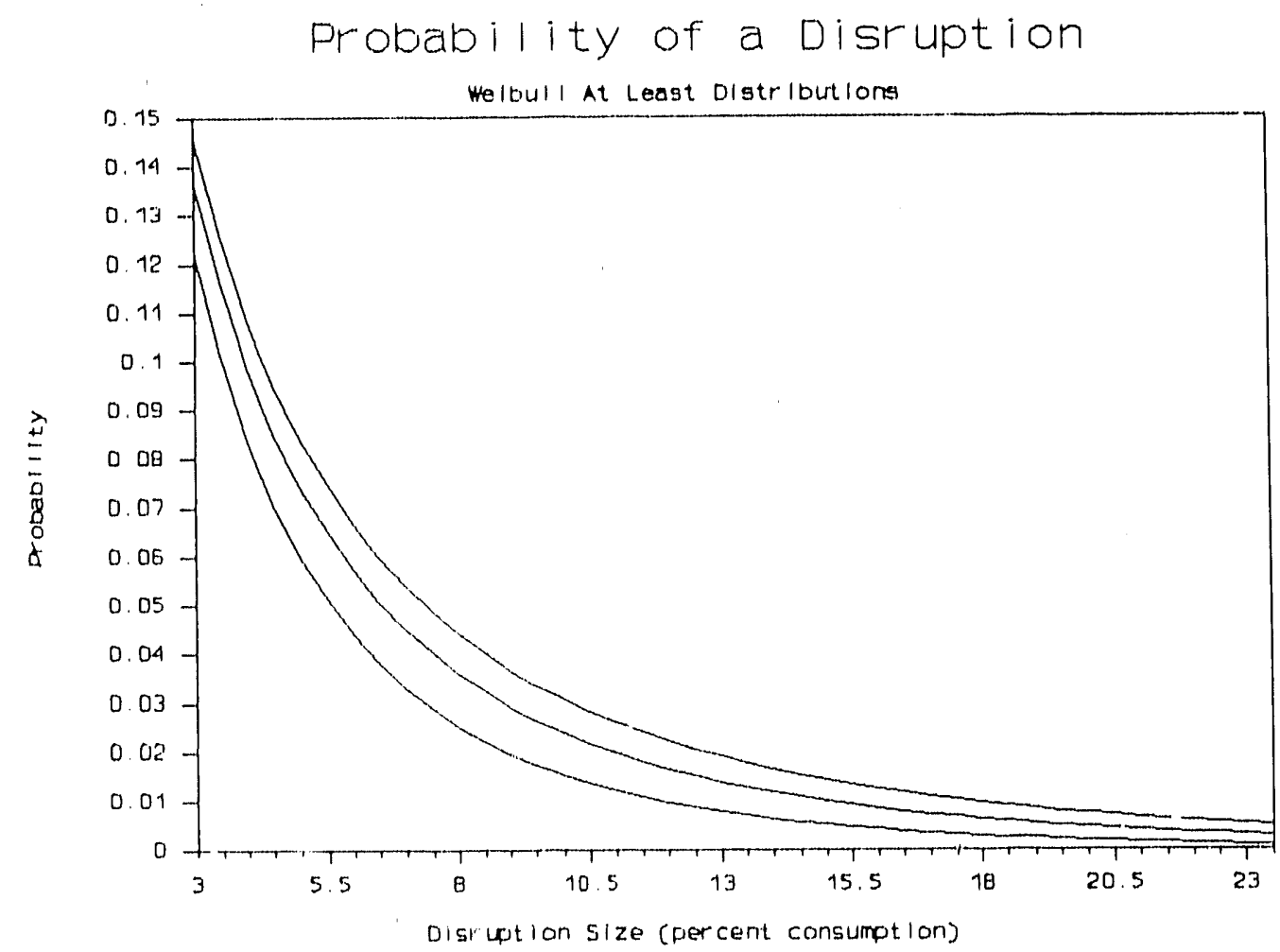

The second probability can be broken down further:

$$
\begin{aligned}
\mathrm{P}(\text { exactly one event }>\mathrm{X}) & =.0952 \\
\mathrm{P}(\text { exactly two events }>\mathrm{X}) & =.0047 \\
\mathrm{P}(3 \text { or more events }>\mathrm{X}) & =.0001
\end{aligned}
$$

This example can be run out to 30 years as follows:

$$
\begin{aligned}
& \mathrm{P}(0 \text { events }>\mathrm{X})=.8100 \\
& \mathrm{P}(1 \text { event }>\mathrm{X})=.1713 \\
& \mathrm{P}(2 \text { events }>\mathrm{X})=.0175 \\
& \mathrm{P}(2+\text { events }>\mathrm{X})=.0012
\end{aligned}
$$

Again the single events dominate because the high threshold for incremental benefits forces $x$ into the 1 percent annual probability range. In other words given the distribution adopted in the analysis the probability of having a multiple disruption over 30 years is less than 2 percent. 


\section{Figure 15}

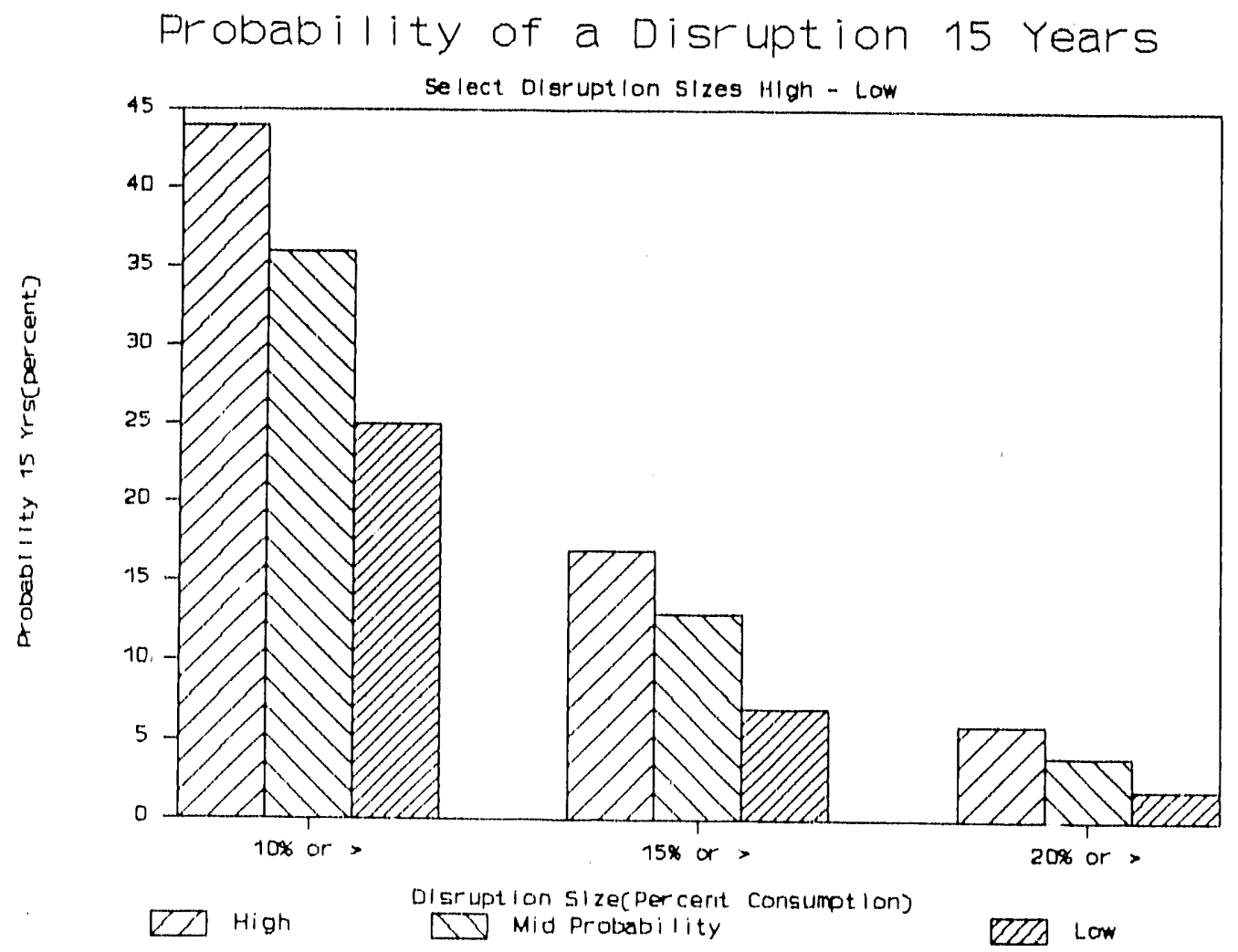




\title{
7. Offsetting Assumptions to Reduce Gross Disruption Size
}

\author{
Excess Production Capacity
}

A major offset to a disruption is the spare or excess production capacity which is forecast to be available outside of the area of the supply disruption. An assessment of the possible "moderate" to "worst" case oil supply disruptions through the year 2010 was provided by experts. Based on these definitions of possible supply disruption scenarios, and on assumptions of OPEC capacity utilization rates, excess capacity estimates were developed.

The high and low excess capacity assumptions were developed based on recent trends and forecasts of production capacity utilization in OPEC. For both high and low ranges the free world outside of OPEC, or non-OPEC, is assumed to be capable of at least 200,000 barrels per day of excess capacity from 1995 forward, and 500,000 barrels per day in 1990. OPEC, outside of disrupted areas, would provide the remaining excess production capacity forecast (See Table 14). All estimates were rounded to the nearest 500,000 barrels per day.

OPEC excess capacity for the forecast period was based on a review of recent trends (since the time that world petroleum demand has been increasing, as in the forecast period) in the relationship of OPEC production to OPEC capacity, or capacity utilization. The mid case forezast for 1990 to 2020 of OPEC capacity utilization was increased or decreased in each year by 5 percent (as recommended by experts) to arrive at the high and low excess capacity ranges. For the high excess capacity range, OPEC capacity utilization is assumed to be 5 percent lower than in the mid case, lower production results in higher excess capacity. Cupacity utilization rates vary from 73 percent in 1990 to 90 percent in 2020 for the high end of the range. Combined with these assumptions of lower OPEC production, in order to get the highest excess capacity range the "moderate disruption" definition was used to determine the producing countries unaffected by the supply disruption.

The low excess capacity range was developed by adding 5 percent to the mid case OPEC capacity utilization estimates. So higher OPEC production (utilization rates of 83 to 100 percent) and a "worst case" disruption definition of countries affected results in the low excess capacity range. In all cases it is assumed that all available excess capacity is brought on line when the disruption begins. 
Table 14

Disruption Offset Assumptions

(Mililon Barrels per Day)

Excess Capacity

$1990 \quad \underline{1995} \quad \underline{2000} \quad \underline{2005} \quad \underline{2010} \quad \underline{2015} \quad \underline{2020}$

Low

Mid

High

3.5
5
6.5

2

1.5

4

0.5

0.5

2

6
6

4.5

4.0

3.5

3.5

Foreign Stock Draws

Low

Mid

High

1
2
25

1
2
5

2
3

2
3

2

2

3

2

3.5

3.5

3.5

3.5

3.5

Fuel Swltching

$\begin{array}{lllllll}0.5 & 0.35 & 0.35 & 0.35 & 0.35 & 0.35 & 0.35\end{array}$

Total Offset Rrunge (Million Barrels per Day)

$\begin{array}{rrrr} & \text { Low } & \text { Mid } & \text { High } \\ 1990 & 5 & 7.5 & 9.5 \\ 1995 & 4.35 & 8.35 & 8.85 \\ 2000 & 4.35 & 8.35 & 8.85 \\ 2005 & 3.85 & 7.35 & 8.35 \\ 2010 & 2.85 & 6.35 & 7.85 \\ 2015 & 2.85 & 5.35 & 7.35 \\ 2020 & 2.35 & 4.85 & 7.35\end{array}$


Foreign Stock Draw/Fuel Switching Assumptions

Foreign governments' stock levels in the future are detailed in Chapter V of the SPR Sizing study (not this service report) and are based on assumptions about stock building plans of those governments. The stock draw assumptions were decided on by the SPR sizing study group and in the high end of the range the drawdown rates (for 6 month periods) sometimes exceed the amount of storks forecast to be held or controlled by allied governments. Hence, the drawdown rates are for foreign stocks and may include some commercial stock draws.

In the ongoing Interagency study "An Energy Evaluation", most of the fuel switching potential from oil to gas is assumed to be in the United States and the assumption of 500 thousand barrels per day, from that study, is used for 1990. The fuel switching potential after 1990 is based on an EIA report "Estimates of ShortTerm Petroleum Fuel Switching Capability" May 1989 DOE/EIA 0526. The switching capability for 6 months is currently assumed to be 350 to 620 thousand barrels per day of oil that could be displaced with natural gas. The bottom of that range is assumed in this analysis for 1995 through 2020.

Table 14 also provides a summary or total offset range, used in this analysis to offset a gross disruption. The total offsets are as low as 3 MMBD to as high as over 9.5 MMBD. 


\section{Summary Results of Sensitivity Analysis}

Table 15 summarizes the results of the cost/benefit analysis. Under "Mid" assumptions across all variables, neither the $750 \mathrm{MMB}$ to $1000 \mathrm{MMB}$ increment nor the $600 \mathrm{MMB}$ to $750 \mathrm{MMB}$ increment exhibit a positive net benefit (gross benefit - incremental cost). The cost to benefit ratio for these "mid" cases is approximately 4.5:1 for the $750 \mathrm{MMB}$ to $1000 \mathrm{MMB}$ increment and $2: 1$ for the $600 \mathrm{MMB}$ to $750 \mathrm{MMB}$ increment.

A series of sensitivity cases was developed that investigated the effect on the gross benefit of varying a single parameter across its assumed range of values. While no single parameter sensitivity case resulted in a positive net benefit posture, it is important to note that certain parameters had a much more pronounced impact on the gross benefit than did others. The following table illustrates this fact for the sensitivity cases associated with the $750 \mathrm{MMB}$ to $1000 \mathrm{MMB}$ increment:

Parameter

Foreign Draw, Excess Capacj.ty

Disruption Duration

Disruption Probability

Discount Rate

Demand Elasticity

Feedback (GNP) Elasticity

SPR rill Rate

World Oil Price

Setting
Low
9 Months
High
0.08
Low
-0.04
100 MBD
High

Setting

Low

High

$50 \mathrm{MBD}$

0.12

$\mathrm{High}$

$-0.02$

Low

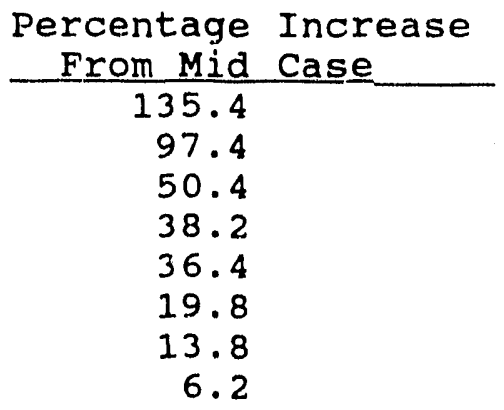

Percentage Decrease From Mid Case

53.2

29.8

26.5

25.3

19.2

6.6

2.7

world oil Price

the incremental 250 MMB would be economic loss associated with disruptions of longer duration and as a measure that protects against minimal cooperation from foreign governments in reducing the impacts of a disruption.

The remainder of the sensitivity cases examined the impacts on the gross benefit of combining several of the parameters at their extreme values. If all parameters are combined in a manner that would tend to maximize the gross benefit, it is not surprising that the net benefit is robustly positive. While such a case is academically interesting, the likelihood of such a biased combination of parameters is quite small. Of more interest are the 
Table 15. Summary of Results

Mid Cases

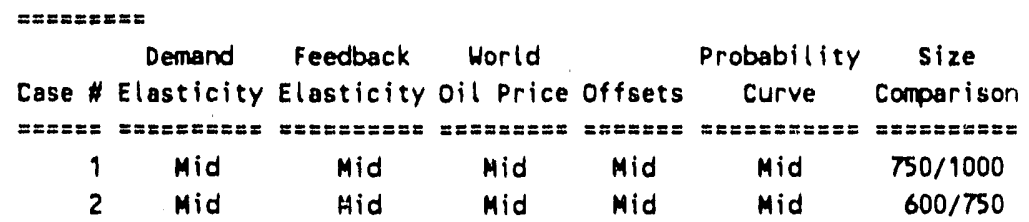

\begin{tabular}{|c|c|c|}
\hline other & $\begin{array}{c}\text { Gross } \\
\text { Benefit }\end{array}$ & $\begin{array}{c}\text { Incremental } \\
\text { Cost }\end{array}$ \\
\hline 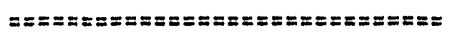 & $z=\Sigma x= \pm==$ & $=z====z=z==$ \\
\hline - & 0.7461 & 3.3716 \\
\hline$\ldots$ & 0.9396 & 1.9890 \\
\hline
\end{tabular}

Single Parameter Sensitivity Cases

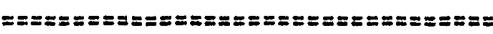

Demand Feedback Horld Probability size

Case \# Elasticity Elasticity oil Price offsets Curve comparison

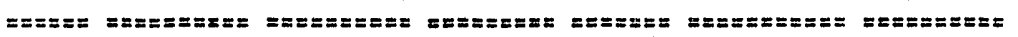

3 Mid Low Mid Mid Mid $750 / 1000$

4 Mid High Mid Mid Mid $750 / 1000$

5 Mid Mid Mid Low Mid $750 / 1000$

6 Mid Mid Mid High Mid $750 / 1000$

7 Low Mid Mid Mid Mid $750 / 1000$

8 High Mid Mid Mid Mid $750 / 1000$

9 Mid Mid Low Mid Mid $750 / 1000$

10 Mid Mid High Mid Mid $750 / 1000$

$\begin{array}{lllll}11 & \text { Mid } & \text { Mid } & \text { Mid Mid Low } & 750 / 1000 \\ 12 & \text { Mid Mid Mid Mid Migh } 750 / 1000\end{array}$

13 Mid Mid Mid Mid Mid $600 / 1000$

14 Mid Mid Mid Mid Mid $750 / 1000$

15 Mid Mid Mid Mid Mid $750 / 1000$

16 Mid Mid Mid Mid Mid $750 / 1000$

\begin{tabular}{|c|c|c|c|c|c|}
\hline Mid & Mid & Mid & Mid & Mid & $750 / 1000$ \\
\hline Mid & Mid & Mid & inid & Mid & $750 / 1000$ \\
\hline
\end{tabular}

Multiple Parameter Sensitivity Cases

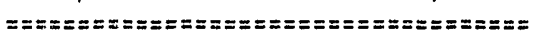

Demand Feedback World Probability size

Case \# Elasticity Elasticity Oil Price offsets Curve Comparison

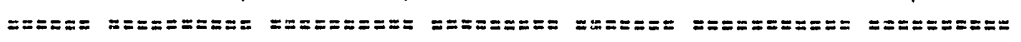

$\begin{array}{rrrlllr}20 & \text { Low } & \text { High } & \text { Low } & \text { Low } & \text { High } & 750 / 1000 \\ 21 & \text { Low } & \text { High } & \text { Low } & \text { Low } & \text { High } & 600 / 750 \\ 22 & \text { High } & \text { Low } & \text { High } & \text { High } & \text { LOW } & 750 / 1000 \\ 23 & \text { High } & \text { Low } & \text { High } & \text { High } & \text { LOW } & 600 / 750\end{array}$

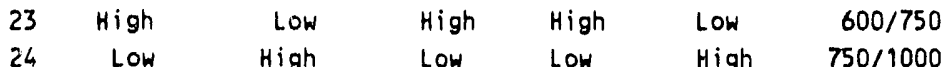

25 LOW High LOW Low High $600 / 750$

26 High Low High High Low $750 / 1000$

27 digh Low High High LOW $600 / 750$

28 Low High Low Low High $750 / 1000$

29 Mid Mid Low Low Mid $750 / 1000$

30 Mid Mid High High Mid $750 / 1000$

31 Mid Mid Low Low Mid $750 / 1000$

32 Mid Mid Low Low Mid Mid $600 / 730$

33 Mid Mid Low $\ldots$ Mid $750 / 1000$

34 Mid Mid Low Mid M... $750 / 1000$

35 Mid Mid Low $\ldots$ Mid $600 / 750$

\begin{tabular}{|c|c|c|c|c|}
\hline \multirow{2}{*}{\multicolumn{3}{|c|}{ 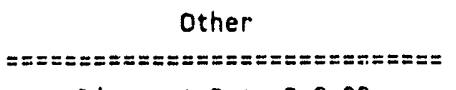 }} & \multirow{2}{*}{$\begin{array}{l}\text { Benefit } \\
====\pi==\end{array}$} & \multirow{2}{*}{$\begin{array}{c}\text { Cost } \\
=========\end{array}$} \\
\hline & & & & \\
\hline & Discount & Rate a 0.08 & 5.5311 & 3.1878 \\
\hline & Discount & Rate a 0.08 & 7.1188 & 1.7770 \\
\hline & Discount & Rate a 0.12 & 0.1399 & 3.3849 \\
\hline & Discount & Rate a 0.12 & 0.1997 & 2.3157 \\
\hline & & $\cdots$ & 3.9665 & 2.7346 \\
\hline & & . & 5.5472 & 1.6879 \\
\hline & & $\cdots$ & 0.1809 & 3.9587 \\
\hline & & $\cdots$ & 0.2424 & 2.4344 \\
\hline & 9 Month & Disruption & 7.2023 & 2.7346 \\
\hline & & . & 1.7120 & 2.7346 \\
\hline & & $\cdots$ & 0.5545 & 3.9587 \\
\hline & 9 Month & Disruption & 3.3153 & 2.7346 \\
\hline & 9 Month & Disruption & 3.8912 & 1.6879 \\
\hline & Low Excess & S/Mid Foreign & 1.2963 & 2.7346 \\
\hline Low & Excess/Mid & Foreign/9 Month & 2.7907 & 2.7346 \\
\hline Low & Excess/Mid & f foreign/9 Month & 3.3161 & 1.6879 \\
\hline
\end{tabular}

Notes: Unless specified, Fill Rate $=75$ MBD, Discount Rate $=0.1$, and Disruption Duration $=6$ Months. Gross Benefit and Incremental Cost are in Billions of 1988 Discounted Dollars.

Gross Benefit is Probability Weighted.

Gross Benefit excludes Post-2020 Salvage Value of the SPR.

Incremental cost excludes Increased Import Cosis due to SPR Fill. 
cases which vary only two or three parameters. For example, if low disruption offsets (low excess production capacity and low drawdown of foreign stocks) are combined with a longer disruption duration ( 9 months), a positive net benefit is achieved. Detailed results of all cases ("mid" and sensitivity) are presented in Appendix B of this report.

\section{Figure 16}

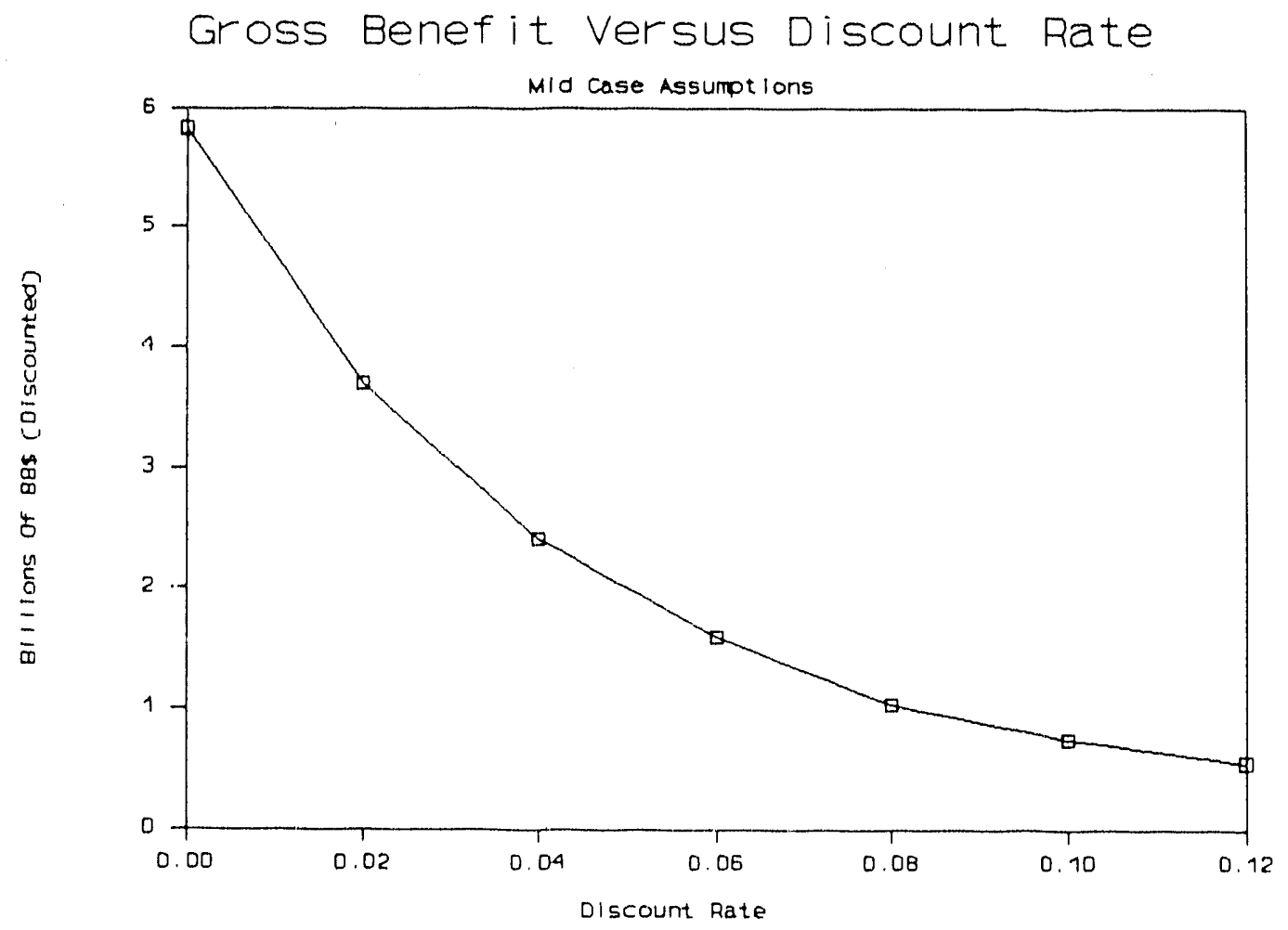

The benefit estimates were highly dependent on the assumptions made about discount rates and probability. The critical importance of these two factors resulted in additional analyses of their impact on these benefit estimates. Figure 16 examines an expanded range for discount rates from zero (no discounting) up to a rate of 12 percent. At the zero rate, gross benefits are somewhat less than $\$ 6$ billion compared to the mid case estimate of $\$ 0.75$ billion at a discount rate of 10 percent. Due to the shape of the curve, benefits are very sensitive to lower rates whereas higher rates have marginal impacts on gross benefits. Figure 17 examines the impact of varying the mid case probability assumption (of a disruption of "at least" 15 percent of consumption being 0.01 ) up to the probability level where gross benefits equal incremental costs. This probability for the severe disruption was near 0.044 , 
over four times the mid case probability assumption. As observed, gross benefits are very sensitive to changes in probability. However, while the change in probability appears to be small, it is a one-year probability. Figure 18 converts the one-year probability into the implied probability that such a severe disruption would occur within 15 years. For instance, the one year probability of .044 implies that a severe disruption has nearly a 50-50 chance of occurring once over the next 15 years.

Figure 17

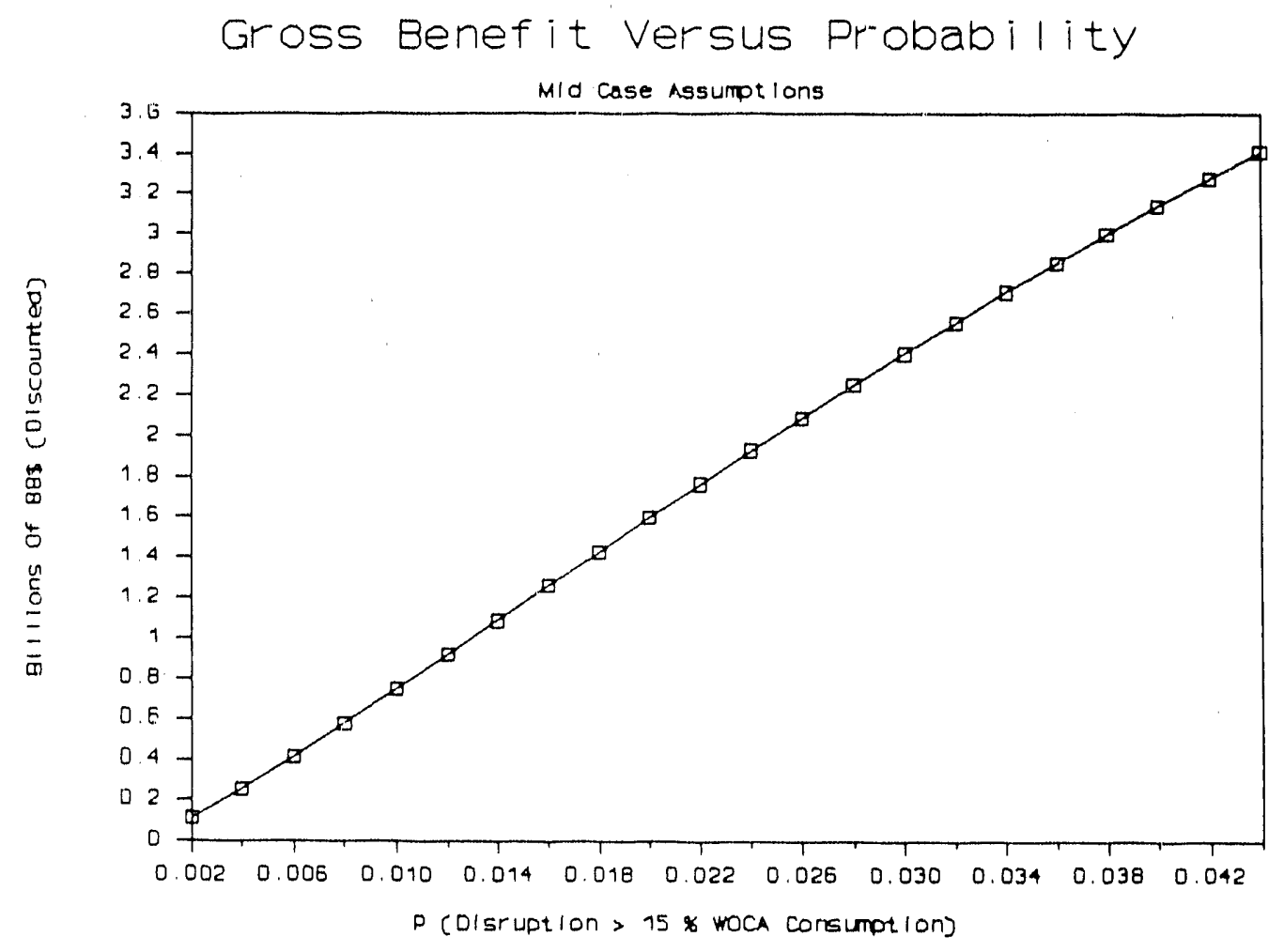


Figure 18

15-Year Probability of A Disruption

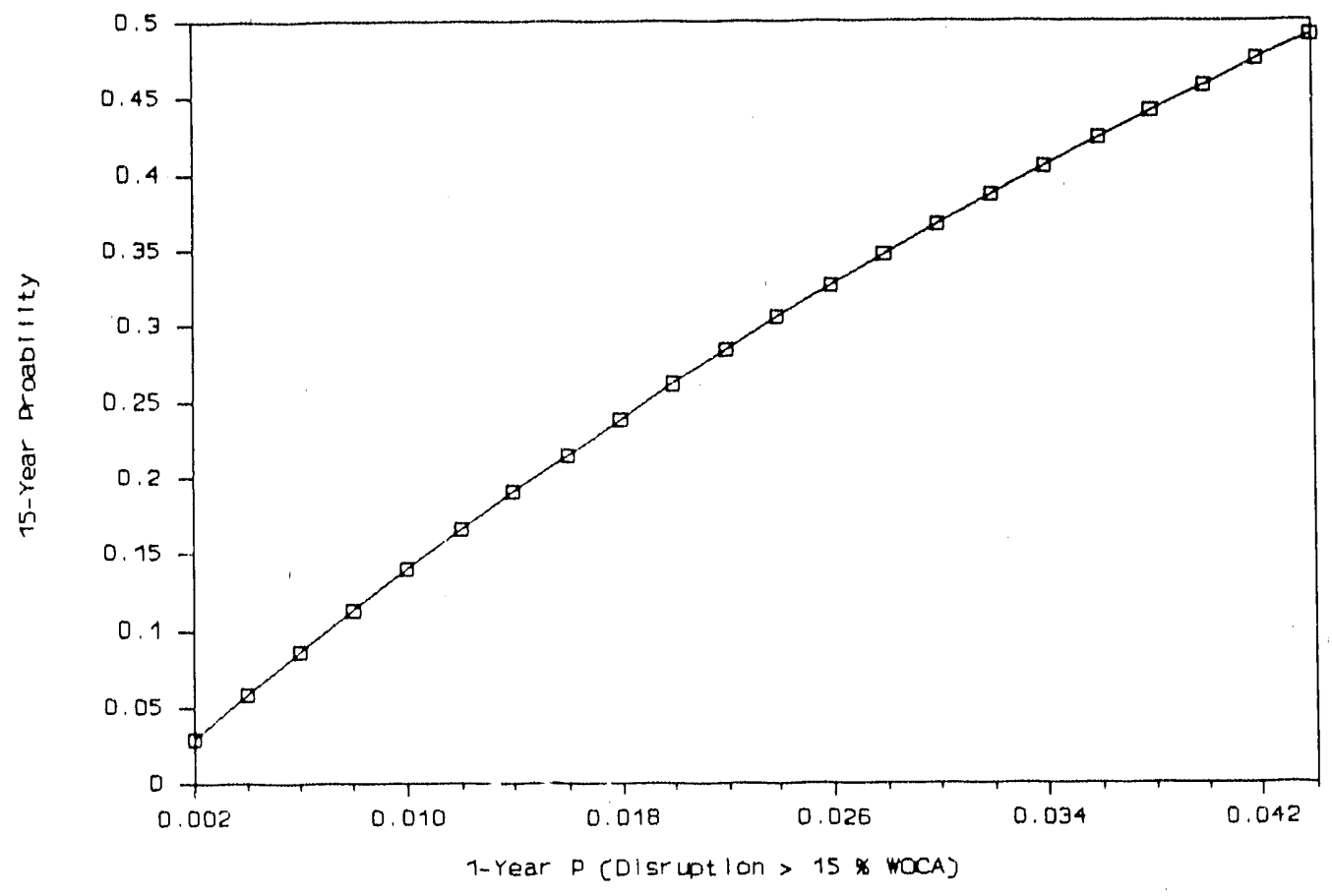


Appendix A

Macroeconomic Impact of an Oil Supply Disruption

$55 / 56$ 
where $P$ is the old price, is the elastlelty, and I regers to the shock case and 0 to the base case. While there is some doubt about whether the response of GNP is log-linear, this seems a reasonable simplifleation.

To estimate the elasticity, we simulated a two-quarter oil Frice stock lising the Meyer and Associates macro mode: and the 2R: mode:. We therefore have ovidence from two major macro rode:s used by the Troika agencies. We also considered earlier ousside reslizts produced by the EMF-7 study and by Michael Darby.

Besore presenting the estimates, a word of caution is recessazy about the elasticities. The elasticity is defined as the C'Mi:-at:Ve impact on GNP Der percent increase in od d price dirifg the ouarters of disfuption expressed as a percent of GNP dufing a disfuption crafter. The response of GNP is therefore assumed to be proportional to the length of the disruption as well as the oll price increase. This formulation greatly sacilitates the modeling of supply shocks. The lagged response of GNP (and possibly oli prices) is already taken into account in the elasticity parameter. To count additional eyclieal effects aiter the discuption ends would be double counting.

For a 50 percent price increase sustalned for two guarters, the Meyer model simulations give an elastlelty pe

-.017 to -.023 , depending on whether oil prices adjust quickly or slowly. In the DRI simulations, the elasticitles range from -.031 to -.043 when oil prices adjust qulekly or slowiy, respectively.

For these two models, the constant elastlelty formulation seems to be reasonable. Slmulations with 100 percent price increases yielded inilar lasticlties.

Given the ranges of estlmates and based on a review of the Darby and EMF-7 results, our recommendation is that 2 range of elasticities between -.02 and -.04 he usad our prelerred estimate howeyer, is -1025 .

The total inpact of a discuption 1s the sum of the loot surplus and the cyclical GNP efect. Our detalied analyolo lollows below. 


\section{INTRODLTION}

\section{The DCE ReTiest to I3/T2}

DOE asked $I 3 / T 2$ to recomend wethods, and wheze appropriate, parameter values fur estimating the economic berefits from a release of SPR oll during an oil supply disruption. Broad outlines of the oil supfiy disruption scenario were specified by DOE:

1. The oll supply distuption is temporary, lasting less than 1 year, and the short-term nature of the disruption is fully foreseen by economic decisionmakers.

2. Oil prices, after rising during a disruption, return to the reference prediscuption oil price path at the end of the supply discuption.

3. We also consider an alternative post-discuption path, which the 1987 Energy securlty study and the DOE Blue Book use. In this scenario, world oll prices de not decline to the base path lmmediately after the conditions causing the oupply disruption are eliminated. Instead, due to lags or gradual decay of cartel discipline, prices return to the base path at a rate of 38 percent of the difference between the discuption price and base case price each quarter.

\section{TOTAL EFFECTS OF NN OIL PRICE SHOCK}

The affects of an oll price shock due to a supply discuption on the U.S. economy can be decomposed into two broad categories.

\section{Gycldeal Effects on Grose Nat Lenal Product (GNP):}

These are the "temporary," "erlotlonal, or "sbort-run" cost. of adfusting to an oll price shock. Econonic agents cannot adjust to a sudden rise in the price of an 1mportant input auch a oll instantanoously. Thlo 1s due partly to a downward stlckiness in noninal wages which prevents relative vages son gulekly roadfusting to clear the labor market. Another chuse of unemployment during an o11 price shock 1s the laperfoct mobility of labor, whlch prevents needed redistribution of resources between sectors.

\section{Losses in consumers' and Producers' surpluen:}


Attachment 1 11lustrates the rat loss in consumers' and producers! ouppluses, which is area $B+C+D$ under the $0 . s$. oll. demand curve. The helght of the domestic supply clirve can be interpreted as the cost of producing each additiona: unit of oil. The height of the demand curve can be thought of as the marginal value of each additional unit of oll. At any giver guantity, the area between the demand (supply) eurve and the market price is the consumers' (producers') surplus accruing to tre last additional unit of consurption (output).

The loss to consumezs' surplus from the oll price increasa is $A-B-C+D$. However, domestic producers benefit from the hisher oil prices, and their producers' surplus increases by area $A$. Therefore, the net loss to consumers' and producers' surpluses is B-C+D. This area i.: just the average of pze- and fost-shock oil import levels times the increase in prices.

We defer to the SPR study group's eindings on the response of world oil prices and domestic oll demand and supply to a supply disruption. However, an estimate of the elasticity of GNP with respect to the world oil price is needed to capture cyclical GNP effects. It seems appropriate to look to siaulation models which purport to capture erictional and cyclical aspects of the -conomy and empirical estimates of short-run effects for sone guldance.

\section{EVIDENCE CONSIDERED}

The proper size of the GNP elastlelty ("*n) 1s dffelcult to determine grom the avallable evidence. Two nafor outside ourcese fOr estimates of the GNP elasticity are the ERT 7 results and a 1981 Darby AER paper. Both estimates bave problews.

OUTSIDE SOURCES

Ex 7

Both the DrT 7 and the Darby GNP elastlelty values are averages. The Er 7 result is the average guarterly effect over a 4-year time perlod. The Darby elasticity is an average annual efrect over the period 1957-1976.

The Ea 7 rune imulation experiments with it models and considers the averay of the 14 individual modul results. A permanent 50 percent oll prlce Increase causes an average quarterly deciline in GNP of 2.1 percent below lts base path. Th1s 1mpiles an elasticity of -.042 . They find that these results are robust for a range of price varlation. 
The advantage of using the EMF 7 estimate lo that it is an average derived from many well-respected models all using ldentical disruption scenarios.

The disadvantages of using the EMF 7 estimates are that:

(1) The scenario used is a permanent 4-year change in oll prises of 50 percent above the base path, which should overstate the total GNP effects compared with the short-lived price increases we were asked to consider. The implications of these results for the temporary disruption case are quite unclear.

(2) The EMF baseline assumes a current price o: oil of $\$ 36$ a barrel, which makes the oll share of the oconomy much larger than it is today (consumption of petroleum and natural gas per dollar of GNP has fallen from a level of 20.9 thousand BTUs per 1982 dollar in 2973 to 12.9 in the second guarter of 1989 ).

(3) The total GNP effect includes some of the tarms of trade and consumer and producer surplus componants.

(4) The sensitivity of the outcome to 1mportant parameters is not discussed.

(5) Results of our own imulation experiments lndicate that true sodeling of the oll sector $1 \mathrm{n}$ our econoly bas changed considerably ince the models vere run for the ExP7 report. Oll shocks do not seem to be consldered as loportant as they were in the early 1980. This is probably due to a reconsideration of whether GNP in the i970e was reacting more to oll price shocks or to prlce controls.

\section{DARBY}

Darby estinates a Lucas-Barro real incone equation for the 0.s. diractly eron quarterly hlotorlcal data coverling 1957-1976. The eunctional forn forces the cumulative ubort-run elfect of one perlod'. oll price rise to damp out to zero after four quartere, capturing the tenporary nature of adfustment effects. Darby linds a temporary GNP lastlc1ty of -.021 (the pernanent GNP - lastlcity also takes on this value) of the current perlod's real GNP with respect to the current real world oll price. Unfortunately, two of the four distrlbuted lag term incorporated In the oodel to capture the ohort-run effects of an oll price increase are tatiatically inelgniflcant, and the remalining two are only marginally igniflcant. 
There are also problems in Interpreting Darby's result tor our purpose. His estimate is an average of the reaction to many different oll price shoeks under many different clreumstances. As he remarks, "the results... are mixed and confounded by price control and decontrol programs whleh were widespread at nearly the saue time as the 1973-74 oil-price change." Price control programs in place during 1971-73 overstated real GNP and understated the GNP detlator. When the controls were relaxed during 1973-75, measured real income feli back to cetual real income, generating a spuriols decline in real GNP smultaneous with the OPEC oil embargo. In lact, a direct test of the two hypotheses eavors the price control argument as an explanation of the oil shock in the United states.

The 1986 T3/T2 study of which GNP elasticity estimate to use selected the Darby extimate despite these problems.

\section{SIMLLATION RESULTS}

Because of the problems with previous estiates, we used current versions of simulation models used by the Trolka agencies to test the effect of a temporary oll shock on GNP. These model. are not ldeally ulted for analyzing the impact of oll price shocks, but they are based on more recent data.

\section{MEYER AND DRI MODELS}

The new version of the Laurence $H$. Meyer and Assoclates (Meyer) moded was used with thelr september data package. simulations vere alco run with the PC version of the DRI quarterly nacro nodal. In the epirit of the mo 7 otudy, ve did not change the adfactors or exogenous assumptlons fron those given in the Meyer and DRI packages. No pollcy accomodatione were made for the oll shock.

In both model., reflner's ocquistion cost for laported petroleum (NSA, S/barral) 1s exogenous. The bletorleal data are culled Iroa the DOE Neckly Petroleun status Beport. In the Moyer model, changes in this price are transaltted to the inpliclt price deflator for imports. A dumy for the opze oll ambargoes whlch has a negative effect on consumption was not uned on the advice of a Meyer vice prosldent. A major drawback of this nodel 1s that there is no direct IInkage of the o1l price to the productive sector via the price of factor inputs, because the producer price index play only a ninor role in the nodel.

The DRI nodel treate the energy sector in nuch greater deta11. DRI's energy sector 1ncludes four elnal denand equations, one for each major euel group, where the lovel of demand in each ector 1. a function of energy-using capital otock, disposable personal income, energy prices, and changes in 
hating and cooling degree-days. Also lneludad is an equation for total energy use as a function of linal energy damande and -conomic factor aftecting industrial and comercial unes of energy. DRI's energy supply sector includes production indexes for natural gas and oi: extraction and for uining. Production levels are taken from DRI's energy model, and thus are exogenous to the macro model, but th. macro model uses a simulation rule to adjust production leveis for charges in real crude oi: prieas.

In the Moyer model, private nonsarm business output is modeled by a cobb-Douglas production function with labor and two types of capital as its components. Since energy is not ineluded separately, oll price shocks do not direetly affect the path of potential output. Oil price shocks do affect the path of potential GNP in the DRI model, through total tactor productivity. ORI treats total factor productivity as a eunction of total energy demand, which in turn is a elunction of energy. pricas.

Exchange rate effects may capture something of a terms of trade effect through theis effect on net exports. However it $1 \mathrm{~s}$ difficult to discern how much of the change in GWP can be attributed to this effect. The worsening of the trade balance due to oil price shocks was not large for most scenarlos. As H11. Huntington points out in a recent unpublished article, nacro policy models such as DRI and Meyer take a value-added approach to calculating real GNP, which meane that there is no direct terms of trade effect in the elasticleles we have calculated.

\section{RESULIS}

We focus on two oll price shock reenarlos:

(1) A 50-percent increase in the elrat two quarters, followed by an lanediate return to the base price path.

(2) A 50-percent increase in the e1rot two guarters, tollowed by a decline in price of 38.2 partent of the differance between the disruption price and base caee price each quarter until the base price path 10 rogalried. (The 38.2 percent 1s the rule of thunb used by DOE and Trodke in ariler studles).

We attribute the total GNP eftect for all quarters to only those quarters during which the shock 1taelf occurs. Onder the 38 porcent per annua return rule of thumb ve attribute the total GNP effect to the two disruption guarters.

Future GNP effects are dlecounted at a rate of 10 percent per annua for the calculation of all elasticltios.

The reaults are roported in attacbrent 2. At the request of Doz, results for a 100 percent oll price shock are also reported. The GNP lastlolties for the 100 percent sbock are lese then .01 
higher than 105 the 50 percent shock under the Meyer noded, but the results from DRI are the same under both scenarios.

Estimated elasticities range from -0.043 for a temporary 50 percent price shock with a 38 percent adjustment rule in the DRI model to -0.017 for a temporary 50 percent price shock with an insediate return to the base price path in the Meyer model. The average GNP elasticity for the two models with an immediate return to the base price path was -.024.

v. CONCLLSIONS

We recomend a two component measure of the total cost of an oil price disruption. The components are a producer and consumer surplus effect which includes the terms of riade effeci, and a cyclical GNP effect.

We recomend that a range of elasticities between -.02 and -.04 be tested with the SPR size cost-benefit model. While we are recommending a range, we recommend -.025 as the elasticity for any simulation experiments related to the SPR size study for which a reference case is needed.

Attachments 


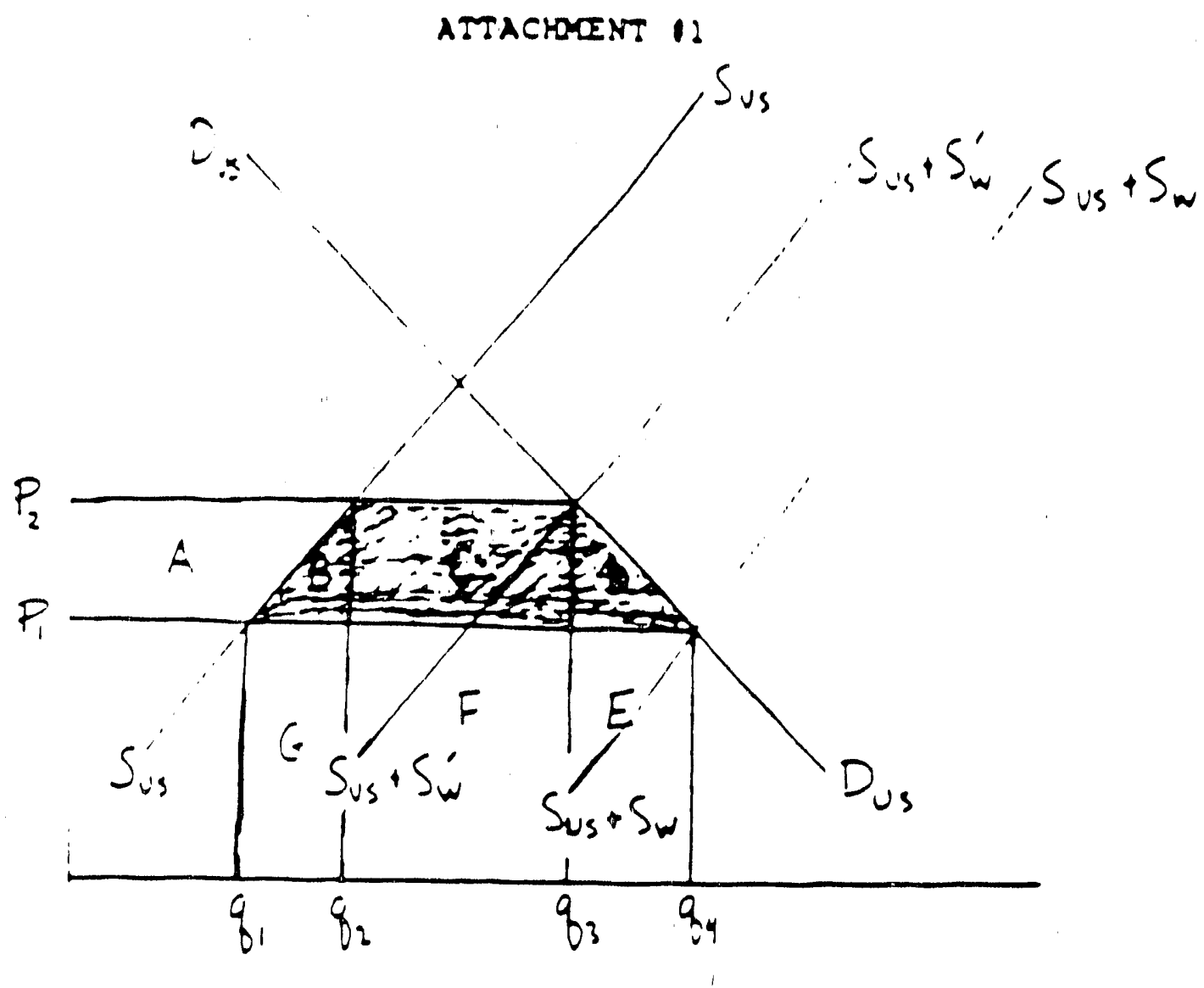

$A$ - gain in producers' surplus to us manufacturers $A-B-C+D=$ loss in consumers' surplus to us consumers $=>$ net vel fare change $=-(B+C+D)$

64 


\section{ATIACHDENT 12}

GNP ELASTICITIES WITH RESPECT TO WORLD OIL PRICE

MONEIARY POLICY: MONEY SUPPIY EXOGENOUS

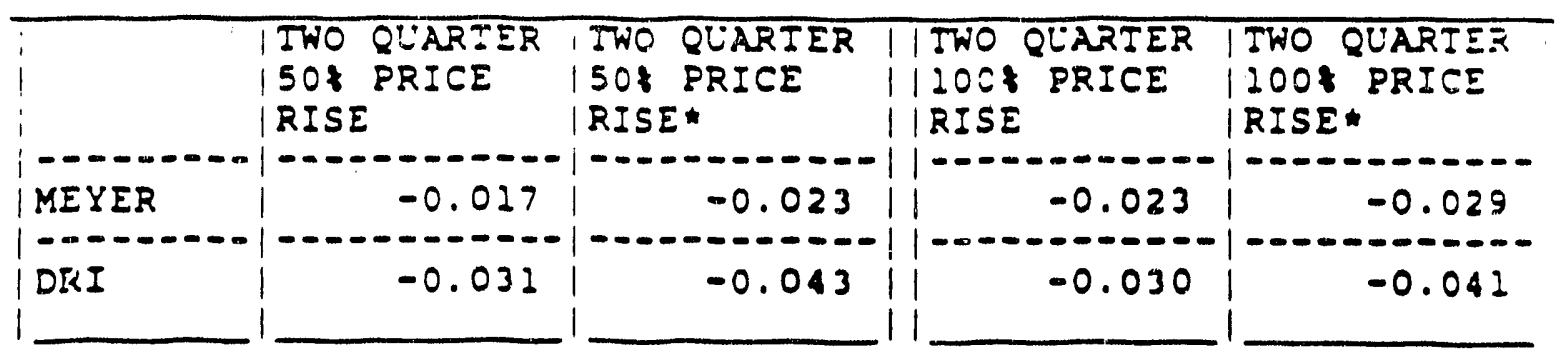

-WIIH 38:/QUARTER ADTUSTMENT FACTOR 
accommodate short-run supply shocks. The reaction to an ofl shock will be less severe since "stop-go" policies, with an accompanying recession, are not expected. For example, when oll prlces rose earller this year, upward pressure on the PPI and CPI was recognized as temporary and did not bring about a significant monetary tightening. Eventually the inflation rate fell as oll prices dropped back. For these reasons, the simulated GNP response is likely to be a bit high. 
Appendix B

\section{Detailed Results}


Table B1. Case 1 - Summary Comparison of 750 MMB system Versus 1000 MMB System

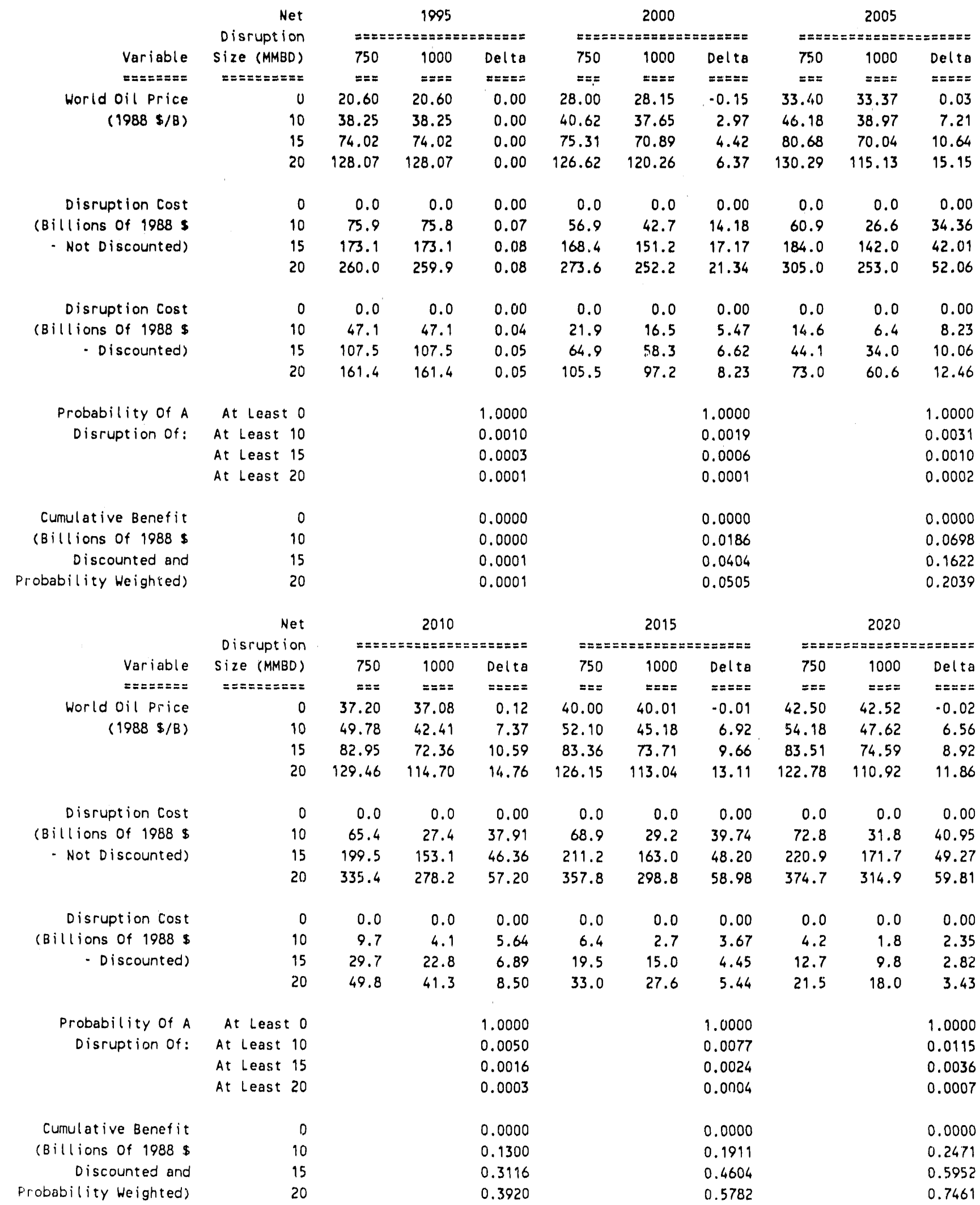

Notes: The World Oil Prices are averages over the quarters of the disruption. The costs and Benefits are accumulated guer gix quarters beginning with the start of thic disruption. 
Table B2. Case 2 - Summary Comparison of 600 MMB system Versus 750 MMB System

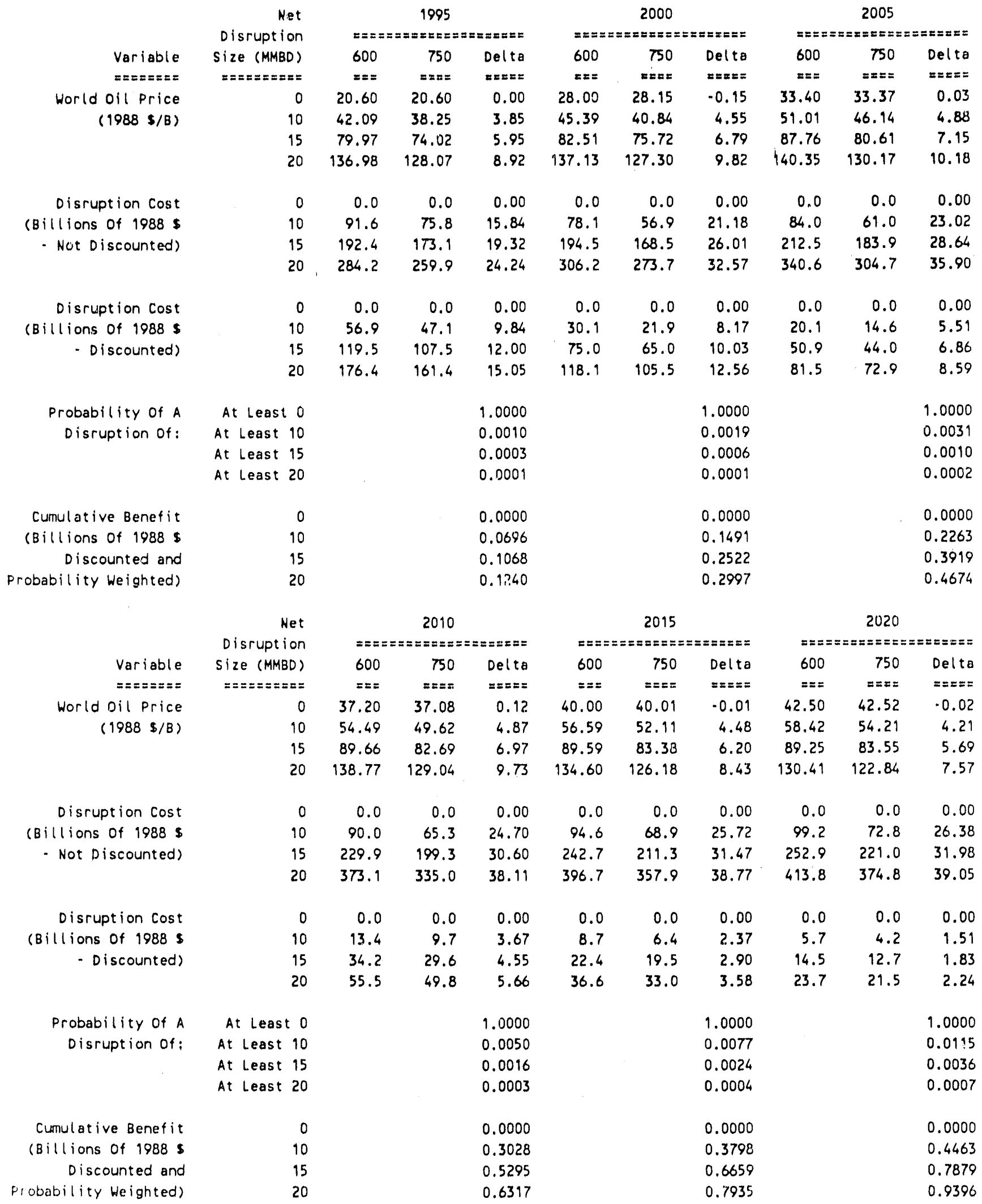

Notes: The World Oil prices are averages over the quarters of the disruption.

The costs and Benefits are accumulated over six quarters beginning with the start of the disruption. 
Table 83. Case 3. Summary Comparison of 750 MMB system Versus 1000 MMB system

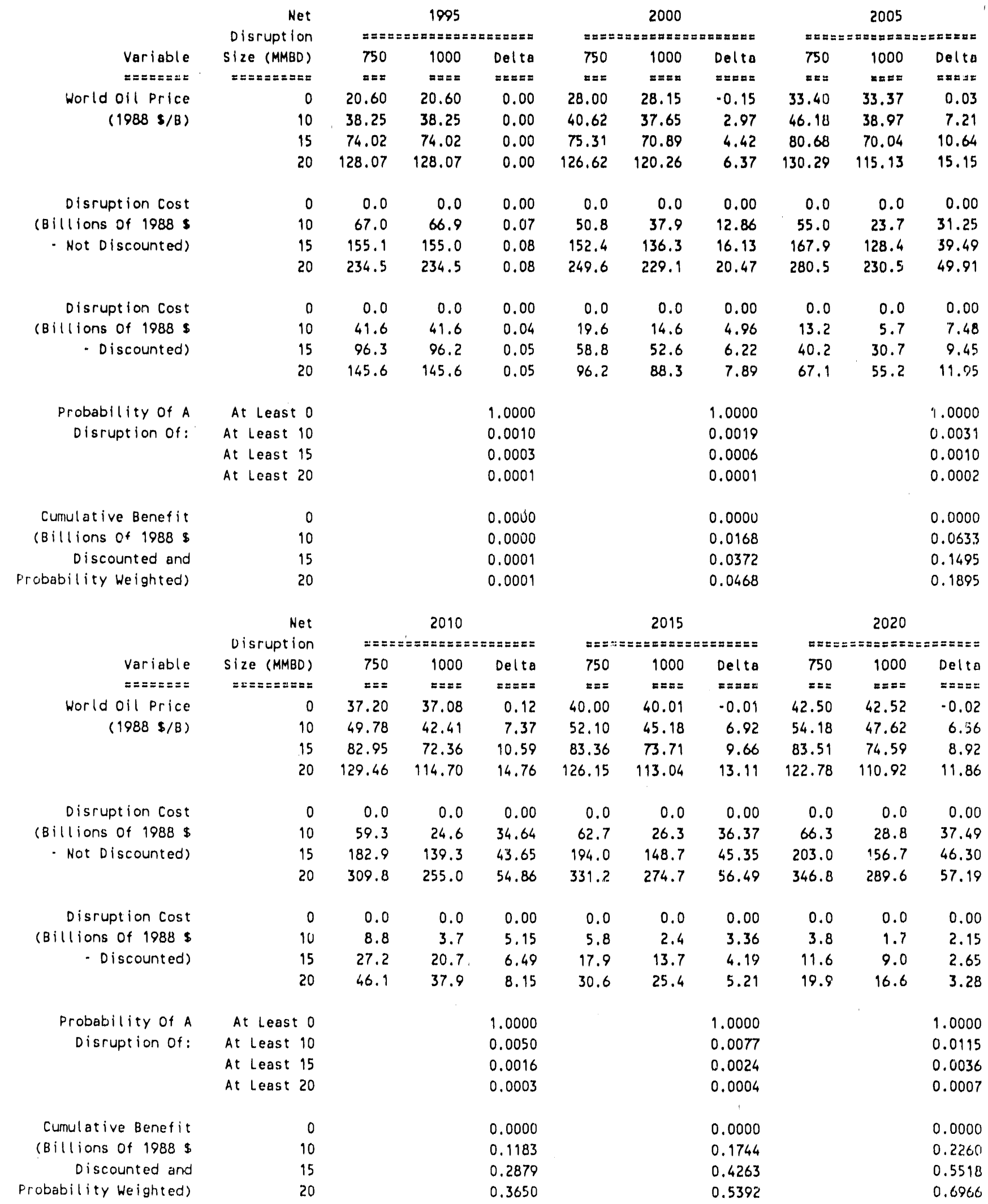

Notes: The World Oi! Prices are averages over the quarters of the disruption. The costs and Benefits are accumulated over six quarters beginning with the start of the disruption. 
Table B4. Case 4. Sumary Comparison of 750 MHB System Versus 1000 MMB system

\begin{tabular}{|c|c|c|c|c|c|c|c|c|c|c|}
\hline & Net & & 1995 & & & 2000 & & & 2005 & \\
\hline & Disruption & $z=z x$ & $\Rightarrow z=28 z y=$ & 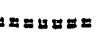 & $x=z:$ & $z=\Sigma z=a x=$ & $a x z z=z$ & $m=x=$ & 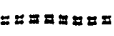 & $z=2 \pm=2 x$ \\
\hline Variable & size (MMBD) & 750 & 1000 & Delta & 750 & 1000 & Delta & 750 & 1000 & Delta \\
\hline$\forall=z=8 z=z$ & $\Rightarrow=28 z=8 z=8$ & $\approx \pm \geq$ & $z= \pm z$ & $y= \pm \| z$ & $m a z$ & $E z=\mathbb{Z}$ & घyz=z & $y=$ & 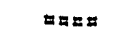 & 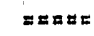 \\
\hline World oll Price & 0 & 20.60 & 20.60 & 0.00 & 28.00 & 28.15 & .0 .15 & 33.40 & 33.37 & 0.03 \\
\hline$(1988 \mathrm{~S} / \mathrm{B})$ & 10 & 38.25 & 38.25 & 0.00 & 40.62 & 37.65 & 2.97 & 46.18 & 38.97 & 7.21 \\
\hline & 15 & 74.02 & 74.02 & 0.00 & 75.31 & 70.89 & 4.42 & 80.68 & 70.04 & 10.64 \\
\hline & 20 & 128.07 & 128.07 & 0.00 & 126.62 & 120.26 & 6.37 & 130.29 & 115.13 & 15.15 \\
\hline Disruption Cost & 0 & 0.0 & 0.0 & 0.00 & 0.0 & 0.0 & 0.00 & 0.0 & 0.0 & 0.00 \\
\hline (B)llians of 1988 s & 10 & 102.3 & 102.3 & 0.07 & 75.0 & 56.9 & 18.10 & 78.9 & 35.2 & 43.65 \\
\hline - Not D(scounted) & 15 & 220.6 & 226.6 & 0.08 & 215.6 & 195.4 & 20.21 & 231.9 & 182.4 & 49.45 \\
\hline & 20 & उ.j. 0 & 334.9 & 0.08 & 344.4 & 320.5 & 23.88 & 377.7 & 319.3 & 58.33 \\
\hline Disruption Cost & 0 & 0.0 & 0.0 & 0.00 & 0.0 & 0.0 & 0.00 & 0.0 & 0.0 & 0.00 \\
\hline (Billlons of 1988 s & 10 & 63.5 & 63.5 & 0.04 & 28.9 & 21.9 & 6.98 & 18.9 & 8.4 & 10.45 \\
\hline - Discounted) & 15 & 140.7 & 140.7 & 0.05 & 83.1 & 75.3 & 7.79 & 55.5 & 43.7 & 11.84 \\
\hline & 20 & 208.0 & 208.0 & 0.05 & 132.8 & 123.6 & 9.21 & 90.4 & 76.4 & 13.96 \\
\hline Probabillity of $A$ & At Least 0 & & & 1.0000 & & & 1.0000 & & & 1.0000 \\
\hline Disruption of: & At least 10 & & & 0.0010 & & & 0.0019 & & & 0.0031 \\
\hline & At least 15 & & & 0.0003 & & & 0.0006 & & & 0.0010 \\
\hline & At Least 20 & & & 0.0001 & & & 0.0001 & & & 0.0002 \\
\hline Cumulative Benefit & 0 & & & 0.0000 & & & 0.0000 & & & 0.0000 \\
\hline (Billions of 1988 \$ & 10 & & & 0.0000 & & & 0.0238 & & & 0.0891 \\
\hline Discounted and & 15 & & & 0.0001 & & & 0.0501 & & & 0.2000 \\
\hline Probability Weighted) & 20 & & & 0,0001 & & & 0.0615 & & & 0.2469 \\
\hline & Net & & 2010 & & & 2015 & & & 2020 & \\
\hline & Disruption & $z==z$ & $\Sigma=\Xi \approx=\Sigma \approx=$ & $=z=x=z=$ & $z=:$ & $\Rightarrow \approx z=\pi=\pi$ & $=\approx z=\Sigma \approx=$ & $z==$ & $=\Sigma=z=z=\pi$ & $z=z==\Sigma=$ \\
\hline Varlable & Size (MMBD) & 750 & 1000 & Delta & 750 & 1000 & Delta & 750 & 1000 & Delte \\
\hline$E=:==z=$ & $==z: x=z=z=$ & $z=z$ & $==s=$ & $z=z=z$ & $==2$ & $==z=$ & $=z==2$ & $=z=$ & $z=:=$ & $z=x=$ \\
\hline World oil Price & 0 & 37.20 & 37.08 & 0.12 & 40.00 & 40.01 & .0 .01 & 42.50 & 42.52 & .0 .02 \\
\hline$(1988 \$ / B)$ & 10 & 49.78 & 42.41 & 7.37 & 52.10 & 45.18 & 6.92 & 54.18 & 47.62 & 6.56 \\
\hline & 15 & 82.95 & 72.36 & 10.59 & 83.36 & 73.71 & 9.66 & 83.51 & 74.59 & 8.92 \\
\hline & 20 & 129.46 & 114.70 & 14.76 & 126.15 & 113.04 & 13.11 & 122.78 & 110.92 & 11.86 \\
\hline Disruption Cost & 0 & 0.0 & 0.0 & 0.00 & 0.0 & 0.0 & 0.00 & 0.0 & 0.0 & 0.00 \\
\hline (Billions of 1988 \$ & 10 & 83.6 & 35.9 & 47.70 & 87.7 & 37.8 & 49.83 & 92.3 & 41.0 & 51.31 \\
\hline - Not Discounted) & 15 & 248.9 & 194.5 & 54.38 & 262.5 & 205.9 & 56.63 & 274.4 & 216.3 & 58.07 \\
\hline & 20 & 411.0 & 346.9 & 64.07 & 436.9 & 370.6 & 66.29 & 457.6 & 390.1 & 67.52 \\
\hline Disruption Cost & 0 & 0.0 & 0.0 & 0.00 & 0.0 & 0.0 & 0.00 & 0.0 & 0.0 & 0.00 \\
\hline (Billions of $1988 \mathrm{~s}$ & 10 & 12.4 & 5.3 & 7.09 & 8.1 & 3.5 & 4.60 & 5.3 & 2.3 & 2.94 \\
\hline - Discounted) & 15 & 37.0 & 28.9 & 8.08 & 24.2 & 19.0 & 5.23 & 15.7 & 12.4 & 3.33 \\
\hline & 20 & 61.1 & 51.6 & 9.52 & 40.3 & 34.2 & 6.12 & 26.2 & 22.4 & 3.87 \\
\hline Probability of A & At least 0 & & & 1.0000 & & & 1.0000 & & & 1.0000 \\
\hline Disruption of: & At Least 10 & & & 0.0050 & & & 0.0077 & & & 0.0115 \\
\hline & At Least 15 & & & 0.0016 & & & 0.0024 & & & 0.0036 \\
\hline & At least 20 & & & 0.0003 & & & 0.0004 & & & 0.0007 \\
\hline Cumulative Benefit & 0 & & & 0.0000 & & & 0.0000 & & & 0.0000 \\
\hline (Billions of 1988 s & 10 & & & $0.165^{\circ}$ & & & 0.2411 & & & 0.3103 \\
\hline Discounted and & 15 & & & 0.3829 & & & 0.5620 & & & 0.7245 \\
\hline Frobability Weighted) & 20 & & & 0.4724 & & & 0.6940 & & & 0.8937 \\
\hline
\end{tabular}

Notes: The World oil prices are averages over the quarters of the disruption.

The costs and Benefits are accumulated over six quarters beginning with the start of the disruption. 
Table B5. Case 5. Sumnary Comparison of 750 MMB Systen Versus 1000 MMB System

\begin{tabular}{|c|c|c|c|c|c|c|c|c|c|c|}
\hline \multirow[b]{2}{*}{$\begin{array}{l}\text { Varlable } \\
x=x=a=z=\end{array}$} & $\begin{array}{r}\text { Net } \\
\text { Disruption }\end{array}$ & \multicolumn{2}{|r|}{1995} & $y= \pm=x a$ & \multicolumn{3}{|c|}{2000} & \multicolumn{2}{|c|}{ 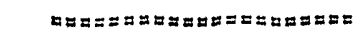 } & \\
\hline & $\begin{array}{l}\text { Size (MMBD) } \\
=z=z=z=z=z\end{array}$ & $\begin{array}{l}750 \\
= \pm=\end{array}$ & $\begin{array}{l}1000 \\
x=2 z\end{array}$ & $\begin{array}{l}\text { Delta } \\
x= \pm=\end{array}$ & $\begin{array}{l}750 \\
\square==\end{array}$ & $\begin{array}{l}1000 \\
z= \pm=\end{array}$ & $\begin{array}{l}\text { Delta } \\
z===\end{array}$ & $\begin{array}{l}750 \\
= \pm=\end{array}$ & $\begin{array}{l}1000 \\
=2=5\end{array}$ & $\begin{array}{l}\text { Delta } \\
z= \pm=z\end{array}$ \\
\hline World Oll Price & 0 & 20.60 & 20.60 & 0.00 & 28.00 & 28.15 & -0.15 & 33.40 & 33.37 & 0.03 \\
\hline \multirow[t]{3}{*}{$(1988 s / B)$} & 10 & 44.19 & 44.19 & 0.00 & 46.45 & 43.23 & 3.22 & 52.05 & 44.23 & $7.8 ?$ \\
\hline & 15 & 83.20 & 83.20 & 0.00 & 84.10 & 79.33 & $4 . \pi 7$ & 89.27 & 77.81 & 11.46 \\
\hline & 20 & 141.84 & 141.84 & 0.00 & 139.46 & 132.58 & 6.89 & 142.51 & 126.20 & 16.32 \\
\hline Disruption Cost & 0 & 0.0 & 0.0 & 0.00 & 0.0 & 0.0 & 0.00 & 0.0 & 0.0 & 0.00 \\
\hline (B)llions of 1988 s & 10 & 95.9 & 95.8 & 0.07 & 795 & 64.8 & 14.65 & 85.6 & 49.9 & 35.65 \\
\hline \multirow[t]{2}{*}{ - Not Discciunted) } & 15 & 191.6 & 191.5 & 0.08 & 190.1 & 172.2 & 17.93 & 208.6 & 164.7 & 43.89 \\
\hline & 20 & 275.6 & 275.5 & 0.08 & 293.3 & 270.9 & 22.39 & 328.6 & 274.1 & 54.53 \\
\hline Disruption Cost & 0 & 0.0 & 0.0 & 0.00 & 0.0 & 0.0 & 0.00 & 0.0 & 0.0 & 0.00 \\
\hline (billions of $1988 \$$ & 10 & 59.6 & 59.5 & 0.05 & 30.6 & 25.0 & 5.65 & 20.5 & 11.9 & 8.53 \\
\hline \multirow[t]{2}{*}{ - Discounted) } & 15 & 119.0 & 118.9 & 0.05 & 73.3 & 66.4 & 6.91 & 49.9 & 39.4 & 10.51 \\
\hline & 20 & 171.1 & 171.1 & 0.05 & 113.1 & 104.4 & 8.63 & 78.7 & 65.6 & 13.05 \\
\hline Probability of A & At Least 0 & & & 1.0000 & & & 1.0000 & & & 1.0000 \\
\hline \multirow[t]{3}{*}{ Disruption of: } & At Least 10 & & & 0.0017 & & & 0.0037 & & & 0.0063 \\
\hline & At Least 15 & & & 0.0005 & & & 0.0011 & & & 0.0018 \\
\hline & At Least 20 & & & 0.0001 & & & 0.0002 & & & 0.0003 \\
\hline Cumulative Benefit & 0 & & & 0.0000 & & & 0.0000 & & & 0.0000 \\
\hline (Billions of $1988 \mathrm{~s}$ & 10 & & & 0.0002 & & & 0.0757 & & & 0.2768 \\
\hline Discounted and & 15 & & & 0.0002 & & & 0.1243 & & & 0.4710 \\
\hline \multirow[t]{3}{*}{ Probability Weighted) } & 20 & & & 0.0003 & & & 0.1446 & & & 0.5505 \\
\hline & Het & \multicolumn{3}{|c|}{2010} & \multicolumn{3}{|c|}{2015} & \multicolumn{3}{|c|}{2020} \\
\hline & Disruption & \multicolumn{3}{|c|}{ 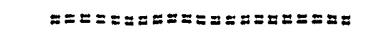 } & \multicolumn{3}{|c|}{ 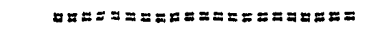 } & \multicolumn{3}{|c|}{ 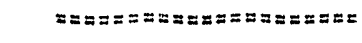 } \\
\hline Variable & Size (MMBD) & 750 & 1000 & Delta & 750 & 1000 & Delta & 750 & 1000 & Delta \\
\hline$== \pm=z z=\pi$ & 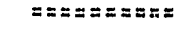 & $z==$ & 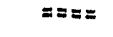 & $z==2=$ & $y==$ & $z= \pm= \pm$ & $z= \pm=z$ & $==2$ & $\Delta= \pm=$ & $==2 z=$ \\
\hline World Oll Price & 0 & 37.20 & 37.08 & 0.12 & 40.00 & 40.01 & -0.01 & 42.50 & 42.52 & -0.02 \\
\hline \multirow[t]{3}{*}{$(1988 \$ / B)$} & 10 & 55.50 & 47.55 & 7.95 & 57.55 & 50.13 & 7.42 & $59.35^{\circ}$ & 52.36 & 6.99 \\
\hline & 15 & 91.09 & 79.74 & 11.35 & 90.91 & 80.63 & 10.29 & 90.51 & 81.04 & 9.46 \\
\hline & 20 & 140.76 & 124.94 & 15.81 & 136.41 & 122.44 & 13.97 & 132.09 & 119.50 & 12.58 \\
\hline Disruption Cost & 0 & 0.0 & 0.0 & 0.00 & 0.0 & 0.0 & 0.00 & 0.0 & 0.0 & 0.00 \\
\hline (Billions of 1988 \& & 10 & 91.9 & 52.6 & 39.38 & 97.0 & 55.7 & 41.23 & 101.9 & 59.5 & 42.43 \\
\hline - Not Discounted) & 15 & 226.7 & 178.3 & 48.38 & 240.3 & 190.1 & 50.20 & 251.3 & 200.1 & 51.23 \\
\hline & 20 & 362.6 & 302.7 & 59.85 & 387.6 & 326.0 & 61.61 & 406.2 & 343.9 & 62.36 \\
\hline Disruption Cost & 0 & 0.0 & 0.0 & 0.00 & 0.0 & 0.0 & 0.00 & 0.0 & 0.0 & 0.00 \\
\hline (Billions of $1988 \$$ & 10 & 13.7 & 7.8 & 5.85 & 9.0 & 5.1 & 3.81 & 5.8 & 3.4 & 2.43 \\
\hline - Discounted) & 15 & 33.7 & 26.5 & 7.19 & 22.2 & 17.5 & 4.63 & 14.4 & 11.5 & 2.94 \\
\hline & 20 & 53.9 & 45.0 & 8.90 & 35.8 & 30.1 & 5.69 & 23.3 & 19.7 & 3.57 \\
\hline Probability of $A$ & At Least 0 & & & 1.0000 & & & 1.0000 & & & 1.0000 \\
\hline Disruption of: & At Least 10 & & & 0.0100 & & & 0.0146 & & & 0.0203 \\
\hline & At least 15 & & & 0.0028 & & & 0.0041 & & & 0.0057 \\
\hline & At Least 20 & & & 0.0005 & & & 0.0007 & & & 0.0010 \\
\hline Cumulative Benefit & 0 & & & 0.0000 & & & 0.0000 & & & 0.0000 \\
\hline (Blllions of $1988 \mathrm{~s}$ & 10 & & & 0.5106 & & & 0.7114 & & & 0.8633 \\
\hline Discounted and & 15 & & & 0.8811 & & & 1.2315 & & & 1.5015 \\
\hline Probability Weighted) & 20 & & & 1.0303 & & & 1.4397 & & & 1.7564 \\
\hline
\end{tabular}

Notes: The world oil prices are averages over the quarters of the disruption.

The costs and Benefits are accumulated over six quarters beginning with the start of the disruption. 
Table 86, Case 6. Sumnary Comparlson of 750 MMB systeil Versus 1000 MMB system

\begin{tabular}{|c|c|c|c|c|c|c|c|c|c|c|}
\hline & $\begin{array}{r}\text { Net } \\
\text { Disruption }\end{array}$ & $=t=28$ & 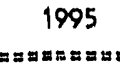 & $z z=z z z z$ & $x a= \pm 2$ & $\begin{array}{c}2000 \\
= \pm \pi=x=2 \pi\end{array}$ & $a y= \pm x=2$ & $y= \pm \approx z$ & $=\begin{array}{c}2005 \\
=x= \pm x=0 x:\end{array}$ & 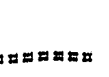 \\
\hline Varlable & S|ze (MMBD) & 750 & 1000 & Delta & 750 & 1000 & Delta & 750 & 1000 & Delta \\
\hline$z=2 x z=x=$ & 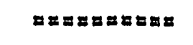 & $m= \pm$ & $m=z=$ & $y=z x z$ & $x:=$ & 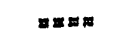 & $z= \pm x=$ & $m=2$ & $x y=z$ & 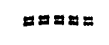 \\
\hline World 011 Price & 0 & 20.60 & 20.60 & 0.00 & 28.00 & 28.15 & .0 .15 & 33.40 & 33.37 & 0.03 \\
\hline$(1988 \mathrm{~S} / \mathrm{B})$ & 10 & 35.46 & 35.46 & 0.00 & 37.89 & 35.05 & 2.84 & 43.41 & 36.49 & 6.92 \\
\hline & 15 & 69.71 & 69.71 & 0.00 & 71.17 & 66.91 & 4.26 & 76.62 & 66.36 & 10.25 \\
\hline & 20 & 121.61 & 121.61 & 0.00 & 120.58 & 114.45 & 6.13 & 124.51 & 109.90 & 14.61 \\
\hline Disruption Cost & 0 & 0.0 & 0.0 & 0.00 & 0.0 & 0.0 & 0.00 & 0.0 & 0.0 & 0.00 \\
\hline (B) lllions of 1988 s & 10 & 65.7 & 65.6 & 0.07 & 45.2 & 31.5 & 13.97 & 48.6 & 14.9 & 33.77 \\
\hline - Not Discounted) & 15 & 163.8 & 163.7 & 0.08 & 157.4 & 140.6 & 16.81 & 171.7 & 130.6 & 41.12 \\
\hline & 20 & 252.0 & 251.9 & 0.08 & 263.5 & 242.7 & 20.84 & 293.1 & 242.3 & 50.88 \\
\hline Disruption Cost & 0 & 0.0 & 0.0 & 0.00 & $(1.0$ & 0.0 & 0.00 & 0.0 & 0.0 & 0.00 \\
\hline (B)lllions of 1988 & 10 & 40.8 & 40.8 & 0.04 & 17.5 & 12.9 & 5.39 & 11.6 & 3.6 & 8.08 \\
\hline - Discounted) & 15 & 101.7 & 101.6 & 0.05 & 60.7 & 54.2 & 6.48 & 41.1 & 31.3 & 9.84 \\
\hline & 20 & 156.4 & 156.4 & 0.05 & 101.6 & 93.6 & 8.03 & 70.2 & 58.0 & 12.18 \\
\hline Probabllity of $A$ & At Least 0 & & & 1.0000 & & & 1.0000 & & & 1.0000 \\
\hline Disruption of: & At Least 10 & & & 0.0012 & & & 0.0021 & & & 0.0033 \\
\hline & At Least 15 & & & 0.0004 & & & 0.0006 & & & 0.0010 \\
\hline & At Least 20 & & & 0.0001 & & & 0.0001 & & & 0.0002 \\
\hline Cumulative Benefit & 0 & & & 0.0000 & & & 0.0000 & & & 0.0000 \\
\hline (Billions of 1988 \$ & 10 & & & 0.0000 & & & 0.0133 & & & 0.0455 \\
\hline Discounted and & 15 & & & 0.0001 & & & 0.0345 & & & 0.1302 \\
\hline Probabillty Weighted) & 20 & & & 0.0001 & & & 0.0442 & & & 0.1687 \\
\hline & Net & & 2010 & & & 2015 & & & 2020 & \\
\hline & Disruption & $=z==$ & $=z=x=z=x$ & $z=:==:=$ & $=z=z$ & $=z=z=z x z$ & $z=z=z z=$ & $z=z=$ & $=z=z=z z=$ & $z=== \pm==$ \\
\hline Variable & size (MMBD) & 750 & 1000 & Delta & 750 & 1000 & Delta & 750 & 1000 & Delta \\
\hline$z=z=\approx z=\pi$ & $z=\pi z=z=2 z=$ & $z=z$ & $z=2=$ & $m= \pm x=$ & 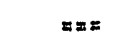 & $= \pm=z$ & $=z=z=$ & $= \pm \pi$ & $=z=2$ & $==\approx=z$ \\
\hline World Oil Price & 0 & 37.20 & 37.08 & 0.12 & 40.00 & 40.01 & -0.01 & 42.50 & 42.52 & -0.02 \\
\hline$(1988 \$ / 8)$ & 10 & 47.07 & 39.98 & 7.09 & 49.51 & 42.83 & 6.68 & 51.72 & 45.37 & 6.35 \\
\hline & 15 & 79.09 & 68.86 & 10.23 & 79.76 & 70.41 & 9.35 & 80.17 & 71.51 & 8.66 \\
\hline & 20 & 124.09 & 109.83 & 14.26 & 121.26 & 108.55 & 12.70 & 118.34 & 106.82 & 11.52 \\
\hline Disruption Cost & 0 & 0.0 & 0.0 & 0.00 & 0.0 & 0.0 & 0.00 & 0.0 & 0.0 & 0.00 \\
\hline <Billions of 1988 & 10 & 52.1 & 14.9 & 37.23 & 55.0 & 15.9 & 39.04 & 58.3 & 18.0 & 40.26 \\
\hline - Not Discounted) & 15 & 185.9 & 140.6 & 45.39 & 196.8 & 149.6 & 47.23 & 205.8 & 157.5 & 48.33 \\
\hline & 20 & 321.8 & 265.8 & 55.94 & 343.0 & 285.3 & 57.73 & 359.1 & 300.5 & 58.59 \\
\hline Disruption Cost & 0 & 0.0 & 0.0 & 0.00 & 0.0 & 0.0 & 0.00 & 0.0 & 0.0 & 0.00 \\
\hline (Billions of $1988 \mathrm{~s}$ & 10 & 7.7 & 2.2 & 5.53 & 5.1 & 1.5 & 3.60 & 3.3 & 1.0 & 2.31 \\
\hline - Discounted) & 15 & 27.6 & 20.9 & 6.75 & 18.2 & 13.8 & 4,36 & 11.8 & 9.0 & 2.77 \\
\hline & 20 & 47.8 & 39.5 & 8.31 & 31.7 & 26.3 & 5.33 & 20.6 & 17.2 & 3.36 \\
\hline Probability of $A$ & At least 0 & & & 1.0000 & & & 1.0000 & & & 1.0000 \\
\hline Disruption of: & At Least 10 & & & 0.0048 & & & 0.0067 & & & 0.0091 \\
\hline & At least 15 & & & 0.0015 & & & 0.0021 & & & 0.0029 \\
\hline & At Loast 20 & & & 0.0003 & & & 0.0004 & & & 0.0006 \\
\hline Cumulative Benefit & 0 & & & 0.0000 & & & 0.0000 & & & 0.0000 \\
\hline (Billions of 1988 s & 10 & & & 0.0780 & & & 0.1069 & & & 0.1318 \\
\hline Discounted and & 15 & & & 0.2345 & & & 0.3263 & & & 0.4024 \\
\hline Probability Welghted) & 20 & & & 0.3050 & & & 0.4249 & & & 0.5239 \\
\hline
\end{tabular}

Hotes: The World Oil Prices are averages over the quarters of the disruption.

The costs and Benefits are accumulated over six quarters beginning with the start of the disruption. 
Table B7. Case 7. Sumbry Comparlson of 750 MMB System Versus 1000 MMB System

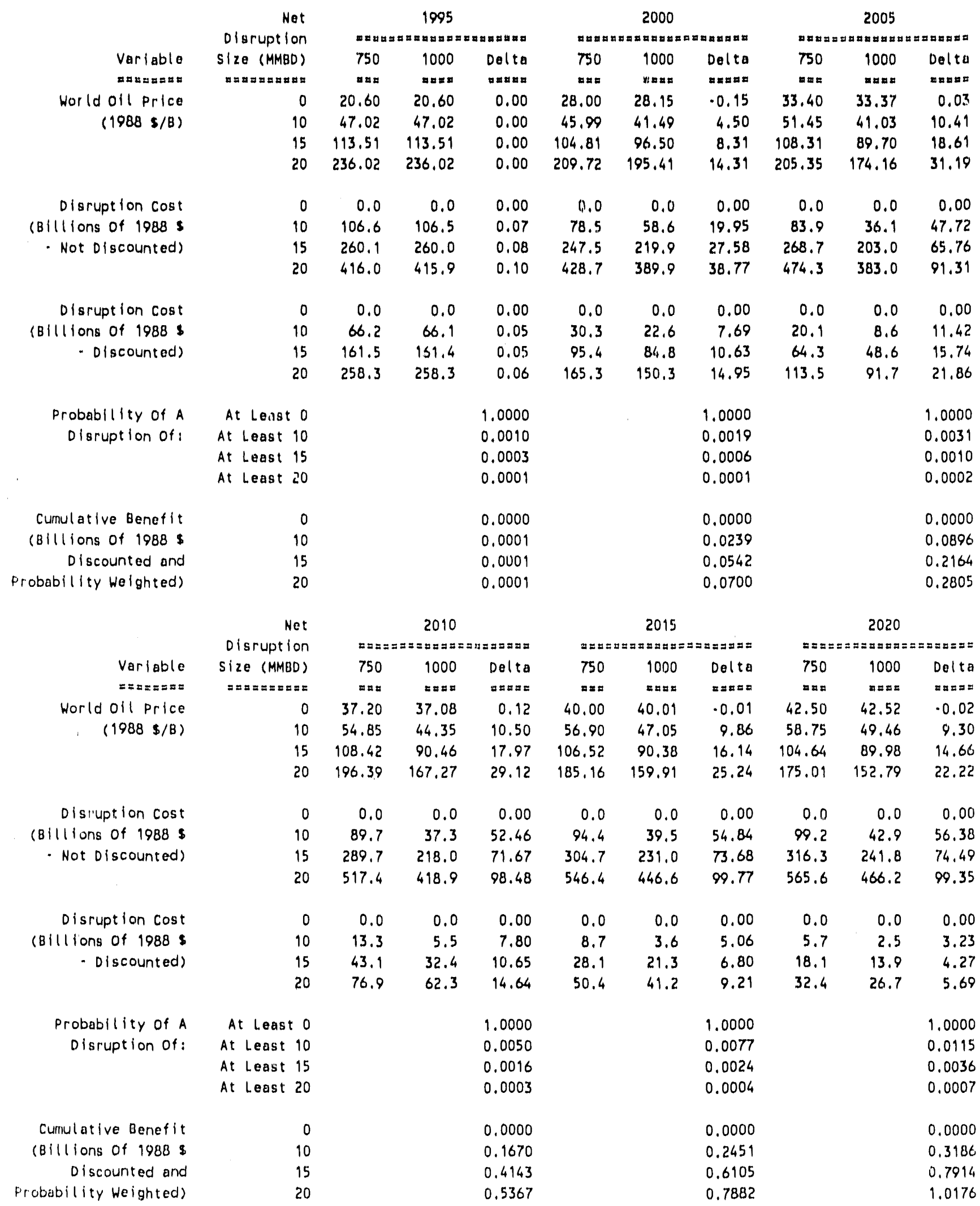

Notes: The World oil prices are averages over the quarters of the disruption.

The costs and Benefits are accumulated over six quarters beginning with the start of the disruption. 
Table B8. Case 8. Surmary Comparison of 750 MMB System Versug 1000 MMB System

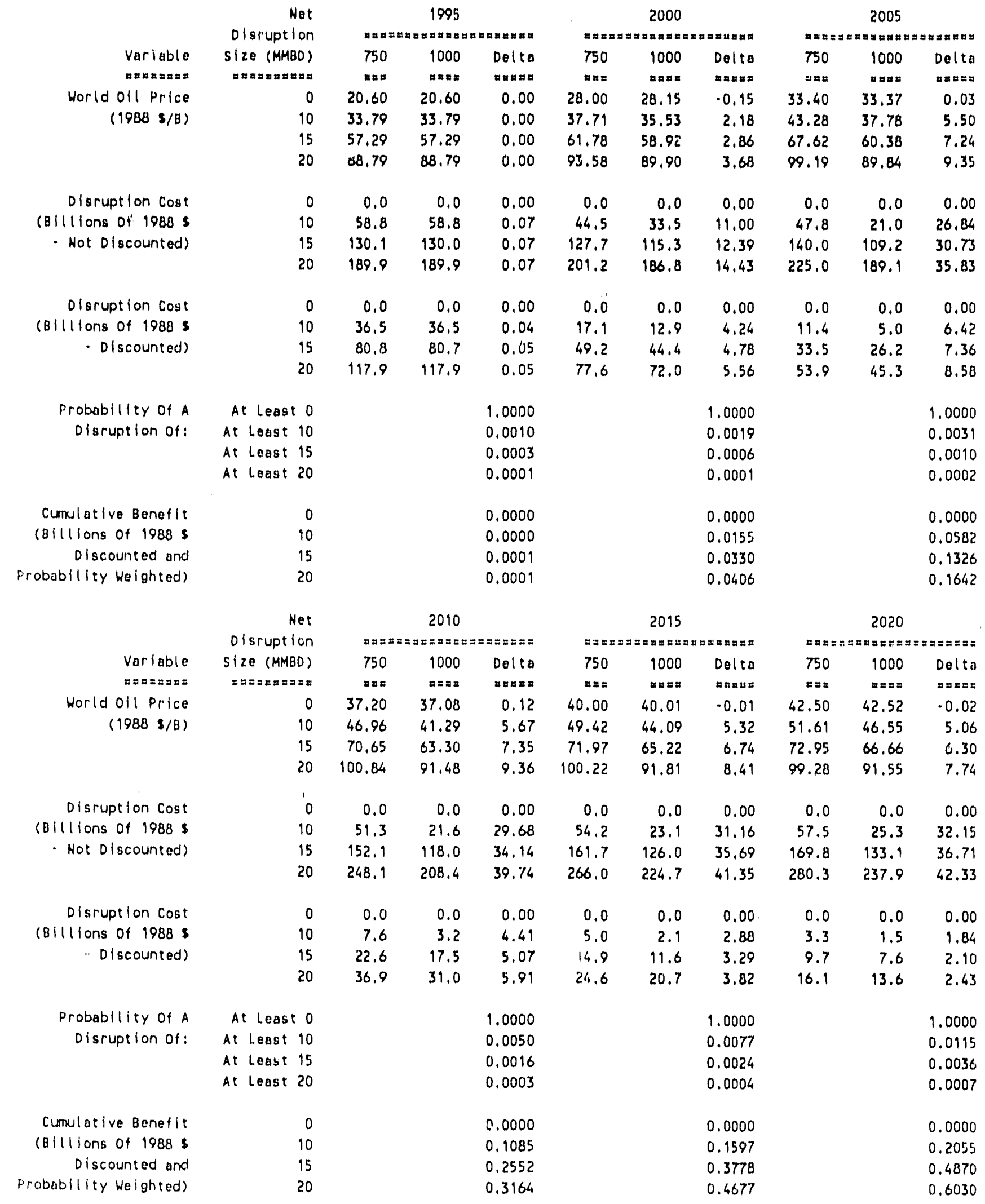

Notes: The World Oil prices are averages over the quarters of the disruption.

The costs and Benefits are accumulated over six quarters beginning with the start of the disruption. 
Table 89. Case 9. Summary Comparlson. of 750 MMB system Versus 1000 MMB systern

\begin{tabular}{|c|c|c|c|c|c|c|c|c|c|c|}
\hline & Net & & 1095 & & & 2000 & & & 2005 & \\
\hline & Disruption & $x \geq y=$ & 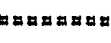 & $x y=x=x=$ & 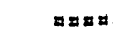 & 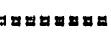 & 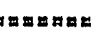 & $x \geq x$ & $\alpha y m z=z z$ & 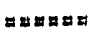 \\
\hline Vartable & $S \mid z e(M M B D)$ & 750 & 1000 & Delta & 750 & 1000 & Del ta & 750 & 1000 & Delta \\
\hline 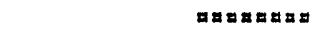 & 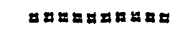 & 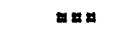 & ะมะ & $y=a z z$ & $\forall=$ & घะघี & $m \pm= \pm z$ & $m y=$ & $a \geq z z$ & 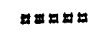 \\
\hline World oll Price & 0 & 16.70 & 16.70 & 0.00 & 21,70 & 21.70 & 0.00 & 24.80 & 24.80 & 0.00 \\
\hline$(1988 \$ / 8)$ & 10 & 32.74 & 32.74 & 0.00 & 32.44 & 29.72 & 2.71 & 35.23 & 29.35 & 5.88 \\
\hline & 15 & 66.49 & 66.49 & 0.00 & 62.70 & 58.45 & 4.25 & 64.05 & 55.12 & 8.93 \\
\hline & 20 & 119.90 & 119.90 & 0.00 & 109.16 & 102.71 & 6.45 & 106.87 & 93.73 & 13.15 \\
\hline Disruption Cost & 0 & 0.0 & 0.0 & 0.00 & 0.0 & 0.0 & 0.00 & 0.0 & 0.0 & 0.00 \\
\hline (Billlons of $1988 \mathrm{~s}$ & 10 & 82.3 & 82.3 & 0.00 & 61.0 & $1,6.0$ & 14.98 & 63.8 & 28.2 & 35.55 \\
\hline - Not D(acounted) & 15 & 190.1 & 190.1 & 0.00 & 182.8 & 164.6 & 18.24 & 194.6 & 151.5 & 43.06 \\
\hline & 20 & 294.9 & 294.9 & 0.00 & 307.7 & 284.5 & 23.22 & 331.9 & 277.7 & 54.24 \\
\hline Disruption Cost & 0 & 0.0 & 0.0 & 0.00 & 0.0 & 0.0 & 0.00 & 0.0 & 0.0 & 0.00 \\
\hline (Billlons of 1988 s & 10 & 51.1 & 51.1 & 0.00 & 23.5 & 17.7 & 5.78 & 15.3 & 6.8 & 8.51 \\
\hline - D(scounted) & 15 & 118.0 & 118.0 & 0.00 & 70.5 & 63.5 & 7.03 & 46.6 & 36.3 & 10.31 \\
\hline & 20 & 183.1 & 183.1 & 0.00 & 118.6 & 109.7 & 8.95 & 79.5 & 66.5 & 12.99 \\
\hline Probability of $A$ & At Least 0 & & & 1.0000 & & & 1.0000 & & & 1.0000 \\
\hline Disruption of: & At loast 10 & & & 0.0010 & & & 0.0019 & & & 0.0031 \\
\hline & At Least 15 & & & 0.0003 & & & 0.0006 & & & 0.0010 \\
\hline & At Least 20 & & & 0.0001 & & & 0.0001 & & & 0.0002 \\
\hline Cumul at ive Benefit & 0 & & & 0.0000 & & & 0.0000 & & & 0.0000 \\
\hline (B)llions of 1988 s & 10 & & & 0.0000 & & & 0.0180 & & & 0.0696 \\
\hline Discounted and & 15 & & & 0.0000 & & & 0.0395 & & & 0.1610 \\
\hline Probability Woighted) & 20 & & & 0.0000 & & & 0.0495 & & & 0.2022 \\
\hline & Net & & 2010 & & & 2015 & & . & 2020 & \\
\hline & Disruption & $x=z z$ & $=\approx \approx=\Sigma \approx \approx n$ & $\Rightarrow a n z=a=$ & $\approx= \pm z$ & 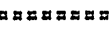 & 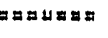 & $=m z=$ & $=x= \pm x=$ & $\approx= \pm \approx \approx \Sigma x$ \\
\hline Varlable & Size (MMBD) & 750 & 1000 & Delta & 750 & 1000 & Delta & 750 & 1000 & Delta \\
\hline$=z=z \pi=z \pi$ & $z=\Sigma \Delta x=\Sigma a z=$ & $z=z$ & $z= \pm=$ & $z=\Sigma z z$ & $x= \pm$ & $x x=$ & $m= \pm \approx z$ & $\nexists x=$ & $z= \pm=$ & $\approx x=\approx x$ \\
\hline World ofl Price & 0 & 26.70 & 26.70 & 0.00 & 28.30 & 28.30 & 0.00 & 29.40 & 29.40 & 0.00 \\
\hline$(1988 \$ / 8)$ & 10 & 36.62 & 30.90 & 5.72 & 37.67 & 32.29 & 5.38 & 38.23 & 33.24 & 4.99 \\
\hline & 15 & 63.26 & 54.87 & 8.39 & 62.26 & 54.59 & 7.67 & 60.73 & 53.82 & 6.92 \\
\hline & 20 & 101.66 & 89.66 & 12.00 & 96.80 & 86.09 & 10.70 & 91.54 & 82.12 & 9.42 \\
\hline Disruption Cost & 0 & 0.0 & 0.0 & 0.00 & 0.0 & 0.0 & 0.00 & 0.0 & 0.0 & 0.00 \\
\hline (B)lllons of 1988 s & 10 & 66.7 & 28.5 & 38.16 & 69.0 & 29.7 & 39.31 & 71.3 & 31.5 & 39.84 \\
\hline - Not D(scounted) & 15 & 204.7 & 158.7 & 45.94 & 211.9 & 165.0 & 46.90 & 217.0 & 170.1 & 46.94 \\
\hline & 20 & 351.5 & 294.2 & 57.28 & 364.7 & 306.9 & 57.78 & 372.4 & 315.4 & 57.00 \\
\hline Disruption Cost & 0 & 0.0 & 0.0 & 0.00 & 0.0 & 0.0 & 0.00 & 0.0 & 0.0 & 0.00 \\
\hline (Billions of $1988 \mathrm{~s}$ & 10 & 9.9 & 4.2 & 5.67 & 6.4 & 2.7 & 3.63 & 4.1 & 1.8 & 2.28 \\
\hline - Discounted) & 15 & 30.4 & 23.6 & 6.83 & 19.6 & 15.2 & 4.33 & 12.4 & 9.7 & 2.69 \\
\hline & 20 & 52.2 & 43.7 & 8.51 & 33.7 & 28.3 & 5.33 & 21.3 & 18.1 & 3.27 \\
\hline Probability of A & At least 0 & & & 1.0000 & & & 1.0000 & & & 1.0000 \\
\hline Disruption of: & At Least 10 & & & 0.0050 & & & 0.0077 & & & 0.0115 \\
\hline & At Least 15 & & & 0.0016 & & & 0.0074 & & & 0.0036 \\
\hline & At Least 20 & & & 0.0003 & & & 0.0004 & & & 0.0007 \\
\hline Cumulative Benefit & 0 & & & 0.0000 & & & 0.0000 & & & 0.0000 \\
\hline (B)llions of $1988 \mathrm{~s}$ & 10 & & & 0.1290 & & & 0.1890 & & & 0.2445 \\
\hline Discounted and & 15 & & & 0.3074 & & & 0,4490 & & & 0.5811 \\
\hline Probability Weighted) & 20 & & & 0.3855 & & & 0.5617 & & & 0.7260 \\
\hline
\end{tabular}

Notes: The world Oil Prices are averages over the quarters of the disruption. The Costs and Benefits are accumulated over slx quarters beginning with the start of the disruption. 
Table B10. Case 10 - Summary Comparison of 750 MMB System Versus 1000 MMB System

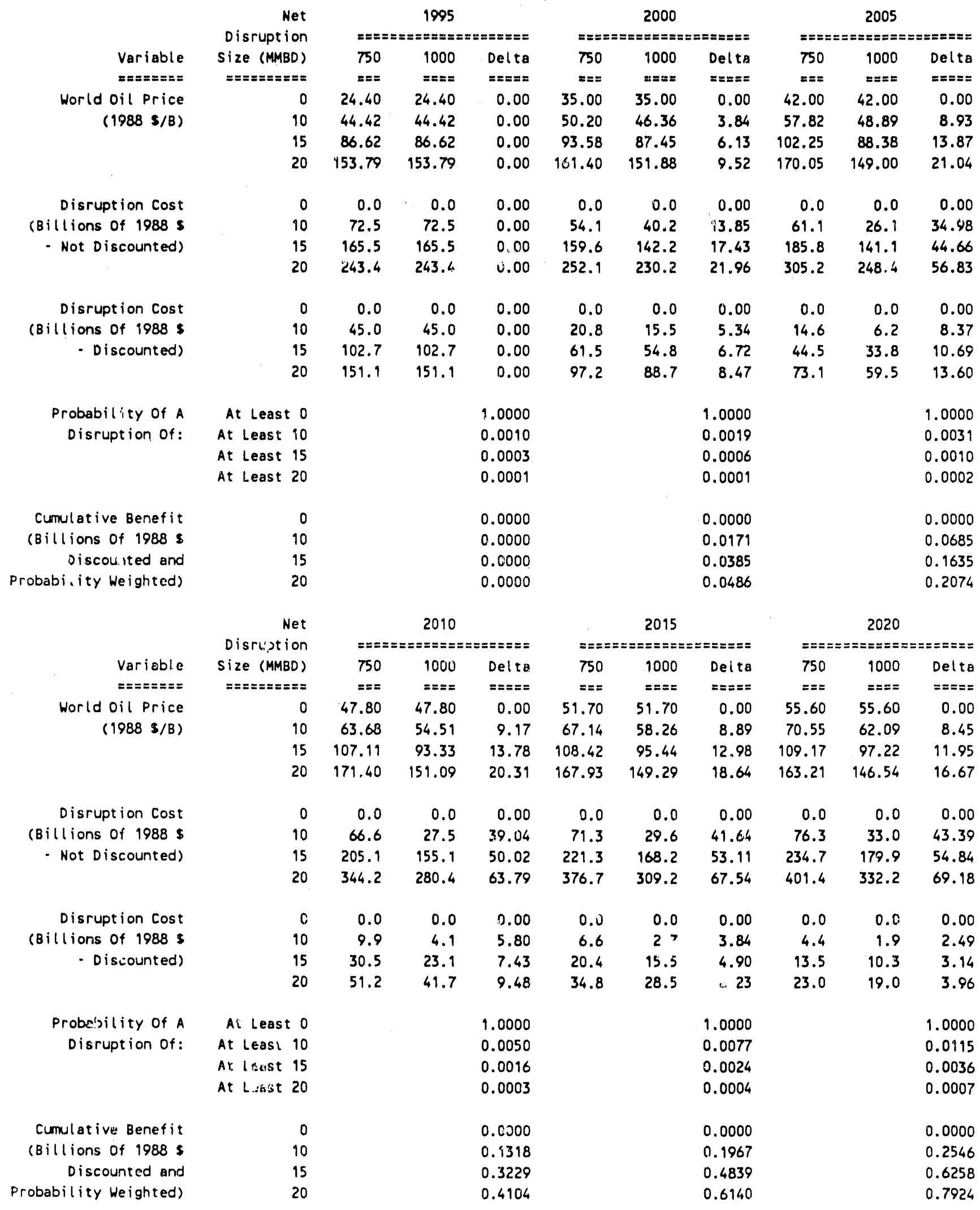

Notes: The World Dil Prices are averages over the quarters of the disruption.

The costs and Benefits are accumulated over six quarters beginning with the start of the disruption. 
Table B11. Case 11. Summary Comparison of 750 MMB System Versus 1000 MMB System

\begin{tabular}{|c|c|c|c|c|c|c|c|c|c|c|}
\hline \multirow{3}{*}{$\begin{array}{l}\text { Variable } \\
==z== \pm=z\end{array}$} & $\begin{array}{r}\text { Net } \\
\text { Disruption }\end{array}$ & $z=z=2$ & \multicolumn{2}{|l|}{1995} & \multicolumn{3}{|c|}{2000} & \multicolumn{3}{|c|}{2005} \\
\hline & size (MAABD) & 750 & 1000 & Delta & 750 & 1000 & Dotta & 750 & 1000 & Delta \\
\hline & 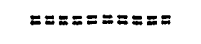 & $===$ & $z=x=$ & $z=x=2$ & $z=\Sigma$ & $z=z=$ & $==\Sigma==$ & $z==$ & $z=z=$ & $x====$ \\
\hline World Oll Price & 0 & 20.60 & 20.60 & 0.00 & 28.00 & 28.15 & -0.15 & 33.40 & 33.37 & 0.03 \\
\hline \multirow[t]{3}{*}{$(1988 \$ / 8)$} & 10 & 38.25 & 38.25 & 0.00 & 40.62 & 37.65 & 2.97 & 46.18 & 38.97 & 7.21 \\
\hline & $\because 5$ & 74.02 & 74.02 & 0.00 & 75.31 & 70.89 & 4.42 & 80.68 & 70.04 & 10.64 \\
\hline & 20 & 128.07 & 128.07 & 0.00 & 126.62 & 120.26 & 6.37 & 130.29 & 115.13 & 15.15 \\
\hline Disruption cost & 0 & 0.0 & 0.0 & 0.00 & 0.0 & 0.0 & 0.00 & 0.0 & 0.0 & 0.00 \\
\hline (Billions of $1988 \mathrm{~s}$ & 10 & 75.9 & 75.8 & 0.07 & 56.9 & 42.7 & 14.18 & 60.9 & 26.6 & 34.36 \\
\hline \multirow[t]{2}{*}{ - Not Discounted) } & 15 & 173.1 & 173.1 & 0.08 & 168.4 & 151.2 & 17.17 & 184.0 & 142.0 & 42.01 \\
\hline & 20 & 260.0 & 259.9 & 0.08 & 273.6 & 252.2 & 21.34 & 305.0 & 253.0 & 52.06 \\
\hline Disruption Cost. & 0 & 0.0 & 0.0 & 0.00 & 0.0 & 0.0 & 0.00 & 0.0 & 0.0 & 0.00 \\
\hline (Billions of $1988 \mathrm{~s}$ & 10 & 47.1 & 47.1 & 0.04 & 21.9 & 16.5 & 5.47 & 14.6 & 6.4 & 8.23 \\
\hline \multirow[t]{2}{*}{ Discounted) } & 15 & 107.5 & 107.5 & 0.05 & 64.9 & 58.3 & 6.62 & 44.1 & 34.0 & 10.06 \\
\hline & 20 & 161.4 & 161.4 & 0.05 & 105,5 & 97.2 & 8.23 & 73.0 & 60.6 & 12.46 \\
\hline \multirow{4}{*}{$\begin{array}{l}\text { Probability of A } \\
\text { Disruption of: }\end{array}$} & At Least 0 & & & 1.0000 & & & 1.0000 & & & 1.0000 \\
\hline & At Least 10 & & & 0.0004 & & & 0.0008 & & & 0.0013 \\
\hline & At Least 15 & & & 0.0001 & & & 0.0002 & & & 0.0003 \\
\hline & At Least 20 & & & 0.0000 & & & 0.0000 & & & 0.0000 \\
\hline Cumulative Benefit & 0 & & & 0.0000 & & & 0.0000 & & & 0.0000 \\
\hline (Billions of 1988 \$ & 10 & & & 0.0000 & & & 0.0084 & & & 0.0330 \\
\hline Discounted and & 15 & & & 0.0000 & & & 0.0165 & & & 0.0694 \\
\hline \multirow[t]{3}{*}{ Pr.babili (y Weighted) } & 20 & & & 0.0000 & & & 0.0193 & & & 0.0818 \\
\hline & Net & \multicolumn{3}{|c|}{2010} & \multicolumn{3}{|c|}{2015} & \multicolumn{3}{|c|}{2020} \\
\hline & Disruption & \multicolumn{3}{|c|}{ 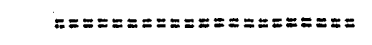 } & \multicolumn{3}{|c|}{ 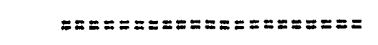 } & \multicolumn{3}{|c|}{ 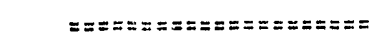 } \\
\hline Variable & Size (MMBD) & 750 & 1000 & Delta & 750 & 1000 & Delta & 750 & 1000 & Delta \\
\hline$====\pi===$ & 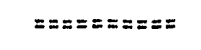 & $===$ & $z===$ & $==2=x$ & $===$ & 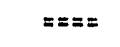 & $=: z==$ & $== \pm$ & $====$ & $====$ \\
\hline World oil Price & 0 & 37.20 & 37.08 & 0.12 & 40.00 & 40.01 & -0.01 & 42.50 & 42.52 & -0.02 \\
\hline$(1988 \$ / B)$ & 10 & 49.78 & 42.41 & 7.37 & 52.10 & 45.18 & 6.92 & 54.18 & 47.62 & 6.56 \\
\hline & 15 & 82.95 & 72.36 & 10.59 & 83.36 & 73.71 & 9.66 & 83.51 & 74.59 & 8.92 \\
\hline & 20 & 129.46 & 114.70 & 14.76 & 126.15 & 113.04 & 13.11 & 122.78 & 110.92 & 11.86 \\
\hline Disruption Cost & 0 & 0.0 & 0.0 & 0.00 & 0.0 & 0.0 & 0.00 & 0.0 & 0.0 & 0.00 \\
\hline (Billions of $1988 \$$ & 10 & 65.4 & 27.4 & 37.91 & 68.9 & 29.2 & 39.74 & 72.8 & 31.8 & 40.95 \\
\hline - Not Discounted) & 15 & 199.5 & 153.1 & 46.36 & 211.2 & 163.0 & 48.20 & 220.9 & 171.7 & 49.27 \\
\hline & 20 & 335.4 & 278.2 & 57.20 & 357.8 & 298.8 & 58.98 & 374.7 & 314.9 & 59.81 \\
\hline Disruption Cost & 0 & 0.0 & 0.0 & 0.00 & 0.0 & 0.0 & 0.00 & 0.0 & 0.0 & 0.00 \\
\hline (Billions of $1988 \$$ & 10 & 9.7 & 4.1 & 5.64 & 6.4 & 2.7 & 3.67 & 4.2 & 1.8 & 2.35 \\
\hline - Discounted) & 15 & 29.7 & 22.8 & 6.89 & 19.5 & 15.0 & 4.45 & 12.7 & 9.8 & 2.82 \\
\hline & 20 & 49.8 & 41.3 & 8.50 & 33.0 & 27.6 & 5.44 & 21.5 & 18.0 & 3.43 \\
\hline Probability of A & At Least 0 & & & 1.0000 & & & 1.0000 & & & 1.0000 \\
\hline Disruption of: & At Least 10 & & & 0.0022 & & & 0.0038 & & & 0.0060 \\
\hline & At least 15 & & & 0.0005 & & & 0.0009 & & & 0.0014 \\
\hline & At Least 20 & & & 0.0001 & & & 0.0001 & & & 0.0002 \\
\hline Cumulative Benefit & $v$ & & & 0.0000 & & & 0.0000 & & & 0.0000 \\
\hline (Billions of 1988 s & 10 & & & 0.0647 & & & 0.1002 & & & 0.1353 \\
\hline DI: ounted and & 15 & & & 0.1404 & & & 0.2189 & & & 0.2960 \\
\hline rohability بe ighted? & 20 & & & 0.1650 & & & 0.2584 & & & 0.3493 \\
\hline
\end{tabular}

Notes: The World Oil Prices are averages over the quarters of the disruption.

The costs and Benefits are accumulated over. ix quartars beginning with the start of the disruption. 
Table B12. Case 12 - Sumary Comparison of 750 MMB system Versus 1000 AMB System

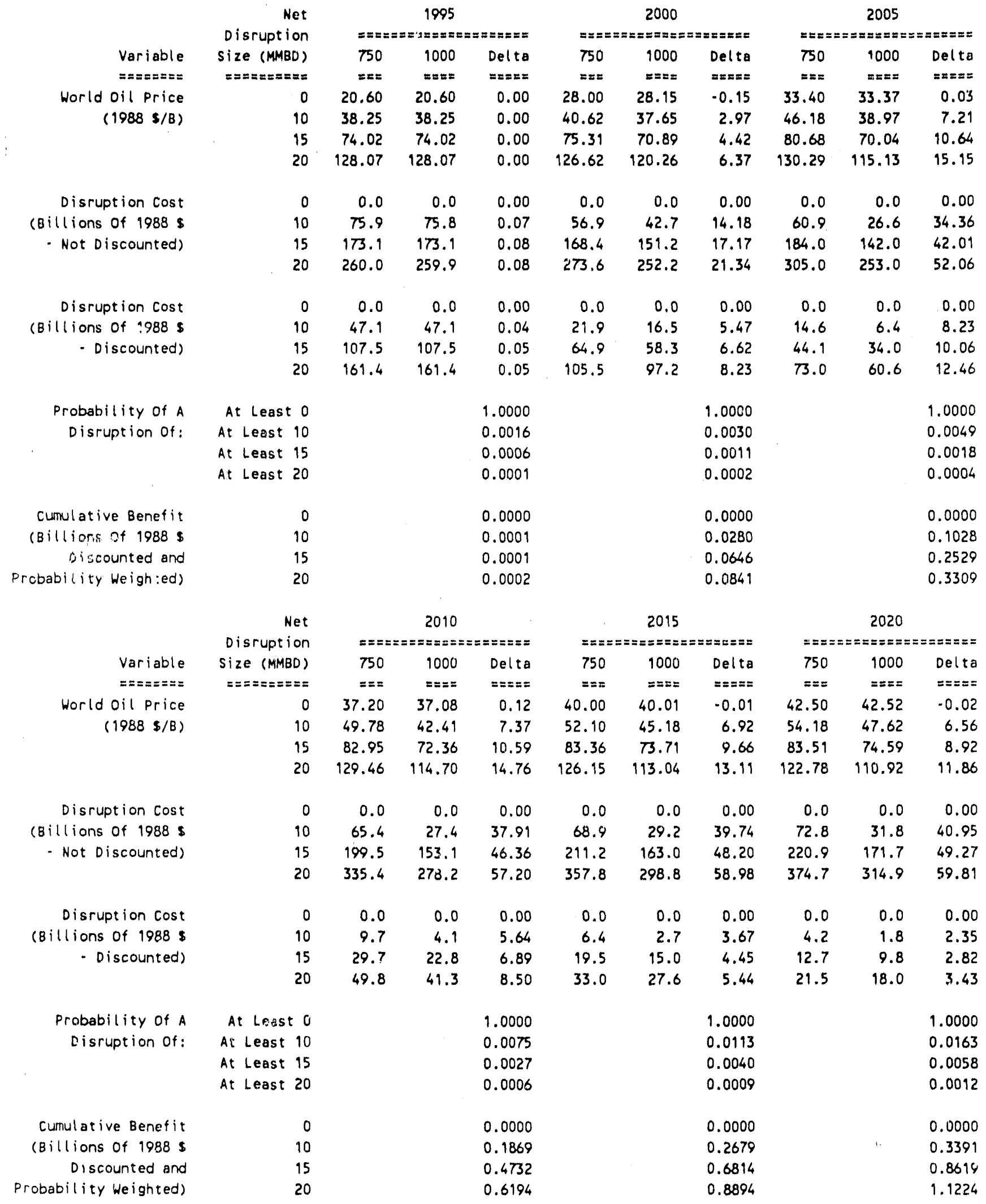

Notes: The Huild oil Frices are averages over the quarters of the disruption.

The costs and Benefits are accumulated over six quarters beginning with the start of the disruption. 
Table B13. Case 13 - summary Comparison of 600 MMB System Versus 1000 MMB System

\begin{tabular}{|c|c|c|c|c|c|c|c|c|c|c|}
\hline \multirow{3}{*}{$\begin{array}{l}\text { Variable } \\
m=:= \pm=x=\end{array}$} & $\begin{array}{r}\text { Net } \\
\text { Disruption }\end{array}$ & \multicolumn{3}{|c|}{1995} & \multicolumn{3}{|c|}{2000} & \multicolumn{3}{|c|}{2005} \\
\hline & Size (MMBD) & 600 & 1000 & Delta & 600 & 1000 & Delta & 600 & 1000 & Delta \\
\hline & $=:=z=x=\pi=x=$ & $z=2$ & $z= \pm z$ & $=\pi z=:=$ & $=:=$ & $=z=\pi$ & $=z=2 \pi$ & $=x=$ & $z=z=$ & $z=z==$ \\
\hline World oil Price & 0 & 20.60 & 20.60 & 0.00 & 28.00 & 28.15 & -0.15 & 33.40 & 33.37 & 0.03 \\
\hline \multirow[t]{3}{*}{$(19885 / B)$} & 10 & 42.09 & 38.25 & 3.85 & 45.39 & 37.65 & 7.73 & 51.01 & 38.97 & 12.05 \\
\hline & 15 & 79.97 & 74.02 & 5.95 & 82.51 & 70.89 & 11.62 & 87.76 & 70.04 & 17.72 \\
\hline & 20 & 136.98 & 128.07 & 8.92 & 137.13 & 120.26 & 16.87 & 140.35 & 115.13 & 25.22 \\
\hline Disruption Cost & 0 & 0.0 & 0.0 & 0.00 & 0.0 & 0.0 & 0.00 & 0.0 & 0.0 & 0.00 \\
\hline (Billions of $1988 \mathrm{~s}$ & 10 & 91.6 & 75.8 & 15.84 & 78.1 & 42.7 & 35.43 & 84.0 & 26.6 & 57.40 \\
\hline \multirow[t]{2}{*}{ - Not Discounteds } & 15 & 192.4 & 173.1 & 19.32 & 194.5 & 151.2 & 43.32 & 212.5 & 142.0 & 70.53 \\
\hline & 20 & 284.2 & 259.9 & 24.24 & 306.2 & 252.2 & 54.02 & 340.6 & 253.0 & 87.66 \\
\hline Disruption Cost & 0 & 0.0 & 0.0 & 0.00 & 0.0 & 0.0 & 0.00 & 0.0 & 0.0 & 0.00 \\
\hline (Billions of 1988 s & 10 & 56.9 & 47.1 & 9.84 & 30.1 & 16.5 & 13.66 & 20.1 & 6.4 & 13.74 \\
\hline \multirow[t]{2}{*}{ - Discounted) } & 15 & 119.5 & 107.5 & 12.00 & 75.0 & 58.3 & 16.70 & 50.9 & 34.0 & 16.88 \\
\hline & 20 & 176.4 & 161.4 & 15.05 & 118.1 & 97.2 & 20.83 & 81.5 & 60.6 & 20.98 \\
\hline Probability of A & At Least 0 & & & 1.0000 & & & 1.0000 & & & 1.0000 \\
\hline \multirow[t]{3}{*}{ Disruption of: } & At Least 10 & & & 0.0010 & & & 0.0019 & & & 0.0031 \\
\hline & At Least 15 & & & 0.0003 & & & 0.0006 & & & 0.0010 \\
\hline & At Least 20 & & & 0.0001 & & & 0.0001 & & & 0.0002 \\
\hline Cumulative Benefit & 0 & & & 0.0000 & & & 0.0000 & & & 0.0000 \\
\hline (Billions of $1988 \$$ & 10 & & & 0.0696 & & & 0.1668 & & & 0.2949 \\
\hline Discounted and & 15 & & & 0.1068 & & & 0.2914 & & & 0.5525 \\
\hline \multirow[t]{3}{*}{ Probability Weighted) } & 20 & & & 0.1240 & & & 0.3487 & & & 0.6693 \\
\hline & Net & \multicolumn{3}{|c|}{2010} & \multicolumn{3}{|c|}{2015} & \multicolumn{3}{|c|}{2020} \\
\hline & Disruption & \multicolumn{3}{|c|}{ 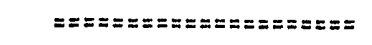 } & \multicolumn{3}{|c|}{ 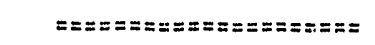 } & \multicolumn{3}{|c|}{ 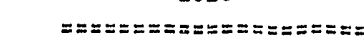 } \\
\hline Variable & size (MMBD) & 600 & 1000 & Delta & 600 & 1000 & Delta & 600 & 1000 & velta \\
\hline$=:=z==z=$ & $==z=z=z=z=$ & $===$ & $== \pm=$ & $==z==$ & $===$ & $====$ & $=====$ & 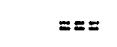 & $==x=$ & $\therefore===z$ \\
\hline World Oil Price & 0 & 37.20 & 37.08 & 0.12 & 40.00 & 40.01 & -0.01 & 42.50 & 42.52 & -0.02 \\
\hline$(1988 \$ / 8)$ & 10 & 54.49 & 42.41 & 12.08 & 56.59 & 45.18 & 11.41 & 58.42 & 47.62 & 10.80 \\
\hline & 15 & 89.66 & 72.36 & 17.29 & 89.59 & 73.71 & 15.88 & 89.25 & 74.59 & 14.66 \\
\hline & 20 & 138.77 & 114.70 & 24.07 & 134.60 & 113.04 & 21.57 & 130.41 & 110.92 & 19.49 \\
\hline Disruption Cost & 0 & 0.0 & 0.0 & 0.00 & 0.0 & 0.0 & 0.00 & 0.0 & 0.0 & 0.00 \\
\hline (Billions of 1988 & 10 & 90.0 & 27.4 & 62.52 & 94.6 & 29.2 & 65.47 & 99.2 & 31.8 & 67.35 \\
\hline - Not Discounted) & 15 & 229.9 & 153.1 & 76.74 & 242.7 & 163.0 & 79.70 & 252.9 & 171.7 & 81.28 \\
\hline & 20 & 373.1 & 278.2 & 94.97 & 396.7 & 298.8 & 97.84 & 413.8 & 314.9 & 98.93 \\
\hline Disruption Cost & 0 & 0.0 & 0.0 & 0.60 & 0.0 & 0.0 & 0.00 & 0.0 & 0.0 & 0.00 \\
\hline (Billions of 1988 & 10 & 13.4 & 4.1 & 9.29 & 8.7 & 2.7 & 6.04 & 5.7 & 1.8 & 3.86 \\
\hline - Discounted) & 15 & 34.2 & 22.8 & 11.41 & $2 ? .4$ & 15.0 & 7.36 & 14.5 & 9.8 & 4.66 \\
\hline & 20 & 55.5 & 41.3 & 14.12 & 36.6 & 27.6 & 9.03 & 23.7 & 13.0 & 5.67 \\
\hline Probability of A & At Leas: 0 & & & 1.0000 & & & 1.0000 & & & 1.0000 \\
\hline Disruption of: & At Least 10 & & & 0.0050 & & & 0.0077 & & & 0.0115 \\
\hline & At least 15 & & & 0.0016 & & & 0.0024 & & & 0.0036 \\
\hline & At Least 20 & & & 0.0403 & & & 0.0004 & & & 0.0007 \\
\hline Cumulative Benefit & 0 & & & 0.0000 & & & 0.0000 & & & 0.0000 \\
\hline (Billions of 1988 \& & 10 & & & 0.4323 & & & 0.570 .5 & & & 0.6855 \\
\hline Discounted and & 15 & & & 0.8400 & & & 1.1255 & & & 1.3621 \\
\hline Probability Weighted) & 20 & & & 1.0223 & & & 1.3706 & & & 1.6574 \\
\hline
\end{tabular}


Table B14. Case 14 - Summary Comparison of 750 MMB system Versus 1000 MMB System

\begin{tabular}{|c|c|c|c|c|c|c|c|c|c|c|}
\hline & Net & \multicolumn{3}{|c|}{1995} & \multicolumn{3}{|c|}{2000} & \multicolumn{3}{|c|}{2005} \\
\hline & Disruption & \multicolumn{3}{|c|}{ 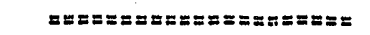 } & \multicolumn{3}{|c|}{ 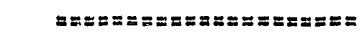 } & \multicolumn{3}{|c|}{ 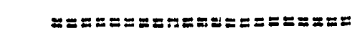 } \\
\hline & Size (MMBD) & 750 & 1000 & Delta & 750 & 1000 & Delto & 750 & 1000 & Delto \\
\hline & $m= \pm \approx z== \pm=2$ & $z=2$ & $=x z=$ & $z=2 x=2$ & $y=z$ & $y=z=$ & $s y=z=$ & 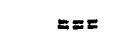 & 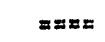 & $\varepsilon=\Sigma=0$ \\
\hline World oil Price & 0 & 20.60 & 20.60 & 0.00 & 28.00 & 28.15 & -0.15 & 33.40 & 33.37 & 0.03 \\
\hline \multirow[t]{3}{*}{$(19885 / 8)$} & 10 & 39.70 & 39.70 & 0.00 & 40.62 & 40.39 & 0.23 & 46.18 & 42.91 & 3.27 \\
\hline & 15 & 76.27 & 76.27 & 0.00 & $\pi 5.31$ & 75.04 & 0.27 & 80.68 & 75.87 & 4.81 \\
\hline & 20 & 131.43 & 131.43 & 0.00 & 126.62 & 126.31 & 0.31 & 130.29 & 123.43 & 6.86 \\
\hline Di-ruption Cost & 0 & 0.0 & 0.0 & 0.00 & 0.0 & 0.0 & 0.00 & 0.0 & 0.0 & 0.00 \\
\hline (Billions of $1988 \mathrm{~s}$ & 10 & 81.8 & 81.8 & 0.07 & 56.9 & 54.9 & 1.93 & 60.9 & 45.6 & 15.39 \\
\hline \multirow[t]{2}{*}{ - Not Discounted) } & 15 & 180.4 & 180.3 & 0.08 & 168.4 & 166.0 & 2.31 & 184.0 & 165.0 & 19.00 \\
\hline & 20 & 269.1 & 269.0 & 0.08 & 273.6 & 270.6 & 2.93 & 305.0 & 281.3 & 23.79 \\
\hline Disruption Cost & 0 & 0.0 & 0.0 & 0.00 & 0.0 & 0.0 & 0.00 & 0.0 & 0.0 & 0.00 \\
\hline (Billions of 1988 s & 10 & 50.8 & 50.8 & 0.04 & 21.9 & 21.2 & 0.74 & 14.6 & 10.9 & 3.68 \\
\hline \multirow[t]{2}{*}{ - Discounted) } & 15 & 112.0 & 192.0 & 0.05 & 64.9 & 64.0 & 0.89 & 44.1 & 39.5 & 4.55 \\
\hline & 20 & 167.1 & 167.0 & 0.05 & 105.5 & 104.3 & 1.13 & 73.0 & 67.3 & 5.68 \\
\hline Probability of $A$ & At Least 0 & & & 1.0000 & & & 1.0000 & & & 1.0000 \\
\hline \multirow[t]{3}{*}{ Disruption of: } & At Least 10 & & & 0.0010 & & & 0.0019 & & & 0.0031 \\
\hline & At Least 15 & & & 0.0003 & & & 0.0006 & & & 0.0010 \\
\hline & At Least 20 & & & 0.0001 & & & 0.0001 & & & 0.0002 \\
\hline Cumulative Benefit & 0 & & & 0.0000 & & & 0.0000 & & & 0.0000 \\
\hline (Billions of $1988 \$$ & 10 & & & 0.0001 & & & 0.0020 & & & 0.0254 \\
\hline Discounted and & 15 & & & 0.0001 & & & 0.0034 & & & 0.0547 \\
\hline \multirow[t]{3}{*}{ Probability Weighted) } & 20 & & & 0.0001 & & & 0.0049 & & & 0.0681 \\
\hline & Net & \multicolumn{3}{|c|}{2010} & \multicolumn{3}{|c|}{2015} & \multicolumn{3}{|c|}{2020} \\
\hline & Disruption & \multicolumn{3}{|c|}{ 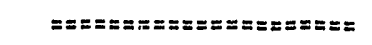 } & \multicolumn{3}{|c|}{ 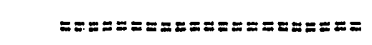 } & \multicolumn{3}{|c|}{ 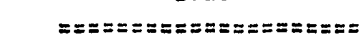 } \\
\hline Variable & size (MMBD) & 750 & 1000 & Delta & 750 & 1000 & Delta & 750 & 1000 & Delta \\
\hline$==\pi=z===$ & 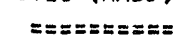 & $===$ & $s=:=$ & $=z==\pi$ & $===$ & $===$ & $== \pm==$ & $===$ & $====$ & $== \pm=$ \\
\hline World oil Price & 0 & 37.20 & 37.08 & 0.12 & 40.00 & 40.01 & -0.01 & 42.50 & 42.52 & -0.02 \\
\hline$(1988 s / B)$ & 10 & 49.78 & 43.87 & 5.91 & 52.10 & 45.18 & 6.92 & 54.18 & 47.62 & 6.56 \\
\hline & 15 & 82.95 & 74.46 & 8.50 & 83.36 & 73.71 & 9.66 & 83.51 & 74.59 & 8.92 \\
\hline & 20 & 129.46 & 117.61 & 11.84 & 126.15 & 113.04 & 13.11 & 122.78 & 110.92 & 11.86 \\
\hline Disruption Cost & 0 & 0.0 & 0.0 & 0.00 & 0.0 & 0.0 & 0.00 & 0.0 & 0.0 & 0.00 \\
\hline (Billions of $1988 \$$ & 10 & 65.4 & 35.1 & 30.24 & 68.9 & 29.2 & 39.74 & 72.8 & 31.8 & 40.95 \\
\hline - Not Discounted) & 15 & 199.5 & 162.4 & 37.06 & 211.2 & 163.0 & 48.20 & 220.9 & 171.7 & 49.27 \\
\hline & 20 & 335.4 & 289.6 & 45.79 & 357.8 & 298.8 & 58.98 & 374.7 & 314.9 & 59.81 \\
\hline Disruption Cost & 0 & 0.0 & 0.0 & 0.00 & 0.0 & 0.0 & 0.00 & 0.0 & 0.0 & 0.00 \\
\hline (Billions of 1988 s & 10 & 9.7 & 5.2 & 4.49 & 6.4 & 2.7 & 3.67 & 4.2 & 1.8 & 2.35 \\
\hline - Discounted) & 15 & 29.7 & 24.1 & 5.51 & 19.5 & 15.0 & 4.45 & 12.7 & 9.8 & 2.82 \\
\hline & 20 & 49.8 & 43.0 & 6.81 & 33.0 & 27.6 & 5.44 & 21.5 & 18.0 & 3.43 \\
\hline Probability of $A$ & At Leas * 0 & & & 1.0000 & & & 1.0000 & & & 1.0000 \\
\hline Disrup:ion of: & At Least 10 & & & 0.0050 & & & 0.0077 & & & 0.0115 \\
\hline & At Least 15 & & & 0.0016 & & & 0.0024 & & & 0.0036 \\
\hline & At Least 20 & & & 0.0003 & & & 0.0004 & & & 0.0007 \\
\hline Cumulative Benefit & 0 & & & 0.0000 & & & 0.0000 & & & 0.0000 \\
\hline (Billions of 1988 s & 10 & & & 0.0710 & & & 0.1307 & & & 0.1866 \\
\hline Discounted and & 15 & & & 0.1590 & & & 0.3046 & & & 0.4394 \\
\hline Probability Weighted) & 20 & & & 0.1995 & & & 0.3805 & & & 0.5485 \\
\hline
\end{tabular}

Noies: ine worid uil prices are averages over the quarters of the disruption.

The costs and Benefits are accumulated over six quarters beginning with the start of the disruption. 
Table B15. Case 15 - Sumary Comparison of 750 MMB System Versus 1000 MMB System

\begin{tabular}{|c|c|c|c|c|c|c|c|c|c|c|}
\hline \multirow{2}{*}{$\begin{array}{l}\text { Variable } \\
y== \pm-= \pm=\end{array}$} & $\begin{array}{r}\text { Net } \\
\text { Disruption }\end{array}$ & \multicolumn{3}{|c|}{1995} & \multicolumn{3}{|c|}{ 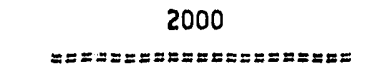 } & \multicolumn{3}{|c|}{ 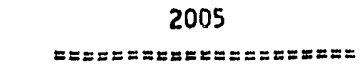 } \\
\hline & 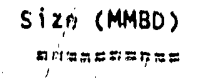 & $\begin{array}{l}750 \\
= \pm=\end{array}$ & $\begin{array}{l}1000 \\
=x=2\end{array}$ & $\begin{array}{l}\text { Delte } \\
===2\end{array}$ & $\begin{array}{l}750 \\
===\end{array}$ & $\begin{array}{l}1000 \\
x=2=\end{array}$ & $\begin{array}{l}\text { Delta } \\
z=a z=\end{array}$ & $\begin{array}{l}750 \\
= \pm=\end{array}$ & $\begin{array}{l}1000 \\
x=2=5\end{array}$ & $\begin{array}{l}\text { Delt } a \\
x==2=\end{array}$ \\
\hline World oil Prine:! & 0 & 20.60 & 20.60 & 0.00 & 28.00 & 28.15 & -0.15 & 33.40 & 33.37 & 0.03 \\
\hline \multirow{3}{*}{$(1988$ T, } & 10 & 37.28 & 36.83 & 0.45 & 40.62 & 35.04 & 5.58 & 46.18 & 38.77 & 7.41 \\
\hline & 15 & 72.52 & 71.83 & 0.70 & 75.31 & 66.90 & 8.41 & 80.68 & 60.74 & 10.94 \\
\hline & 20 & $i 25.82$ & 124.78 & 1.04 & 126.62 & 114.43 & 12.19 & 130.29 & 114.72 & 15.57 \\
\hline Disruption Cost & 0 & 0.0 & 0.0 & 0.00 & 0.0 & 0.0 & 0.00 & 0.0 & 0.0 & 0.00 \\
\hline \multirow{3}{*}{$\begin{array}{l}\text { (Billions of } 1988 \mathrm{~s} \\
\text { - Not Discounted) }\end{array}$} & 10 & 71.9 & 70.0 & 1.93 & 56.9 & 30.8 & 20.01 & 60.9 & 25.6 & 35.31 \\
\hline & 15 & 168.3 & 166.0 & 2.31 & 168.4 & 137.0 & 31.35 & 184.0 & 140.9 & 43.16 \\
\hline & 20 & 254.0 & 251.1 & 2.87 & 273.6 & 234.8 & 38.80 & 305.0 & 251.5 & 53.47 \\
\hline Disruption Cost & 0 & 0.0 & 0.0 & 0.00 & 0.0 & 0.0 & 0.00 & 0.0 & 0.0 & 0.00 \\
\hline (Billions of $1988 \mathrm{~s}$ & 10 & 44.6 & 43.4 & 1.20 & 21.9 & 11.9 & 10.03 & 14.6 & 6.1 & 8.45 \\
\hline \multirow[t]{2}{*}{ - Discounted) } & 15 & 104.5 & 103.1 & 1.44 & 64.9 & 52.8 & 12.09 & 44.1 & 33.7 & 10.33 \\
\hline & 20 & 157.7 & 155.9 & 1.78 & 105.5 & 90.5 & 14.96 & 73.0 & 60.2 & 12.80 \\
\hline Probability of $A$ & At Least 0 & & & 1.0000 & & & 1.0000 & & & 1.0000 \\
\hline \multirow[t]{3}{*}{ Disruption of: } & At Least 10 & & & 0.0010 & & & 0.0019 & & & 0.0031 \\
\hline & At least 15 & & & 0.0003 & & & 0.0006 & & & 0.0010 \\
\hline & At Least 20 & & & 0.0001 & & & 0.0001 & & & 0.0002 \\
\hline Cumulative Benefit & 0 & & & 0.0000 & & & 0.0000 & & & 0.0000 \\
\hline (Billions of $1988 \$$ & 10 & & & 0.0018 & & & 0.0408 & & & 0.1014 \\
\hline Discounted and & 15 & & & 0.0032 & & & 0.0927 & & & 0.2434 \\
\hline \multirow[t]{3}{*}{ Probatility weighted) } & 20 & & & 0.0038 & & & 0.1167 & & & 0.3074 \\
\hline & Net & \multicolumn{3}{|c|}{2010} & \multicolumn{3}{|c|}{2015} & \multicolumn{3}{|c|}{2020} \\
\hline & Disruption & \multicolumn{3}{|c|}{ 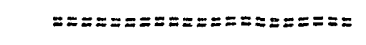 } & \multicolumn{3}{|c|}{ 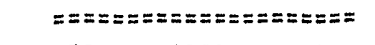 } & \multicolumn{3}{|c|}{ 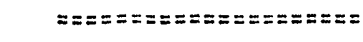 } \\
\hline Variable & Size (MMBD) & 750 & 1000 & Delta & 750 & 1000 & Delta & 750 & 1000 & Delta \\
\hline$==\pi===\pi=$ & $==\Omega=\pi==\pi==$ & $===$ & $==s=$ & $== \pm==$ & $===$ & $== \pm=$ & $== \pm==$ & $===$ & $==z=$ & $==\approx==$ \\
\hline World oil Price. & 0 & 37.20 & 37.08 & 0.12 & 40.00 & 40.01 & -0.01 & 42.50 & 42.52 & .0 .02 \\
\hline \multirow[t]{3}{*}{$(1988 \$ / B)$} & 10 & 49.78 & 42.41 & 7.37 & 52.10 & 45.18 & 0.92 & 54.18 & 47.62 & 6.56 \\
\hline & 15 & 82.95 & 72.36 & 10.59 & 83.36 & 73.71 & 9.66 & 83.51 & 74.59 & 8.92 \\
\hline & 20 & 129.46 & 114.70 & 14.76 & 126.15 & 113.04 & 13.11 & 122.78 & 110.92 & 11.86 \\
\hline Disruption Cost & 0 & 0.0 & 0.0 & 0.00 & 0.0 & 0.0 & 0.00 & 0.0 & 0.0 & 0.00 \\
\hline (Billions of $1988 \mathrm{~s}$ & 10 & 65.4 & 27.4 & 37.91 & 68.9 & 29.2 & 39.74 & 72.8 & 31.8 & 40.95 \\
\hline \multirow[t]{2}{*}{ - Not Discounted) } & 15 & 199.5 & 153.1 & 46.36 & 211.2 & 163.0 & 48.20 & 220.9 & 171.7 & 49.27 \\
\hline & 20 & 335.4 & 278.2 & 57.20 & 357.8 & 298.8 & 58.98 & 374.7 & 314.9 & 59.81 \\
\hline Disruption Cost & 0 & 0.0 & 0.0 & 0.00 & 0.0 & 0.0 & 0.00 & 0.0 & 0.0 & 0.00 \\
\hline (Billions of 1988 \$ & 10 & 9.7 & 4.1 & 5.64 & 6.4 & 2.7 & 3.67 & 4.2 & 1.8 & 2.35 \\
\hline \multirow[t]{2}{*}{ - Discounted) } & 15 & 29.7 & 22.8 & 6.89 & 19.5 & 15.0 & 4.45 & 12.7 & 9.8 & 2.82 \\
\hline & 20 & 49.8 & 41.3 & 8.50 & 33.0 & 27.6 & 5.44 & 21.5 & 18.0 & 3.43 \\
\hline Probability of $A$ & At Least 0 & & & 1.0000 & & & 1.0000 & & & 1.0000 \\
\hline \multirow[t]{3}{*}{ Disruption of: } & At Least 10 & & & 0.0050 & & & 0.0077 & & & 0.0115 \\
\hline & At Least 15 & & & 0.0016 & & & 0.0024 & & & 0.0036 \\
\hline & At Least 20 & & & 0.0003 & & & 0.0004 & & & 0.0007 \\
\hline Cumulative Benefit & 0 & & & 0.0000 & & & 0.0000 & & & 0.0000 \\
\hline (Billions of 1988 \$ & 10 & & & 0.1616 & & & 0.2227 & & & 0.2787 \\
\hline Discounted and & 95 & & & 0.3926 & & & 0.5414 & & & 0.6762 \\
\hline Probability Weiginted) & 2.0 & & & 0.4953 & & & 0.6814 & & & 0.8494 \\
\hline
\end{tabular}

Notes: The World Oil Prices are averages over the quarters of the disruption.

The costs and Benefits are accumulated over six quarters begirining with the start of the disruption. 
Table 816. Case 16 - Summary Comparison of 750 MMB System versus 1000 MMB system

\begin{tabular}{|c|c|c|c|c|c|c|c|c|c|c|}
\hline & Net & & 1995 & & & 2000 & & & 2005 & \\
\hline & Disruption & $z=z=$ & $z=z=x=z$ & $=z=\pi=x=$ & $= \pm=z$ & $==\approx z=z=z$ & $z==\varepsilon x=2$ & $m==$ & $=z= \pm x=z=$ & $=z=z= \pm z$ \\
\hline $\begin{array}{l}\text { Variable } \\
===== \pm=\end{array}$ & $\begin{array}{l}\text { Size (MMBD) } \\
==:======\end{array}$ & $\begin{array}{l}750 \\
z=2\end{array}$ & $\begin{array}{l}1000 \\
== \pm=\end{array}$ & $\begin{array}{l}\text { Delt } \theta \\
=== \pm=\end{array}$ & $\begin{array}{l}750 \\
==2\end{array}$ & $\begin{array}{l}1000 \\
z=z=\end{array}$ & $\begin{array}{l}\text { Deltr } \\
=====\end{array}$ & $\begin{array}{l}750 \\
==2\end{array}$ & $\begin{array}{l}1000 \\
== \pm=\end{array}$ & $\begin{array}{l}\text { Delta } \\
=== \pm=\end{array}$ \\
\hline World oll Price & 0 & 20.60 & 20.60 & 0.00 & 28.00 & 28.15 & .0 .15 & $33.40^{\circ}$ & 33.37 & 0.03 \\
\hline$(1988 s / B)$ & 10 & 38.25 & 38.25 & 0.00 & 40.62 & 37.65 & 2.97 & 46.18 & 38.97 & 7.21 \\
\hline & 15 & 74.02 & 74.02 & 0.00 & 75.31 & 70.89 & 4.42 & 80.68 & 70.04 & $: 0.64$ \\
\hline & 20 & 128.07 & 128.07 & 0.00 & 126.62 & 120.26 & 6.37 & 130.29 & 115.13 & 15.15 \\
\hline Disruption Cost & 0 & 0.0 & 0.0 & 0.00 & 0.0 & 0.0 & 0.00 & 0.0 & 0.0 & 0.00 \\
\hline (Billions of 1988 s & 10 & 75.9 & 75.8 & 0.07 & 56.9 & 42.7 & 14.18 & 60.9 & 26.6 & 34.36 \\
\hline - Not Discounted) & 15 & 173.1 & 173.1 & 0.08 & 168.4 & 151.2 & 17.17 & 184.0 & 142.0 & 42.01 \\
\hline & 20 & 260.0 & 259.9 & 0.08 & 273.6 & 252.2 & 21.34 & 305.0 & 253.0 & 52.06 \\
\hline Disruption Cost & 0 & 0.0 & 0.0 & 0.00 & 0.0 & 0.0 & 0.00 & 0.0 & 0.0 & 0.00 \\
\hline (Billions of $1988 \$$ & 10 & 51.6 & 51.6 & 0.05 & 26.3 & 19.8 & 6.57 & 18.2 & 8.4 & 10.83 \\
\hline - Discounted) & 15 & 117.8 & 117.8 & 0.05 & 78.0 & 70.0 & 7.95 & 58.0 & 44.8 & 13.24 \\
\hline & 20 & 177.0 & 176.9 & 0.06 & 126.7 & 116.8 & 9.88 & 96.2 & 79.7 & 16.41 \\
\hline Probability of $A$ & At Least 0 & & & 1.0000 & & & 1.0000 & & & 1.0000 \\
\hline Disruption of: & At Least 10 & & & 0.0010 & & & 0.0018 & & & 0.0031 \\
\hline . & At Least 15 & & & 0.0003 & & & 0.0006 & & & 0.0010 \\
\hline & At Least 20 & & & 0.0001 & & & 0.0001 & & & 0.0002 \\
\hline Cumulative Benefit & 0 & & & 0.0000 & & & 0.0000 & & & 0.0000 \\
\hline (Billions of 1988 s & 10 & & & 0.0000 & & & 0.0215 & & & 0.0854 \\
\hline Discounted and & 15 & & & 0.0001 & & & 0.0467 & & & 0.1981 \\
\hline Probability weighted) & 20 & & & 0.0001 & & & 0.0583 & & & 0.2484 \\
\hline & Net & & 2010 & & & 2015 & & & 2020 & \\
\hline & Disruption & $=z==$ & $z=z=z=z=$ & 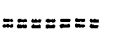 & $== \pm=$ & $==\pi=z=z=$ & $===\approx== \pm$ & $z=:=$ & $=z=z==z=$ & $z=z=z==$ \\
\hline Variable & Size (MMBD) & 750 & 1000 & Delta & 750 & 1000 & Delta & 750 & 1000 & Delta \\
\hline$=:==== \pm=$ & 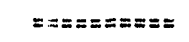 & $===$ & $=z==$ & $z===$ & $z==$ & $=x= \pm$ & $== \pm=\Sigma$ & $z==$ & $z===$ & $=== \pm=$ \\
\hline World Dil Price & 0 & 37.20 & 37.08 & 0.12 & 40.00 & 40.01 & -0.01 & 42.50 & 42.52 & -0.02 \\
\hline$(1988 \$ / B)$ & 10 & 49.78 & 42.41 & 7.37 & 52.10 & 45.18 & 6.92 & 54.18 & 47.62 & 6.56 \\
\hline & 15 & 82.95 & 72.36 & 10.59 & 83.36 & 73.71 & 9.66 & 83.51 & 74.59 & 8.92 \\
\hline & 20 & 129.46 & 114.70 & 14.76 & 126.15 & 113.04 & 13.11 & 122.78 & 110.92 & 11.86 \\
\hline Disruption Cost & 0 & 0.0 & 00 & 0.00 & 0.0 & 0.0 & 0.00 & 0.0 & 0.0 & 0.00 \\
\hline (Billions of $1988 \$$ & 10 & 65.4 & 27.4 & 37.91 & 68.9 & 29.2 & 39.74 & 72.8 & 31.8 & 40.95 \\
\hline - Not Discounted) & 15 & 199.5 & 153.1 & 46.36 & 211.2 & 163.0 & 48.20 & 220.9 & 171.7 & 49.27 \\
\hline & 20 & 335.4 & 278.2 & 57.20 & 357.8 & 298.8 & 58.98 & 374.7 & 314.9 & 59.81 \\
\hline Disruption Cost & 0 & 0.0 & 0.0 & 0.00 & 0.0 & 0.0 & 0.00 & 0.0 & 0.0 & 0.00 \\
\hline (Billions of 1988 s & 10 & 14.0 & 5.9 & 8.13 & 10.1 & 4.3 & 5.80 & 7.2 & 3.2 & 4.07 \\
\hline - Discounted) & 15 & 42.8 & 32.9 & 7.95 & 30.8 & 23.8 & 7.04 & 22.0 & 17.1 & 4.90 \\
\hline & 20 & 71.9 & 59.7 & 12.27 & 52.2 & 43.6 & 3.61 & 37.2 & 31.3 & 5.94 \\
\hline Projability of A & At Least 0 & & & 1.0000 & & & 1.0000 & & & 1.0000 \\
\hline Disruption of: & At Least 10 & & & 0.0050 & & & 0.0077 & & & 0.0115 \\
\hline & At Least 15 & & & 0.0016 & & & 0.0024 & & & 0.0036 \\
\hline & At Least 20 & & & 0.0003 & & & 0.0004 & & & 0.0007 \\
\hline Cumulative Benefit & 0 & & & 0.0000 & & & 0.0000 & & & 0.0000 \\
\hline (Billions of $1988 \$$ & 10 & & & 0.1670 & & & 0.2564 & & & 0.3449 \\
\hline Discounted and & 15 & & & 0.3989 & & & 0.6150 & & & 0.826 \\
\hline Frobability weighted) & 20 & & & 0.4999 & & & 0.7689 & & & $1.03 .1 n$ \\
\hline
\end{tabular}

Notes: The World Oil Prices are averages over the guarters of the discuption.

The costs and Benefits are accumulated over six quarters beginning with the start of the disruption. 
Table B17. Lase 17 - Sumnary Comparison of 750 MMB System Versus 1000 MMB System

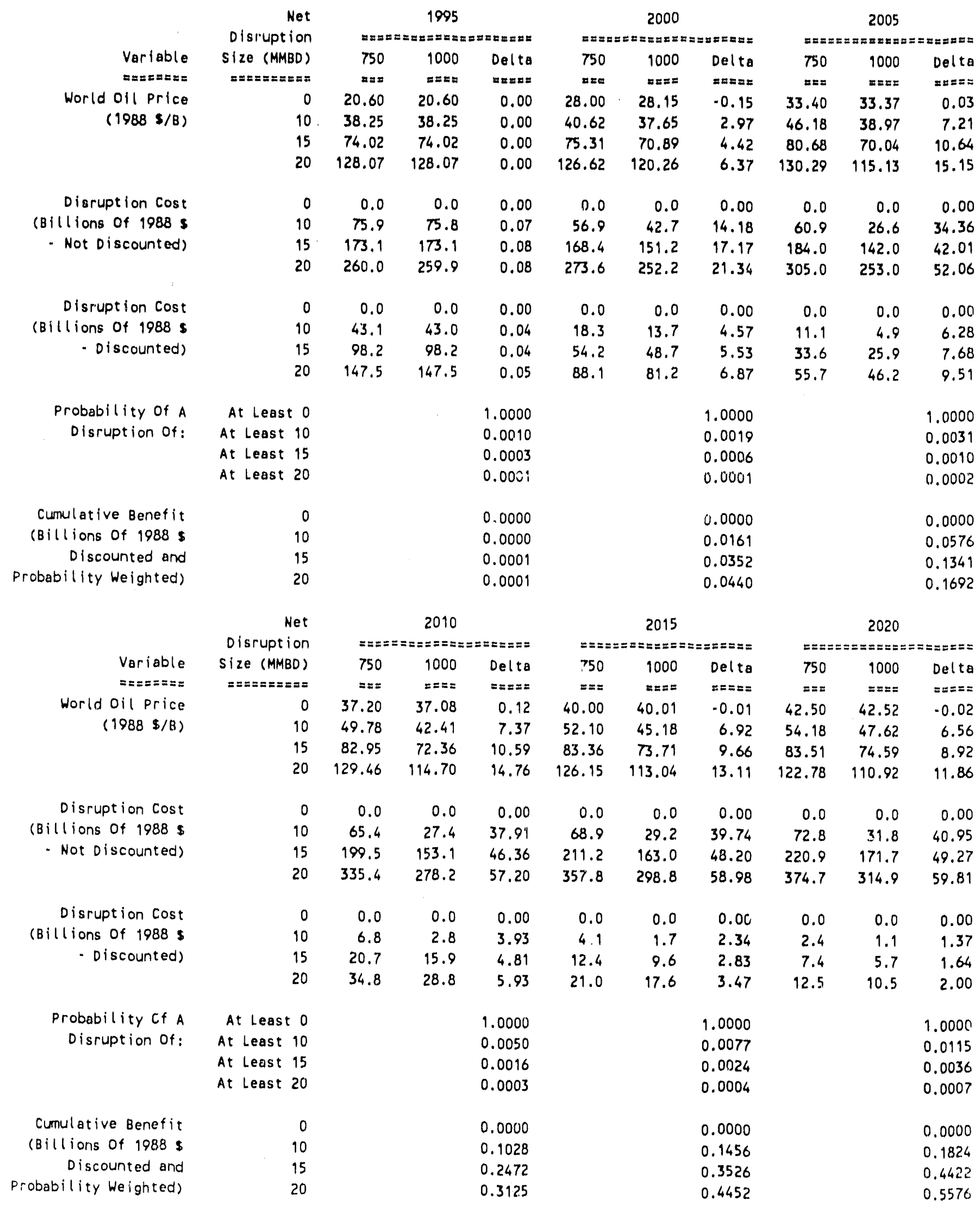

Notes: The world oil prices are averages ovar the guarters of the disruption.

The costs and Benefits are accumulated over six quarters beginning with the start of the disruption. 
Table 818. Case 18 - Summary Comparison of 750 MMB System Versus 1000 MMB System

\begin{tabular}{|c|c|c|c|c|c|c|c|c|c|c|}
\hline & Net & & 1995 & & & 2000 & & & 2005 & สมะะมะล \\
\hline & Disruption & $\Rightarrow g x=$ & $\Rightarrow=\pi \approx x=\pi y=$ & $:=z=z=x$ & $=\approx 8=0$ & $\Rightarrow=\pi \approx=x z=5$ & $z=z= \pm z=$ & $z= \pm x z$ & $=z=z=g=z z$ & 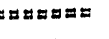 \\
\hline Variable & Size (MMBD) & 750 & 1000 & Delta & 750 & 1000 & Delta & 750 & 1000 & Delta \\
\hline$=\approx a n \geq \pi \approx=$ & 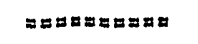 & $z=z$ & $y=z=$ & $\exists घ \pm z=$ & $= \pm=$ & $z=z z$ & 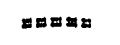 & 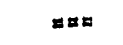 & 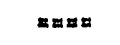 & $\exists= \pm \pm \approx$ \\
\hline World Oil price & 0 & 20.60 & 20.60 & 0.00 & 28.00 & 28.15 & .0 .15 & 33.40 & 33.37 & 0.03 \\
\hline$(19803 / 8)$ & 10 & 48.67 & 48.67 & 0.00 & 53.66 & 51.53 & 2.13 & 59.41 & 53.92 & 5.50 \\
\hline & 15 & 86.96 & 86.96 & 0.00 & 92.03 & 89.01 & 3.02 & 97.23 & 89.44 & 7.80 \\
\hline & 20 & 142.88 & 142.88 & 0.00 & 147.04 & 142.76 & 4.28 & 150.11 & 139.14 & 10.96 \\
\hline Disruption Cost & 0 & 0.0 & 0.0 & 0.00 & 0.0 & 0.0 & 0.00 & 0.0 & 0.0 & 0.00 \\
\hline (B) 1 llions of 1988 \$ & 10 & 155.8 & 155.8 & 0.08 & 147.5 & 133.8 & 13.63 & 158.9 & 125.3 & 33.56 \\
\hline - Not Discounted) & 15 & 276.8 & 276.7 & 0.08 & 288.0 & 271.3 & 16.68 & 315.7 & 274.4 & 41.21 \\
\hline & 20 & 376.4 & 376.3 & 0.09 & 411.9 & 391.0 & 20.87 & 461.6 & 410.4 & 51.21 \\
\hline Disruption Cost & 0 & 0.0 & 0.0 & 0.00 & 0.0 & 0.0 & 0.00 & 0.0 & 0.0 & 0,00 \\
\hline (Billions of 1988 s & 10 & 96.8 & 96.7 & 0.05 & 56.9 & 51.6 & 5.26 & 38.0 & 30.0 & 8.04 \\
\hline - Discounted) & 15 & 171.9 & 171.8 & 0.05 & 111.0 & 104.6 & 6.43 & 75.6 & 65.7 & 9.86 \\
\hline & 20 & 233.7 & 233.7 & 0.05 & 158.8 & 150.8 & 8.05 & $\$ 10.5$ & 98.3 & 12.26 \\
\hline Probability of $A$ & At least 0 & & & 1.0000 & & & 1.0000 & & & 1.0000 \\
\hline Disruption of: & At Least 10 & & & 0.0010 & & & 0.0019 & & & 0.0031 \\
\hline & At least 15 & & & 0.0003 & & & 0.0006 & & & 0.0010 \\
\hline & At least 20 & & & 0.0001 & & & 0.0001 & & & 0.0002 \\
\hline Cumulative Benefit & 0 & & & 0.0000 & & & 0.0000 & & & 0.0000 \\
\hline (Billions of 1988 s & 10 & & & 0.0063 & & & 0.0909 & & & 0.2595 \\
\hline Discounted and & 15 & & & 0.0100 & & & 0.1365 & & & 0.3847 \\
\hline Probability Weighted) & 20 & & & 0.0122 & & & 0.1598 & & & 0.1438 \\
\hline & Net & & 2010 & & & 2015 & & & 2020 & \\
\hline & Disruption & $=z=2$ & $z=z=z=z=5$ & $==\Sigma= \pm \approx=$ & $=z=2$ & $=z=z=z=$ & $=x z==2 x$ & $= \pm= \pm$ & $z=z=z=z=$ & $==z=\leq=\leq$ \\
\hline Variable & Size (MMBD) & 750 & 1000 & Delta & 750 & 1000 & Delta & 750 & 1000 & Delta \\
\hline$=z=\Sigma E=z=$ & $==\pi=\pi=\pi=z z$ & $y=z$ & $z===$ & $z=z==$ & $==2$ & $n= \pm=$ & $y=x=z$ & $= \pm=$ & $== \pm=$ & $=z=\approx=$ \\
\hline World Oll price & 0 & 37.20 & 37.08 & 0.12 & 40 90 & 40.01 & .0 .01 & 42.50 & 42.52 & .0 .02 \\
\hline$(1988 \$ / 8)$ & 10 & 62.63 & 57.03 & 5.61 & 64.33 & 59.20 & 5.12 & 65.65 & 60.86 & 4.79 \\
\hline & 15 & 98.65 & 90.87 & 7.78 & 97.94 & 91.04 & 6.90 & 96.90 & 90.58 & 6.32 \\
\hline & 20 & 147.86 & 137.14 & 10.71 & 142.90 & 133.64 & 9.26 & 137.85 & 129.55 & 8.30 \\
\hline Disruption Cost & 0 & 0.0 & 0.0 & 0.00 & $0.1)$ & 0.0 & 0.00 & 0.0 & 0.0 & 0.00 \\
\hline CBillions of $1988 \mathrm{~s}$ & 10 & 170.2 & 133.3 & 36.91 & 179.2 & 140.8 & 38.36 & 186.5 & 147.2 & 39.31 \\
\hline - Not Discounted) & 15 & 342.3 & 297.3 & 45.09 & 302.7 & 316.4 & 46.35 & 378.1 & 331.0 & 47.10 \\
\hline & 20 & 509.3 & 453.6 & 55.69 & 545.3 & 488.5 & 56.74 & 571.2 & 514.1 & 57.17 \\
\hline Disruption Cost & 0 & 0.0 & 0.0 & 0.00 & 0.0 & 0.0 & 0.00 & 0.0 & 0.0 & 0.00 \\
\hline (Billions of 1988 s & 10 & 25.3 & 19.8 & 5.49 & 16.5 & 13.0 & 3.54 & 10.7 & 8.4 & 2.25 \\
\hline - Discounted) & 15 & 50.9 & 44.2 & 6.70 & 33.5 & 29.2 & 4.28 & 21.7 & 19.0 & 2.70 \\
\hline & 20 & 75.7 & 67.4 & 8.28 & 50.3 & 45.1 & 5.24 & 32.7 & 29.5 & 3.28 \\
\hline Probability of A & At Least 0 & & & 1.0000 & & & 1.0000 & & & 1.0000 \\
\hline Disruption of: & At least 10 & & & 0.0050 & & & 0.0077 & & & 0.0115 \\
\hline & At Least 15 & & & 0.0016 & & & 0.0024 & & & 0.0036 \\
\hline & At Least 20 & & & 0.0003 & & & 0.0004 & & & 0.0007 \\
\hline Cumulative Benefit & 0 & & & 0.6000 & & & $0.00 C 0$ & & & 0.0000 \\
\hline (Billions of $1988 \mathrm{~s}$ & 10 & & & 0.4915 & & & $0.725 t_{1}$ & & & 0.9037 \\
\hline Discounted and & 15 & & & 0.7150 & & & 1.0449 & & & 1.2983 \\
\hline Probability Weighted) & 20 & & & 0.8169 & & & 1.1863 & & & 1.4725 \\
\hline
\end{tabular}

Notes: The World oil prices are averages over the quarters of the discuption. The costs and berieflits are actuinilated over sin quarters begining with the start of the disruption. 
Table 819. Case 19. Summary Comparison of 600 MMB System Versus 750 MMB System

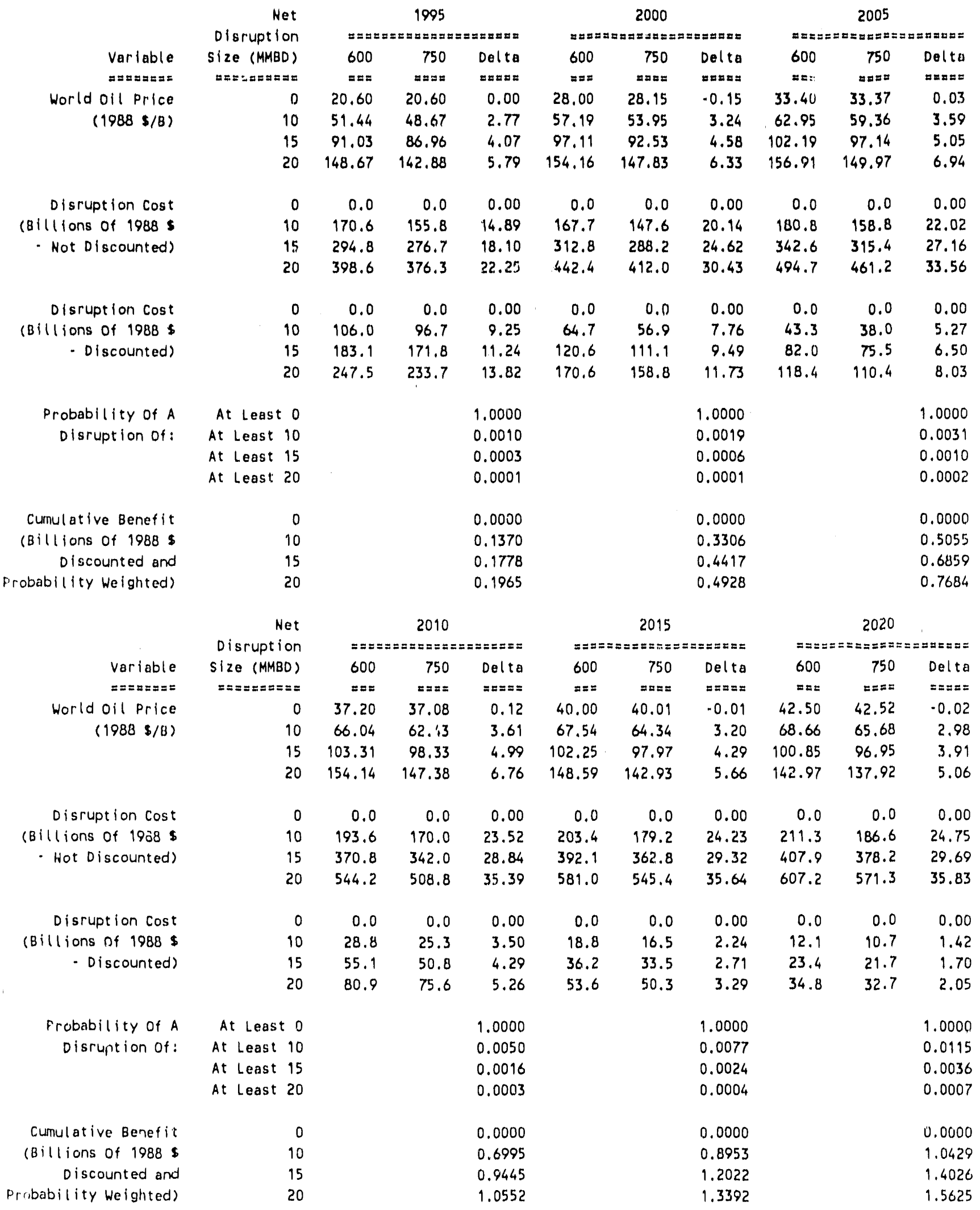

Notes: The World Oil Prices are averages over the quarters of the disruption.

The costs and Benefits are accumulated over six quarters beginning with the start of the disruption. 
Table 820. Case 20 - Summary Comparison of 750 MMB System Versus 1000 MMB Systern

\begin{tabular}{|c|c|c|c|c|c|c|c|c|c|c|}
\hline & Net & & 1995 & & & 2000 & & & 2005 & \\
\hline & Disruption & $x \mathrm{xa}$ & 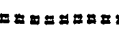 & 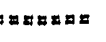 & $= \pm \approx=$ & 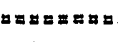 & 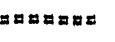 & 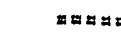 & 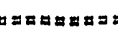 & $= \pm x=a x$ \\
\hline Variable & $S(Z E$ (MMBD) & 750 & 1000 & Delta & 750 & 1000 & Delta & 750 & 1000 & Delta \\
\hline$\Rightarrow \approx z=z x=z$ & $a=z=z a n a z=$ & $z=z$ & $y= \pm x$ & $\forall m w a z$ & 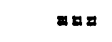 & $m z= \pm$ & 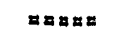 & $z=x$ & $m= \pm z$ & $m z=a=$ \\
\hline World oll price & 0 & 16.70 & 16.70 & 0.00 & 21.70 & 21.70 & 0.00 & 24.80 & 24.80 & 0.00 \\
\hline$(1988 \mathrm{~s} / \mathrm{B})$ & 10 & 50.42 & $50 . \cdots$ & 0.00 & 44.93 & 40.24 & 4.70 & 47.05 & 37.28 & 9.77 \\
\hline & 15 & 124.75 & 124.75 & 0.00 & 104.54 & 95.48 & 9.06 & 101.56 & 83.62 & 17.94 \\
\hline & 20 & 268.52 & 268.52 & 0.00 & 215.00 & 198.52 & 16.48 & 197.91 & 166.63 & 31.28 \\
\hline Disruption Cost & 0 & 0.0 & 0.0 & 0.00 & 0.0 & 0.0 & 0.00 & 0.0 & 0.0 & 0.00 \\
\hline (Billions of $1988 \mathrm{~s}$ & 10 & 195.0 & 195.0 & 0.00 & 154.3 & 126.6 & 27.68 & 159.8 & 94.8 & 64.96 \\
\hline - Not Discounted) & 15 & 409.9 & 409.9 & 0.00 & 3870 & 350.7 & 36.35 & 406.0 & 322.5 & 83.53 \\
\hline & 20 & 641.5 & 641.5 & 0.00 & 65.0 .1 & 599.0 & 51.06 & 689.1 & 574.4 & 114.70 \\
\hline Disruption Cost & 0 & 0.0 & 0.0 & 0.00 & 0.0 & 0.0 & 0.00 & 0.0 & 0.0 & 0.00 \\
\hline (Billions of 1988 s & 10 & 132.7 & 132.7 & 0.00 & 71.5 & 58.7 & 12.82 & 50.4 & 29.9 & 20.48 \\
\hline - Discounted) & 15 & 279.0 & 279.0 & 0.00 & 179.3 & 162.4 & 16.84 & 128.0 & 101.7 & 26.33 \\
\hline & 20 & 436.6 & 436.6 & 0.00 & 301.1 & $27 ! .5$ & 23.65 & 217.2 & 181.1 & 36.16 \\
\hline Probabllity of $A$ & At Least 0 & & & 1.0000 & & & 1.0000 & & & 1.0000 \\
\hline Disruption of: & At Least 10 & & & 0.0026 & & & 0.0055 & & & 0.0091 \\
\hline & At Least 15 & & & 0.0009 & & & 0.0018 & & & 0.0030 \\
\hline & At Least 20 & & & 0.0002 & & & 0.0004 & & & 0.0006 \\
\hline Cumulative Benefit & 0 & & & 0.0000 & & & 0.0000 & & & 0.0000 \\
\hline (Blllions of $1988 \mathrm{~s}$ & 10 & & & 0.0000 & & & 0.2008 & & & 0.7719 \\
\hline Discounted and & 15 & & & 0.0000 & & & 0.3492 & & & 1.3756 \\
\hline Frobability Weighted) & 20 & & & 0.0000 & & & 0.4255 & & & 1.6773 \\
\hline & Net & & 2010 & & & 2015 & & & 2020 & \\
\hline & Disruption & $=z= \pm$ & $=\pi \approx z=z \approx z$ & $z=z=2=2$ & $=2 x=$ & $z=z=z=y$ & $==2 z= \pm \approx$ & $y=z=$ & $==\approx z= \pm z=$ & $y=z=z=z$ \\
\hline Variable & Size (MMBD) & 750 & 1000 & Delta & 750 & 1000 & Delta & 750 & 1000 & Delto \\
\hline 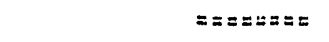 & $==\approx z=\pi=\pi=z=$ & $+1=$ & $=2=x$ & $=z=z=$ & $z==$ & $=z=\Sigma$ & $= \pm: 2=$ & $=z=$ & $=z=z$ & $=\approx=: \therefore=$ \\
\hline World oil Price & 0 & 26.70 & 26.70 & 0.00 & 28.30 & 28.30 & 0.00 & 29.40 & 29.40 & 0.170 \\
\hline$(1988 s / 8)$ & 10 & 47.57 & 38.27 & 9.24 & 47.79 & 39.20 & 8.60 & 47.56 & 39.70 & $7.8 i$ \\
\hline & 15 & 96.37 & 80.12 & 16.25 & 91.64 & 77.23 & 14,40 & 86.74 & 74.09 & 12.65 \\
\hline & 20 & 179.01 & 151.82 & 27.19 & 163.13 & 139.88 & 23.25 & 148.38 & 128.66 & 19.71 \\
\hline Disruption Cost & 0 & 0.0 & 0.0 & 0.00 & 0.0 & 0.0 & 0.00 & 0.0 & 0.0 & 0.00 \\
\hline (Billions of 1988 & 10 & 165.9 & 96.7 & 69.21 & 170.9 & 99.9 & 70.97 & 175.8 & 104.0 & 71.78 \\
\hline - Not Discounted) & 15 & 422.9 & 335.1 & 87.72 & 434.7 & 346.2 & 88.41 & 443.0 & 355.4 & 87.60 \\
\hline & 20 & 719.9 & 601.7 & 118.22 & 738.2 & 621.6 & 116.67 & 747.0 & 634.1 & 112.90 \\
\hline Disruption Cost & 0 & 0.0 & 0.0 & 0.00 & 0.0 & 0.0 & 0.00 & 0.0 & 0.0 & 0.00 \\
\hline (Billions of 1988 s & 10 & 35.6 & 20.7 & 14.85 & 25.0 & 14.6 & 10.36 & 17.5 & 10.3 & 7.13 \\
\hline - Discounted) & 15 & 90.7 & 71.9 & 18.82 & 63.5 & 50.6 & 12.91 & $44 . C$ & 35.3 & 8.71 \\
\hline & 20 & 154.5 & 129.1 & 25.36 & 107.8 & 90.8 & 17.04 & 74.2 & 63.0 & 11.22 \\
\hline Probability of $A$ & At Least 0 & & & 1.0000 & & & $i .0000$ & & & 1.0000 \\
\hline Disruption of: & At Least 10 & & & 0.0139 & & & 0.0159 & & & 0.0270 \\
\hline & At Least 15 & & & 0.0045 & & & 0.0064 & & & 0.0087 \\
\hline & At Leost 20 & & & 0.0009 & & & 0.0013 & & & 0.0018 \\
\hline Cumulative Benefit & 0 & & & 0.0000 & & & 0.0000 & & & 0.0000 \\
\hline (billions of 1988 s & 10 & & & 1.4527 & & & 2.0460 & & & 2.5441 \\
\hline Discounted and & 15 & & & 2.6060 & & & 3.6729 & & & 4.5717 \\
\hline Prabability Weighted) & 20 & & & 3.1658 & & & 4.4512 & & & 5.5311 \\
\hline
\end{tabular}

Hotes: The World Oil Prices are averages over the quarters of the disruption.

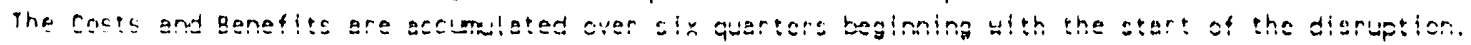


Table B21. Case 21. Sumnary Comparison of 600 MMB systom Versus 750 MMB Syc.em

\begin{tabular}{|c|c|c|c|c|c|c|c|c|c|c|}
\hline & Net & & 1995 & & & 2000 & & & 2005 & \\
\hline & Olsruption & $x= \pm$ & $a y z=y z x=$ & $y= \pm x= \pm$ & $y= \pm$ & $\tan \operatorname{xaz} \approx \pi x$ & |มีมีมี & $x y=0$ & 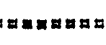 & 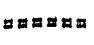 \\
\hline Variable & Slze (MMBD) & 600 & 750 & Delta & 600 & 750 & Delta & 600 & 750 & Delta \\
\hline 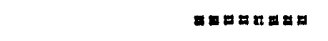 & 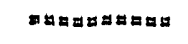 & $m=$ & $y=z=$ & $y=y \geq x$ & z: & 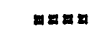 & $x= \pm x=$ & $m z=$ & 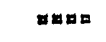 & 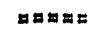 \\
\hline World oll Price & 0 & 16.70 & 16.70 & 0.00 & 29.70 & 21.70 & 0.00 & 24.80 & 24.80 & 0.00 \\
\hline$(19885 / B)$ & 10 & 57.41 & 50.42 & 7.02 & 52.2 .6 & 44.93 & 7.33 & 53.97 & 47.05 & 6.92 \\
\hline & 15 & 138.80 & 124.75 & 14.06 & 118.54 & 104.54 & 14.00 & 114.09 & 109.56 & 12.53 \\
\hline & 20 & 294.89 & 268.52 & 26.36 & 240.40 & 215.00 & 25.40 & 219.68 & 197.91 & 21.77 \\
\hline Disruption Cost & 0 & 0.0 & 0.0 & 0.00 & 0.0 & 0.0 & 0.00 & 0.0 & 0.0 & 0.00 \\
\hline CBilllons of $1988 \mathrm{~s}$ & 10 & 227.1 & 195.0 & 32.09 & 195.6 & 154.3 & 41.29 & 203.0 & 159.8 & 43.25 \\
\hline - Not D(scounted) & 15 & 454.1 & 409.9 & 44.14 & 442.7 & 387.0 & 55.71 & 463.5 & 406.0 & 57.52 \\
\hline & 20 & 705.1 & 641.5 & 63.62 & 729.5 & 650.1 & 79.39 & 769.6 & 689.1 & 80.51 \\
\hline Disruption cost & 0 & 0.0 & 0.0 & 0.00 & 0.0 & 0.0 & 0.00 & 0.0 & 0.0 & 0.00 \\
\hline (B) 11 lons of 1988 \$ & 10 & 154.6 & 132.7 & 21.84 & 90.6 & 71.5 & 19.13 & 64.0 & 50.4 & 13.63 \\
\hline - Discounted) & 15 & 309.0 & 279.0 & 30.04 & 205.1 & 179.3 & 25.80 & 146.1 & 128.0 & 18.13 \\
\hline & 20 & 479.9 & 436.6 & 43.30 & 337.9 & 301.1 & 36.77 & 242.6 & 217.2 & 25.38 \\
\hline Probabllitty of $A$ & At least 0 & & & 1.0000 & & & 1.0000 & & & 1.0000 \\
\hline Disruption of: & At Least 10 & & & 0.0026 & & & 0.0055 & & & 0.0091 \\
\hline & At Least 15 & & & 0.0009 & & & 0.0018 & & & 0.0030 \\
\hline & At Least 20 & & & 0.0002 & & & 0.0004 & & & 0.0006 \\
\hline Cumulative Benefit & 0 & & & 0.0000 & & & 0.0000 & & & 0.0000 \\
\hline (Blllions of 1988 s & 10 & & & 0.6150 & & & 1.4223 & & & 2.1780 \\
\hline Discounted and & 15 & & & 0.8569 & & & 2.1032 & & & 3.2556 \\
\hline Probabillity Weighted) & 20 & & & 0.9889 & & & 2.4643 & & & 3.8158 \\
\hline & Net & & 2010 & & & 2015 & & & 2020 & \\
\hline & Disruption & $z=\pi=$ & $= \pm= \pm= \pm: 32$ & $y==2=2 z$ & 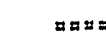 & $:=3 \pm x \Delta=0$ & $y=x=\pi=$ & $z==2$ & $=z=\pi \approx x=z$ & 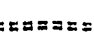 \\
\hline Varlable & Sizo (MNBD) & 600 & 750 & Delta & 600 & 750 & Delta & 600 & 750 & Delta \\
\hline$z=z=z=z=$ & 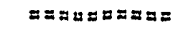 & $= \pm=$ & $z=z=$ & $E= \pm \approx z$ & $=2:=$ & $y=t z$ & $7 \pm=2:$ & 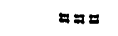 & $z=2 z$ & $=2 \approx z=$ \\
\hline World Dil Price & 0 & 26.70 & 26.70 & 0.00 & 28.30 & 28.30 & 0.00 & 29.40 & 29.40 & 0.00 \\
\hline$(1988 \$ / 8)$ & 10 & 53.90 & 47.57 & 6.33 & 53.60 & 47.79 & 5.80 & 52.81 & 47.56 & 5.25 \\
\hline & 15 & 107.32 & 96.37 & 10.95 & 101.27 & 91.64 & 9.63 & 95.12 & 86.74 & 8.38 \\
\hline & 20 & 197.26 & 179.01 & 18.25 & 178.60 & 163.13 & 15.48 & 161.40 & 148.38 & 13.02 \\
\hline Disruption Cost & 0 & 0.0 & 0.0 & 0.00 & 0.0 & 0.0 & 0.00 & 0.0 & 0.0 & 0.00 \\
\hline (B) 1 llions of $1988 \&$ & 10 & 210.5 & 165.9 & 44.59 & 216.4 & 170.9 & 45.48 & 221.5 & 175.8 & 45.72 \\
\hline - Not D (scounted) & 15 & 481.1 & 422.9 & 58.20 & 492.8 & 434.7 & 58.12 & 500.0 & 443.0 & 57.05 \\
\hline & 20 & 799.7 & 719.9 & 79.80 & 816.1 & 738.2 & 77.89 & 821.5 & 747.0 & $74.5 \%$ \\
\hline Disi.ption Cost & 0 & 0.0 & 0.0 & 0.00 & 0.0 & 0.0 & 0.00 & 0.0 & 0.0 & 0.00 \\
\hline (Billions of $1988 \mathrm{~s}$ & 10 & 45.2 & 35.6 & 9.57 & 31.6 & 25.0 & 6.64 & 22.0 & 17.5 & 4.54 \\
\hline - Discounted) & 15 & 103.2 & 90.7 & 12.49 & 72.0 & 63.5 & 8.49 & 49.7 & 44.0 & 5.67 \\
\hline & 20 & 171.6 & 154.5 & 17.12 & 119.2 & 107.8 & 11.37 & 81.6 & 74.2 & 7.41 \\
\hline Probability of $A$ & At Least 0 & & & 1.0000 & & & 1.0000 & & & 1.0000 \\
\hline Disruption of: & At Least 10 & & & 0.0139 & & & 0.0199 & & & 0.0270 \\
\hline & At Least 15 & & & 0.0045 & & & 0.0064 & & & 0.0087 \\
\hline & At Least 20 & & & 0.0009 & & & 0.0013 & & & 0.01918 \\
\hline Cumulative Benefit & 0 & & & 0.0000 & & & 0.0000 & & & $n .0000$ \\
\hline (Billions of $1988 \$$ & 10 & & & 2.9135 & & & 3.5521 & & & 4.0769 \\
\hline Discounted and & 15 & & & 4.3610 & & & 5.3151 & & & 6.1071 \\
\hline Frobabillty Welghted) & 20 & & & 5.0995 & & & 6.2027 & & & $i .1188$ \\
\hline
\end{tabular}

Nutes: The World Oll prices are aver gas over the quarters of the disruption.

The costs and Beneflts are ai mulated over six quarters beginning with the start of the disription. 
Table 822. Case 22 - Sunnary Comparison of 750 MMB System Versus 1000 MMB System

\begin{tabular}{|c|c|c|c|c|c|c|c|c|c|c|}
\hline & \multirow[t]{2}{*}{$\begin{array}{r}\text { Net } \\
\text { Dlsruption }\end{array}$} & \multicolumn{3}{|c|}{1995} & \multicolumn{3}{|c|}{2000} & \multicolumn{3}{|c|}{2005} \\
\hline & & \multicolumn{3}{|c|}{ 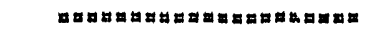 } & \multicolumn{3}{|c|}{ 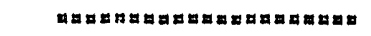 } & \multicolumn{3}{|c|}{ 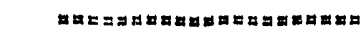 } \\
\hline & 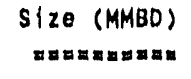 & $\begin{array}{l}750 \\
\text { aม }\end{array}$ & $\begin{array}{l}1000 \\
m x= \pm\end{array}$ & $\begin{array}{l}\text { Delta } \\
\text { घayan }\end{array}$ & $\begin{array}{l}750 \\
=0: 1\end{array}$ & $\begin{array}{l}1000 \\
\text { श्या }\end{array}$ & $\begin{array}{l}\text { Delta } \\
\text { घy्यस= }\end{array}$ & $\begin{array}{l}750 \\
= \pm=\end{array}$ & $\begin{array}{l}1000 \\
z=0 x\end{array}$ & $\begin{array}{l}\text { Delta } \\
a x=x a\end{array}$ \\
\hline World Oll Price & 0 & 24.40 & 24.40 & 0.00 & 35.00 & 35.00 & 0.00 & 42.00 & 42.00 & 0.00 \\
\hline \multirow[t]{3}{*}{$(1988 s / \theta)$} & 10 & 37.12 & 37.12 & 0.00 & 44.22 & 41.44 & 2.78 & 51.63 & 45.05 & 6.59 \\
\hline & 15 & 63.97 & 63.97 & 0.00 & 73.36 & 69.44 & 3.92 & 81.97 & 72.85 & 9.12 \\
\hline & 20 & 101.76 & 101.76 & 0.00 & 113.96 & 108.53 & 5.44 & 123.56 & 111.11 & 12.45 \\
\hline Disruption Cost & 0 & 0.0 & 0.0 & 0.00 & 0.0 & 0.0 & 0.00 & 0.0 & 0.0 & 0.00 \\
\hline (Billions of 1988 s & 10 & 42.8 & 42.8 & 0.00 & 30.0 & 20.5 & 9.56 & 34.4 & 10.0 & 24.36 \\
\hline \multirow[t]{2}{*}{ " Hot Discounted) } & 15 & 104.9 & 104.9 & 0.00 & 102.2 & 90.6 & 11.59 & 120.1 & 90.1 & 30.01 \\
\hline & 20 & 155.3 & 155.3 & 0.00 & 163.1 & 149.0 & 14.04 & 198.4 & 161.7 & 36.66 \\
\hline Disruption Cost & 0 & 0.0 & 0.0 & 0.00 & 0.0 & 0.0 & 0.00 & 0.0 & 0.0 & 0.00 \\
\hline (Billlions of $1988 \mathrm{~s}$ & 10 & 24.3 & 24.3 & 0.00 & 9.7 & 6.6 & 3.08 & 6.3 & 1.8 & 4.45 \\
\hline \multirow[t]{2}{*}{ - Discounted) } & 15 & 59.5 & 59.5 & 0.00 & 32.9 & 29.2 & 3.73 & 21.9 & 16.5 & 5.48 \\
\hline & 20 & 88.1 & 88.1 & 0.00 & 52.5 & 48.0 & 4.52 & 36.2 & 29.5 & 6.70 \\
\hline Probability of A & At Least 0 & & & 1.0000 & & & 1.0000 & & & 1.0000 \\
\hline \multirow[t]{3}{*}{ Disruption Df: } & At Least 10 & & & 0.0005 & & & 0.0004 & & & 0.0014 \\
\hline & At Least 15 & & & 0.0001 & & & 0.0002 & & & 0.0003 \\
\hline & At Least 20 & & & 0.0000 & & & 0.0000 & & & 0.0000 \\
\hline Cumulative Benefit & 0 & & & 0.0000 & & & 0.0000 & & & 0.0000 \\
\hline (Billions of 1988 \$ & 10 & & & 0.0000 & & & 0.0035 & & & 0.0131 \\
\hline Discounted and & 15 & & & 0.0000 & & & 0.0087 & & & 0.0348 \\
\hline \multirow[t]{3}{*}{ Probablllty Welghted) } & 20 & & & 0.0000 & & & 0.0104 & & & 0.0423 \\
\hline & Net & \multicolumn{3}{|c|}{2010} & \multicolumn{3}{|c|}{2015} & \multicolumn{3}{|c|}{2020} \\
\hline & Disruption & \multicolumn{3}{|c|}{ 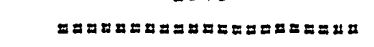 } & \multicolumn{3}{|c|}{ 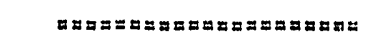 } & \multicolumn{3}{|c|}{ 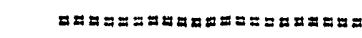 } \\
\hline Variable & $S\{z e(M M B D)$ & 750 & 1000 & Delta & 750 & 1000 & Dolta & 750 & 1000 & Delte \\
\hline$=z=z=z=z$ & $=z=\pi=z=z x \Sigma$ & $z=z$ & $a=m$ & $z x=z=$ & $z=z$ & $=t=\pi$ & $y=x=2$ & $a= \pm$ & $x= \pm x$ & $y=x=$ \\
\hline World 011 Price & 0 & 47.80 & 47.80 & 0.00 & 51.70 & 51.70 & 0.00 & 55.60 & $\$ 5.60$ & 0.00 \\
\hline \multirow[t]{3}{*}{$(1988 \$ / 8)$} & 10 & 57.52 & 50.70 & 6.82 & 61.18 & 54.54 & 6.65 & 64.83 & 58.48 & 6.36 \\
\hline & 15 & 87.60 & 78.38 & 9.23 & 90.12 & 81.31 & 8.81 & 92.24 & 84.00 & 8.24 \\
\hline & 20 & 127.98 & 115.65 & 12.33 & 128.21 & 116.65 & 11.57 & 127.50 & 116.93 & 10.57 \\
\hline Disruption Cost & 0 & 0.0 & 0.0 & 0.00 & 0.0 & 0.0 & 0.00 & 0.0 & 0.0 & 0.00 \\
\hline (Billions of 1988 s & 10 & 37.0 & 10.5 & 27.37 & 40.7 & 11.3 & 29.33 & 44.2 & 13.5 & 30.68 \\
\hline - Not Discounted) & 15 & 133.6 & 99.7 & 33.87 & 144.8 & 108.7 & 36.18 & 154.7 & 117.1 & 37.61 \\
\hline & 20 & 225.1 & 183.6 & 41.47 & 247.6 & 203.4 & 44.23 & 265.8 & 220.1 & 45.73 \\
\hline Disruption Cost & 0 & 0.0 & 0.0 & 0.00 & 0.0 & 0.0 & 0.00 & 0.0 & 0.0 & 0.00 \\
\hline (Billions of $1988 \mathrm{~s}$ & 10 & 3.9 & 1.1 & 2.84 & 2.4 & 0.7 & 1.73 & 1.5 & 0.5 & 1.02 \\
\hline - Discounted) & 15 & 13.8 & 10.3 & 3.51 & 8.5 & 6.4 & 2.13 & 5.2 & 3.9 & 1.26 \\
\hline & 20 & 23.3 & 19.0 & 4.30 & 14.6 & 12.0 & 2.60 & 8.9 & 7.3 & 1.53 \\
\hline Probability of $A$ & At Least 0 & & & 1.0000 & & & 1.0000 & & & 1.0000 \\
\hline Disruption of: & At Least 10 & & & 0.0021 & & & 0.0031 & & & 0.0044 \\
\hline & At Least 15 & & & 0.0005 & & & $0.000 i$ & & & 0.0011 \\
\hline & At Least 20 & & & 0.0001 & & & 0.0001 & & & 0.0002 \\
\hline Cumulative Benefit & 0 & & & 0.0000 & & & 0.0000 & & & 0.0000 \\
\hline (B)llions of 1988 s & 10 & & & 0.0234 & & & 0.0328 & & & 0.0406 \\
\hline Discounted and & 15 & & & 0.0649 & & & 0.0925 & & & 0.1140 \\
\hline Probabllity Weighted) & 20 & & & 0.0794 & & & 0.1134 & & & 0.1399 \\
\hline
\end{tabular}

Notes: The World 011 Prices ore averages over the quarters of the disruption.

The costs and Benefits are accumulated over slx quarters beginning with the start of the disruption. 
Table B23. Case 23. Summary Comparlson of 600 MMB system Versus 750 mMa Syatem

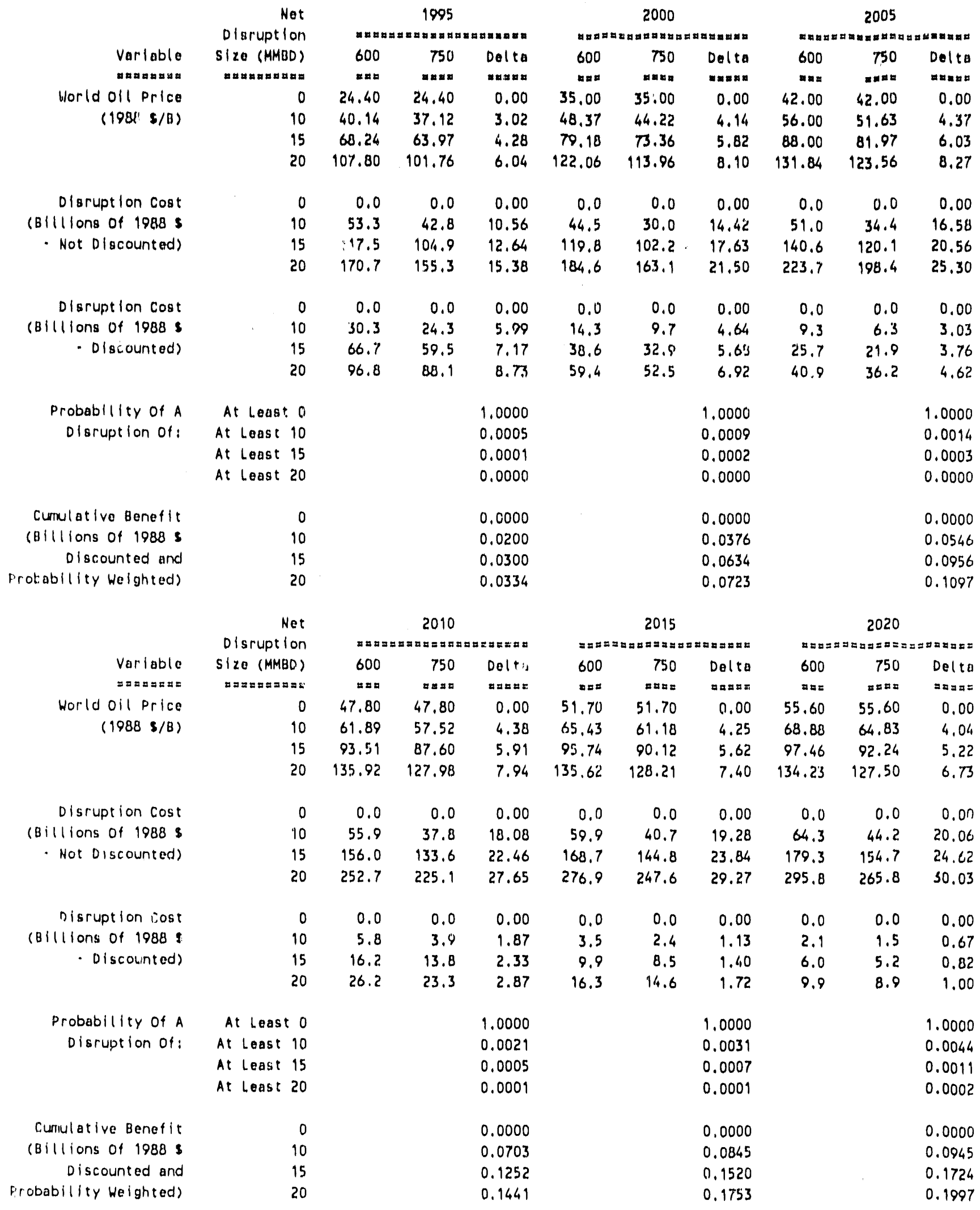

Notes: The World Oll Prices are averages over the quarters of the disruption.

The costs and Benefits are accumulated over six quarters beginning with the start of the disruption. 
Yable B24. Case 24 - Summary Comparison of 750 MMB System Versus 1000 MMB System

\begin{tabular}{|c|c|c|c|c|c|c|c|c|c|c|}
\hline & Net & & 1995 & & & 2000 & & & 2005 & \\
\hline & Disruption & $=z==$ & $=x=\pi=\pi=$ & $z==x==$ & $=x==8$ & $==\pi=z=\Sigma=$ & $=== \pm x=2$ & $x= \pm=:$ & $== \pm=E x=\pi$ & $E======$ \\
\hline Variable & Size (MMBD) & 750 & 1000 & Delta & 750 & 1000 & Delta & 750 & 1000 & Delta \\
\hline$x=z=x===$ & $==\pi==\pi=z==$ & $z==$ & $t====$ & $== \pm==$ & $==2$ & $===x$ & $=z===$ & $x==$ & $m=x=$ & $== \pm==$ \\
\hline World Dil Price & 0 & 16.70 & 16.70 & 0.00 & 21.70 & 21.70 & 0.00 & 24.80 & 24.80 & 0.00 \\
\hline$(1988 S / B)$ & 10 & 50.42 & 50.42 & 0.00 & 44.93 & 40.24 & 4.70 & 47.05 & 37.28 & 0.77 \\
\hline & 15 & 124.75 & $124 . \pi$ & 0.00 & 104.54 & 95.48 & 9.06 & 101.56 & 83.62 & 17.94 \\
\hline & 20 & 268.52 & 268.52 & 0.00 & 215.00 & 198.52 & 16.48 & 197.91 & 166.63 & 31.28 \\
\hline Disruption Cost & 0 & 0.0 & 0.0 & 0.00 & 0.0 & 0.0 & 0.00 & 0.0 & 0.0 & 0.00 \\
\hline (Billions of 1988 s & 10 & 195.0 & 195.0 & 0.00 & 154.3 & 126.6 & 27.68 & 159.8 & 94.8 & 64.96 \\
\hline - Not Discounted) & 15 & 409.9 & 409.9 & 0.00 & 387.0 & 350.7 & 36.35 & 406.0 & 322.5 & 83.53 \\
\hline & 20 & 641.5 & 641.5 & 0.00 & 650.1 & 599.0 & 51.06 & 609.1 & 574.4 & 114.70 \\
\hline Disruption Cost & 0 & 0.0 & 0.0 & 0.00 & 0.0 & 0.0 & 0.00 & 0.0 & 0.0 & 0.00 \\
\hline (Billions if 1988 s & 10 & 121.1 & 121.1 & 0.00 & 59.5 & 48.8 & 10.67 & 38.2 & 22.7 & 15.55 \\
\hline - Discounted) & 15 & 254.5 & 254.5 & 0.00 & 149.2 & 135.2 & 14.02 & 97.2 & 77.2 & 20.00 \\
\hline & 20 & 398.3 & 398.3 & 0.00 & 250.6 & 231.0 & 19.69 & 165.0 & 137.5 & 27.46 \\
\hline Probability of $A$ & At Least 0 & & & 1.0000 & & & 1.0000 & & & 1.0000 \\
\hline Disruption of: & At Least 10 & & & 0.0026 & & & 0.0055 & & & 0.0091 \\
\hline & At Least 15 & & & 0.0009 & & & 0.0018 & & & 0.0030 \\
\hline & At Least 20 & & & 0.0002 & & & 0.0004 & & & 0.0006 \\
\hline Cumulative Benefit & 0 & & & 0.0000 & & & 0.0000 & & & 0.0000 \\
\hline (Billions of 1988 s & 10 & & & 0.0000 & & & 0.1704 & & & 0.6201 \\
\hline Discounted and & 15 & & & 0.0000 & & & 0.2968 & & & 1.1070 \\
\hline Probability Weighted) & 20 & & & 0.0000 & & & 0.3623 & & & 1.3525 \\
\hline & Net & & 2010 & & & 2015 & & & 2020 & \\
\hline & Disruption & $z===$ & $x=s=z=z=$ & $z===x= \pm$ & $=z==$ & $==x=x=x=$ & $z==z=x=$ & $=\approx==$ & $:==x=z==\pi$ & $s==x===$ \\
\hline Variable & size (MMBD) & 750 & 1000 & Delta & 750 & 1000 & Delta & 750 & 1000 & Delta \\
\hline$=====z==$ & 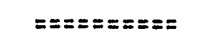 & $==:$ & $= \pm==$ & $====$ & $==x$ & $z=x=$ & $z=x==$ & $===$ & $z===$ & 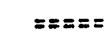 \\
\hline World Oil Price & 0 & 26.70 & 26.70 & 0.00 & 28.30 & 28.30 & 0.00 & 29.40 & 29.40 & 0.00 \\
\hline$(1988 \mathrm{~S} / \mathrm{B})$ & 10 & 47.57 & 38.27 & 9.29 & 47.79 & 39.20 & 8.60 & 47.56 & 39.70 & 7.86 \\
\hline & 15 & 96.37 & 80.12 & 16.25 & 91.64 & $\pi .23$ & 14.40 & 86.74 & 74.09 & 12.65 \\
\hline & 20 & 179.01 & 151.82 & 27.19 & 163.13 & 139.88 & 23.25 & 148.38 & 128.66 & 19.71 \\
\hline Disruption Cost & 0 & 0.0 & 0.0 & 0.00 & 0.0 & 0.0 & 0.00 & 0.0 & 0.0 & 0.00 \\
\hline (Billions of 1988 s & 10 & 165.9 & 96.7 & 69.21 & 170.9 & 99.9 & 70.97 & 175.8 & 104.0 & 71.78 \\
\hline - Not Discounted) & 15 & 422.9 & 335.1 & 87.72 & 434.7 & 346.2 & 88.41 & 443.0 & 355.4 & 87.60 \\
\hline & 20 & 719.9 & 601.7 & 118.22 & 738.2 & 621.6 & 116.67 & 747.0 & 634.1 & 112.90 \\
\hline Disruption Cost & 0 & 0.0 & 0.0 & 0.00 & 0.0 & 0.0 & 0.00 & 0.0 & 0.0 & 0.00 \\
\hline (Billions of $1988 \mathrm{~s}$ & 10 & 24.7 & 14.4 & 10.29 & 15.8 & 9.2 & 6.55 & 10.1 & 6.0 & 4.11 \\
\hline - Discounted) & 15 & 62.9 & 49.8 & 13.04 & 40.1 & 32.0 & 8.16 & 25.4 & 20.4 & 5.02 \\
\hline & 20 & 107.0 & 89.4 & 17.57 & 86.1 & 57.4 & 10.77 & 42.8 & 36.3 & 6.47 \\
\hline Erobability of $A$ & At Least 0 & & & 1.0000 & & & 1.0000 & & & 1.0000 \\
\hline Disruption of: & At Least 10 & & & 0.0139 & & & 0.0199 & & & 0.0270 \\
\hline & At Least 15 & & & 0.0045 & & & 0.0064 & & & 0.0087 \\
\hline & At Least 20 & & & 0.0009 & & & 0.0013 & & & 0.0018 \\
\hline Cumulative Benefit & 0 & & & 0.0000 & & & 0.0000 & & & 0.0000 \\
\hline (Billions of $1988 \mathrm{~s}$ & 10 & & & 1.1125 & & & 1.5066 & & & 1.8107 \\
\hline Discounted and & 15 & & & 2.0003 & & & 2.7123 & & & 3.2664 \\
\hline Probability Weighted) & 20 & & & 2.4370 & & & 3.2981 & & & 3.9665 \\
\hline
\end{tabular}

Notes: The World oil Prices are averages over the quarters of the disruption. The costs and Benefits are accumulated over six quarters beginning with the start of the disruption. 
Table B25. Case 25 - Sumary Comparison of 600 MMB System versus 750 MMB System

\begin{tabular}{|c|c|c|c|c|c|c|c|c|c|c|}
\hline & Net & & 1995 & & & 2000 & & & 2005 & \\
\hline & Disruption & $x===$ & $==\pi===\pi=$ & $===\pi==\pi$ & $x===$ & $====\mathbf{=}=\mathbf{=}$ & $===\mathbf{x =}=$ & $==x==$ & $===\pi==\pi=$ & $==2== \pm=$ \\
\hline Variable & size (MMBD) & 600 & 750 & Delta & 600 & 750 & Delta & 600 & 750 & Delta \\
\hline$y=2=2 x=2$ & $x=x=x=x=2 z$ & $=x=$ & $x=x=$ & $= \pm= \pm=$ & $= \pm=$ & $== \pm=$ & $=z==2$ & $z==$ & $=z x=$ & $=====$ \\
\hline World Oil Price & 0 & 16.70 & 16.70 & 0.00 & 21.70 & 21.70 & 0.00 & 24.80 & 24.80 & 0.00 \\
\hline$(1988 s / 8)$ & 10 & 57.44 & 50.42 & 7.02 & 52.26 & 44.93 & 7.33 & 53.97 & 47.05 & 6.92 \\
\hline & 15 & 138.80 & 124.75 & 14.06 & 118.54 & 104.54 & 14.00 & 114.09 & 101.56 & 12.53 \\
\hline & 20 & 294.89 & 268.52 & 26.36 & 240.40 & 215.00 & 25.40 & 219.68 & 197.91 & $21 . \pi$ \\
\hline Disruption Cost & 0 & 0.0 & 0.0 & 0.00 & 0.0 & 0.0 & 0.00 & 0.0 & 0.0 & 0.00 \\
\hline (Billions of 1988 & 10 & 227.1 & 195.0 & 32.09 & 195.6 & 154.3 & 41.29 & 203.0 & 159.8 & 43.25 \\
\hline - Not Discounted) & 15 & 454.1 & 409.9 & 44.14 & 442.7 & 387.0 & 55.71 & 463.5 & 406.0 & 57.52 \\
\hline & 20 & 705.1 & 641.5 & 63.62 & 729.5 & $650: 1$ & 79.39 & 769.6 & 689.1 & 80.51 \\
\hline Disruption Cost & 0 & 0.0 & 0.0 & 0.00 & 0.0 & 0.0 & 0.00 & 0.0 & 0.0 & 0.00 \\
\hline (Billions of $1988 \mathrm{~s}$ & 10 & 141.0 & 121.1 & 19.92 & 75.4 & 59.5 & 15.92 & 48.6 & 38.2 & 10.35 \\
\hline - Discounted) & 15 & 281.9 & 254.5 & 27.40 & 170.7 & 149.2 & 21.48 & 111.0 & 97.2 & 13.77 \\
\hline & 20 & 437.8 & 398.3 & 39.50 & 281.3 & 250.6 & 30.61 & 184.2 & 165.0 & 19.27 \\
\hline Probability of A & At Least 0 & & & 1.0000 & & & 1.0000 & & & 9.0000 \\
\hline Disruption of: & At Least 10 & & & 0.0026 & & & 0.0055 & & & 0.0091 \\
\hline & At Least 15 & & & 0.0009 & & & $0.00: 8$ & & & 0.0030 \\
\hline & At Least 20 & & & 0.0002 & & & 0.0004 & & & 0.0006 \\
\hline Cumularive Benefit & 0 & & & 0.0000 & & & 0.0000 & & & 0.0000 \\
\hline (Billions of 1988 s & 10 & & & 0.5746 & & & 1.2739 & & & 1.8746 \\
\hline Discounted and & 15 & & & 0.8019 & & & 1.8834 & & & 2.8026 \\
\hline Probability Weighted) & 20 & & & 0.9251 & & & 2.2089 & & & 3.2901 \\
\hline & Net & & 2010 & & & 2015 & & & 2020 & \\
\hline & Disruption & $===$ & $==\approx=\pi===$ & $===x== \pm$ & $====$ & 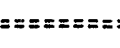 & 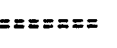 & $====$ & $==\pi=z==z$ & $=== \pm==$ \\
\hline Variable & size (MMBD) & 600 & 750 & Delta & 600 & 750 & Delta & 600 & 750 & Delta \\
\hline$==\Sigma==\Sigma==$ & $z==\pi=z= \pm==$ & $===$ & $====$ & $====$ & $===$ & $== \pm=$ & $=====$ & $x==$ & $=z==$ & $==\pi==$ \\
\hline World Oil Price & 0 & 26.70 & 26.70 & 0.00 & 28.30 & 28.30 & 0.00 & 29.40 & 29.40 & 0.00 \\
\hline$(1988 \$ / B)$ & 10 & 53.90 & 47.57 & 6.33 & 53.60 & 47.79 & 5.80 & 52.81 & 47.56 & 5.25 \\
\hline & 15 & 107.32 & 96.37 & 10.95 & 109.27 & 91.64 & 9.63 & 95.12 & 86.74 & 8.38 \\
\hline & 20 & 197.26 & 179.01 & 18.25 & 178.60 & 163.13 & 15.48 & 161.40 & 148.38 & 13.02 \\
\hline Disruption Cost & 0 & 0.0 & 0.0 & 0.00 & 0.0 & 0.0 & 0.00 & 0.0 & 0.0 & 0.00 \\
\hline (Billions of $1988 \mathrm{~s}$ & 10 & 210.5 & 165.9 & 44.59 & 216.4 & 170.9 & 45.48 & 224.5 & 175.8 & 45.72 \\
\hline - Hot Discounted) & 15 & 481.1 & 422.9 & 58.20 & 492.8 & 434.7 & 58.12 & 500.0 & 443.0 & 57.05 \\
\hline & 20 & 799.7 & 719.9 & 79.80 & 816.1 & 738.2 & 77.89 & 821.5 & 747.0 & 74.57 \\
\hline Disruption Cost & 0 & 0.0 & 0.0 & 0.00 & 0.0 & 0.0 & 0.00 & 0.0 & 0.0 & 0.00 \\
\hline (Billions of 1988 s & 10 & 31.3 & $2 \pi .7$ & 6.63 & 20.0 & 15.8 & 4.20 & 12.7 & 10.1 & 2.62 \\
\hline - Discounteds & 15 & 71.5 & $6 i .9$ & 8.65 & 45.5 & 40.1 & 5.36 & 28.7 & 25.4 & 3.27 \\
\hline & 20 & 118.9 & 907.0 & 11.86 & $\pi .3$ & 68.1 & 7.19 & $4,7.1$ & 42.8 & 4.27 \\
\hline Probability of $A$ & At Leas: 0 & & & 1.0000 & & & 1.0000 & & & 1.0000 \\
\hline Disruption 04: & At Least 10 & & & 0.0139 & & & 0.0198 & & & 0.0270 \\
\hline & At Least 15 & & & 0.0045 & & & 0.0064 & & & 0.0087 \\
\hline & At Least 20 & & & 0.0008 & & & 0.0013 & & & 0.0018 \\
\hline Cumulative Benefit & 0 & & & 0.0000 & & & 0.0000 & & & 0.0000 \\
\hline (Billions of 1988 s & 10 & & & 2.4100 & & & 2.8375 & & & 3.1575 \\
\hline giscounted and & 95 & & & 3.6910 & & & 4.2527 & & & 4.7428 \\
\hline Probability Weighted) & 20 & & & 4.2322 & & & 4.9769 & & & 5.5472 \\
\hline
\end{tabular}

Notes: The World Oil Prices are averages over the quarters it the disruption.

The costs and Benefits are accumulated over six quarters beginning with the start of the disruption. 
Table B26. Case 26 - Sumbry Comparison of 750 MMB system Versus 1000 MMB system

\begin{tabular}{|c|c|c|c|c|c|c|c|c|c|c|}
\hline & Net & & 1995 & & & 2000 & & & 2005 & \\
\hline & Disruption & $x=x=2$ & $\varepsilon=\pi=z= \pm=$ & $=\pi=2 x=2$ & $z=x=$ & $=\pi \approx x=x==$ & $=.2 x=\pi x=$ & $z===$ & $==2 x=x=2$ & $==\varepsilon=x==$ \\
\hline $\begin{array}{l}\text { Variable } \\
=======\end{array}$ & $\begin{array}{l}\text { Size (MMBD) } \\
====\approx=====\end{array}$ & $\begin{array}{l}750 \\
x=2\end{array}$ & $\begin{array}{l}1000 \\
z==\approx\end{array}$ & $\begin{array}{l}\text { Delta } \\
=====\end{array}$ & $\begin{array}{l}750 \\
===\end{array}$ & $\begin{array}{l}1000 \\
z==2\end{array}$ & $\begin{array}{l}\text { Delta } \\
x=z==\end{array}$ & $\begin{array}{l}750 \\
x=2\end{array}$ & $\begin{array}{l}1000 \\
x==\end{array}$ & $\begin{array}{l}\text { Delta } \\
=== \pm=\end{array}$ \\
\hline World nil Price & 0 & 24.40 & 24.40 & 0.70 & 35.00 & 35.00 & 0.00 & 42.00 & 42.00 & 0.00 \\
\hline$(1988 \$ / B)$ & 10 & 37.12 & 37.12 & 0.00 & 44.22 & 41.44 & 2.78 & 51.63 & 45.05 & 6.59 \\
\hline & 15 & 63.97 & 63.97 & 0.00 & 73.36 & 69.44 & 3.92 & 81.97 & 72.85 & 9.12 \\
\hline & 20 & 101.76 & 101.76 & 0.00 & 113.96 & 108.53 & 5.44 & 123.56 & 111.11 & 12.45 \\
\hline Disruption Cost & 0 & 0.0 & 0.0 & 0.00 & 0.0 & 0.0 & 0.00 & 0.0 & 0.0 & 0.00 \\
\hline (Billions of 1988 s & 10 & 42.8 & 42.8 & 0.00 & 30.0 & 20.5 & 9.56 & 34.4 & 10.0 & 24.36 \\
\hline - Not Discounted) & 15 & 104.9 & 104.9 & 0.00 & 102.2 & 90.6 & 11.50 & 120.1 & 90.1 & 30.01 \\
\hline & 20 & 155.3 & 155.3 & 0.00 & 163.1 & 149.0 & 14.04 & 198.4 & 161.7 & 36.66 \\
\hline Disruption cost & 0 & 0.0 & 0.0 & 0.00 & 0.0 & 0.0 & 0.00 & 0.0 & 0.0 & 0.00 \\
\hline (Billions of $1988 \mathrm{~s}$ & 10 & 26.6 & 26.6 & 0.00 & 11.6 & 7.9 & 3.68 & 8.2 & 2.4 & 5.83 \\
\hline - Discounted) & 15 & 65.1 & 65.1 & 0.00 & 39.4 & 34.9 & 4.47 & 28.7 & 21.6 & 7.18 \\
\hline & 20 & 96.4 & 96.4 & 0.00 & 62.9 & 57.5 & 5.41 & 47.5 & 38.7 & 8.77 \\
\hline Probability of A & At Least 0 & & & 1.0000 & & & 1.0000 & & & 1.0000 \\
\hline Disruption of: & At Least 10 & & & 0.0005 & & & 0.0009 & & & 0.0014 \\
\hline & At Least is & & & 0.0001 & & & 0.0002 & & & 0.0003 \\
\hline & At Least 20 & & & 0.0000 & & & 0.0000 & & & 0.0000 \\
\hline Cumulative Benefit & 0 & & & 0.0000 & & & 0.0000 & & & 0.0000 \\
\hline (Billions of $1988 \mathrm{~s}$ & 10 & & & 0.0000 & & & 0.0040 & & & 0.0156 \\
\hline Discounted and & 15 & & & 0.0000 & & & 0.0098 & & & 0.0412 \\
\hline Probability Weighted) & 20 & & & 0.0000 & & & 0.0118 & & & 0.0500 \\
\hline & Net & & 2010 & & & 2015 & & & 2020 & \\
\hline & Disruption & $==z=$ & 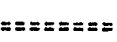 & $==\approx===[$ & $===$ & $z==\pi=z=z$ & $==== \pm==$ & $===$ & $== \pm== \pm==$ & $=====-=$ \\
\hline Variable & size (MMBD) & 750 & 1000 & Delta & 750 & 1000 & Delta & 750 & 1000 & Delta \\
\hline$=s=z=s=z$ & $==x=x=x=z=$ & $===$ & $==z=$ & $z=z==$ & $==$ & $z=s=$ & $=====$ & $==$ & $== \pm=$ & $s====$ \\
\hline World oil Price & 0 & 47.80 & 47.80 & 0.00 & 51.70 & 51.70 & 0.00 & 55.60 & 55.60 & 0.00 \\
\hline$(19885 / B)$ & 10 & 57.52 & 50.70 & 6.82 & 61.18 & 54.54 & 6.65 & 64.83 & 58.48 & 6.36 \\
\hline & 15 & 87.60 & 78.38 & 9.23 & 90.12 & 81.31 & 0.81 & 92.24 & 84.00 & 8.24 \\
\hline & 20 & 127.98 & 115.65 & 12.33 & 128.21 & 116.65 & 11.57 & 127.50 & 116.93 & 10.57 \\
\hline Disruption Cost & 0 & C. 0 & 0.0 & 0.00 & 0.0 & 0.0 & 0.00 & 0.0 & 0.0 & 0.00 \\
\hline (Billions of 1988 s & 10 & 37.8 & 10.5 & 27.37 & 40.7 & 19.3 & 29.33 & 44.2 & 13.5 & 30.68 \\
\hline - Not Discounted) & 15 & 133.6 & 99.7 & 33.87 & 144.8 & 108.7 & 36.18 & 154.7 & 117.1 & 37.61 \\
\hline & 20 & 225.1 & 183.6 & 49.47 & 247.6 & 203.4 & 44.23 & 265.8 & 220.1 & 45.73 \\
\hline Disruption Cost & 0 & 0.0 & 0.0 & 0.00 & 0.0 & 0.0 & 0.00 & 0.0 & 0.0 & 0.00 \\
\hline (Billions of 1988 s & 10 & 5.6 & 1.6 & 4.07 & 3.8 & 1.0 & 2.71 & 2.5 & 0.8 & 1.76 \\
\hline - Discounted) & 15 & 19.9 & 14.8 & 5.03 & 13.4 & 10.0 & 3.34 & 3.9 & 6.7 & 2.16 \\
\hline & 20 & 33.5 & 27.3 & 6.16 & 22.9 & 18.8 & 4.08 & 15.2 & 12.6 & 2.62 \\
\hline Probability of A & At Least 0 & & & 1.0000 & & & 1.0000 & & & 1.0000 \\
\hline Disruption of: & At Least 10 & & & 0.0021 & & & 0.0031 & & & 0.0044 \\
\hline & At Least 15 & & & 0.0005 & & & 0.0007 & & & 0.0019 \\
\hline & At Least 20 & & & 0.0001 & & & 0.0001 & & & 0.0002 \\
\hline Cumulative Benefit & 0 & & & 0.0000 & & & 0.0000 & & & 0.0000 \\
\hline (Billions of 1988 s & 10 & & & 0.0287 & & & 0.0415 & & & 0.0526 \\
\hline Discounted and & 15 & & & 0.0796 & & & 0.1168 & & & 0.1479 \\
\hline Probability Weighted) & 20 & & & 0.0970 & & & 0.1426 & & & 0.1809 \\
\hline
\end{tabular}

Notes: The World Oil Prices are averages over the quarters of the disruption.

The costs and Benefits are accumulated over six quarters beginning with the start of the disruption. 
Table B27. Case 27 - Sumary Comparison of 600 MMB System Versus 750 MMB System

\begin{tabular}{|c|c|c|c|c|c|c|c|c|c|c|}
\hline & Net & & 1995 & & & 2000 & & & 2005 & \\
\hline & Disruption & $==x=$ & $=z=z=z=z$ & $:===:==$ & $z===$ & $z=:=x=x=$ & $=:== \pm==$ & $== \pm=$ & $z=z=z=z=$ & $=:=== \pm=$ \\
\hline Variable & size (MMBD) & 600 & 750 & Delta & 600 & 750 & Delto & 600 & 750 & Delta \\
\hline$==\pi==\pi==$ & 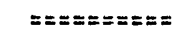 & $===$ & $====$ & $==z==$ & $===$ & $== \pm=$ & $=== \pm=$ & $===$ & $== \pm=$ & $==x==$ \\
\hline World Oil Price & 0 & 24.40 & 24.40 & 0.00 & 35.00 & 35.00 & 0.00 & 42.00 & 42.00 & 0.00 \\
\hline$(1988 \$ / B)$ & 10 & 40.14 & 37.12 & 3.02 & 48.37 & 44.22 & 4.14 & 56.00 & 51.63 & 4.37 \\
\hline & 15 & 68.24 & 63.97 & 4.28 & 79.18 & 73.36 & 5.82 & 88.00 & 81.97 & 6.03 \\
\hline & 20 & 107.80 & 901.76 & 6.04 & 122.06 & 113.96 & 8.10 & 131.84 & 123.56 & 8.27 \\
\hline Disruption Cost & 0 & 0.0 & 0.0 & 0.00 & 0.0 & 0.0 & 0.00 & 0.0 & 0.0 & 0.00 \\
\hline (Billions of $1988 \mathrm{~s}$ & 10 & 53.3 & 42.8 & 10.56 & 44.5 & 30.0 & 14.42 & 51.0 & 34.4 & 16.58 \\
\hline - Not Discounted) & 15 & 117.5 & 104.9 & 12.64 & 119.8 & 102.2 & 17.63 & 140.6 & 120.1 & 20.56 \\
\hline & 20 & 170.7 & 155.3 & 15.38 & 184.0 & 163.1 & 21.50 & 223.7 & 198.4 & 25.30 \\
\hline Disruption Cost & 0 & 0.0 & 0.0 & 0.00 & 0.0 & 0.0 & 0.00 & 0.0 & 0.0 & 0.00 \\
\hline (Eillions of $1988 \mathrm{~s}$ & 10 & 33.1 & 26.6 & 6.56 & 17.1 & 11.6 & 5.56 & 12.2 & 8.2 & 3.97 \\
\hline Discounted) & 15 & 73.0 & 65.1 & 7.85 & 46.2 & 39.4 & 6.80 & 33.7 & 28.7 & 4.92 \\
\hline & 20 & 106.0 & 96.4 & 9.55 & 71.2 & 62.9 & 8.29 & 53.5 & 47.5 & 6.06 \\
\hline Probability of $A$ & At Least 0 & & & 1.0000 & & & 9.0000 & & & 1.0000 \\
\hline Disruption of: & At Least 10 & & & 0.0005 & & & 0.0009 & & & 0.0014 \\
\hline & At Least 15 & & & 0.0001 & & & 0.0002 & & & 0.0003 \\
\hline & At Least 20 & & & 0.0000 & & & 0.0000 & & & 0.0000 \\
\hline Cumulat ive Benefit & 0 & & & 0.0000 & & & 0.0000 & & & 0.0000 \\
\hline (Billions of $1988 \$$ & 10 & & & 0.0211 & & & 0.0408 & & & 0.0612 \\
\hline Discounted and & 15 & & & 0.0316 & & & 0.0690 & & & 0.1073 \\
\hline Probability Weighted) & 20 & & & 0.0352 & & & 0.0786 & & & 0.1229 \\
\hline & Net & & 2010 & & & 2015 & & & 2020 & \\
\hline & Disruption & $====$ & 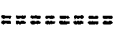 & $z=:=:==$ & $==z=$ & $===2=z=3$ & $=z=:=z=$ & $===$ & $==x=\leq=\leq=$ & $==s=z=$ \\
\hline Variable & Size (MMBD) & 600 & 750 & Delta & 600 & 750 & Delta & 600 & 750 & Delta \\
\hline$=z===s=$ & $==x==x=z=x$ & $===$ & $====$ & $=====$ & $===$ & $===$ & $==x==$ & $===$ & $== \pm=$ & $=:==$ \\
\hline World oil Price & 0 & 47.80 & 47.80 & 0.00 & 51.70 & 51.70 & 0.00 & 55.60 & 55.60 & 0.00 \\
\hline$(1988 \$ / B)$ & 10 & 61.89 & 57.52 & 4.38 & 65.43 & 61.18 & 4.25 & 68.88 & 64.83 & 4.04 \\
\hline & 15 & 93.51 & 87.60 & 5.91 & 95.74 & 90.12 & 5.62 & 97.46 & 92.24 & 5.22 \\
\hline & 20 & 135.92 & 127.98 & $i .94$ & 135.62 & 128.21 & 7.40 & 134.23 & 127.50 & 6.73 \\
\hline Disruption Cost & 0 & 0.0 & 0.0 & 0.00 & 0.0 & 0.0 & 0.00 & 0.0 & 0.0 & 0.00 \\
\hline (Billions of 1988 s & 10 & 55.9 & 37.8 & 18.08 & 59.9 & 40.7 & 19.28 & 64.3 & 44.2 & 20.06 \\
\hline - Not Discounted) & 15 & 156.0 & 133.6 & 22.46 & 168.7 & 144.8 & 23.84 & 179.3 & 154.7 & 24.62 \\
\hline & 20 & 252.7 & 225.1 & 27.65 & 276.9 & 247.6 & 29.27 & 295.8 & 265.8 & 30.03 \\
\hline Disruption Cost & 0 & 0.0 & 0.0 & 0.00 & 0.0 & 0.0 & 0.00 & 0.0 & 0.0 & 0.00 \\
\hline (Billions of 1988 s & 10 & 8.3 & 5.6 & 2.69 & 5.5 & 3.8 & 1.78 & 3.7 & 2.5 & 1.15 \\
\hline - Discounted) & 15 & 23.2 & 19.9 & 3.34 & 15.6 & 13.4 & 2.20 & 10.3 & 8.9 & 1.49 \\
\hline & 20 & 37.6 & 33.5 & 4.91 & 25.6 & 22.9 & 2.70 & 17.0 & $15 . ?$ & 1.72 \\
\hline Probability of $A$ & At Least 0 & & & 1.0000 & & & 1.0000 & & & 1.0000 \\
\hline Disruption of: & At Least 10 & & & 0.0021 & & & 0.0031 & & & 0.0044 \\
\hline & At Least 15 & & & 0.0005 & & & 0.0007 & & & 0.0011 \\
\hline & At Least 20 & & & 0.0001 & & & 0.0001 & & & 0.0002 \\
\hline Cumulative Benefit & 0 & & & 0.0000 & & & 0.0000 & & & 0.0000 \\
\hline (Billiors of $1988 \mathrm{~s}$ & 10 & & & 0.0819 & & & 0.1002 & & & 0.1150 \\
\hline Discounted and & 15 & & & 0.1446 & & & 0.1804 & & & 0.2097 \\
\hline Probability Weighted) & 20 & & & 0.1662 & & & 0.2078 & & & 0.2424 \\
\hline
\end{tabular}

Notes: The World oil Prices are averages over the quarters of the disruption.

The costs and Benefits are accumulated over six quarters beginning with the start of the disruption. 
rable 828. Case 28 - Summary Comparison of 750 MMB system Versus 1000 MMB System

\begin{tabular}{|c|c|c|c|c|c|c|c|c|c|c|}
\hline & Net & & 1995 & & & 2000 & & & 2005 & \\
\hline & Disruption & $== \pm=$ & 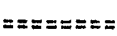 & $=\because=z=z=0$ & $==2 x$ & Еニニニニニニニ & $==z=0=8$ & $x== \pm$ & $== \pm===$ = & $z==:=z=$ \\
\hline $\begin{array}{l}\text { Variable } \\
========\end{array}$ & $\begin{array}{l}\text { Size (MMBD) } \\
=====\pi=\pi==\end{array}$ & $\begin{array}{l}750 \\
==2\end{array}$ & $\begin{array}{l}1000 \\
z=z=\end{array}$ & $\begin{array}{l}\text { Delta } \\
=== \pm=\end{array}$ & $\begin{array}{l}750 \\
===\end{array}$ & $\begin{array}{l}1000 \\
s===\end{array}$ & $\begin{array}{l}\text { Delta } \\
= \pm E==\end{array}$ & $\begin{array}{l}750 \\
==2\end{array}$ & $\begin{array}{l}1000 \\
z= \pm=\end{array}$ & $\begin{array}{l}\text { Delta } \\
=====\end{array}$ \\
\hline World Dil Price & 0 & 16.70 & 16.70 & 0.00 & 21.70 & 21.70 & 0.00 & 24.80 & 24.80 & 0.00 \\
\hline$(19885 / B)$ & 10 & 65.31 & 65.31 & 0.00 & 61.60 & 57.89 & 3.80 & 62.80 & 54.91 & 7.89 \\
\hline & 15 & 147.31 & 147.31 & 0.00 & 130.61 & 123.74 & 6.86 & 125.09 & 111.42 & 13.66 \\
\hline & 20 & 298.23 & 298.23 & 0.00 & 252.62 & 240.77 & 11.85 & 230.66 & 207.82 & 22.84 \\
\hline Disruption Cost & c & 0.0 & 0.0 & 0.00 & 0.0 & 0.0 & 0.00 & 0.0 & 0.0 & 0.00 \\
\hline (Billions of $1988 \mathrm{~s}$ & 10 & 355.2 & 355.2 & 0.00 & 328.9 & 302.2 & 26.75 & 342.6 & 279.8 & 62.78 \\
\hline - Not Discounted) & 15 & 632.4 & 632.4 & 0.00 & 636.4 & 601.1 & 35.31 & 669.8 & 588.3 & 81.42 \\
\hline & 20 & 906.8 & 906.8 & 0.00 & 964.6 & 916.1 & 48.52 & 1029.1 & 918.8 & 110.29 \\
\hline Disruption Cost & 0 & 0.0 & 0.0 & 0.00 & 0.0 & 0.0 & 0.00 & 0.0 & 0.0 & 0.00 \\
\hline (Billions of 1988 s & 10 & 220.6 & 220.6 & 0.00 & 126.8 & 116.5 & 10.31 & 82.0 & 67.0 & 15.03 \\
\hline - Discounted) & 15 & $39 \therefore 6$ & 392.6 & 0.00 & 245.4 & 231.7 & 13.61 & 160.3 & 140.8 & 19.49 \\
\hline & 20 & 563.1 & 563.1 & 0.00 & 371.9 & 353.2 & 18.71 & 246.4 & 219.9 & 26.40 \\
\hline Probability Oi A & At Least 0 & & & 1.0000 & & & 1.0000 & & & 1.0000 \\
\hline Disruption of: & At Least 10 & & & 0.0026 & & & 0.0055 & & & 0.0091 \\
\hline & At Least 15 & & & 0.0009 & & & 0.0018 & & & 0.0030 \\
\hline & At Least 20 & & & 0.0002 & & & 0.0004 & & & 0.0006 \\
\hline Cumulative Benefit & 0 & & & 0.0000 & & & 0.0000 & & & 0.0000 \\
\hline :Billions of 1988 \$ & 10 & & & 0.0268 & & & 0.5409 & & & 1.6474 \\
\hline Discounted and & 15 & & & 0.0447 & & & 0.7688 & & & 2.2670 \\
\hline Probability Weighted) & 20 & & & 0.0583 & & & 0.9073 & & & 2.6046 \\
\hline & Net & & 2010 & & & 2015 & & & 2020 & \\
\hline & Disruption & $z===$ & $===\approx==\pi=$ & $==ニ=ニ==$ & $===$ & $\therefore===\approx== \pm$ & $z===x==$ & $====$ & $=ニ=ニ ニ=ニ=$ & $=== \pm===$ \\
\hline Variable & size (MMBD) & 750 & 1000 & Delta & 750 & 1000 & Delta & 750 & 1000 & Delta \\
\hline$z=\pi=\pi=\pi=$ & $==x=x=z=x=$ & $===$ & $===$ & $=z= \pm x$ & $===$ & 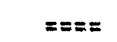 & $== \pm==$ & $n=2$ & $==x=$ & $==\approx=z$ \\
\hline World Oil Price & 0 & 26.70 & 26.70 & 0.00 & 28.30 & 28.30 & 0.00 & 29.40 & 29.40 & 0.00 \\
\hline$(1988 \$ / B)$ & 10 & 61.94 & 54.58 & 7.36 & 60.92 & 54.23 & 6.69 & 59.36 & 53.34 & 6.02 \\
\hline & 15 & 116.95 & 104.73 & 12.22 & 109.75 & 99.04 & 10.71 & 102.44 & 93.14 & 9.30 \\
\hline & 20 & 206.59 & 186.91 & 19.68 & 186.61 & 169.93 & 16.68 & 168.06 & 154.03 & 14.03 \\
\hline Disruption Cost & 0 & 0.0 & 0.0 & 0.00 & 0.0 & 0.0 & 0.00 & 0.0 & 0.0 & 0.00 \\
\hline (Billions of 1988 s & 10 & 355.5 & 289.1 & 66.47 & 365.9 & 298.2 & 67.74 & 374.0 & 305.9 & 68.12 \\
\hline - Not Discounted) & 15 & 697.9 & 613.1 & 84.73 & 717.8 & 633.2 & 84.72 & 730.3 & 647.0 & 83.34 \\
\hline & 20 & 1079.1 & 966.3 & 112.79 & 1110.2 & 999.7 & 110.55 & 1124.6 & 1018.3 & 106.33 \\
\hline Disruption Cost & 0 & 0.0 & 0.0 & 0.00 & 0.0 & 0.0 & 0.00 & 0.0 & 0.0 & 0.00 \\
\hline (Billions of 1988 s & 10 & 52.9 & 43.0 & 9.88 & 33.8 & 27.5 & 6.25 & 29.4 & 17.5 & 3.90 \\
\hline - Discounted) & 15 & 103.7 & 91.1 & 12.60 & 66.3 & 58.4 & 7.82 & 41.9 & 37.1 & 4.78 \\
\hline & 20 & 160.4 & 143.6 & 16.77 & 102.5 & 92.3 & 10.20 & 64.4 & 58.4 & 6.09 \\
\hline Probability of $A$ & At Least 0 & & & 1.0000 & & & 1.0000 & & & 1.0000 \\
\hline Disruption of: & At Least 10 & & & 0.0139 & & & 0.0199 & & & 0.0270 \\
\hline & At Least 15 & & & 0.0045 & & & 0.0064 & & & 0.0087 \\
\hline & At Least 20 & & & 0.0009 & & & 0.0013 & & & 0.0018 \\
\hline Cumulative benefit & 0 & & & 0.0000 & & & 0.0000 & & & 0.0000 \\
\hline (Billions of 1988 s & 10 & & & 2.9693 & & & 4.0248 & & & 4.7754 \\
\hline Discuunted and & 15 & & & 4.0145 & & & 5.4017 & & & 6.3918 \\
\hline Probability Weighted) & 20 & & & 4.5580 & & & 6.1027 & & & 7.2023 \\
\hline
\end{tabular}

Notes: The World Oil Prices are averages over the quarters of the disruption.

The costs and Benefits are accurmulated over six quarters beginning with the start of the disruption. 
Table B29. Case 29. Summary Comparison of 750 MMB system Versus 1000 MMB System

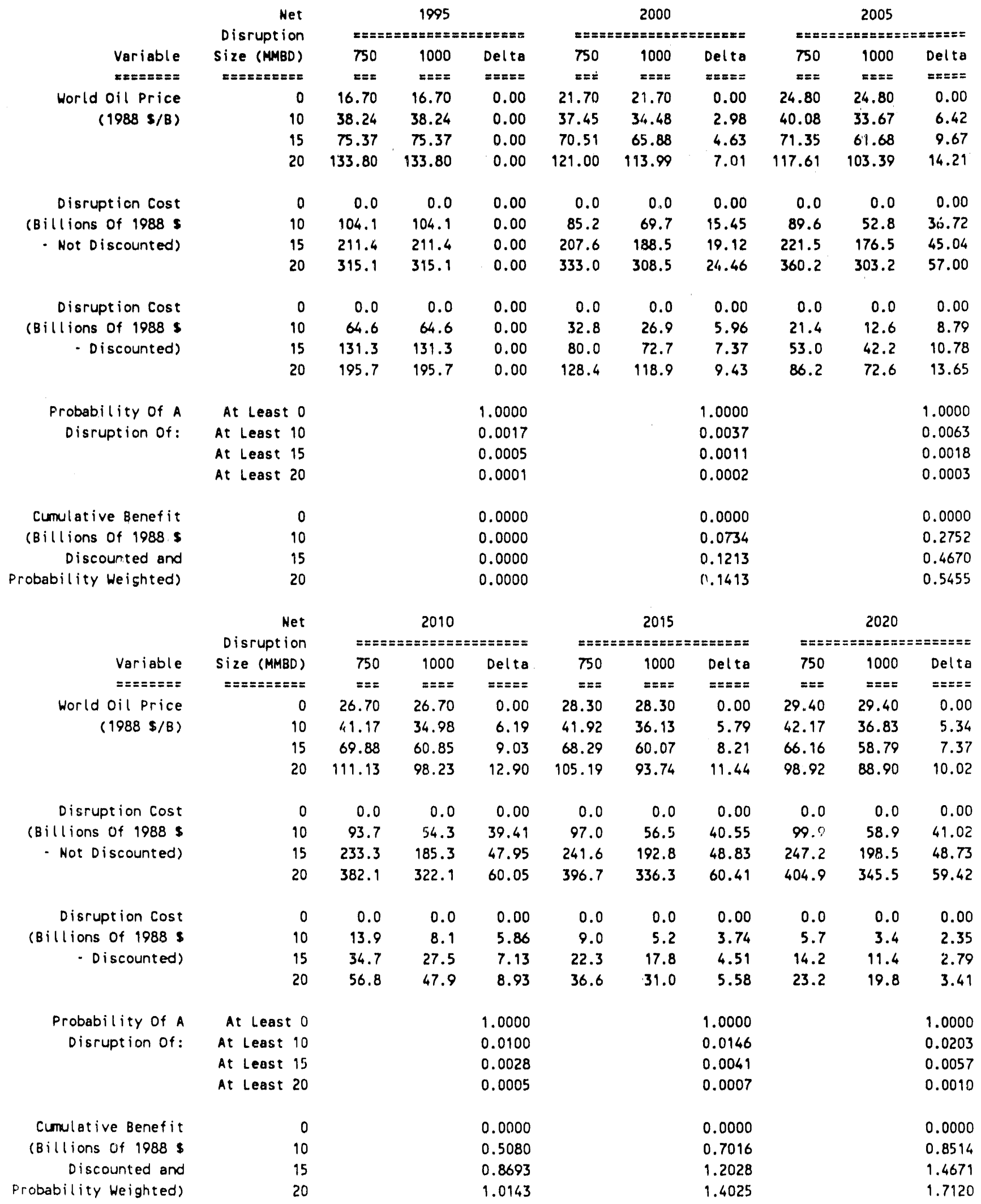

Notes: The World Oil Prices are averages over the quarters of the disruption.

The costs and Benefits are accumulated over six quarters beginning with the start of the disruption. 
Table 830. Case 30 - Sumary Comparison of 750 mMB system versus 1000 MMB system

\begin{tabular}{|c|c|c|c|c|c|c|c|c|c|c|}
\hline & Net & & 1995 & & & 2000 & & & 2005 & \\
\hline & Disruption & $== \pm x$ & $==x=x=x z$ & $y==1 t=z=$ & $== \pm=$ & $z=z=z x z=$ & $=z:=z=x$ & $x= \pm=$ & $:=z=x \pi=\pi$ & $==2=\pi=$ \\
\hline Variable & size (MMBD) & 730 & 1000 & Delta & 750 & 1000 & Delta & 730 & 1000 & Delta \\
\hline$=z=x=2=z$ & $=z= \pm 2=z x=z$ & $==z$ & $E z=z$ & $z=2=2$ & $=2=$ & $= \pm=2$ & $=x=2 x$ & $==2$ & $z==5$ & $z=z==$ \\
\hline World oil Price & 0 & 24.40 & 24.40 & 0.00 & 35.00 & 35.00 & 0.00 & 42.00 & 42.00 & 0.00 \\
\hline$(1988 s / 8)$ & 10 & 41.23 & 41.23 & 0.00 & 46.89 & 43.23 & 3.66 & 54.37 & 45.84 & 8.53 \\
\hline & 15 & 81.43 & 81.43 & 0.00 & 88.29 & 82.44 & 5.86 & 96.90 & 83.61 & 13.29 \\
\hline & 20 & 145.57 & 145.57 & 0.00 & 153.19 & 144.10 & 9.09 & 161.92 & 141.78 & 20.14 \\
\hline Disruption Cost & 0 & 0.0 & 0.0 & 0.00 & 0.0 & 0.0 & 0.00 & 0.0 & 0.0 & 0.00 \\
\hline (Billions of $1988 \mathrm{~s}$ & 10 & 62.7 & 62.7 & 0.00 & 43.: & 29.6 & 13.56 & 48.7 & 14.5 & 34.18 \\
\hline - Not Discounted) & 15 & 156.6 & 156.6 & 0.00 & 149.6 & 132.4 & 17.02 & 173.4 & 129.8 & 43.56 \\
\hline & 20 & 236.7 & 236.7 & 0.00 & 243.9 & 222.5 & 21.45 & 293.9 & 238.4 & 55.43 \\
\hline Disruption Cost & 0 & 0.0 & 0.0 & 0.00 & 0.0 & 0.0 & 0.00 & 0.0 & 0.0 & 0.00 \\
\hline (Billions of $1988 \mathrm{~s}$ & 10 & 38.9 & 38.9 & 0.00 & 16.7 & 11.4 & 5.23 & 11.6 & 3.5 & 8.18 \\
\hline - Discounted) & 15 & 97.3 & 97.3 & 0.00 & 57.6 & 51.1 & 6.56 & 49.5 & 31.1 & 10.43 \\
\hline & 20 & 147.0 & 147.0 & 0.00 & 94.0 & 85.8 & 8.27 & 70.4 & 57.1 & 13.27 \\
\hline Probability of $A$ & At Least 0 & & & 1.0000 & & & 1.0000 & & & 1.0000 \\
\hline Disruption of: & At Least 10 & & & 0.0012 & & & 0.0021 & & & 0.0033 \\
\hline & At least is & & & 0.0004 & & & 0.0006 & & & 0.0010 \\
\hline & At Least 20 & & & 0.0001 & & & 0.0001 & & & 0.0002 \\
\hline Cumulative Benefit & 0 & & & 0.0000 & & & 0.0000 & & & 0.0000 \\
\hline (Billions of $1988 \mathrm{~s}$ & 10 & & & 0.0000 & & & 0.0121 & & & 0.0443 \\
\hline Discounted and & 15 & & & 0.0000 & & & 0.0328 & & & 0.1308 \\
\hline Probability Weighted) & 20 & & & 0.0000 & & & 0.0425 & & & 0.1713 \\
\hline & Net & & 2010 & & & 2015 & & & 2020 & \\
\hline & Disruption & $=z==$ & $==s=z=2=$ & $=z==\pi==$ & $===$ & $==s=z=s$ & $==:===$ & $===$ & $=== \pm=z=\pi$ & $z=z==z=$ \\
\hline Variable & size (MMBD) & 750 & 1000 & Delta & 750 & 1000 & Delta & 750 & 1000 & Delta \\
\hline$z==\Sigma=z=z$ & $===z=\pi z=z=$ & $===$ & $===$ & $====$ & $===$ & $=2=2$ & $=== \pm=$ & $=\leq=$ & $=x=$ & $=x==$ \\
\hline World ail price & 0 & 47.80 & 47.80 & 0.00 & 51.70 & 51.70 & 0.00 & 55.60 & 55.60 & 0.00 \\
\hline$(1988 \mathrm{~s} / \mathrm{B})$ & 10 & 60.24 & 51.45 & 8.79 & 63.82 & 55.27 & 8.54 & 67.37 & 59.22 & 8.16 \\
\hline & 15 & 101.95 & 88.70 & 13.25 & 103.57 & 91.06 & 12.51 & 104.69 & 93.14 & 11.56 \\
\hline & 20 & 163.78 & 144.28 & 19.50 & 160.96 & 143.01 & 17.95 & 156.96 & 160.85 & 16.11 \\
\hline Disruption Cost & 0 & 0.0 & 0.0 & 0.00 & 0.0 & 0.0 & 0.00 & 0.0 & 0.0 & 0.00 \\
\hline (Billions of $1988 \mathrm{~s}$ & 10 & 53.0 & 14.9 & 38.12 & 56.7 & 16.0 & 40.67 & 61.1 & 18.7 & 42.40 \\
\hline - Not Discounted) & 15 & 199.1 & 142.3 & 48.79 & 206.0 & 154.2 & 51.83 & 218.5 & 164.9 & 53.56 \\
\hline & 20 & 330.5 & 268.3 & 62.20 & 361.0 & 295.2 & 65.87 & 384.4 & 316.9 & 67.53 \\
\hline Disruption Cos: & 0 & 0.0 & 0.0 & 0.00 & 0.0 & 0.0 & 0.00 & 0.0 & 0.0 & 0.00 \\
\hline (Billions of 1988 s & 10 & 7.9 & 2.2 & 5.67 & 5.2 & 1.5 & 3.75 & 3.5 & 1.1 & 2.43 \\
\hline - Discounted) & 15 & 28.4 & 21.2 & 7.25 & 19.0 & 14.2 & 4.78 & 12.5 & 9.4 & 3.07 \\
\hline & 20 & 49.1 & 39.9 & 9.25 & 33.3 & 27.2 & 6.08 & 22.0 & 18.2 & 3.87 \\
\hline Probability of $A$ & At Least 0 & & & 1.0000 & & & 1.0000 & & & 1.0000 \\
\hline Disruption of: & At Least 10 & & & 0.0048 & & & 0.0067 & & & 0.0091 \\
\hline & At Least 15 & & & 0.0015 & & & 0.0021 & & & 0.0029 \\
\hline & At Least 20 & & & 0.0003 & & & 0.0004 & & & 0.0006 \\
\hline Cumulative Benefit & 0 & & & 0.0000 & & & 0.0000 & & & 0.0000 \\
\hline CBillions of 1988 s & 10 & & & 0.0784 & & & 0.1090 & & & 0.1346 \\
\hline Discounted and & 15 & & & 0.2421 & & & 0.3413 & & & 0.4213 \\
\hline Probability Weighted) & 20 & & & 0.3183 & & & 0.4494 & & & 0.5545 \\
\hline
\end{tabular}

Notes: The Horld Oil Prices are averages over the quarters of the disruption.

The costs and Benefits are accumulated over six quarters beginning with the start of the disruption. 
Tuble B31. Case 31. Summary Comparison of 750 MMB System Versus 1000 MMB system

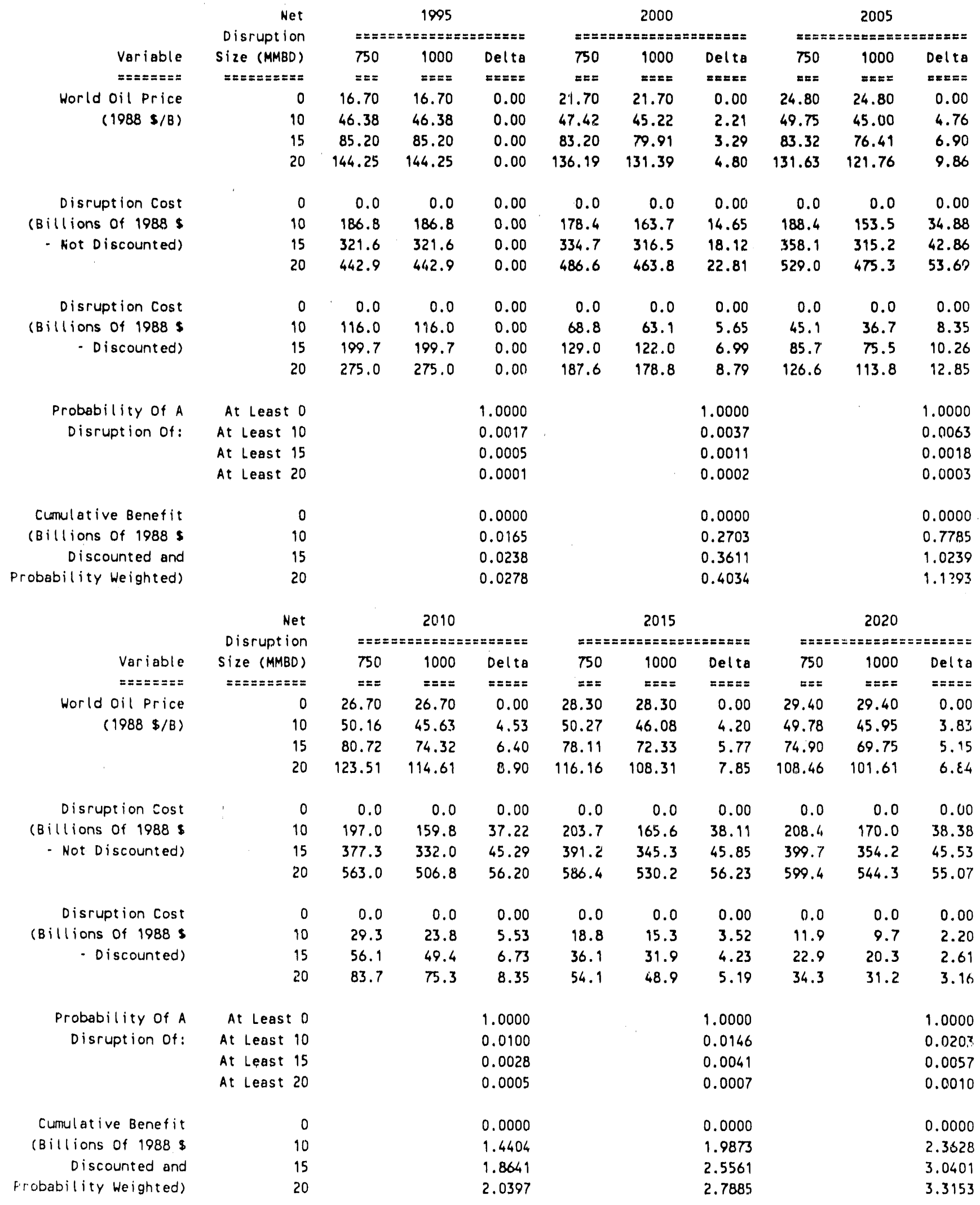

Notes: The World oil Prices are averages over the quarters of the disruption.

The costs and Benefits are accurmulated over six quarters beginning with the start of the disruption. 
Table 832. Case 32 - Summary Comparison of 600 MMB System Versus 750 MMB system

\begin{tabular}{|c|c|c|c|c|c|c|c|c|c|c|}
\hline & Net & \multicolumn{3}{|c|}{1995} & \multicolumn{3}{|c|}{2000} & \multicolumn{3}{|c|}{2005} \\
\hline & Disruption & \multicolumn{3}{|c|}{ 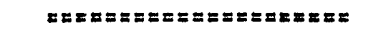 } & \multicolumn{3}{|c|}{ 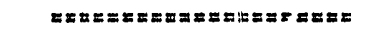 } & \multicolumn{3}{|c|}{ 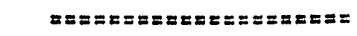 } \\
\hline & $\begin{array}{l}\text { Size (MMBD) } \\
=z=x==x=z\end{array}$ & $\begin{array}{l}600 \\
x=5\end{array}$ & $\begin{array}{r}750 \\
=x=x=\end{array}$ & $\begin{array}{l}\text { Delta } \\
=x=z=\end{array}$ & $\begin{array}{l}600 \\
=x=\end{array}$ & $\begin{array}{r}750 \\
==2=\end{array}$ & $\begin{array}{l}\text { Delta } \\
z=2=2\end{array}$ & $\begin{array}{l}600 \\
==2\end{array}$ & $\begin{array}{l}750 \\
=x=2\end{array}$ & $\begin{array}{l}\text { Delta } \\
=x==z\end{array}$ \\
\hline World oil Price & 0 & 16.70 & 16.70 & 0.00 & 21.70 & 21.70 & 0.60 & 24.80 & 24.80 & 0.00 \\
\hline \multirow[t]{3}{*}{$(19885 / 8)$} & 10 & 49.14 & 46.38 & 2.75 & 50.67 & 47.42 & 3.25 & 52.86 & 49.75 & 3.10 \\
\hline & 15 & 89.42 & 85.20 & 4.23 & 88.04 & 83.20 & 4.84 & 87.80 & 83.32 & 4.49 \\
\hline & 20 & 150.60 & 144.25 & 6.35 & 143.25 & 136.19 & 7.06 & 138.00 & 131.63 & 6.38 \\
\hline Disruption Cost & 0 & 0.0 & 0.0 & 0.00 & 0.0 & 0.0 & 0.00 & 0.0 & 0.0 & 0.00 \\
\hline (Billions of $1988 \mathrm{~s}$ & 10 & 202.7 & 186.8 & 15.95 & 199.9 & 178.4 & 21.54 & 211.1 & 188.4 & 22.74 \\
\hline \multirow[t]{2}{*}{ - Not Discounted) } & 15 & 349.5 & 321.6 & 19.91 & 361.5 & 334.7 & 26.86 & 386.2 & 358.1 & 28.18 \\
\hline & 20 & 468.2 & 442.9 & 25.29 & 520.6 & 486.6 & 33.97 & 564.4 & 529.0 & 35.39 \\
\hline Disruption Cost & 0 & 0.0 & 0.0 & 0.00 & 0.0 & 0.0 & 0.00 & 0.0 & 0.0 & 0.00 \\
\hline (Billions of 1988 s & 10 & 125.9 & 116.0 & 9.91 & 77.1 & 68.8 & 8.31 & 50.5 & 45.1 & 5.44 \\
\hline \multirow[t]{2}{*}{ - Discounted) } & 15 & 212.1 & 199.7 & 12.36 & 139.4 & 129.0 & 10.36 & 92.5 & 85.7 & 6.75 \\
\hline & 20 & 290.7 & 275.0 & 15.71 & 200.7 & 187.6 & 13.10 & 135.1 & 126.6 & 8.47 \\
\hline Probability of A & At Least 0 & & & 1.0000 & & & 1.0000 & & & 1.0000 \\
\hline \multirow[t]{3}{*}{ Disruption of: } & At ceast 10 & & & 0.0017 & & & 0.0037 & & & 0.0063 \\
\hline & At Least 15 & & & 0.0005 & & & 0.0011 & & & 0.0018 \\
\hline & At Least 20 & & & 0.0001 & & & 0.0002 & & & 0.0003 \\
\hline Cumulat ive Benefit & 0 & & & 0.0000 & & & 0.0000 & & & 0.0300 \\
\hline (Billions of 1988 s & 10 & & & 0.4316 & & & 1.0705 & & & 1.6121 \\
\hline Discounted and & 15 & & & 0.5145 & & & 1.3007 & & & 1.9754 \\
\hline \multirow[t]{3}{*}{ Probability Weighted) } & 20 & & & 0.5502 & & & 1.3980 & & & 2.1275 \\
\hline & Net & \multicolumn{3}{|c|}{2010} & \multicolumn{3}{|c|}{2015} & \multicolumn{3}{|c|}{2020} \\
\hline & Disruption & \multicolumn{3}{|c|}{ 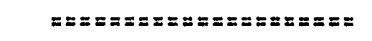 } & \multicolumn{3}{|c|}{ 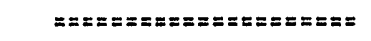 } & \multicolumn{3}{|c|}{ 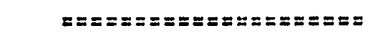 } \\
\hline Variable & size (MMBD) & 600 & 750 & Delta & 600 & 750 & Delta & 600 & 750 & Delta \\
\hline$==\pi=\Sigma==\Omega$ & 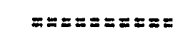 & $z=2$ & $z=z=$ & $s== \pm=$ & $z==$ & $z= \pm=$ & $=2 x=2$ & $=2=$ & $z=x=$ & $== \pm=\approx$ \\
\hline World Oil Price & 0 & 26.70 & 26.70 & 0.00 & 28.30 & 28.30 & 0.00 & 29.40 & 29.40 & 0.00 \\
\hline \multirow[t]{3}{*}{$(1988 \$ / B)$} & 10 & 53.03 & 50.16 & 2.86 & 52.91 & 50.27 & 2.64 & 52.18 & 49.78 & 2.40 \\
\hline & 15 & 84.74 & 80.72 & 4.03 & 81.73 & 78.11 & 3.62 & 78.12 & 74.90 & 3.22 \\
\hline & 20 & 129.09 & 123.51 & 5.58 & 121.07 & 116.16 & 4.91 & 112.72 & 108.46 & 4.27 \\
\hline Disruption Cost & 0 & 0.0 & 0.0 & 0.00 & 0.0 & 0.0 & 0.00 & 0.0 & 0.0 & 0.00 \\
\hline (Billions of 1988 s & 10 & 220.6 & 197.0 & 23.50 & 227.7 & 203.7 & 23.97 & 232.5 & 208.4 & 24.04 \\
\hline - Not Discounted) & 15 & 406.1 & 377.3 & 28.81 & 420.2 & 391.2 & 29.03 & 428.4 & 399.7 & 28.70 \\
\hline & 20 & 598.9 & 563.0 & 35.83 & 622.1 & 586.4 & 35.68 & 634.2 & 599.4 & 34.79 \\
\hline Disruption Cost & 0 & 0.0 & 0.0 & 0.00 & 0.0 & 0.0 & 0.00 & 0.0 & 0.0 & 0.00 \\
\hline (Billions of $1988 \mathrm{~s}$ & 10 & 32.8 & 29.3 & 3.49 & 21.0 & 18.8 & 2.21 & 13.3 & 11.9 & 1.38 \\
\hline - Discounted) & 15 & 60.4 & 56.1 & 4.28 & 38.8 & 36.9 & 2.68 & 24.6 & 2.9 & 1.64 \\
\hline & 20 & 89.0 & 83.7 & 5.33 & 57.4 & 54.1 & 3.29 & 36.3 & 34.3 & 1.89 \\
\hline Probability of $A$ & At least 0 & & & 1.0000 & & & 1.0000 & & & 1.0000 \\
\hline Disruption of: & At Least 10 & & & 0.0100 & & & 0.0146 & & & 0.0203 \\
\hline & At least 15 & & & 0.0028 & & & 0.0041 & & & 0.0057 \\
\hline & At Least 20 & & & 0.0005 & & & 0.0007 & & & 0.0010 \\
\hline Cumulat ive Benefit & 0 & & & 0.0000 & & & 0.0000 & & & 0.0000 \\
\hline (Billions of 1988 s & 10 & & & 2.1841 & & & 2.6568 & & & 2.9774 \\
\hline Discounted and & 15 & & & 2.6634 & & & 3.2300 & & & 3.6257 \\
\hline Probability weighted) & 20 & & & 2.8613 & & & 3.4648 & & & 3.8912 \\
\hline
\end{tabular}

Notes: The World oil Prices are averages over the quarters of the disruption.

The costs and Benefits are accumulated over six quarters treginning with the start of the disruption. 
Table B33. Case 33 - summary Comparison of 750 MMB system Versus 1000 MMB System

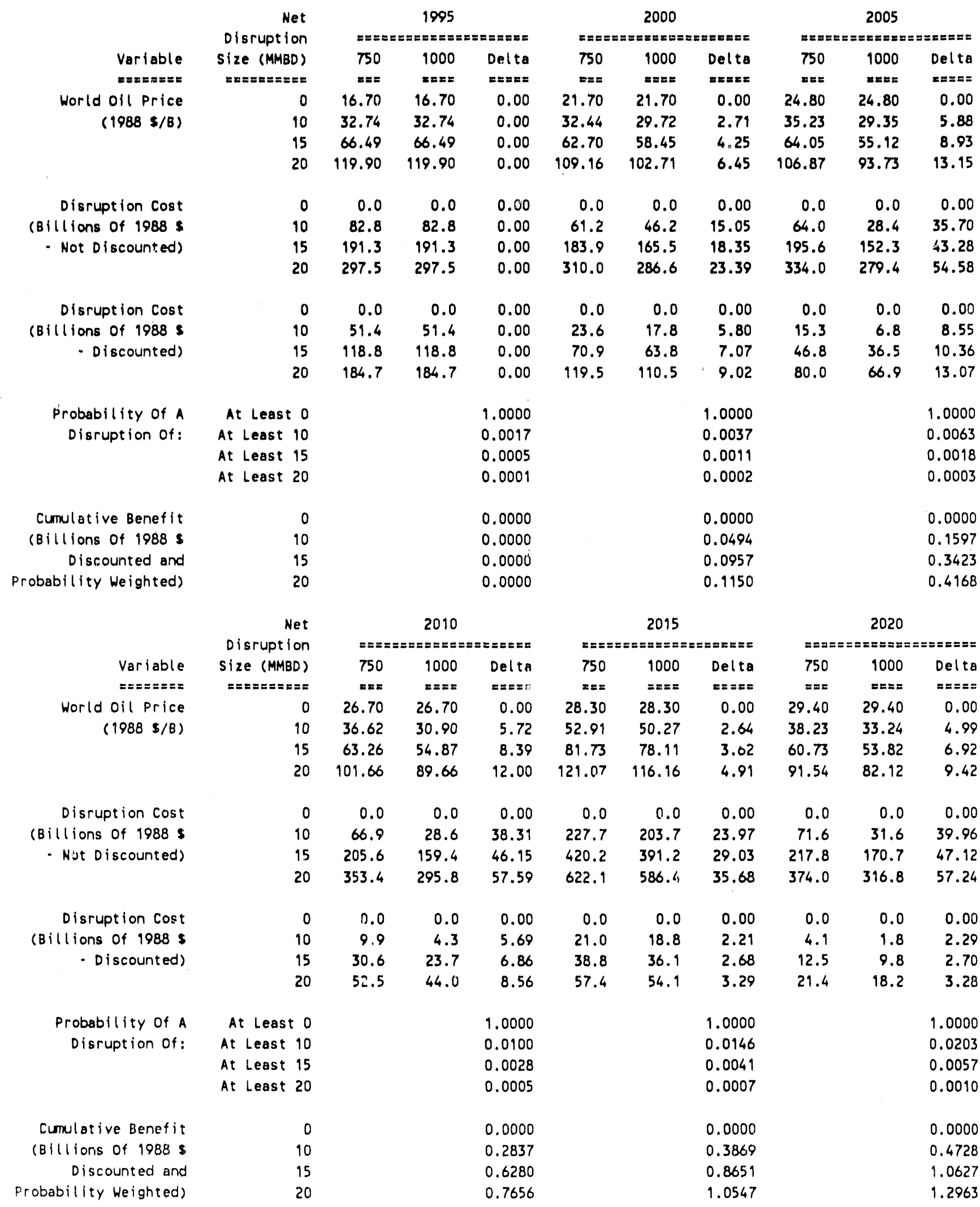

Notes: The World Oil Prices are averages over the quarters of the disruption.

The costs and Benefits are accumulated over six quarters beginning with the start of the disruption. 
Table B34. Case 34 - Summary Comparison of 750 MMB System Versus 1000 MMB System

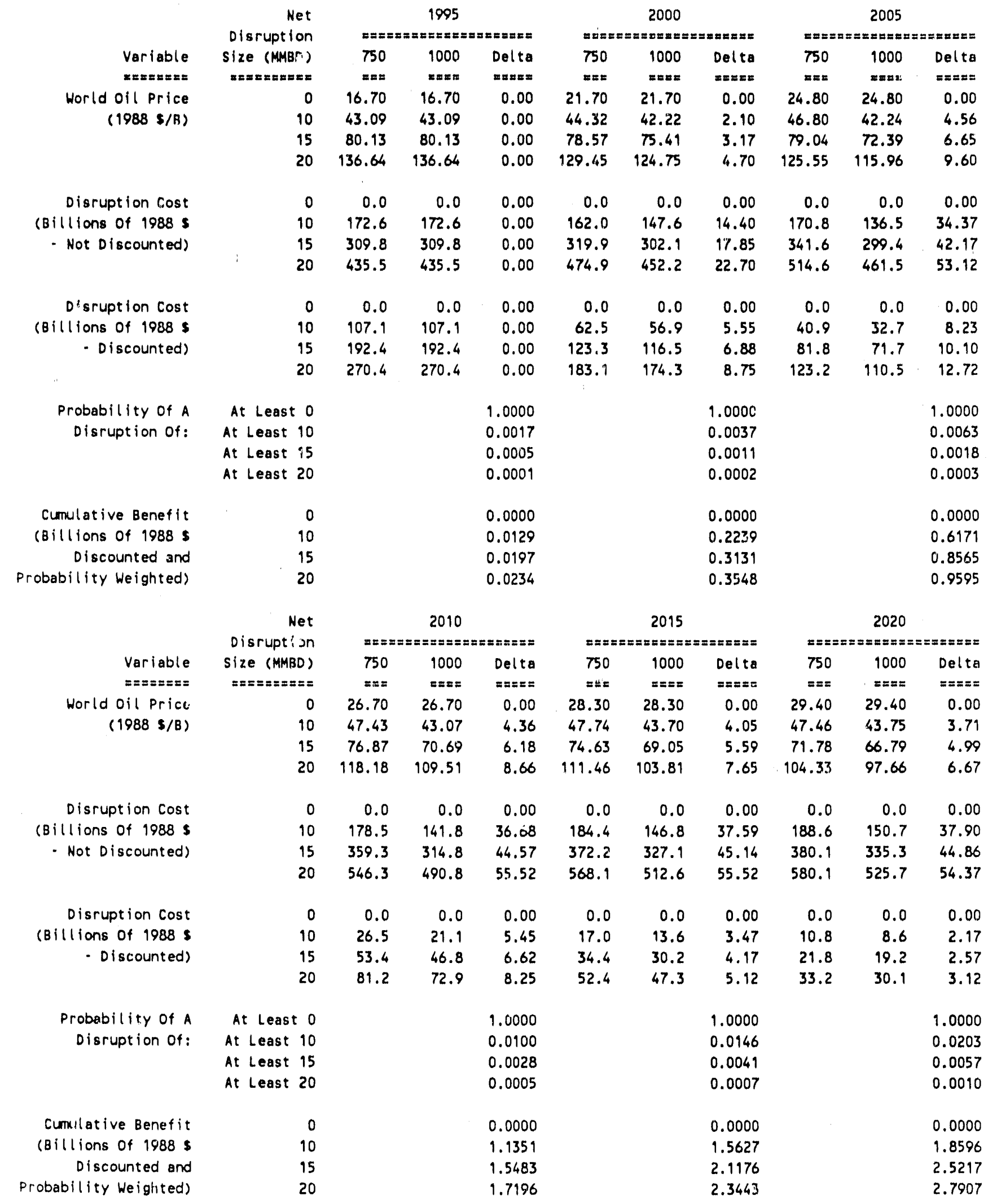

Notes: The World oil Prices are averages over the quarters of the disruption. The costs and Benefit; are accumulated over six quarters beginning with the titart of the disruption. 
Table B35. Case 35. Summary Comparison of 600 MMB system Versus 750 MMB system

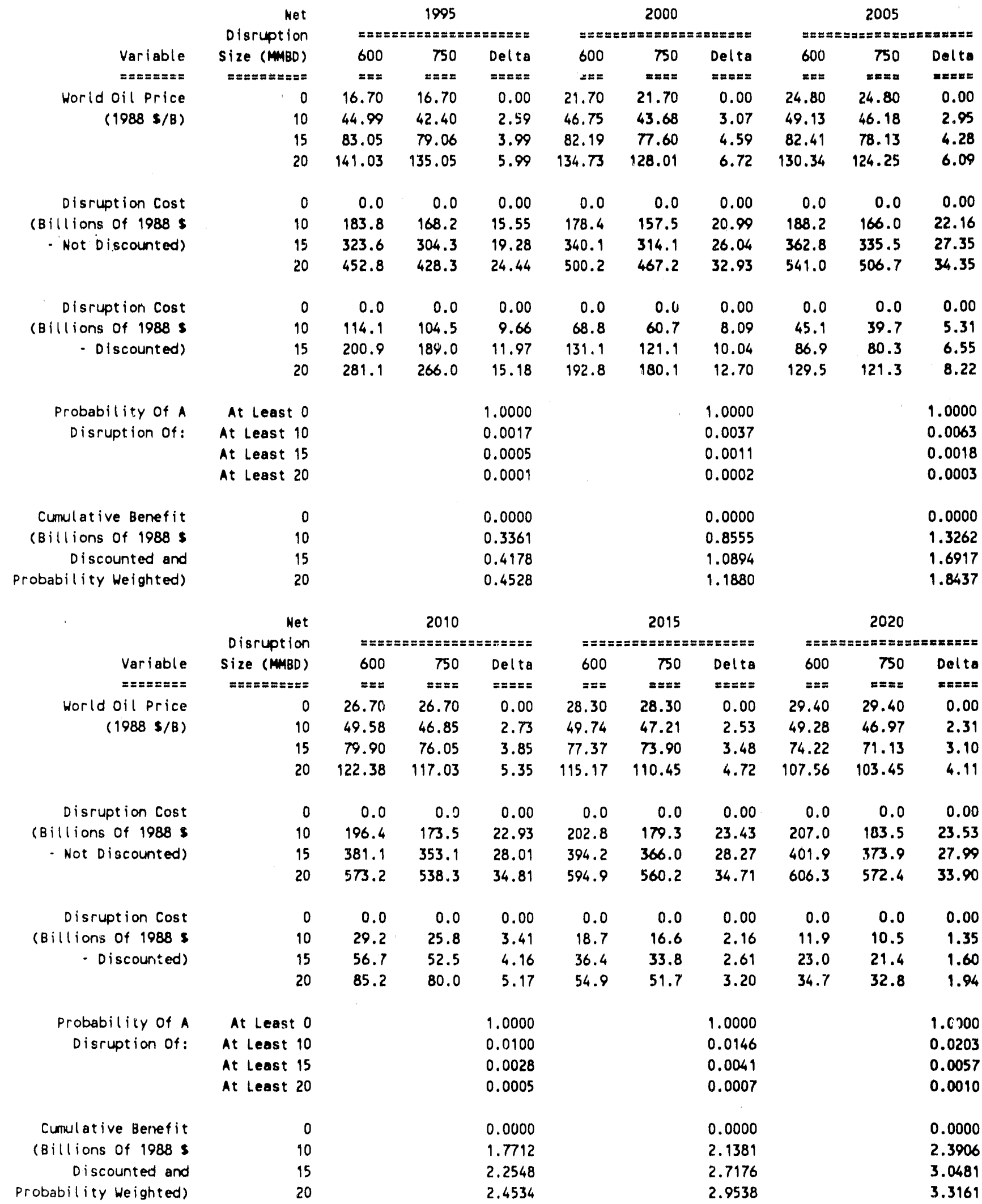

Notes: The World oil prices are averages over the quarters of the disruption. The costs and Benefits are accumulated over six quarters begiming with the start of the disruption. 

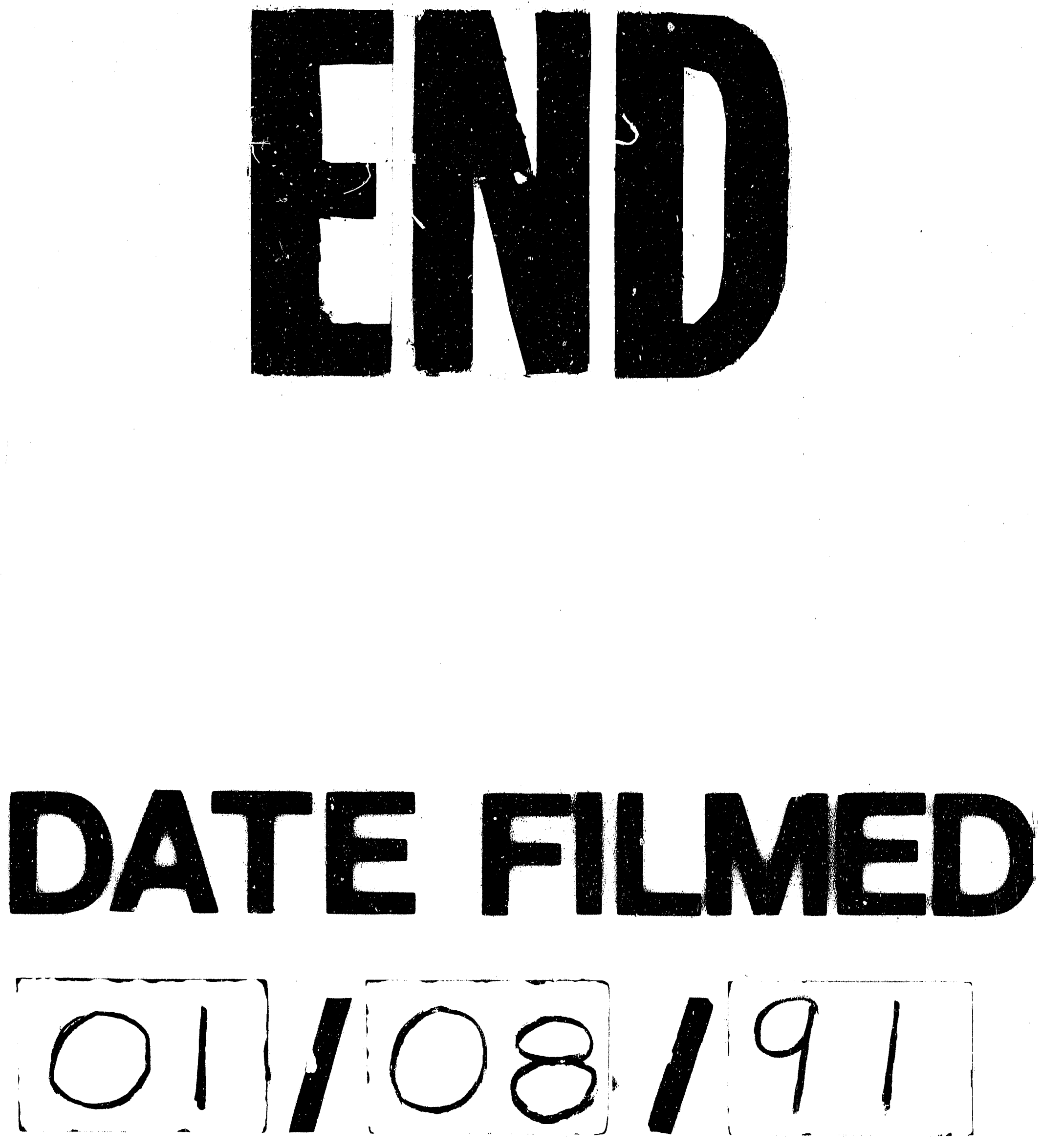
